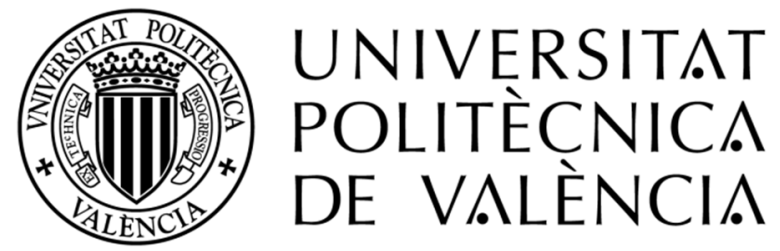

Department of Mechanical Engineering and Materials Program on Engineering and Industrial Production

\title{
Application of demand response strategies for the management of natural gas systems under the smart grid configuration: development of a methodology for technical, economic and envi- ronmental evaluation
}

\author{
Author: \\ Lina Montuori \\ Director: \\ Dr. Carlos Álvarez Bel
}

VALENCIA, July 2017

ISBN: 978-84-17098-19-3 



\section{Acknowledgements}

First and foremost, I would like to thank my major professor Dr. Eng. Carlos Álvarez Bel for his guidance and encouragement. Most especially, I would like to express my gratitude to him for giving me the opportunity and the framework to develop this dissertation.

My most sincere thanks also go to Prof. Eng. Dr. Manuel Alcázar Ortega for his substantial contribution to the completion of this work.

Likewise, I wish to gratefully acknowledge the contribution of the company "2i Rete Gas, S.p.A." where I had the opportunity to acquire the techniques and experience in the management of the natural gas system. Thanks also to my colleagues of the $2 \mathrm{i}$ Rete Gas team for their kindness and friendship and for supporting me during this busy time.

Sincere thanks go to Dr. Alexander Domijan, Director of the Power Center for Utility Explorations for his valuable advice and giving me the opportunity to partially develop my research during my one-year stay at the State University of New York at Buffalo.

Finally, I would like to thank my beloved family, mum Giuseppina, dad Mario and my siblings Caterina, Mariella, Marco and Serena. Despite the distance, they never made me feel lonely. They tirelessly supported and encouraged me during these years of study. Thank you for not having never stop believing in me and being my strength. 



\section{Abstract}

Energy systems are evolving into structures in which the role of the consumer is more and more significant. Consumers are no longer the passive entities that in the past had to be supplied in an unidirectional way (from the network to the customer), but can also supply power to the grid through renewable resources, storage capacity through the batteries of their electric vehicles or operating services through the use of their flexibility. However, when discussing on smart grids, electricity supply and consumption are the only considered side on many occasions, neglecting other dimensions such as natural gas, sanitary hot water or transport.

In this context, this dissertation represents a novel approach to the role of consumers in the natural gas sector. While it is true that electricity consumers have been involved for years in different operation services related to the use of their flexibility (especially in countries such as the United States and more recently in the European Union), the use of demand response resources in the gas sector has been so far non-existent. However, the success of demand response initiatives in electricity systems and their similarity to the gas sector, where their regulatory and technological development has been carried out in parallel in recent years, allows us to expect similar successful results when implementing equivalent programs to gas networks.

This dissertation highlights the huge potential that remains unexplored on the demand side of natural gas, which could be used by gas network operators for the solution of technical constraints, balance services or optimization of programming of underground storage. This potential is especially interesting at the moment, when the massive installation of smart gas meters has started in some European countries, an infrastructure that would facilitate the use of demand response resources for the better operation of gas networks.

The dissertation presents, firstly, an exhaustive analysis of the demand response programs currently used in electrical systems around the world, identifying those services that could be equally applicable to the gas sector. The traditional structure based on which gas systems have been developed in different countries is analyzed below. In order to make better use of resources and to optimize its operation, an architecture based on 
the concept of smart grid is then proposed, identifying the agents that would participate in this structure and emphasizing the role that consumers would play, not only as energy demanders, but also as providers of network services. This active role of demand requires the use of adequate measurement, control and communication technologies, aspect that is also properly analyzed.

Based on the results of the analysis mentioned above, this thesis proposes a new methodology for the development and evaluation of demand response mechanisms that allow a greater participation of gas consumers in the provision of operating services to the manager of the network, increasing the joint efficiency of the system and reducing the costs associated with such services.

The proposed methodology has been successfully applied to the gas network in Italy, where the analyzed operation services have been evaluated in a town of 16,000 inhabitants located in the central north-Italian area. In that town, consumers have been grouped by end-use, sector and size, which evidences the need to enhance the role of the aggregator for the proper use of the potential of smaller consumers, whether they receive a gas supply directly or through a distributed heat network.

The results presented in this dissertation should encourage regulators to empower the use of the consumers' flexibility in order to increase the efficiency of the natural gas system, as it reduces operating costs while favoring the participation of customers in a more dynamic energy structure. This participation of customers is essential for the proper management of smart energy systems, called to be energy networks of the future. 


\section{Resumen}

Los sistemas energéticos están evolucionando hacia estructuras en las que el papel desempeñado por el consumidor es cada vez más importante. Hoy en día, los consumidores ya no son los entes pasivos de antaño a los que había que suministrar energía de forma unidireccional (de la red al cliente), sino que también pueden suministrar energía a la red a través de recursos renovables, capacidad de almacenamiento mediante las baterías de sus vehículos eléctricos o servicios de operación a través de la utilización de su flexibilidad. Sin embargo, al hablar de redes inteligentes, en muchas ocasiones se sobreentiende únicamente lo relativo al suministro y consumo de electricidad, obviando otras dimensiones como pueden ser el gas natural, el agua caliente sanitaria o el transporte.

En este marco, esta tesis supone un enfoque novedoso en lo que se refiere al papel de los consumidores en el sector del gas natural. Si bien es cierto que los consumidores de electricidad han participado desde hace años en diferentes servicios de operación relacionados con el uso de su flexibilidad (especialmente en países como los Estados Unidos y, más recientemente, en la Unión Europea), la utilización de la respuesta de la demanda en el sector gasista ha sido hasta ahora inexistente. Sin embargo, el éxito de iniciativas de respuesta de la demanda en los sistemas eléctricos y su similitud con el sector gasista, cuyo desarrollo normativo y tecnológico se ha realizado en paralelo en los últimos años, permite esperar resultados igualmente exitosos al aplicar programas equivalentes a las redes de gas.

Esta tesis pone de manifiesto el enorme potencial que permanece inexplorado en el lado de la demanda de gas natural, el cual podría ser utilizado por los operadores de la red gasista para la solución de restricciones técnicas, servicios de balance u optimización de la programación de los almacenamientos subterráneos. Este potencial resulta especialmente interesante en estos momentos, cuando en algunos países europeos se ha comenzado la instalación masiva de contadores inteligentes de gas, infraestructura que facilitaría la utilización de recursos de respuesta de la demanda para el mejor funcionamiento de las redes de gas.

La tesis presenta, en primer lugar, un análisis exhaustivo de los programas de respuesta de la demanda utilizados en la actualidad en sistemas eléctricos alrededor del mundo, 
identificándose aquellos servicios que podrían ser igualmente aplicables al sector gasista A continuación se analiza la estructura tradicional en base a la que los sistemas gasistas se han desarrollado en diversos países. De cara a un mejor aprovechamiento de los recursos y a la optimización de su funcionamiento, se propone a continuación una arquitectura basada en el concepto de red inteligente, donde se identifican los agentes que participarían en esta estructura y se enfatiza el rol que los consumidores desempeñarían no sólo como demandantes de energía, sino también como proveedores de servicios de red. Este papel activo de la demanda necesita de la utilización de tecnologías de medición, control y comunicación adecuadas, aspecto que también se analiza en detalle.

En base a los resultados del análisis mencionado, esta tesis propone una nueva metodología para el desarrollo y evaluación de mecanismos de respuesta de la demanda que permitan una mayor participación de los consumidores de gas en la provisión de servicios de operación al gestor de la red, aumentando la eficiencia conjunta del sistema y reduciendo los costes asociados a dichos servicios.

La metodología propuesta ha sido aplicada con éxito a la red gasista de Italia, donde los servicios de operación analizados han sido evaluados en una ciudad de 16.000 habitantes ubicada en el área centro-norte italiana. En dicha ciudad, los consumidores han sido agrupados por uso final, sector y tamaño, lo que ha puesto de manifiesto la necesidad de potenciar el papel del agregador para valorizar el potencial de los consumidores más pequeños, tanto si reciben un suministro de gas directo o a través de una red de calor distribuido.

Los resultados expuestos en esta tesis deberían impulsar a los reguladores a incentivar la utilización de la flexibilidad de los consumidores a fin de incrementar la eficiencia del sistema de gas natural, ya que reduce los costes de operación al tiempo que favorece la participación de los clientes en una estructura energética más dinámica. Esta participación de los clientes resulta esencial para la correcta gestión de los sistemas energéticos inteligentes, llamados a ser redes energéticas del futuro. 
Els sistemes energètics estan evolucionant cap a estructures en què el paper exercit pel consumidor és cada vegada més important. Avui dia, els consumidors ja no són els ens passius d'antany als quals calia subministrar energia de forma unidireccional (de la xarxa al client), sinó que també poden subministrar energia a la xarxa a través de recursos renovables, capacitat d'emmagatzematge mitjançant les bateries dels seus vehicles elèctrics o serveis d'operació a través de la utilització de la seva flexibilitat. No obstant això, en parlar de xarxes intel·ligents, en moltes ocasions se sobreentén únicament quant al subministrament $\mathrm{i}$ consum d'electricitat, obviant altres dimensions com poden ser el gas natural, l'aigua calenta sanitària o el transport.

En aquest marc, aquesta tesi suposa un enfocament nou pel que fa al paper dels consumidors en el sector del gas natural. Si bé és cert que els consumidors d'electricitat han participat des de fa anys en diferents serveis d'operació relacionats amb l'ús de la seva flexibilitat (especialment en països com els Estats Units i, més recentment, a la Unió Europea), la utilització de la resposta de la demanda en el sector gasista ha estat fins ara inexistent. No obstant això, l'èxit d'iniciatives de resposta de la demanda en els sistemes elèctrics i la seva similitud amb el sector gasista, el desenvolupament normatiu i tecnològic s'ha realitzat en paral·lel en els últims anys, permet esperar resultats igualment reeixits en aplicar programes equivalents a les xarxes de gas.

Aquesta tesi posa de manifest l'enorme potencial que roman inexplorat en el costat de la demanda de gas natural, el qual podria ser utilitzat pels operadors de la xarxa gasista per a la solució de restriccions tècniques, serveis de balanç o optimització de la programació dels emmagatzematges subterranis. Aquest potencial és especialment interessant en aquests moments, quan en alguns països europeus s'ha començat la instal·lació massiva de comptadors intel-ligents de gas, infraestructura que facilitaria la utilització de recursos de resposta de la demanda per al millor funcionament de les xarxes de gas.

La tesi presenta, en primer lloc, una anàlisi exhaustiva dels programes de resposta de la demanda utilitzats en l'actualitat en sistemes elèctrics voltant del món, identificant-se aquells serveis que podrien ser igualment aplicables al sector gasista. A continuació s'analitza l'estructura tradicional sobre la base de la qual els sistemes gasistes s'han 
desenvolupat en diversos països. De cara a un millor aprofitament dels recursos i al a optimització del seu funcionament, es proposa a continuació una arquitectura basada en el concepte de xarxa intel ligent, on s'identifiquen els agents que participarien en aquesta estructura i s'emfatitza el paper que els consumidors exercirien no només com a demandants d'energia, sinó també com a proveïdors de serveis de xarxa. Aquest paper actiu de la demanda necessita de la utilització de tecnologies de mesurament, control i comunicació adequades, aspecte que també s'analitza adequadament.

En base als resultats de l'anàlisi esmentat, aquesta tesi proposa una nova metodologia per al desenvolupament i avaluació de mecanismes de resposta de la demanda que permeten una major participació dels consumidors de gas a la provisió de serveis d'operació al gestor de la xarxa, augmentant l'eficiència conjunta del sistema i reduint els costos associats a aquests serveis.

La metodologia proposada ha estat aplicada amb èxit a la xarxa gasista d'Itàlia, on els serveis d'operació analitzats han estat avaluats en una ciutat de 16.000 habitants ubicada a l'àrea centre-nord italiana. En aquesta ciutat, els consumidors han estat agrupats per ús final, sector i grandària, el que ha posat de manifest la necessitat de potenciar el paper de l'agregador per valoritzar el potencial dels consumidors més petits, tant si reben un subministrament de gas directe o a través d'una xarxa de calor distribuïda.

Els resultats exposats en aquesta tesi haurien d'impulsar els reguladors a incentivar la utilització de la flexibilitat dels consumidors a fi d'incrementar l'eficiència del sistema de gas natural, ja que redueix els costos d'operació i alhora afavoreix la participació dels clients en una estructura energètica més dinàmica. Aquesta participació dels clients és essencial per a la correcta gestió dels sistemes energètics intel-ligents, cridats a ser xarxes energètiques del futur. 


\section{Table of contents}

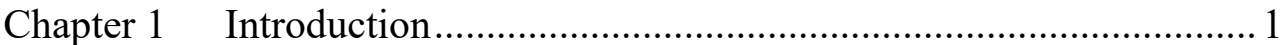

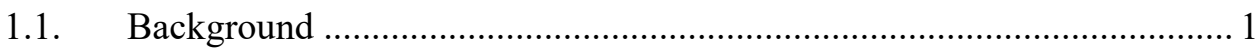

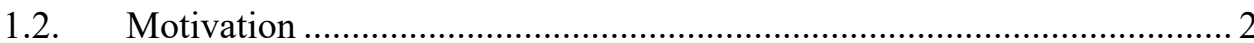

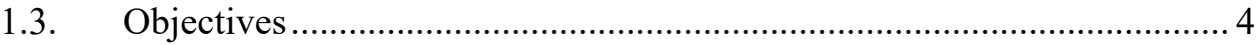

1.4. Organization of the Dissertation......................................................... 5

Chapter 2 Demand response strategies in power systems: potential application to the management of natural gas infrastructures ......................................................................... 7

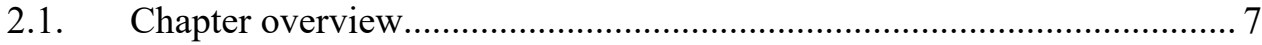

2.2. Demand response applications in Europe and the United States to

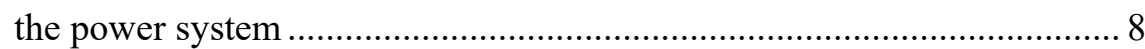

2.2.1. Classification of demand response actions ………….................................. 8

2.2.2. Classification of Demand Response Programs ................................................ 10

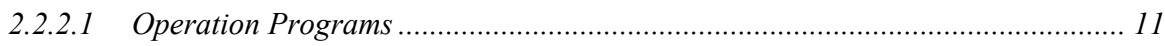

2.2.2.2 Economic Based Programs ........................................................................... 12

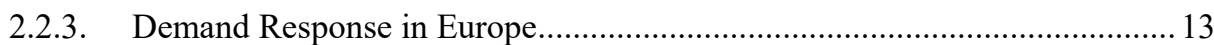

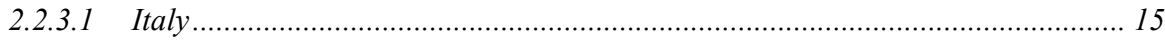

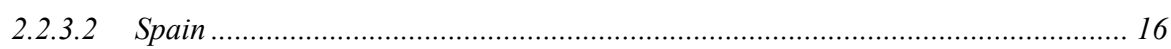

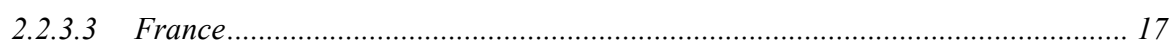

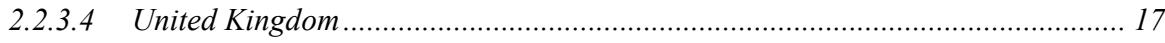

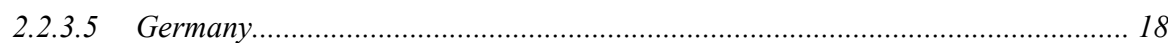




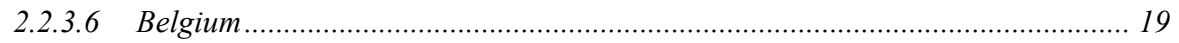

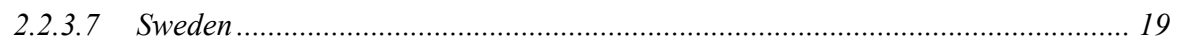

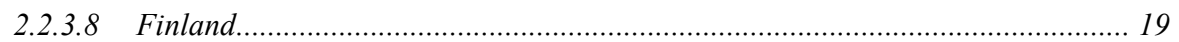

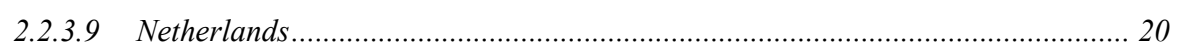

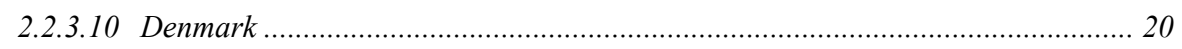

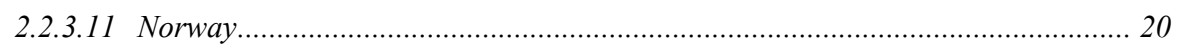

2.2.4. Demand Response in the United States ......................................................21

2.2.4.1 DR Programs Offered by System Operators ........................................................ 24

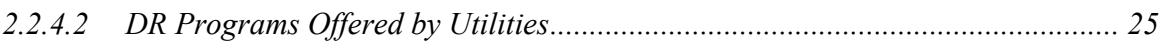

2.3. International experiences of demand response applications to natural

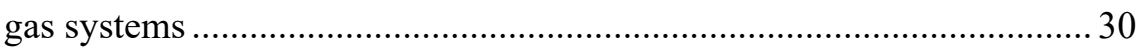

2.4. Analogy between power and natural gas systems .................................. 32

2.5. Barriers to the implementation of demand response strategies in the

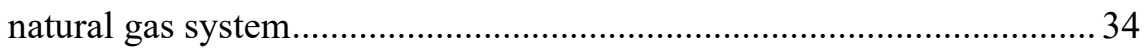

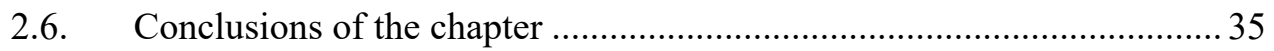

Chapter 3 Smart grid configuration for natural gas systems .................. 37

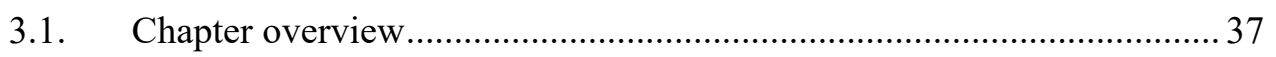

3.2. Traditional architecture of the natural gas system ................................... 38

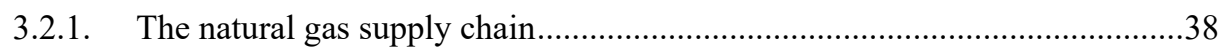

3.2.2. The natural gas system in the United States of America.................................40

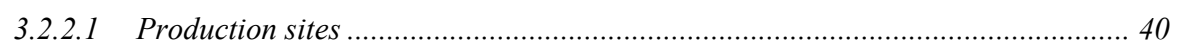

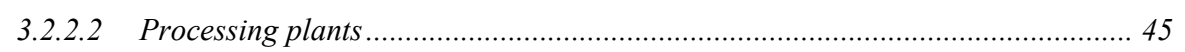

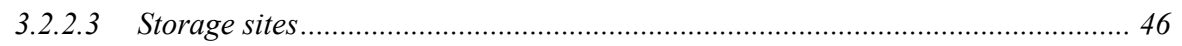

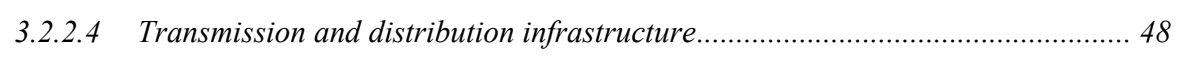

3.2.2.5 Analysis of the natural gas consumption............................................................. 53

3.2.3. The natural gas system in Europe ...........................................................56

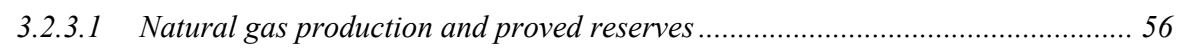

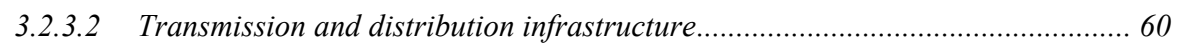

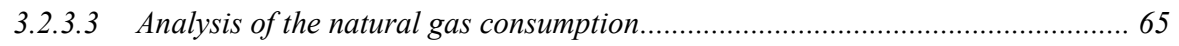

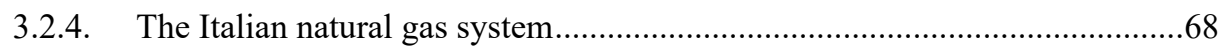

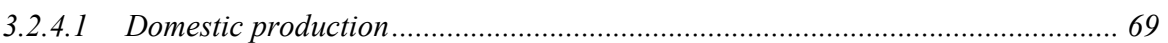




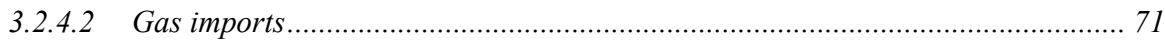

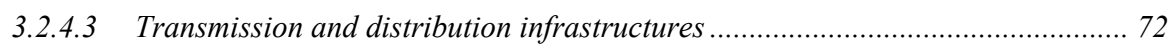

3.2.4.4 Analysis of the natural gas consumption............................................................. 74

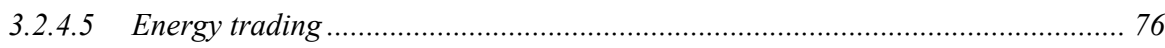

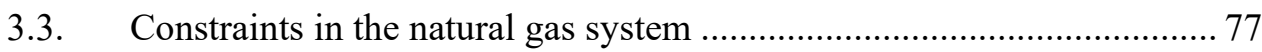

3.3.1. Gas network constraints in the United States of America ............................ 80

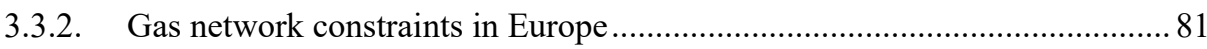

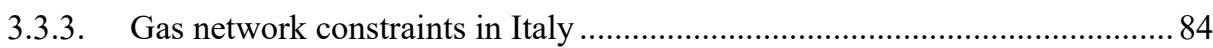

3.4. Smart metering and smart cities in the European Union ...................... 88

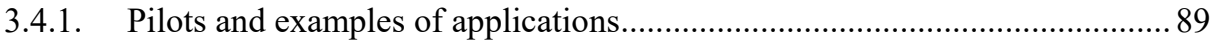

3.4.2. Massive roll-out of smart gas meters in Europe ............................................ 90

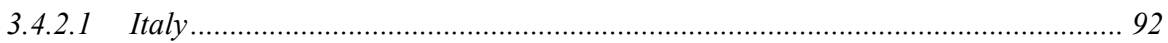

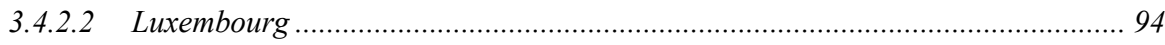

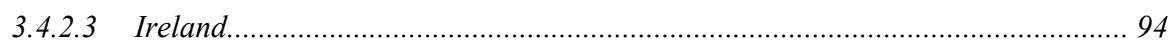

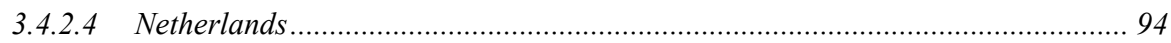

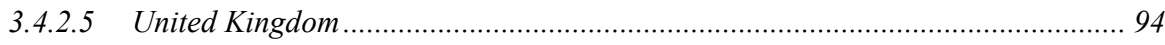

3.5. Architecture of a smart natural gas system........................................ 95

3.5.1. Agents in a smart natural gas system........................................................ 96

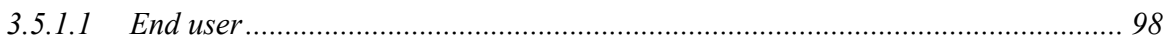

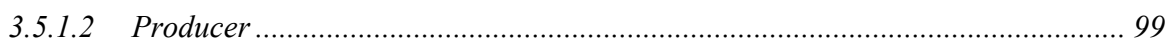

3.5.1.3 Gas store operator .................................................................................... 100

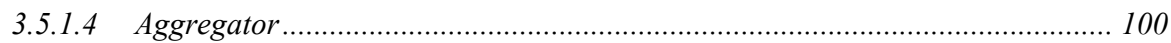

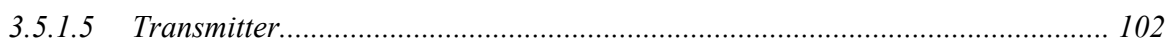

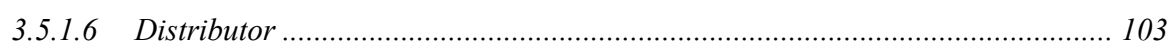

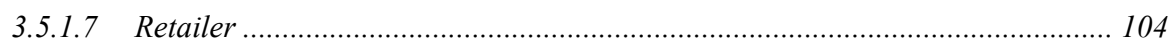

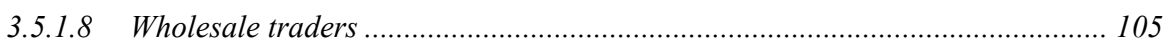

3.5.1.9 Transmission system operator ……............................................................. 105

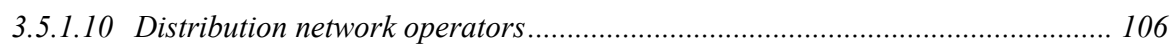

3.5.1.11 Wholesale market operator ........................................................................... 107

3.6. The district heating operator as Demand Response aggregator............. 109

3.6.1. District heating system in the United States of America ............................. 110

3.6.2. District heating systems in Europe ......................................................... 113 


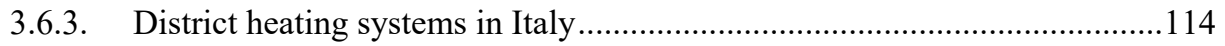

3.6.4. Cost-benefit assessment of district heating systems .....................................116

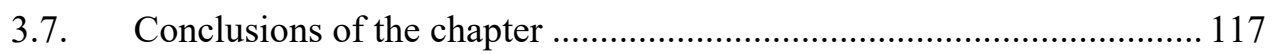

Chapter 4 Metering and communication technology: smart gas

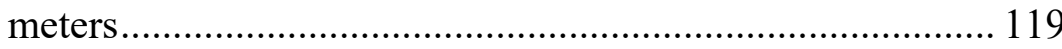

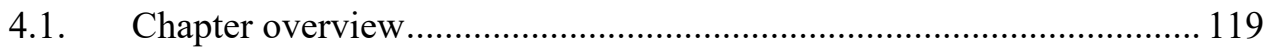

4.2. Smart metering system and smart devices........................................... 120

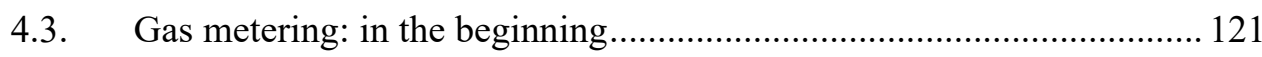

4.4. Smart meters: the new challenge of the gas supply system.................. 125

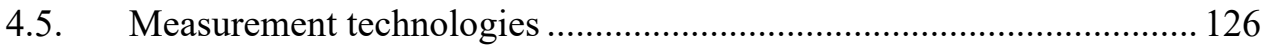

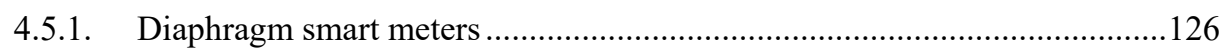

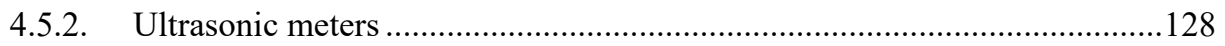

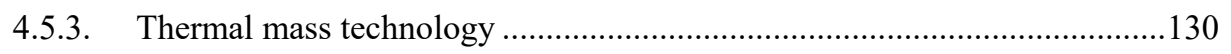

4.6. New communication components and remote control device ............... 131

4.6.1. LCD Display and scrolling buttons..........................................................133

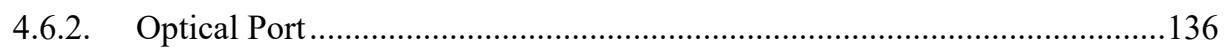

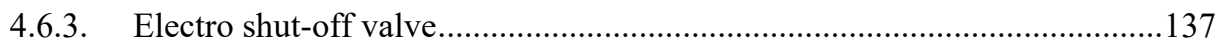

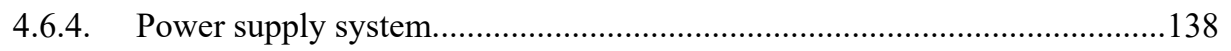

4.6.5. Electronic modules and communication devices .......................................138

4.7. Smart grid communication architecture: focus on Italy........................ 142

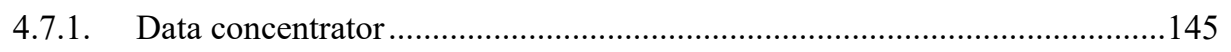

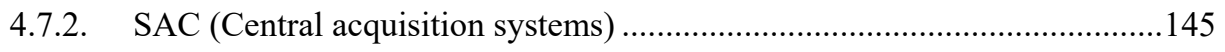

4.8. Communication and remote control devices for the DR integration ..... 146

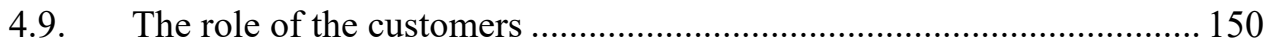

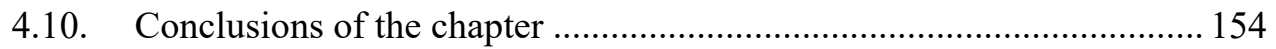

Chapter 5 Methodology for the application of demand response principles to the natural gas system ..................................... 155

X 


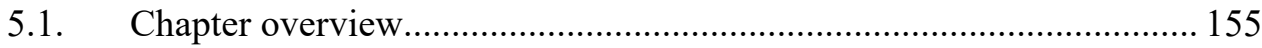

5.2. General structure of the methodology …............................................. 156

5.3. Phase I: Initial specification of actions ............................................... 160

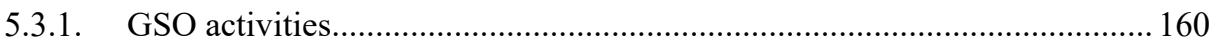

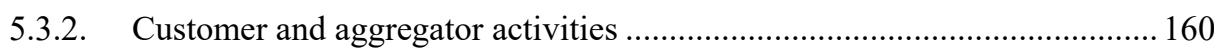

5.4. Phase II: Technical evaluation.............................................................. 162

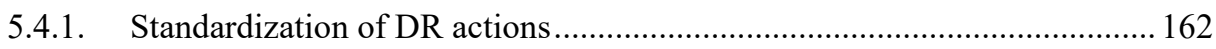

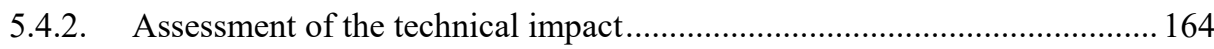

5.5. Phase III: Economic evaluation........................................................... 166

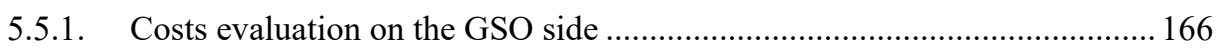

5.5.2. Cost evaluation on the customer/aggregator side ......................................... 168

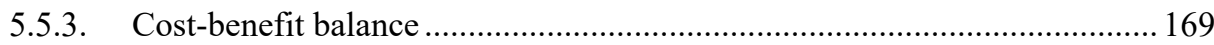

5.6. Phase IV: Environmental evaluation ................................................. 171

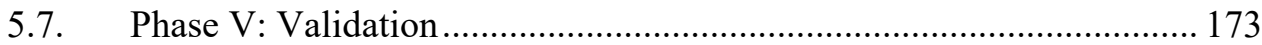

5.8. Phase VI: Final specification of DR products ..................................... 174

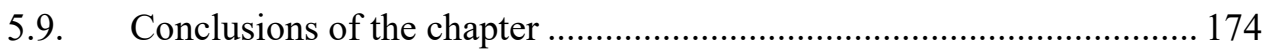

Chapter 6 Case of application: DR evaluation in the Italian natural

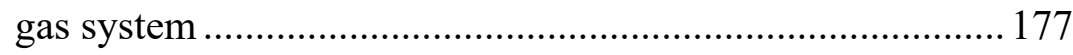

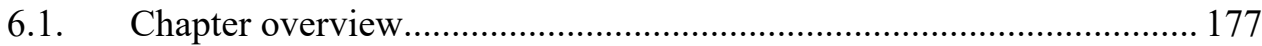

6.2. Considered scenarios: DR strategies and case description .................... 177

6.2.1. Period of analysis and characterization of the natural gas balancing

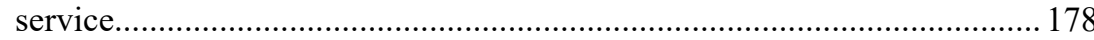

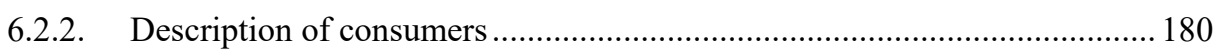

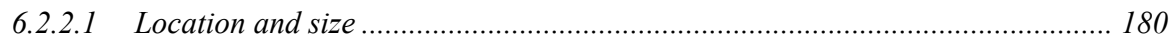

6.2.2.2 Classification of consumers .................................................................... 181

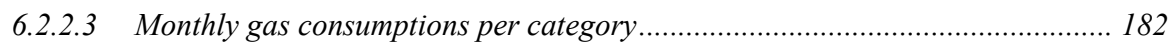

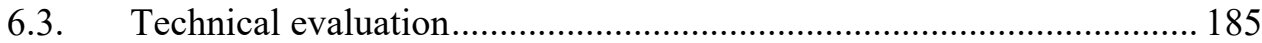

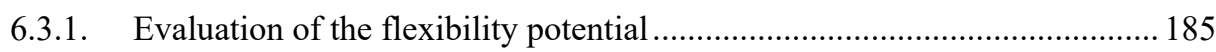


6.3.2. Evaluation of customer's participation in gas balancing services 186

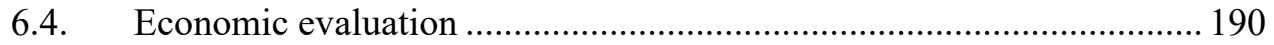

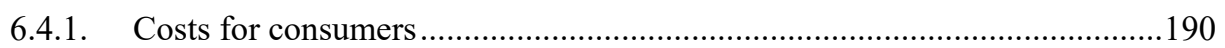

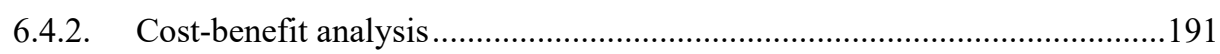

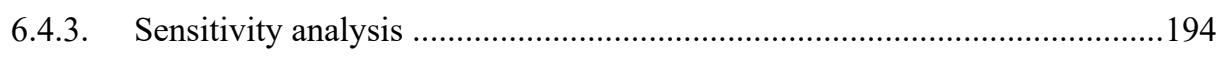

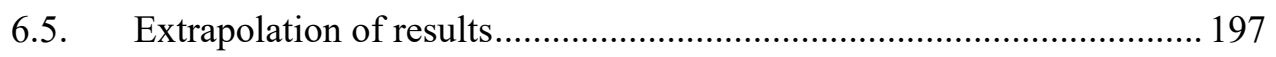

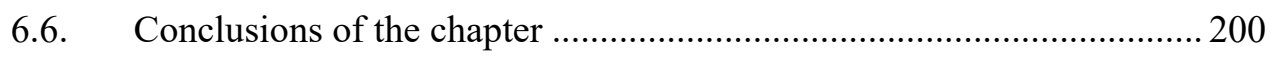

Chapter 7 Conclusions................................................................. 201

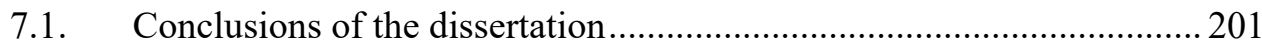

7.1.1. Identification of electricity and natural gas analogies for DR applications Identification of promising DR potential applicable to the natural gas

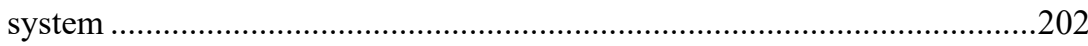

7.1.3. Enhancement of the smart grid architecture in the natural gas system for

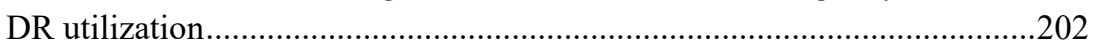

7.1.4. Development of a methodology for the specification of DR products in the natural gas system ........................................................................203

7.1.5. Application of the methodology: Evaluation and assessment of DR applications in the Italian natural gas system........................................203

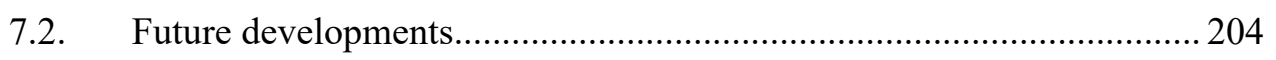

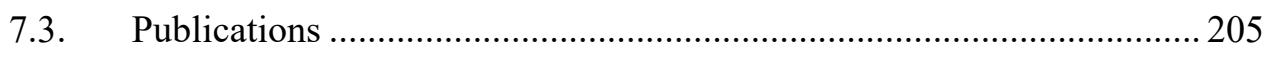




\section{Figures}

Figure 2.1. Different types of demand response actions 9

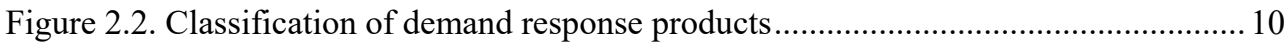

Figure 2.3. Regional power markets in Europe................................................................... 14

Figure 2.4. Demand response forecast in UCTE countries from 2008 to 2020 .................. 15

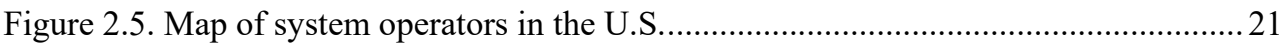

Figure 2.6. Map of the electricity markets in the U.S. ...................................................... 22

Figure 2.7. Potential Peak Reduction from U.S. ISO and RTO DR Programs. Dec 2016 .

Figure 2.8. Electric utility demand-side management programs in the U.S.

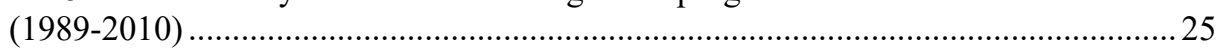

Figure 2.9. Peak savings in the US by customers enrolled in utility DR programs ............26

Figure 2.10. Number of customers enrolled in utility DR programs................................ 27

Figure 3.1. Natural gas supply chain. Source: ENAGAS ................................................. 38

Figure 3.2. Global production of natural gas by country in 2016 (Source: Haver analytics)

Figure 3.3. US Total Natural gas production and imports, and annual changes in production and imports (1983-2016) (Source: Own elaboration using EIA data) ....... 41

Figure 3.4. Gas production regions in USA (Source: EIA) ........................................... 42

Figure 3.5. Shale gas production in USA (Source: Own production using EIA data base).

Figure 3.6. Numbers of gas wells for natural gas production in USA (Source: Own production using EIA)

Figure 3.7. Natural gas production per State in 2015 (Source: EIA) ................................. 44

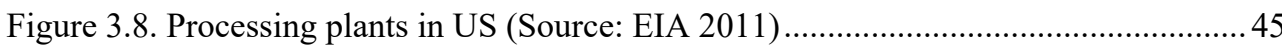


Figure 3.9. Compressor stations on USE (Source: EIA 2008) ……………………...........46

Figure 3.10. Type and total field capacity (Bcf) of the underground storage in the USA (Source: EIA energy mapping system, July 2014)

Figure 3.11. Underground gas storage operation schedule in US, in Bcf (Source: EIA database)

Figure 3.12. Natural gas market centers and hubs in relation to major natural gas transmission corridors (Source: American energy mapping- 2013)...

Figure 3.13. Import and export of NG in US (Source: Own elaboration of EIA DATA)

Figure 3.14. U.S. Natural Gas Import/Export Locations, as of the end of 2008 (Source: EIA Energy Information Administration, Office of Oil and Gas, Natural Gas Division, Imports/Export Points Database

Figure 3.15. Imports from Canada and Mexico (Source: Own elaboration using EIA data)

Figure 3.16. Exports from Canada and Mexico (Source: Own elaboration using EIA data)

Figure 3.17. Imports by pipelines and by ship [Source: Own production using EIA Data].

Figure 3.18. Gas trading location and gas volume capacity .............................................52

Figure 3.19. Evolution of natural gas consumption in the US, 2001-2017 ...........................53

Figure 3.20. Monthly gas consumption in USA, 2013-15 (Source: Own elaboration with EIA data)

Figure 3.21. Annual consumption of natural gas by final end use

Figure 3.22. Trend of the NG consumption in USA (Source: Own elaboration with EIA Data)

Figure 3.23. Natural gas production in Europe (Source: CIA World Factbook 2014) .........57

Figure 3.24. Evolution of natural gas production in the last years for different areas in the world (Source: Own elaboration with data from BP plc tools 2016).....

Figure 3.25. Natural gas production in OEDC Europe in 2015, per country (Source: BP Statistical review of world energy, 2016).

Figure 3.26. Shale gas reserves in Europe (Source: EIA)....................................................60

Figure 3.27. Natural gas pipelines and LNG terminals in Europe......................................61

Figure 3.28. Natural gas imports in Europe and Eurasia, per country (source: Own elaboration with data from the BP statistical review of world energy 2016) .63 
Figure 3.29. Natural imports according the countries of origin (BP Statistical

Review 2016)

Figure 3.30. Existing and planned LNG terminals in Europe (2016)

Figure 3.31. Evolution of the natural gas consumption in Europe and Eurasia

(Source: Own elaboration with data from EIA).

Figure 3.32. Variation of the natural gas consumption in European countries from 2014 to 2015 (Source: Own elaboration with data from EIA)

Figure 3.33. Natural gas consumption in European countries, 2015 (Source: Annual report AEEGSI -2016).

Figure 3.34. Annual evolution of the natural gas consumption in Europe 1990-2013, per sector (Source: European Environmental Agency)....

Figure 3.35. Forecast of the OECD Europe natural gas consumption by end users sector, 2012-2040, in Tcf (Source: EIA)

Figure 3.36. Italian annual natural gas production and consumption, 1980-2015

(Source: BP Statistical data)

Figure 3.37. Natural gas production sites in Italy and national entry and exit points (Source: SNAM rete gas)

Figure 3.38. Natural gas imports in Italy in 2015 per country of origin (Source:

Own elaboration with data from the BP statistics)

Figure 3.39. Natural gas consumption in Italy per sector, in $\mathrm{Gm}^{3}$ (Source: SRG data).

Figure 3.40. Implementation of new pipelines in USA (Source: New pipeline projects increase Northeast natural gas takeaway capacity, January 28,2016$)$........... 81

Figure 3.41. Proved reserves of natural gas worldwide (Source: Eni 2012). 82

Figure 3.42. Smart metering roll-out in Europe (Source: Smart Metering deployment in the European Union-2017)

Figure 3.43. Percentage of smart meter gas installed in Italy in 2013-2015 (Source: RAV2015 AEEGSI)

Figure 3.44. Activities of the end user. .98

Figure 3.45. World gas reserves (Source: Oil \& Gas journal, "Worldwide report 2003)

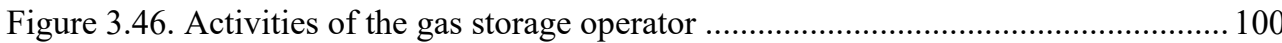

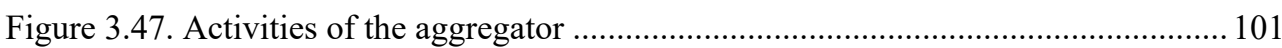

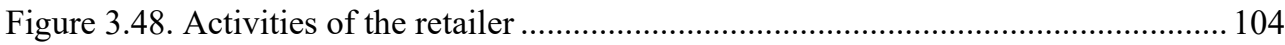


Figure 3.49. Activities of the transmission system operator...............................................106

Figure 3.50. Activities of the distribution network operator ..............................................107

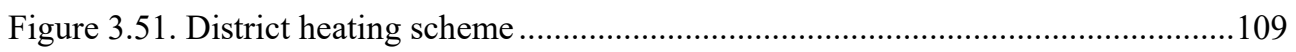

Figure 3.52. The district heating in USA (Source: Environmental and Energy Study Institute - 'What is District Energy?' September 2011) ............................................110

Figure 3.53. Rate of thermal energy produced by district heating in Europe, per country (Source: Potenziale del teleriscaldamento in Italia, FIPER 2013)

Figure 3.54. Geographical distribution of the thermal energy supplied by district heating systems in Italy (Source: GSE, 2015)...

Figure 4.1. Operation of a diaphragm mete gas (Source: $\mathrm{http}: / /$ incoedile.altervista.org) .....

Figure 4.2. Traditional diaphragm gas meter (Source: http://www.autometers.co.uk).......122

Figure 4.3. The working flow range $\left(\mathrm{Nm}^{3} / \mathrm{h}\right)$ of a gas meters ........................................123

Figure 4.4. Different types of smart meters gas available on the market ...........................125

Figure 4.5. Trend of the MPE and Pressure drop in a Diaphragm smart meters. ...............128

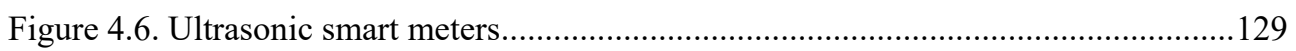

Figure 4.7. Operation of thermal mass meters (Source: www.metersit.it) ……………......130

Figure 4.8. Description of the components of a gas smart meter (Source: http://www.metersit.com/images/catalogo-generale-it-en-metersit.pdf)....................132

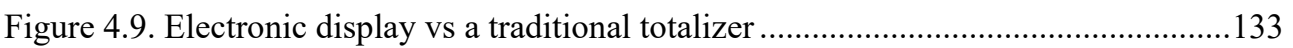

Figure 4.10. Optical port connected through a ZVEI probe (Source:

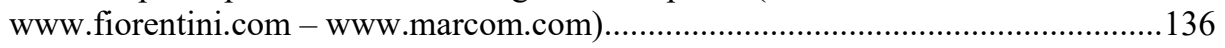

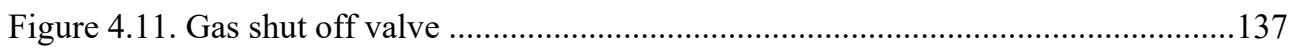

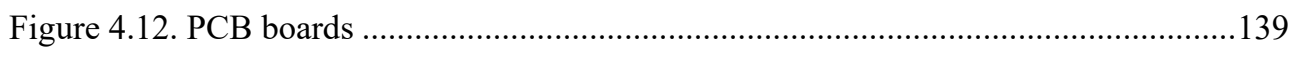

Figure 4.13. Point-to-Point Communication Technology .................................................143

Figure 4.14. Point-to-Multipoint Communication Technology ..........................................144

Figure 4.15. Energy supply systems with DR program devices ...........................................148

Figure 4.16. DR management communication infrastructure.............................................149

Figure 4.17. The role of a consumers in the smart meter system ......................................152

Figure 5.1. Methodology for the implementation of DR strategies in the natural gas sector.

Figure 5.2. Phase 1: Initial Specification. 160

XVI 
Figure 5.3. Standard definition of a DR action for a flexible gas consumer 163

Figure 5.4. Phase 1I: Technical Evaluation................................................................. 165

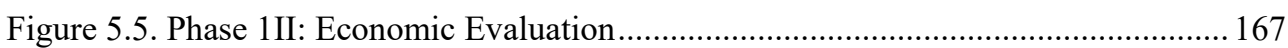

Figure 5.6. Phase IV: Environmental Evaluation........................................................... 172

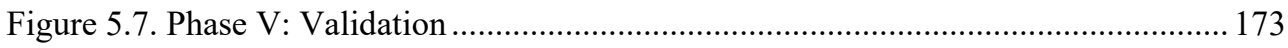

Figure 5.8. Phase VI: Final specification of DR products............................................... 174

Figure 6.1. Prices and amounts of gas for balancing in Italy 2015-2016 (source: Snam)

Figure 6.2. Location of the region of The Marches in Italy ............................................ 180

Figure 6.3. Towns' classification in the region of The Marches, Italy (2012) ................... 181

Figure 6.4. Natural gas load curve profile of consumers in a town of $16,000 \mathrm{inh}$............ 182

Figure 6.5. Natural gas load curve profiles per category .............................................. 183

Figure 6.6. Monthly gas consumption for the considered town of 16,000 inh. October 2015 - September 2016

Figure 6.7. Comparison between the monthly rate of consumption for the considered rate and the whole distribution area of $2 \mathrm{i}$ Rete gas in Italy.....

Figure 6.8. Estimated flexibility potential of gas customers in a town of 16,000 inh........ 187

Figure 6.9. Histogram on the number of consecutive days of gas reduction for balances

Figure 6.10. Example of gas demand packages managed by an aggregator for balancing purposes

Figure 6.11. Daily schedule of DR resources to be used for balancing purposes 189

Figure 6.12. Economic evaluation of DR participation in balancing of the gas network.

Figure 6.13. Economic benefits for customers and the GSO for different DR prices.....

Figure 6.14. Gas DR Potential in towns with a population between 10,000 and 20,000 inhabitants, per region (MWh/year) 


\section{Tables}

Table 2.1. System operators in the United States of America ........................................... 23

Table 3.1. Total proved reserves of natural gas in Europe .............................................. 59

Table 3.2. Consumption and production of natural gas in Italy, 2016............................... 68

Table 3.3. Natural gas imports and exports in Italy in billions of $\mathrm{m}^{3}, 2014-2015$.............. 72

Table 3.4. Characteristics of the entry points into the Italian gas network ......................... 72

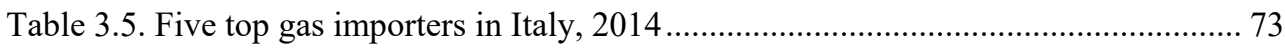

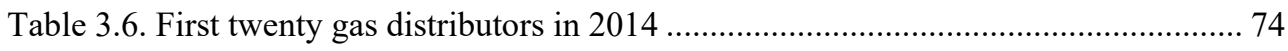

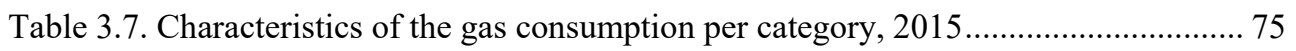

Table 3.8. Earthquake in Italy between the $1^{\text {st }}$ January 2017 and the $1^{\text {st }}$ April 2017 .......... 86

Table 3.9. Most significant district heating facilities in the U.S..................................... 111

Table 4.1. Maximum permissible Error - MPE ............................................................. 123

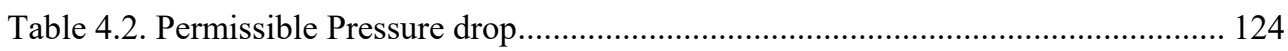

Table 4.3. Classification of meters' class by flow rate .................................................... 124

Table 4.4. Example of list of parameters shown on a LCD display ................................ 134

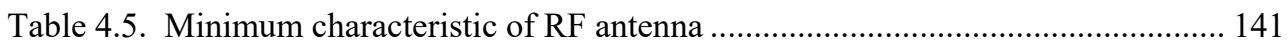

Table 4.6. Characteristic of GPRS communication system.............................................. 142

Table 5.1. Greenhouse emission factors for natural gas. Source: EPA, 2014 ................. 171

Table 6.1. Annual consumption of gas per category ........................................................ 184

Table 6.2. Estimated cost of flexibility for customers ................................................ 191

Table 6.3. Monthly summary of DR participation in gas balancing services ................... 193

Table 6.4. Price of natural gas in the Italian retail market ............................................... 194

Table 6.5. Sensitivity analysis: economic benefits of DR for different offer prices......... 195

Table 6.6. Sensitivity analysis: relative benefits of stakeholders ................................... 196

XVIII 
Table of contents

Table 6.7. Number of towns with a population between 10,000 and 20,000 inhabitants in Italy, per region. . .198 



\section{Chapter 1 Introduction}

\subsection{Background}

The concept of "smart grid" is not clearly established within the scientific and technologic community. One of the first definitions appeared in the Energy Independence and Security Act of 2007, which in its Title XIII provides the characteristics which would define an electricity system as Smart Grid [1]. According to the International Electrotecnichal Commission, a Smart Grid is an electric system endowed with monitoring, control and communication technologies in order to efficiently deliver sustainable, economic and secure electricity supply ${ }^{1}$. However, the concept of Smart Grid can be more widely used, not just applied to the electrical system but also to other energetic and non-energetic infrastructures such as the natural gas network, the clean water supply or the transport of people and goods.

In that understanding, the European Commission defines a Smart City as "a city seeking to address public issues via $\mathrm{ICT}^{2}$-based solutions on the basis of a multi-stakeholder, municipally based partnership" [2]. Here, the concept "Smart" is not just applied to the power system, but also to any other infrastructure enabled by ICT's for the provision of customer's services. According to this more general definition, a Smart Natural Gas System could be defined in equivalent terms to those used by IEC but applied not to the supply of electricity, but natural gas.

Opportunities and benefits for Smart Grids may be different for the electricity and natural gas sectors [3]. However, as discussed in section 2.4, electric and natural gas systems share numerous characteristics which make them comparable in many aspects, especially

\footnotetext{
${ }^{1}$ http://www.iec.ch/smartgrid/background/explained.htm

${ }^{2}$ Information and Communications Technology (ICT)
} 
those related to the system operation. Therefore, strategies successfully used for the operation of electricity systems could be expected to have similar results when applied to the natural gas network.

One tool that has been used for years in the operation of electricity systems is Demand Response (DR), which has provided major benefits not just in terms of operability, but also economic and environmental. However in spite of the similarities existing between the electricity and natural gas systems, there are no successful experiences of DR applications in the natural gas system.

DR has been considered by different researchers as a key tool for the management of Smart Grids [4], [5]. Therefore, it is a matter of time that, sooner or later, such concepts can be applied for a more efficient operation of natural gas systems.

One substantial tie between gas and electricity is the utilization of the first one for power production. Indeed, some efforts have demonstrate that the utilization of flexible natural gas fired generators combined with demand response is an excellent blend so as to favor the integration and valorization of renewable intermittent energy sources, such as solar or wind power [6]. Nevertheless, this is just one of the multiple applications that DR resources based on natural gas customer's flexibility may have for the coming smart energy systems. In this framework, this dissertation evidences the benefits that DR applications may entail for the management of the gas network in terms of efficiency and cost.

\subsection{Motivation}

Natural gas is one of the major energy vectors worldwide. In the United States, natural gas covers the $24 \%$ of the total energy demand of the country [7]. In Europe, natural gas represents the $30 \%$ of the primary energy consumption, being already the most used energy source including renewables [8]. One of the reasons for this success is that this resource emits much less $\mathrm{CO}_{2}$ than other fuels due to the low carbon content of methane, so that it is expected to be the most used fossil fuel internationally in the short and medium term [9].

Natural gas is used for multiple purposes, not just for heating, but also for the production of air conditioning, which has been the main responsible of the increment experienced in Europe during the last two years [10]. However, there are limitations that are intrinsically linked to the nature of this energy source. Many countries where natural gas is essential for the coverage of their energy needs do not have gas deposits on their own territories, which make them strongly dependent from foreign nations. In many European countries, dependency on gas supply from countries which may be politically unstable such as Algeria or Russia, may produce untimely interruptions of supply in the short term [11]. In this scenario, the utilization of storage results essential, which may be combined with flexible demand, properly managed by means of some kind of interruptible contracts or more suited DR products. 
As mentioned before, DR has been a common practice in electricity systems for years, existing many successful examples of application around the world. However, this sort of strategies has been never applied to the management of natural gas systems, where the existing similarities with the power system allows to expect similar results. Therefore, the adaptation of current DR products on electric systems or the design and deployment of more specific DR programs for gas applications is a key aspect which should be further explored.

DR can be also an essential tool for the usual operation of the grid in a more efficient way. Gas system operators must daily balance the amount of natural gas in the pipelines so as to guarantee that the amount consumed from and injected to the network is equilibrated. Moreover, the daily amount of natural gas injected to or extracted from underground stores must remain within the limits technically established in order to keep enough reserves in the system. Therefore, the ability of consumers willing to offer their flexibility may be used for reducing imbalances in the natural gas network and, therefore, reducing the need to pay large amounts of money in the short-term wholesale market.

On the other hand, the growing utilization of natural gas produces in the network technical constraints, which may produce transmission and distribution infrastructures overload or even interruption of supply to customers. However, such constraints have an intense seasonal component, as natural gas consumption is usually higher in winter. Therefore, the capital investment required for building more infrastructures is not always justified as they may be just occasionally needed [12]. Here, the utilization of customers' flexibility would be much more justified than building more infrastructures or reinforce existing ones only to cover occasional peaks of demand.

According to the previous statements, the application of DR principles to the management of the natural gas network seems reasonable. However, there are no examples of DR applications in the world where these resources are used for this purposes. In this sense, the present dissertation proves the convenience of enabling customers so as to provide their flexibility for operation issues in natural gas systems, which would provide significant benefits for the whole system while providing also economic incentives to end users.

Energy systems are evolving towards the so-called smart configuration. Similarly to in the case of electrical smart grids, DR may help one more time to better integrate the different elements in these "intelligent" networks, adjusting the level of consumption to the availability of energy resources in real time.

The research described in the present document has been carried out within the Institute for Energy Engineering of the Polytechnic University of Valencia (UPV), and partially, during a one year research stay at the Power Center for Utility Explorations (PCUE) of the State University of New York at of Buffalo (USA). These groups have extensive experience in the Price Demand Response field, gained in noteworthy research collabo- 
ration projects in Europe and the USA, including "Demand Response in Industrial Production DRIP", focused on the assessment and exploitation of the potential flexibility within the energy consuming processes of industrial customers. Moreover, the author has acquired experience in the management of natural gas systems while working with the company $2 i$ Rete Gas S.p.A. (former Enel Rete Gas S.p.A.) the second largest Italian gas distribution operator. This experience has grown there in such research initiatives as the "Avogadro Project", a pilot conducted in north Italy in order to replace traditional gas meters by smart devices, developing a telecommunication network in the country which, based on the results presented on this dissertation, may be used for DR applications.

The present dissertation builds on the work performed by the author during the last five years at the mentioned institutions, focusing on achieving better management of natural gas resources and the related infrastructures.

\subsection{Objectives}

Even if the active participation of the demand side results essential for the proper development and management of energy systems, initiatives on this direction have rarely occurred in the natural gas sector. Therefore, this dissertation is targeted to make some contributions in this area. Specifically, this dissertation is focused on the development of a novel methodology to be used for DR programs design and the assessment of customer's flexibility so as to actively participate in the operation of natural gas systems. In this line, the objectives of this work are as follows:

- To evaluate the potential application to natural gas systems of DR programs and initiatives which have been successfully used in the electricity sector. Electricity and natural gas systems present many similarities in terms of architecture, management and operability. Therefore, strategies that have resulted in significant benefits for power systems may entail similar results when applied to the natural gas network.

- To assess the necessary structures which may enable natural gas systems as smart grids where the participation of consumers becomes more dynamic and flexible. The role of the different agents which would take part under this configuration needs to be analyzed and defined, as well as the relations which may be established among the different components of the grid. Moreover, technologies related to metering, communication and control have to be properly addressed.

- To provide customers and gas system operators with the adequate tools for the creation, evaluation and validation of DR products to be used in the natural gas sector. This objective should be addressed by the design of a systematic procedure so as to determine the impact of the application of DR strategies under both the customer and the network operator perspectives. Demand side participation 
in energy markets does not happen spontaneously, so that new tools are required for such evaluation.

- To assess the economic impact that DR programs may potentially have on the operation of natural gas systems, related to the retribution that customers may receive in exchange for their services.

\subsection{Organization of the Dissertation}

This dissertation is divided into seven chapters, which structure the work in order to achieve the above objectives.

Chapter 2 presents the background of demand response issues applied to power systems around the world, including a complete summary of the main demand response programs existing in both the U.S. and the European Union (EU), whether these are offered by utilities or system operators. The most significant characteristics of DR programs in power systems are analyzed in order to identify which aspects may be applicable to the natural gas sector. A comparison between the power and natural gas system is done, and some barriers for the application of DR concepts to this last sector are identified.

Chapter 3 analyzes how natural gas systems are made in different countries of and why the development of this kind of systems under the smart grid configuration results essential for de efficient operation of energy systems, where the natural gas is one of the main vectors.

The need of a robust metering architecture will be justified in Chapter 4 in order to enhance the role of the customer as a main actor in smart energy systems, where the application of DR concepts becomes an essential tool for the optimum operation of the whole system. A detailed revision on the metering infrastructure existing in natural gas systems worldwide and the tendency towards a smart grid configuration will be analyzed, identifying the most suitable configurations and devices for DR applications.

Based on the evaluation mentioned before, a methodology for the application of DR principles to the natural gas system is developed in Chapter 5 as one of the most significant contributions of the dissertation. This methodology will help to identify the most appropriated kind of DR programs which may enable customers to participate in the natural gas system operation so as to make it more efficient and manageable. This chapter proposes a method for the technical, environmental and economic evaluation of the considered DR products, either at the customer or the system points of view.

This methodology is validated and applied to the Italian natural gas system in Chapter 6, where the massive implementation of smart metering devices at the customer side is taking place.

Finally, Chapter 7 details the most relevant conclusions of the present study, including a summary of the main contributions and an outline of possible areas for future research. 



\section{Chapter 2 Demand response strategies in power systems: potential ap- plication to the man- agement of natural gas infrastructures}

\subsection{Chapter overview}

This chapter provides an outline of the central concepts in the Demand Response (DR) field in power systems, where DR principles have been used for years ${ }^{3}$. Due to the existing similarities between power and natural gas systems, as will be also introduced and discussed in this chapter, the use of this kind of techniques for this particular use will be analyzed. Thus, the appropriateness of DR strategies for the management of the natural

\footnotetext{
${ }^{3}$ Section 2.2 partially updates what was already analyzed and discussed in [13] and [141].
} 
gas systems under the configuration of the smart grid architecture will be studied in the subsequent chapters of this dissertation.

First of all, an introduction on how customers are able to modify their electric load profiles is presented, including a classification of DR programs that could be used by customers according to the utility that they may have for the system. Following, the current status of DR programs existing in both Europe and the U.S. will be presented, whether these are offered by utilities or systems operators. Technical and economic issues are analyzed in order to get a general overview on how customers are currently participating in electricity markets, what type of actions they are being asked to perform and how much they are receiving in exchange for their participation. The chapter will finish with a feasibility analysis on how DR concepts may also applicable for the operation of natural gas systems, similarly to the case of the power grid, including also a review with some international experiences on this matter.

\subsection{Demand response applications in Europe and the United States to the power system}

The gradual increase in electricity consumption that has been produced during the last years, together with the massive implementation of renewable generation technologies, has motivated a significant increment in the variability and unpredictability of power generation, along with the subsequent increment in the cost of grid management and higher probability of contingencies [13]. In this framework, customers' participation in the solution of these problems by means of DR actions is more and more applied worldwide. The concept of DR is understood as the ability of consumers to modify the power demand from their expected consumption either as a response to a requirement from the grid operator, load-serving entity (LSE) ${ }^{4}$ or other demand response provider when a reliability problem occurs in the system, or as a reaction to variations in the price of electricity. While DR actions can take place at any time, not only during the peak period [14], their implementation could be key during peak periods of electricity use, and are usually less costly than building more power plants [15].

\subsubsection{Classification of demand response actions}

Figure 2.1 divides DR actions into three blocks [16], [17]:

- Demand reductions during on-peak periods, which are not compensated by rises during the rest of the time.

- Demand shifting to off-peak periods, by transfer of some energy packages from on-peak periods to shoulder or valley periods, when electricity is cheaper and the operation of the grid is less critical.

${ }^{4}$ Load-serving entity (LSE) collectively refers to utilities and competitive retail suppliers [27] 
- Autonomous generation ${ }^{5}$, producing the electricity that customers use onsite, which translates to a net reduction of the demanded power from the grid with no load modifications required from the consumer.
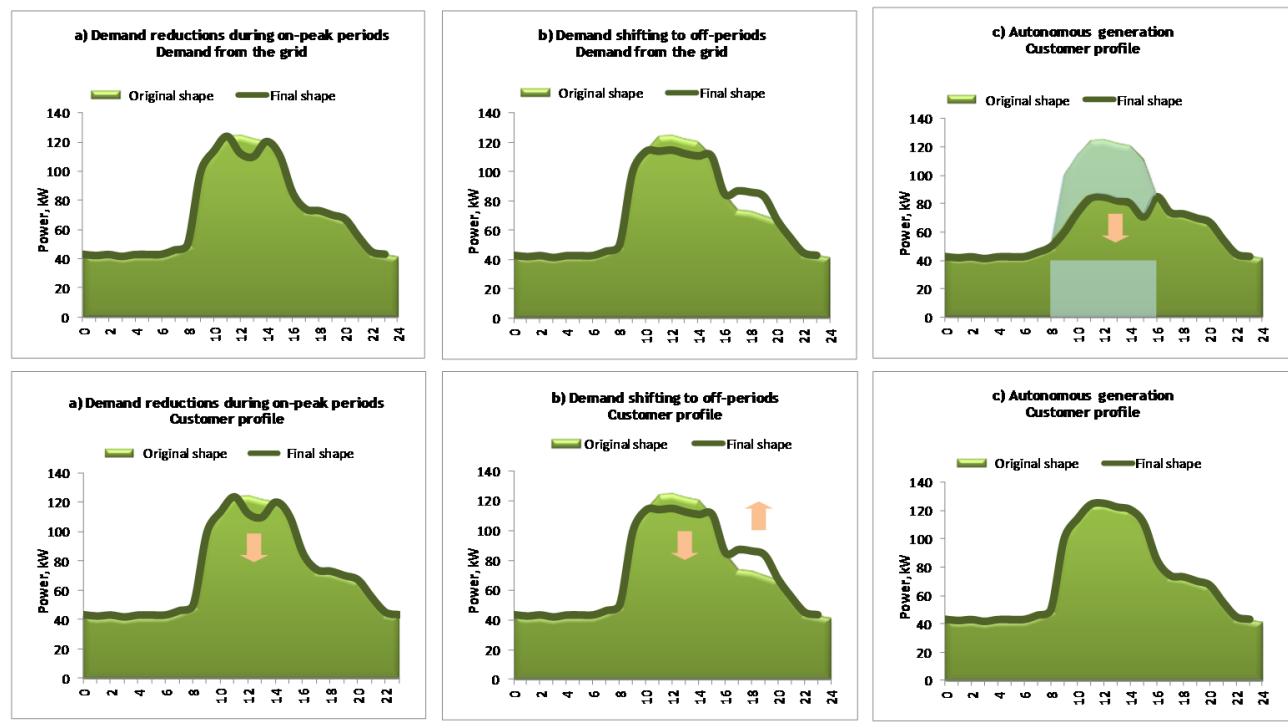

Figure 2.1. Different types of demand response actions

The figure shows the effect of the different types of demand response actions on both the customer's load curve and the power demanded from the grid. In cases a) and b), a modification of the customer load shape produces the same effect in the power demanded from the grid. On the contrary, in case c), the customer does not modify its demand requirements, but the power demanded from the grid is reduced, since the customer produces part of its own required energy, freeing grid capacity.

One mechanism to use these DR actions selectively is to pay end users to become partly or completely interruptible [18]. The planning, implementation and monitoring of activities designed to encourage consumers to modify patterns of electricity usage is known as Demand Side Management (DSM) [19]. DSM has been commonly used in the operation of electricity systems for years [20], but only for large industrial customers. For practical reasons, small and residential consumers have generally not been allowed to participate directly in markets. Additionally, demand response resources have been underutilized in both Europe, where the absence of initiatives on demand response could have been motivated by the inexistence of a single European energy market [21], and in

${ }^{5}$ Also called in bibliography "Behind-the-Meter" (BTM) generation [144] 
the U.S., where existing demand response programs have the capacity to offset only $4 \%$ of current U.S. peak demand [22], [14].

DR is becoming more automatic and easier to implement for customers because electricity prices and the required information may be currently automatically delivered since communication technology is more accessible [23]. Therefore, system operators can allow customers to participate in different DR alternatives. Since the year 2000, in both the USA [18], [24] and Europe [25], [26], research has been carried out in order to develop new DSM programs which involve commercial and residential customers in the operation of the electricity systems. Their main characteristics are detailed in the following sections.

\subsubsection{Classification of Demand Response Programs}

Existing DR programs can be divided into two main groups [16], [27], [28] as shown in Figure 2.2, according to the usefulness that such actions may have for the system operator when contingencies happen. Consequently, there are programs focused on solving reliability problems such as energy imbalances or technical restrictions [22], as well as other programs more focused on encouraging the customer to use energy during cheaper periods.

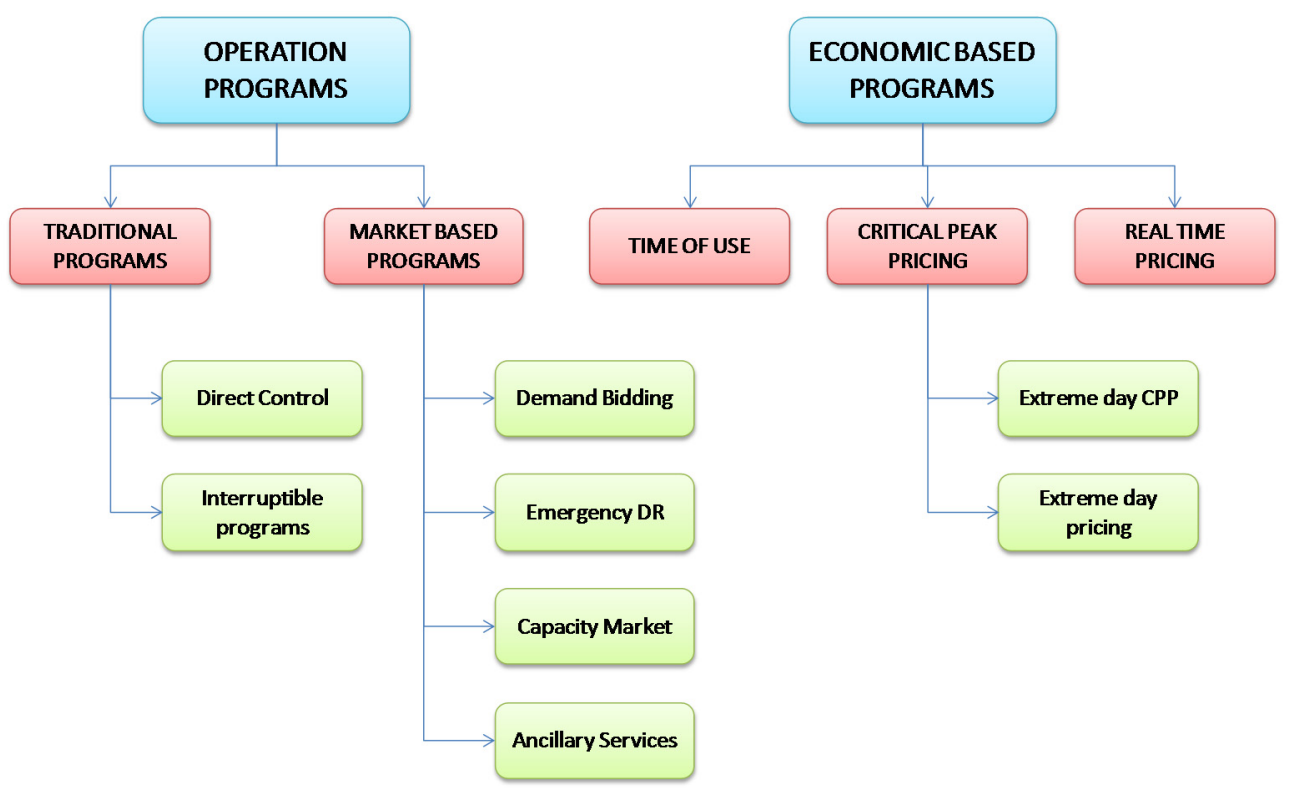

Figure 2.2. Classification of demand response products

This figure shows the different types of demand response programs developed around the world. Two basic types are offered. In the first groups, Operation Programs (OP), 
customer participation is requested when system reliability events appear, either as capacity reserves or by means of interruptible programs. The second group, Economic Based Programs (EPB), is based on voluntary demand bidding programs in response to wholesale electricity price signals [28].

These two blocks can be described as follows:

- Operation programs (OP), also called incentive based (IBP) [27], system-led or stability-based DR programs [16]. Consumers that participate in these types of programs are asked to reduce their consumption when grid operators or LSEs consider that there is a situation that could affect system stability. In that case, consumers are paid for not consuming energy as a response to the operator or LSE request. As a result, the consumer changes its role from client to services provider, whereas the system is actually the client of the consumer.

- Economic Based programs (EBP), also known as price-based (PBP) [27] or market-led DR programs [16]. This is a market option for the customer, which can make a profit if it reduces its energy consumption during on-peak periods, when market prices are higher. The customer can take advantage of lower price periods, avoiding consumption when electricity is more expensive.

\subsubsection{Operation Programs}

As stated above, OPs are activated by the grid operator or the LSE when a contingency occurs that could affect the stability or secure operation of the grid. Operation programs can be divided into traditional programs and market-based programs [27], [29].

In traditional programs, the customer who participates receives a discount rate or a bill credit for its participation in the program. On the other hand, customers who participate in market-based programs receive a direct cash payment, whose amount varies depending on the amount of power actually reduced during the contingency.

Traditional programs are divided into the following categories:

- Direct control programs: the operator of the program is able to switch off and switch on some customer devices by remote control on short notice. This type of program has been commonly contracted by residential or small commercial customers, and it has been applied to water heaters or air conditioning devices.

- Interruptible programs: the operator of the program does not directly act on customer equipment, so customers must reduce the power they require from the grid to predefined values when they are requested to do so by the program operator. If the response is inadequate, the customer may face penalties.

Similarly, market-based programs can be classified as follows:

- Demand bidding programs: the customer bids for a specific load reduction related to the amount previously purchased in the wholesale electricity market. As 
with interruptible programs, if the customer does not respond adequately, it faces penalties.

- Emergency DR Programs: the customer receives incentives for not consuming during emergency conditions when generation reserves are low.

- Capacity market programs: the customer offers a load interruption in order to substitute system capacity, usually supplied by conventional generation or delivery resources. Customers are usually notified the day before the interruption, and they receive a payment in advance as capacity remuneration. Similarly to other programs, customers who do not fulfill their commitment must pay a penalty.

- Ancillary services market: the customer can bid for load reductions as operating reserve. If bids are accepted, customers are paid the market price for their capacity. If their load reductions are actually required, system operators ask customers to reduce consumption, and they receive an additional payment at the spot market price.

\subsubsection{Economic Based Programs}

In EBPs, customers do not reduce their loads to contribute towards solving any emergency or contingency in the system, but rather to take advantage of the different prices of the electricity market in different time periods.

EBPs are based on dynamic pricing rates, so customers are able to offer demand reductions during peak periods when electricity prices are higher or additional consumption during off-peak periods, when electricity prices are lower.

EBPs can be divided into the following five categories [27], [29]:

- Time of use (TOU): this is the most common type of EBP, and it consists of using rates with different electricity prices for different time periods, usually defined within a 24-hour day. Associated prices normally aim to reflect the average cost of generating and delivering power during those time periods. The simplest TOU program has just two periods: the on-peak period (daytime period) and off-peak period (night-time and sometimes also holidays). A description of how to design TOU rates can be found in [30].

- Real Time Pricing (RTP): The price that customers have to pay when contracting this program usually varies according to changes in the wholesale electricity market. RTP customers are usually notified about the prices on a day-ahead or hour-ahead basis.

- Critical Peak Pricing (CPP): This program is a hybrid between TOU and RTP. It is based on the TOU structure, but prices are higher during critical periods and used by program operators for a limited number of days or hours a year during contingencies or when wholesale prices are higher. Critical price pricing 
programs have been also implemented in some countries as OP; however, in this case, the price is not determined by the market but by the system operator.

There are two other EBP based on CPP programs, but with the following special features:

- Extreme Day CPP (ED-CPP): This program establishes different prices for onpeak and off-peak periods, whereas a flat price is fixed for the rest of days.

- Extreme Day Pricing (EDP): The price is established the day before for a full 24-hour day.

\subsubsection{Demand Response in Europe}

The European power market can be divided into seven regional markets, most of which are physically interconnected [21], with different rules and technical standards [31]:

- Apennine Peninsula (Italy)

- Iberian Peninsula, including Spain and Portugal

- Central Western Europe, including Germany, Netherlands, France, Belgium, Switzerland and Austria

- Northern Europe, which includes Sweden, Finland, Denmark, Estonia, Latvia, Lithuania and Norway

- Central Eastern Europe, comprising Poland, the Czech Republic, Hungary, Romania, Slovenia and Slovakia

- British Isles, formed by the United Kingdom and Ireland

- South Eastern Europe, including Greece and Bulgaria

Some years ago, a deregulation process started in EU energy markets, which is expected to culminate in the creation of a single European electricity market [32]. As stated in Directive 96/92/EC, published in December 2006, the activities of generation, transmission, distribution and energy trading have been separated. Competition has been achieved in generation and trading, while activities related to the ownership and management of the grid (transmission and distribution) are regulated and function as monopolies [33].

Different regional initiatives have been launched by the European Commission [32], and some regional markets involving different countries, such as the MIBEL (Iberian Electricity Market) for Spain and Portugal or the Nordpool (Nordic countries) are currently running.

Due to the inexistence of a single European energy market, a joint DR action plan has not been designed for Europe as a whole. Thus, programs developed within EU Member States strongly depend on the initiative of each country and its particular regulation. However, concern has grown with regard to demand participation issues in recent years, 
and different initiatives have been carried out. Some examples are the research projects EU-DEEP or DRIP, funded by the European Commission. The first of them was aimed on identifying and overcoming barriers that prevent the utilization of Distributed Energy and Demand Response Resources [25], [34]. The second one is focused on the assessment of the potential flexibility within the energy consuming process of industrial customers and using this flexibility in order to contribute to grid efficiency and to increase the share of renewable energy resources (RES) in the energy mix [26].

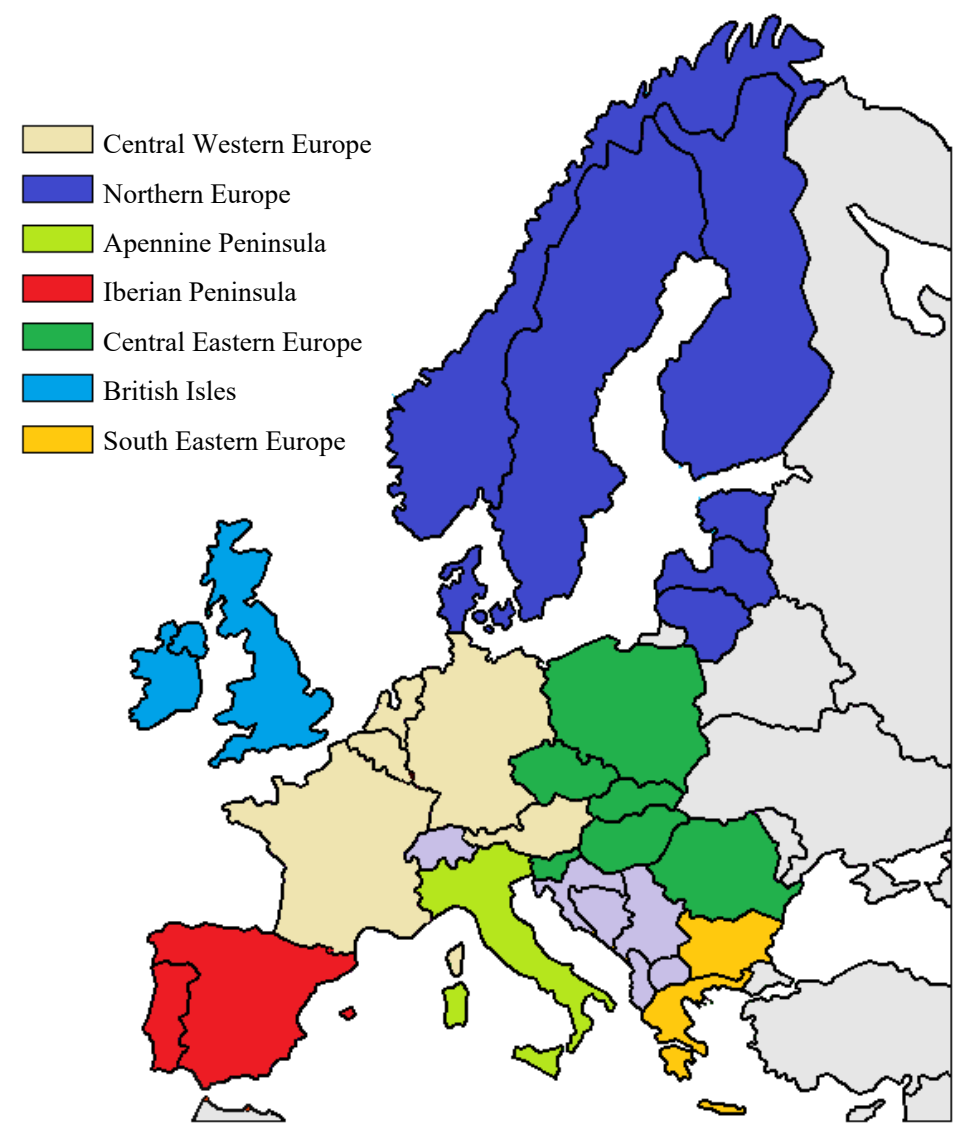

Figure 2.3. Regional power markets in Europe

DR is an efficient and effective method to achieve both energy savings and peak power reductions, as stated in the European Commission objectives, which are focused on finding a sustainable, reliable, cost-efficient energy supply [35].

An increment of about $45 \%$ average DR usage in most European countries is predicted by 2020, as shown in Figure 2.4 [21]. 


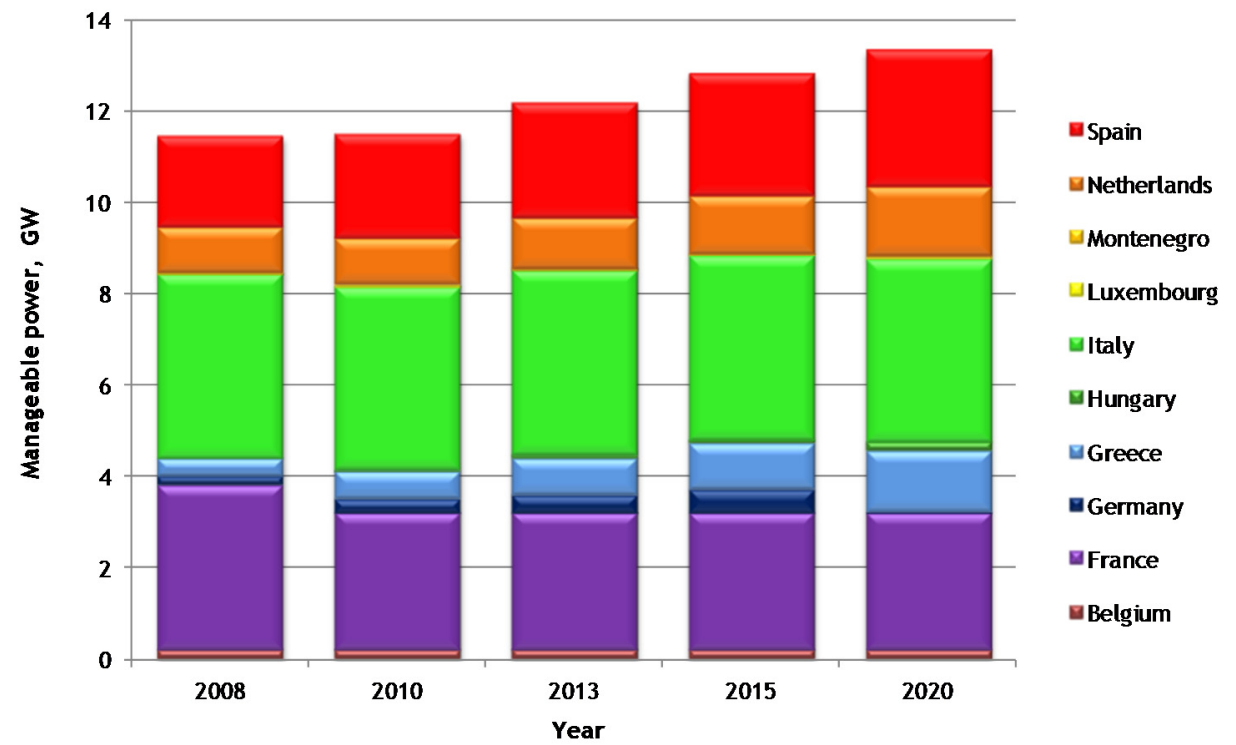

Figure 2.4. Demand response forecast in UCTE countries from 2008 to 2020

In 2014-15, the development and enhancement of DR strategies was included in the European Network Codes, which represents a significant step widespread consumer engagement in European electricity systems [36]. Belgium, Finland, France, Ireland and Switzerland have reached a level where DR is a commercially viable product. In UK, there is a highly competitive energy market and open balancing markets where demand side have been enabled to participate for years. In Sweden, the Netherlands, Austria, Germany and Norway, DR companies are being established, but significant regulatory barriers do not allow the full involvement of consumers in this kind of applications. In the rest of countries, including Italy and Spain, aggregated DR is either illegal or its development is seriously hindered for market participants.

\subsubsection{Italy}

Italy is the European country where the implementation of advanced electricity meters has been the most successful, with about the $90 \%$ of all meters already installed [21]. Currently, the country is involved in a revision of energetic regulation, and the proposals include the evaluation of demand side mechanisms for further market development [37].

Customers willing to participate in load reduction programs can enroll in the interruptible load service, which is based on the availability of customers to interrupt their energy supply when generation resources are not sufficient to maintain the operational security 
of the system [38]. According to the notification time, there are three different types of programs: in real time, with a required response within $200 \mathrm{msec}$ after a remote signal is sent by the TSO; in deferred time under emergency conditions, with an activation time under five seconds after the order emission; and with notice, when customers are allowed 15 minutes to reduce their loads after reception of the reduction order. The enrolment of interruptible loads is currently about $4 \mathrm{GW}$, with a minimum size of $1 \mathrm{MW}$ to participate [39].

Regarding TOU tariffs, used by Italian customers for several years, a new product was launched in 2010 that offers more expensive prices from 8:00 am to 7:00 pm from Monday to Friday, and cheaper prices for the rest of time [21].

\subsubsection{Spain}

Since 1998, the Spanish electricity market has been largely and successfully deregulated. Only customers demanding less than $10 \mathrm{~kW}$ are allowed to buy electricity at a regulated tariff, while the rest must do it directly on the market. The ownership of the grid remains monopolistic under Red Eléctrica de España (REE), which is also the TSO for the Spanish electricity system. The distribution lines are owned by the distributors, which only transmit energy - not buy or sell it. Customers pay a fee, the Access Tariff, to the grid owners as for the use of their lines, but the supplied electricity is bought from the traders at a price that is freely negotiated between customer and seller.

- TOU Access Tariffs ${ }^{6}$ : Customers with an electricity contract must sign an Access Tariff to pay the owner of the grid for its utilization. These tariffs, which represent between the $20 \%$ and the $50 \%$ of the total electricity bill (depending on the month), charge different prices for energy and contracted power depending on the period of time under consideration (peak, shoulder and valley periods are distinguished). The most complex tariff includes six different periods with peak and shoulder in high season, peak and shoulder in medium season, shoulder in low season and valley for the whole year, including nights, weekends and holidays.

- Interruptibility Program ${ }^{7}$ : An interruptibility program was launched by REE in 1995 as a special tariff for large customers. At present, any other customer able to reduce a minimum of $5 \mathrm{MW}$ when required by the TSO during emergencies can participate in this program, where prices are determined by auction. 138 consumers participated in the auction for the provision of this service for 2017, during which the amount of 2975 MW will be provided ${ }^{8}$. The load curve of

\footnotetext{
${ }^{6}$ The Access Tariff was established by the Royal Decree 1164/2001

${ }^{7}$ It is regulated by the Ministerial Order ITC/2370/2007 and IET/2804/2012

${ }^{8}$ This information is available on the website of Red Eléctrica de España, S.A., accessed in November 2016: http://www.ree.es
} 
providers is registered during each interruption event in order to verify the fulfillment of the order, and penalties are applied if customers do not actually reduce their power by the agreed amount.

\subsubsection{France}

The largest utility in France, Électricité de France $(E D F)$, offers an interesting TOU program called Tempo Tariff, used by around 350,000 households and more than 100,000 small business customers [21].

This program, available for customers with a minimum contracted power of $9 \mathrm{kVA}$, is based on different prices for energy according to the day and the hour of utilization. There are three different color-coded prices throughout the year (blue, white and red, where blue is the cheapest and red is the most expensive), and each color is assigned to certain hours on a daily basis. This information is published every day at 5:00 pm. Because customers are informed daily about the next day's pricing regimen, they can adapt their load curve to reduce the consumption during peak hours. Over the course of a year, there are 22 red days and 43 white ones, while the rest are blue. Prices of energy vary between $0.097 € / \mathrm{kWh}$ for blue days during valley hours, and $0.621 € / \mathrm{kWh}$ for red days during peak hours, giving customers a significant incentive to avoid consumption in the latter case ${ }^{9}$.

\subsubsection{United Kingdom}

Different DR programs, including TOU tariffs and interruptible contracts, have been offered to customers in the UK for quite some time [21]. Among the first, Economy 7 and Economy 10 tariffs $^{10}$ allows customers to consume cheaper energy for 7 or 10 hours a day, respectively, so they can adapt their load curve to take advantage of lower prices during valley periods. Customers with interruptible contracts wishing to participate as a demand resource in the British market can do so by means of one of the following programs [40]:

- Short Term Operating Reserve: Activated in 2007 [41], this program caters to customers able to reduce at least $3 \mathrm{MW}$, individually or aggregately (aggregation has only recently been allowed), within 240 minutes of the launch of the order reduction. Additionally, participants must be willing to maintain an energy reduction for a minimum of two hours. Reductions can take place at least three times a week. Customers are paid for both availability and utilization. A typical workday includes two availability periods from 7:30 am to 2:00 pm, and from 4:00 pm to 9:30 pm.

\footnotetext{
${ }^{9} \mathrm{http}: / /$ residential.edf.com/energy-at-home/offers/electricity/tarif-bleu-56121.html Prices in force from 01/01/2016. Accessed on February 2017

${ }^{10} \mathrm{http} / / / \mathrm{www}$. uswitch.com
} 
- Fast Reserve (FR): Participants must be able to deliver a minimum of $50 \mathrm{MW}$ within two minutes of notification, maintaining the reduction for at least 15 minutes. Participants receive annual payments for both availability $(€ / \mathrm{h})$ and utilization ( $€ / \mathrm{MWh})$.

- Firm Frequency Response: Used by the TSO to maintain the system frequency within operational limits, this program requires participants' demand to be automatically reduced by a minimum of $10 \mathrm{MW}$ during at least 10 minutes after an advance notification of 30 seconds. Participants are paid for availability $(€ / \mathrm{h})$, nomination $(€ / \mathrm{h})$ and response energy $(€ / \mathrm{MWh})$.

- Frequency Control by Demand Management: Enrolled customers' energy use is automatically interrupted by means of a frequency relay when the system frequency goes below a predefined reliability value. Participants must deliver a minimum of $3 \mathrm{MW}$, individually or aggregately, within two seconds after notification, maintaining the reduction for a minimum of 30 minutes. Customers receive an availability payment.

\subsubsection{Germany}

The current legislative framework in Germany, studied in detail during the DRIP Project [42], does not contain the implementation of DR measures within the industrial sector even if some open regulatory issues remain.

Recently, the German regulation eased the access to the reserve market, allowing some consumers to participate in tertiary regulation under the so-called service "Minutes Reserve" program. Among others, both minimum positive and negative reserve capacity required to participate in bidding was reduced from 15 to $5 \mathrm{MW}$. The main objective for this change was to attract more players with a single smaller flexible load size. Moreover, it is significant that the international DR Company Enernoc absorbed the German aggregator Entelios in February 2014, showing the increasing interest in Germany for DR participation ${ }^{11}$.

Different evidences show that despite these changes, especially small- and medium-sized industrial companies (peak demand lower than $5 \mathrm{MW}$ ) so far pay little attention to DR measures. Managing the energy demand and other energy related issues generally are not considered to be part of their core business and hence limited knowledge about energy usage as well as energy markets exist in this segment.

New opportunities for Demand Response implementation have appeared in the German power system with the amendment of the Energy Industry Act (EnWG) of 20 December 2012, which imposes a contractual obligation on interruptible loads for the maintenance

\footnotetext{
11 “EnerNOC Acquires Leading European Demand Response Company Entelios AG". Press release available at: http://investor.enernoc.com/releasedetail.cfm?releaseid=825659 accessed in February 2017.
} 
of network and system security. According to this issue, appropriate conditions were specified in the regulation on agreements on interruptible loads (called AbLaV). In accordance with the $\mathrm{AbLaV}$, the German transmission system operators will in future organise a monthly tender for a total interruptible capacity of 3,000 megawatts [43].

\subsubsection{Belgium}

Belgium has recently developed DR products so as to involved consumers in the daily electricity market operation [44]. Large commercial and industrial consumers can participate in the capacity market managed by ELIA, the Belgian TSO.

Moreover, smaller consumers can also participate by means of aggregators such as REstore and Energy Pool. ELIA is using DR resources to supply primary reserve services in the Belgian balancing market from august 2016, amounting about $100 \mathrm{MW}$ of primary reserve in total. Belgium's power and gas regulator CREG has recommended that demand response is given "complete access to the Belgian wholesale power market by January 1, 2017” [45].

\subsubsection{Sweden}

Demand side is practically uninvolved in regulating the power market in Sweden. As a symbolic presence, the Swedish TSO, Svenska Kraftnät (SK), arranges auctions to acquire demand resources from industrial customers, which are used as fast active disturbance reserves [46]. In 2008, $90 \mathrm{MW}$ were contracted by SK, 53\% of which were available within 15 minutes, and the rest were ready to be used in half an hour [47]. For the period 2014/2015, SK contracted 1346 MW from the maximum allowed by law (1.500) for the provision of reserves. According to the original law (2010:2004) the demand side of the strategic reserve share should gradually increase to reach 100 percent in 2017/2018 [48].

The requirements for demand side participation in reserves mechanisms in Sweden are the following:

- Consumers must be connected to the Swedish grid, with a minimum size of 5 MW in a specific area

- The power offered as flexible resource must be at least of $5 \mathrm{MW}$, either directly or by means of an intermediary (balance responsible agent).

- The activation time must be less than 30 minutes

- The duration of the reduction must be, at least, 2 hours, and the time for the restart of the reduced consumption cannot be longer than 24 hours [48].

\subsubsection{Finland}

In Finland, the Finnish TSO Fingrid acquires demand resources by signing annual bilateral contracts with industrial customers; these are used as frequency controlled and fast 
active disturbance reserves [21], [46]. Balancing power offers are accepted until 45 minutes before the operating hour and a merit order list is constructed from all the offers.

Typical customers offering demand resources in Finland comprise the metal industry (iron and steel industry and metallurgy), the forest industry and the chemical industry, with a minimum offer of $10 \mathrm{MW}$ (single or aggregated) to be reduced for at least three hours and a notification in advance of, at least, 12 hours [49]. Disconnections can be performed either manually (with 10 minutes advance notice) or automatically by means of a frequency relay [47].

\subsubsection{Netherlands}

Demand Response can access in the Netherlands the majority of ancillary services. However, the minimum amount of power to participate is $20 \mathrm{MW}$, which means a significant barrier to allow the massive participation of consumers. The total volume for balancing energy activated by the Dutch TSO (Tennet) is $500 \mathrm{GWh} /$ year. Demand Response is allowed in Frequency Restoration Reserves (automatic or manual) and Replacement Reserves, individual or aggregately.

On the other side, residential consumers have a very simple market structure which allows the participation by means of clear and timely price signals [36].

\subsubsection{Denmark}

Danish customers consuming more than $100,000 \mathrm{kWh}$ a year (together representing about half of the total electricity demand nationwide) are provided with interval meters, so they can choose when to consume electricity depending on the spot market price. Nevertheless, only a few customers actually exploit this possibility at the moment [50]. Moreover, TOU tariffs are offered to customers wishing to take advantage of different prices during the day. Such tariffs offer peak prices which are about 1.75 times higher than during the valley.

Regarding demand participation in ancillary services, the participation in tertiary reserve is limited to electric boilers installed at local district heating plants, involving $555 \mathrm{MW}$. The minimum size for participation is $10 \mathrm{MW}$, being still manually operated [36].

\subsubsection{Norway}

The Norwegian TSO Statnett is currently offering an interruptible tariff to customers willing to drastically reduce their energy supply when required by the system operator. Depending on the advance notification time and the duration of the interruption, there are three possible modalities: 15 minutes advance notification with no limitation on the duration of the interruption and a reduction of $5 \%$ of the load (mode 1); two hours advance notification with no limitation on the duration of the interruption and a reduction of $25 \%$ of the load (mode 2); and 15 minutes advance notification with a two-hour limit on the duration of the interruption and a reduction of $75 \%$ of load (mode 3 ). Interruptibility is set using a baseline calculated from the past five years load curve, so that hourly 
measurements are registered and sent to Statnett to verify that interruptions have been successfully fulfilled. Current prices for interruptibility (2017) are 7.75, 5.50 and 23.13 $€$ per $\mathrm{kW}$ reduced for modes 1,2 and 3 respectively [51].

Besides this interruptibility program, Statnett operates a Regulating Capacity Options Market, where demand resources can bid together with generators, in order to acquire reserves for disturbances and balancing purposes [46]. With regards to the commercial sector, pilot studies showed that $4.5 \mathrm{MW}$ could be reduced by using DR, generating savings of around $15 \%$ [21].

\subsubsection{Demand Response in the United States}

The implementation of DR programs varies widely throughout the U.S. due to different factors, such as the growth of the demand, the cost of avoided capacity and the different regulations regarding DR programs in each geographic area [14].

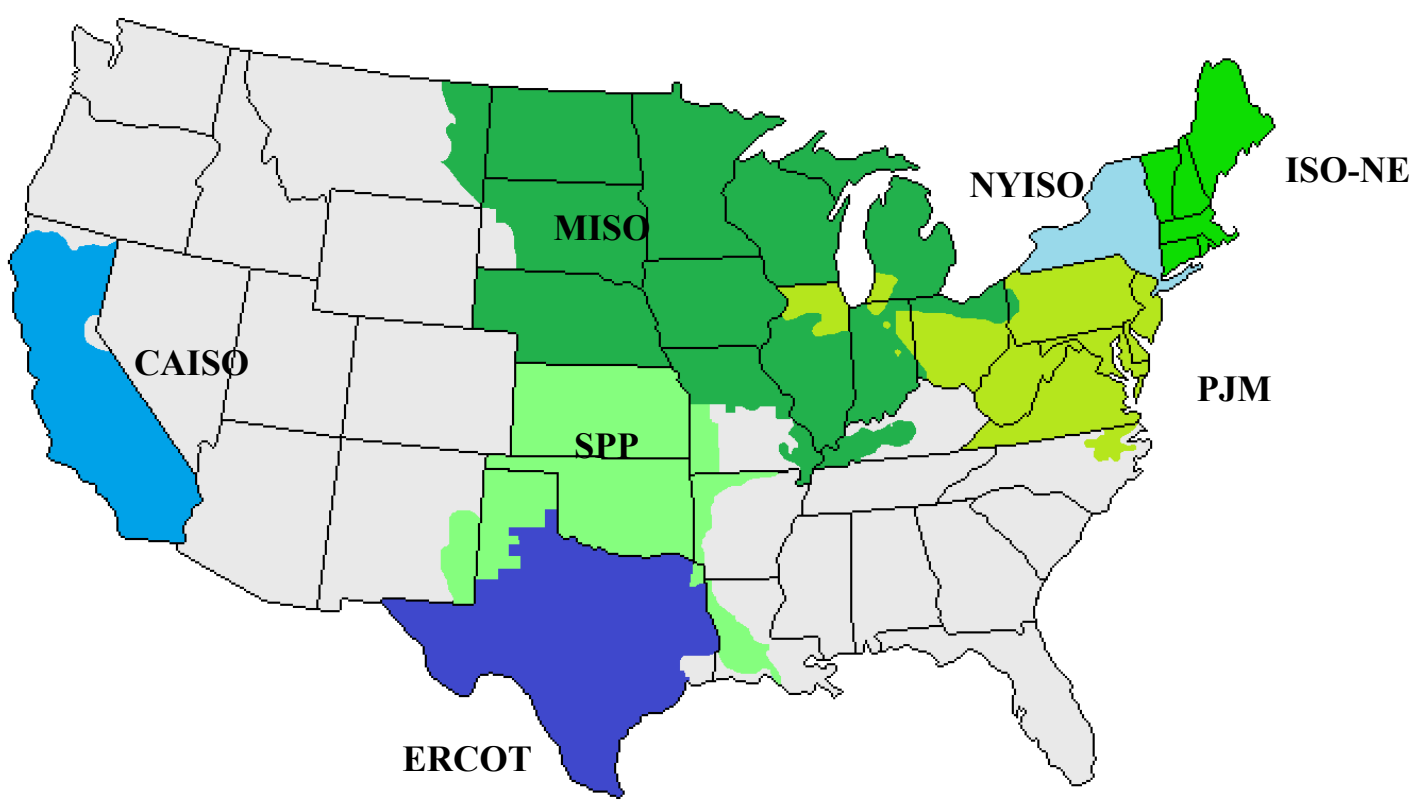

Figure 2.5. Map of system operators in the U.S. 
Some states or regions such as California, Florida or New England have performed significant DR activity, while some others like Alaska, Montana or Wyoming have had little [14].

Traditionally, demand response programs in the U.S. have been offered by utility companies [52]. However, system operators have recently been offering their own. Many have been launched since 1999 due to a combination of unusual events that happened during that year, including generation shortages, congestion on the transmission grid and atypically hot weather, which worked together to increase the price of electricity. As a result, many organizations now offer DR programs in both regulated retail markets and competitive wholesale markets [28].

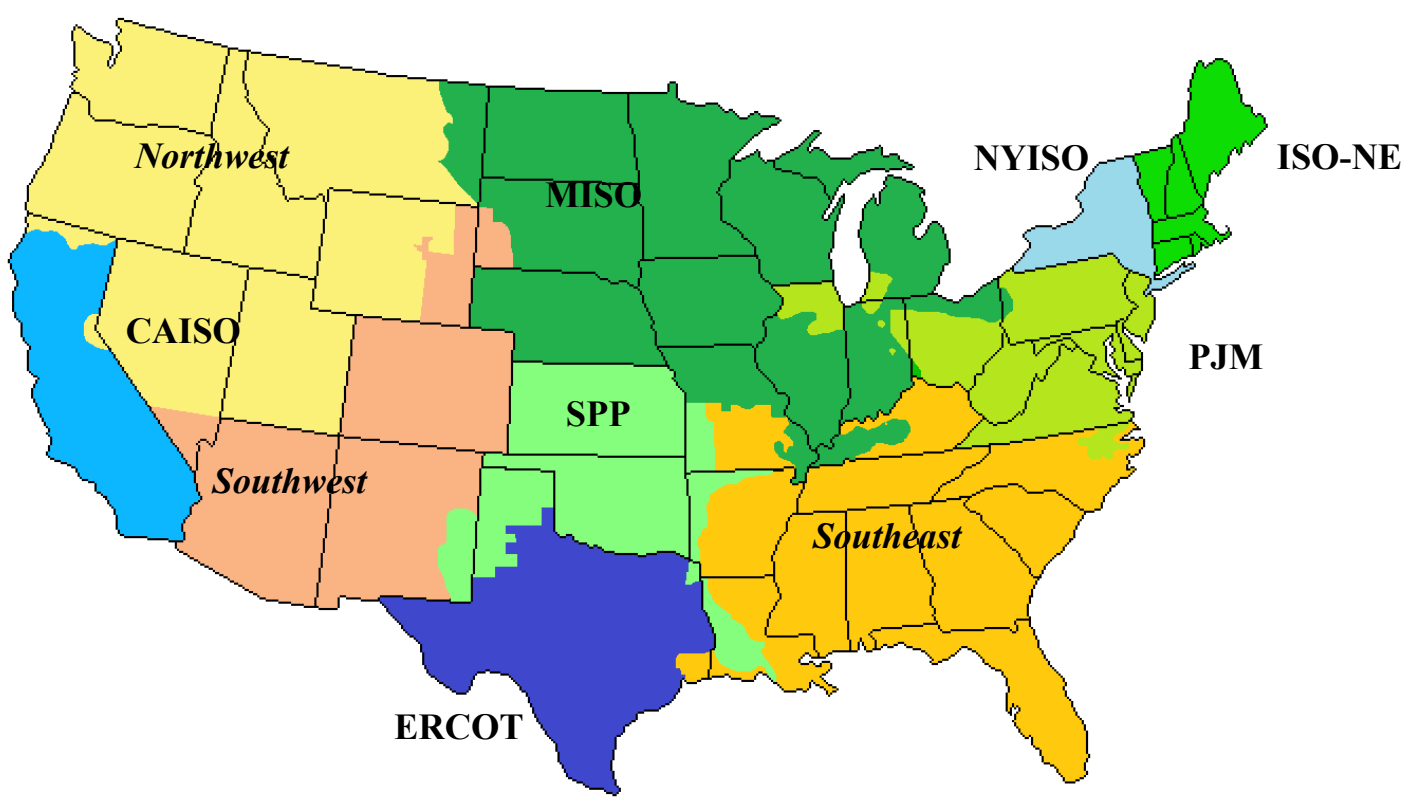

Figure 2.6. Map of the electricity markets in the U.S.

The system operator (SO) controls, coordinates and monitors the operation of the power grid in a given geographic region or area. In the US, when a SO works in a single state, it is called an Independent System Operator (ISO), whereas SOs operating in more than one state are called Regional Transmission Operators (RTO).

According to this definition, seven SOs are currently operating in the U.S. Three of them are ISOs, and the rest are classified as RTOs, as shown in Table 2.1 and Figure 2.5. 
In blue there are three ISOs, working in California, Texas and New York. The other four operators work in more than one state, so they are called Regional System Operators (RTOs). This is the case in New England (ISO-NE), the Pennsylvania-Jersey-Maryland area (PJM), and the central strip of the country divided into two regions, midwest (MISO) and southern (SPP).

Table 2.1. System operators in the United States of America

\begin{tabular}{|c|c|c|}
\hline Type & System Operator & States where it operates \\
\hline \multirow{3}{*}{ ISO } & $\begin{array}{l}\text { New York Independent Sys- } \\
\text { tem Operator }\end{array}$ & New York \\
\hline & $\begin{array}{l}\text { Electric Reliability Council } \\
\text { of Texas }\end{array}$ & Texas \\
\hline & $\begin{array}{l}\text { California Independent Sys- } \\
\text { tem Operator }\end{array}$ & California \\
\hline \multirow{4}{*}{ RTO } & $\begin{array}{l}\text { Independent System Operator } \\
\text { - New England }{ }^{12}\end{array}$ & $\begin{array}{l}\text { Connecticut, Maine, Massachusetts, New } \\
\text { Hampshire, Rhode Island and Vermont }\end{array}$ \\
\hline & PJM Interconnection LLC & $\begin{array}{l}\text { Delaware, Illinois, Indiana, Kentucky, Mary- } \\
\text { land, Michigan, New Jersey, North Carolina, } \\
\text { Ohio, Pennsylvania, Tennessee, Virginia, } \\
\text { West Virginia and the District of Columbia }\end{array}$ \\
\hline & Southwest Power Pool & $\begin{array}{l}\text { Arkansas, Kansas, Louisiana, Missouri, Ne- } \\
\text { braska, New Mexico, Oklahoma, and Texas }\end{array}$ \\
\hline & $\begin{array}{l}\text { Midwest Independent Trans- } \\
\text { mission System Operator }\end{array}$ & $\begin{array}{l}\text { Illinois, Indiana, Iowa, Kentucky, Michigan, } \\
\text { Minnesota, Missouri, Montana, North Da- } \\
\text { kota, Ohio, South Dakota, Pennsylvania, } \\
\text { Wisconsin, and Manitoba (Canada) }\end{array}$ \\
\hline
\end{tabular}

Source: “A primer on demand response..." [52]

Together with these seven areas, which act as a marketplace in wholesale power (especially since the electricity market deregulation process carried out in the 1990s), there are another three marketplaces for the regions where no ISO or RTO is present. These are the northwest, southeast and southwest markets, as shown in Figure 2.6.

\footnotetext{
${ }^{12}$ Despite its name, the ISO-NE is not an Independent System Operator, but a Regional Transmissions Operator
} 
The Northwestern market includes the states of Washington, Oregon, Idaho, Utah, Nevada, Montana, Wyoming and part of California. The Southeastern market includes Florida, Arkansas, Louisiana, Mississippi, Alabama, Georgia, Tennessee, North Carolina, South Carolina and parts of Missouri, Kentucky and Texas. Finally, the Southwestern market includes Arizona, New Mexico, Colorado and parts of Nevada, Wyoming and South Dakota.

DR programs in the US led to energy savings of 1.4 million MWh in 2014 nationwide, with 9.3 million enrolled DR customers [53]. The most significant DR programs, offered by ISOs and RTOs, are described below.

\subsubsection{DR Programs Offered by System Operators}

The System Operators, ISOs and RTOs, are playing a significant role in the development of Demand Response markets. Currently, most System Operators allow customers to participate as demand resources in some of the markets they manage, including DayAhead markets, Real-Time markets and Ancillary Services [15].

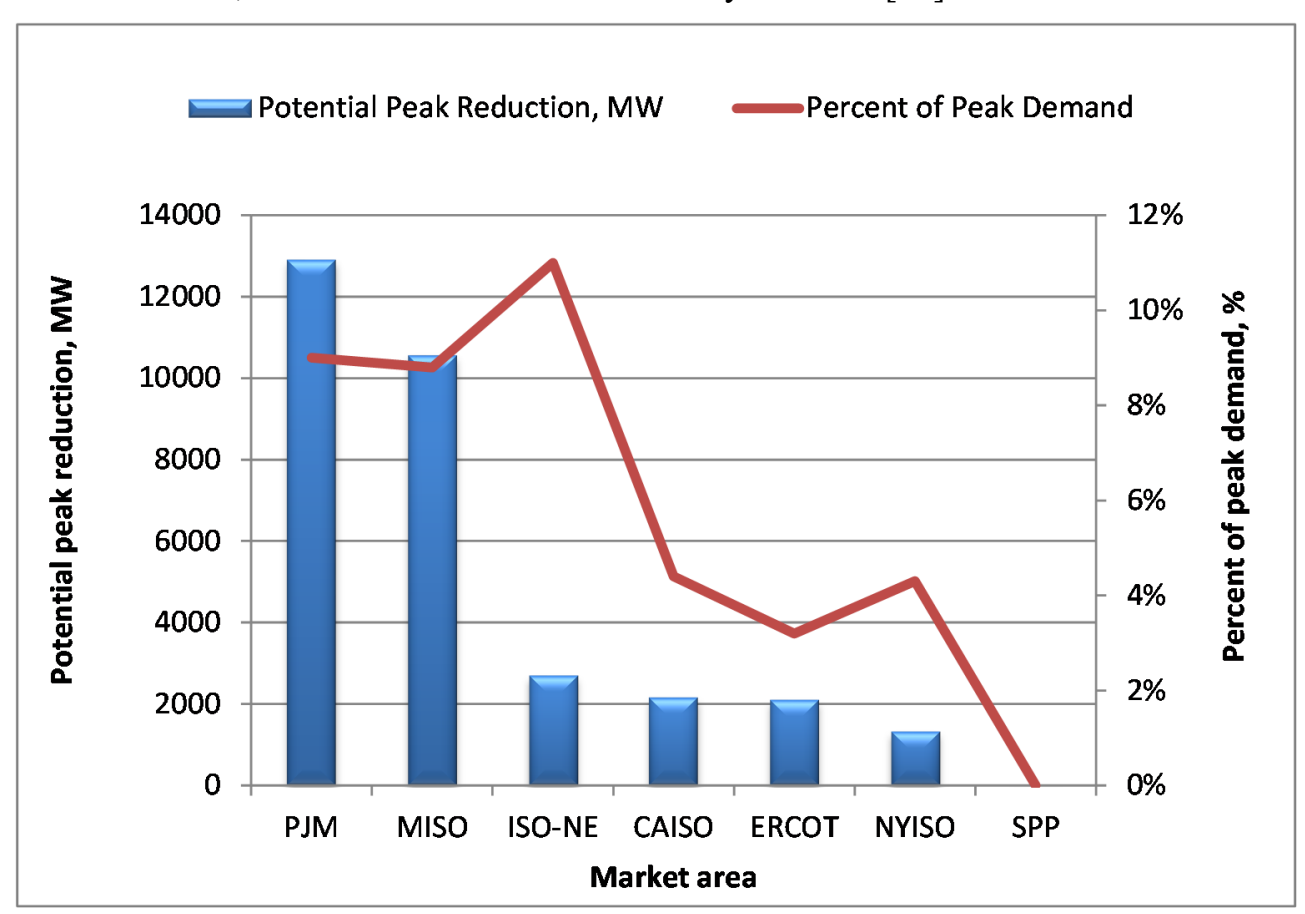

Figure 2.7. Potential Peak Reduction from U.S. ISO and RTO DR Programs. Dec 2016

Indeed, the highest growth of incentive-based DR resources has happened in organized wholesale markets administered by ISOs and RTOs [54]. Namely, the most significant 
results in DR are currently being achieved in the New York ISO, ISO New England, PJM and California ISO, mainly due to two reasons [52]:

- They operate in the most resource-constrained regions of the United States.

- There is no upper limit on demand response capacity that can be called on when a grid event is produced.

DR programs managed by ISOs and RTOs resulted in a total of 31,695 megawatts of available demand response in North America in 2009 [55], amount which was multiplied by two in 2012, when 66,351 MW were reached [56]. The last forecast available on potential peak reduction from US ISO and RTO DR Programs is $31,754 \mathrm{MW}$, which means the $6.6 \%$ of the National power peak [57]. Figure 2.1 shows the detailed potential evaluation per market region, as well as the contribution of DR potential in reducing the regional peak.

\subsubsection{DR Programs Offered by Utilities}

Utilities have offered to their customers for more than 30 years the possibility to get rebates in their bills in exchange for using electricity flexibly.

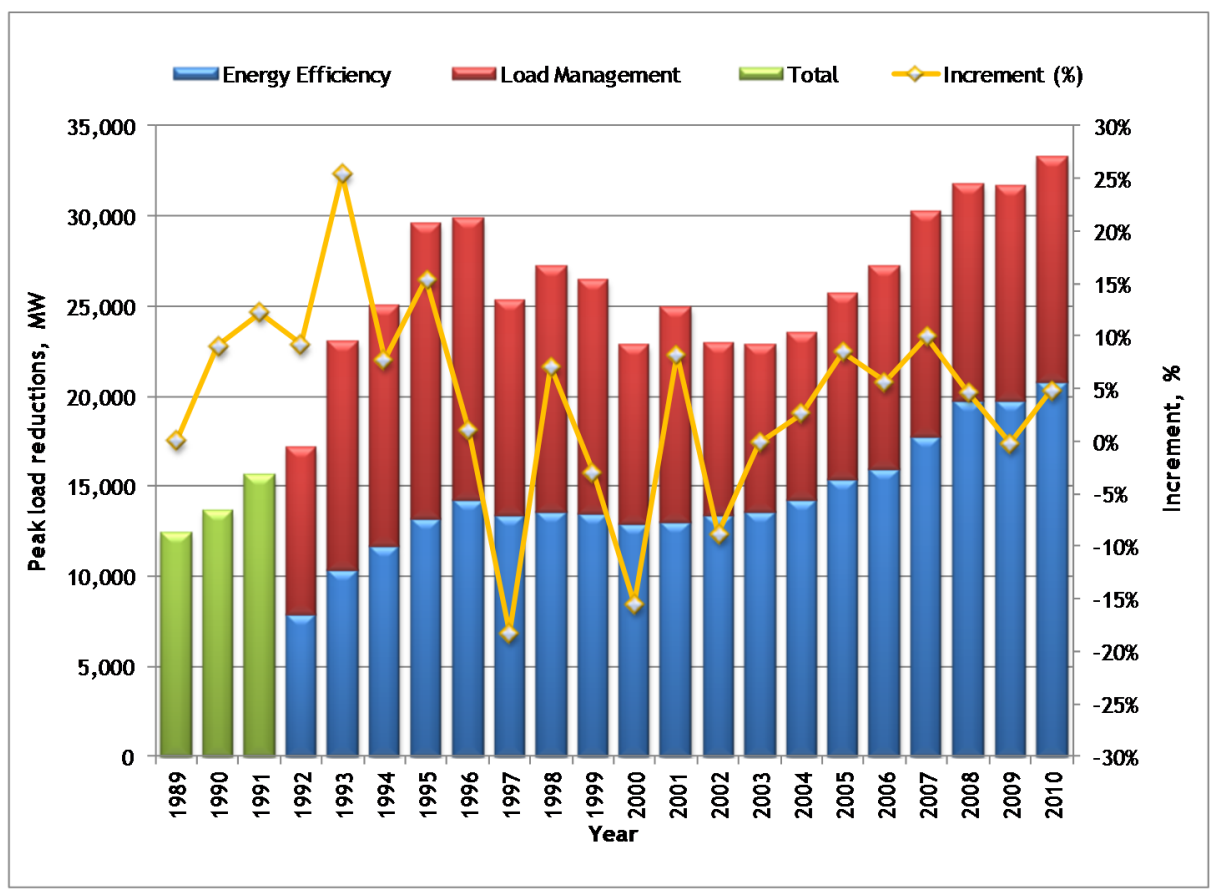

Figure 2.8. Electric utility demand-side management programs in the U.S. (1989-2010) 
According to the US Department of Energy, the electric power industry considers demand response programs "as an increasingly valuable resource option whose capabilities and potential impacts are expanded by grid modernization efforts ${ }^{13}$ ".

Figure 2.8 shows the evolution that DR programs have experienced in the past two decades $^{14}$. While utilities have been offering customers the possibility of reducing their electricity bill in exchange for reducing their power demand at certain times for many years, 2002 marked the beginning of a clear upward trend. In 2007, a peak load reduction of more than 30,000 MW was achieved through these programs.

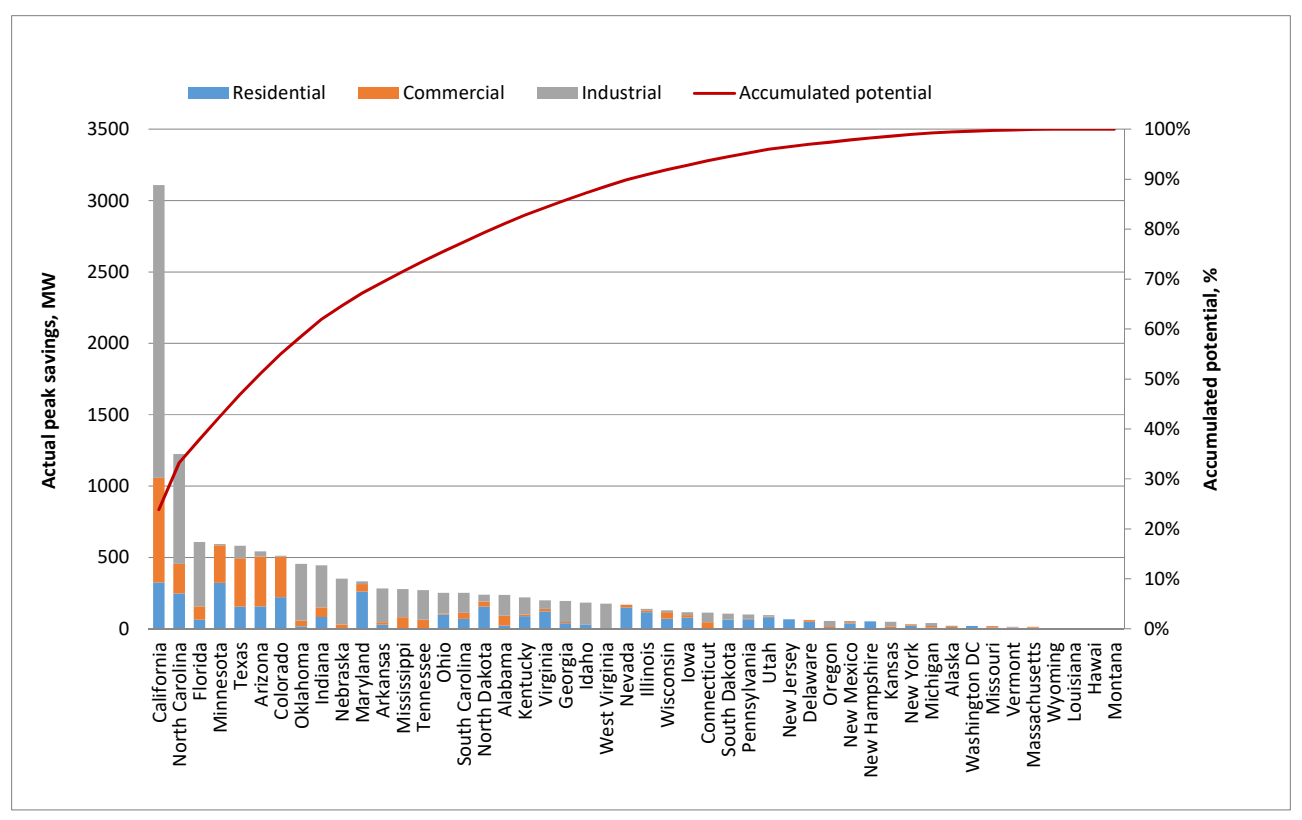

Figure 2.9. Peak savings in the US by customers enrolled in utility DR programs

According to the most recent data published by the US Energy Information Administration for year 2015, the peak savings obtained in the whole country were 13,036 MW, most of which was coming from the industrial sector. Figure 2.9 shows the peak savings per state, divided also by sector (residential, commercial and industrial). Customers in California present the highest potential, which represents the $25 \%$ of the total country.

\footnotetext{
${ }^{13} \mathrm{https} / /$ energy.gov/oe/services/technology-development/smart-grid/demand-response

${ }^{14}$ This charts has been elaborated with information obtained from official energy statistics published by the U.S. Government (http://www.eia.gov)
} 
As it is shown in this figure, the five most active states (California, North Carolina, Florida, Minnesota and Texas) offer almost the $50 \%$ of the total peak saving in the US.

Regarding the number of enrolled consumers, most of customer are residential, in spite their individual potential is low. The three states with a higher number of enrolled customers (California, Florida and Minnesota) represent the 50\% of the most active consumers.

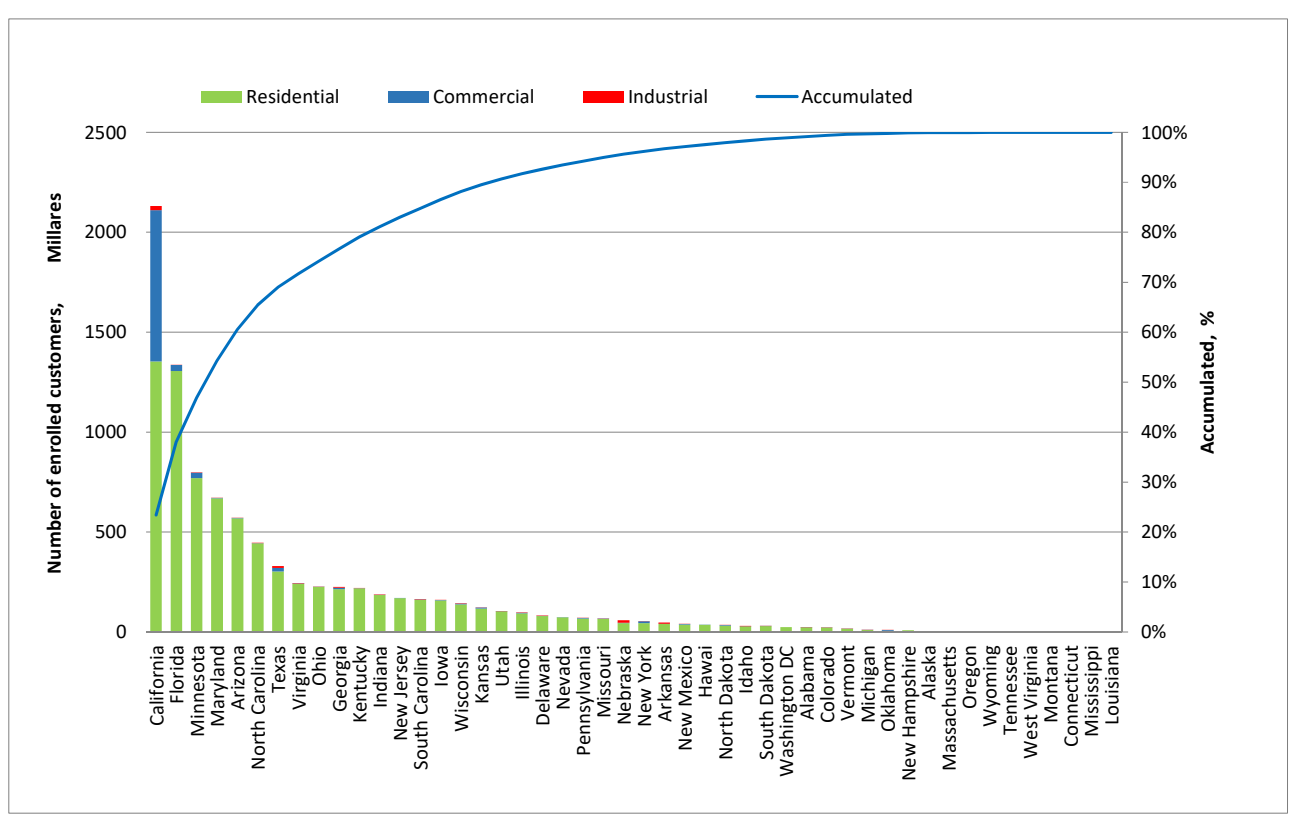

Figure 2.10. Number of customers enrolled in utility DR programs

Regarding the kind of DR programs, the most significant types are the following [58]:

\section{a) California}

In California, the most populated state in the US, the company Pacific Gas \& Electric, has a program for the direct control of the air conditioning devices of residential and commercial customers during the summer peaks. Residential customers receive an incentive of $\$ 50$ for a 6 months period of participation. Regarding larger consumers, this company offers different kinds of programs, such as:

- Peak day pricing, based on discounts on regular summer prices and higher prices during the peak (from 9am to $3 \mathrm{pm}$ ) 
- Base interruptible program, which offers an incentive of $\$ 8-9$ per reduced $\mathrm{kW}$ with a notification time in advance of $30 \mathrm{~min}$. Penalties of $\$ 6$ per $\mathrm{kW}$ are applied if the customer fails an interruption.

- Demand bidding program, that is a day-ahead program by means of which customers can submit load reduction bids (with a minimum of $10 \mathrm{~kW}$ ) on a hourly basis. The incentive payment is $\$ 0.5$ per $\mathrm{kWh}$ of load reduction, and penalties are not applied in case of fail.

- Scheduled Load Reduction Program, offering payments for load reductions during some pre-specified periods with a minimum demand offer of $100 \mathrm{~kW}$. Reductions have duration between 3 and 4 hours and consumers must commit to reduce at least the $15 \%$ of their average monthly consumption.

- Optional binding mandatory curtailment plan. This program may be contracted by customers able to respond within 15 minutes after a notification. The benefit is not economic, but exceptions related to mandatory outages to be performed by other customers enrolled in DR programs. A penalty of $6 \$ / \mathrm{kWh}$ is applied in case of fail and the expulsion from the program for 5 years in case of a second fail.

Even if Pacific G\&G offers the widest variety of DR programs, other two utilities in California also give their customers the possibility to enroll in some DR initiatives. San Diego Gas \& Electric has a bid based program which offers discount credits of $\$ 12$ and $\$ 2$ per $\mathrm{kW}$ during certain periods of the year, with a minimum reduction of $100 \mathrm{~kW}$. There is also another program for capacity bidding, permanent load shifting and summer saver.

Finally, the company Southern California Edison has a DR program specially designed for pumping of agricultural customers. A minimum power of $37 \mathrm{~kW}$ is required, with a maximum duration of 6 hours per interruption and 25 events a year.

\section{b) Texas}

Similar to the case of the Edison Company in California, a DR program specifically designed for agricultural (in this case, for irrigation loads), is offered by the American Electric Power Texas Company in collaboration with the aggregator EnerNOC. Pumps are remotely controlled, being switched off during the peak period, which may take place on weekdays from $1 \mathrm{pm}$ to $7 \mathrm{pm}$. additionally, this company offers the Load Management Standard Offer Program for large customers able to reduce a minimum of $500 \mathrm{~kW}$ with short notification in advance.

The Austin Energy Company manages from 2013 a pilot program so-called Rush Hour Rewards, related to the management of thermostats of residential and commercial customers. An average of two thousand consumers is enrolled at present. This company also offers the Load Cooperative Program, which gives to enrolled customers \$1.25 per kWh 
in exchange for load reductions with a notification in advance of 1 hour during the summer peak periods.

The Center Point Energy Company has a DR program for commercial customers, called Commercial Load Management Program. Enrolled customers must provide an aggregated interruptible demand of at least $750 \mathrm{~kW}$ with a minimum of $100 \mathrm{~kW}$ of individual reducible power to be activated a maximum of 5 times a year.. Load reductions take place in summer from $1 \mathrm{pm}$ to $7 \mathrm{pm}$ on weekdays. Customers receive $\$ 35$ per reduced $\mathrm{kW}$.

A load management program for non-residential customers is offered by El Paso Electric Company. Similar to the DR program offered by the Center Point Energy Company, a minimum of $100 \mathrm{~kW}$ of interruptible power must be offered to be activated during the summer peak period. Incentives for customers are $\$ 60$ per $\mathrm{kW}$, with a maximum of 50 hours of interruption a year. A similar program is also offered for commercial customers by the Oncor Company.

The last significant program is called the Free Nights or Weekends program, offered by the TXU Energy Company. It is an incentive for customers enrolled so as to shift energy to the weekend, where the electricity is free in exchange of higher prices during the weekdays. More than 100,000 customers are enrolled at present in this program.

\section{c) Florida}

DR programs offered by the utilities in Florida are similar to existing programs in California and Texas.

The Florida Power and Light Company has a program for load reduction in commercial customers. It is based on the direct control of some devices for the reduction of demand in some periods of time. Customers receive credits and a flat monthly payment for being enrolled in the program. Another program, called On Call Program, has been designed for the remote management of air conditioning devices. Devices are switched off during periods from 15 to 30 minutes. Customers receive a monthly payment even if no interruptions have been activated.

A load management program for the remote control of air conditioning devices or other specialized devices is offered by the Tampa Electric Company. Customers are paid $\$ 3$ per $\mathrm{kW}$ for being enrolled, plus $\$ 3.5$ per actual interrupted $\mathrm{kW}$. Finally, this company, together with the Progress Energy Company, has a couple of programs for promoting the use of stand-by generators during peak periods: Standby Generator Program and Backup Generator Program. 


\subsection{International experiences of demand response applications to natu- ral gas systems}

As it has been discussed in the previous sections of this chapter, DR concepts have been used for years (with different level of development depending on countries) in the management of power systems. Thus, DR programs, either offered by system operators or utilities, contribute to solve different matters which appear in the habitual operation of the power grid. Nevertheless, and in spite of the similarities existing between the power and natural gas systems, as will be discussed in the next section, there are no successful experiences of DR applications in the natural gas system. However, as agreed by some researchers and professionals, DR concepts will be sooner or later essential for the better and more efficient operation of natural gas systems, as can be deduced, among others, from the following factors [5]:

- Electricity and natural gas markets are closely related as this resource is more and more used for power generation. The main reasons are:

- Environmental issues related to the reduction of power production with such fuels as coal.

- The higher performance of natural gas power plants (especially in combined cycle facilities)

- The massive utilization of renewable energies, which make necessary generation technologies able to quickly respond to the high variability of this kind of generation, providing power reliability and supply guarantee.

- The volatility of natural gas markets is increasing, especially due to the utilization of natural gas for power generation.

- Until recent past, natural gas demand used to be quite stable and seasonal; however, this tendency is changing nowadays [59].

- Natural gas is replacing other fuels in hydrocarbon markets [59].

Examples of DR concepts application to the natural gas system are exceptional, and most of them are just pilots which, in fact, permit to estimate a promising future for this kind of developments [60].

Some experiences have been driven in Canada and the US. In this first country, a pilot based on the management of thermostats for heating purposes in the residential sector demonstrated potential savings between $1.5 \%$ and $21 \%$, depending on the season and the external temperature of the considered period [61]. Another experience took place in Massachusetts, where gas demand reductions up to $20 \%$ where obtained in residential and commercial applications in the winter season [60]. Also in the US, the California Public Utilities Commission has approved the installation of advanced gas meters for all 
the gas customers, providing opportunities for the development of demand response programs applicable to the natural gas sector [62].

Enernoc, the most active company in DR applications for small and medium customers in the electricity sector, is also trying to develop some experiences in the natural gas sector. In particular, this company has developed a platform, which is being tested in customers from National Grid in the State of New York, in order to shift consumptions to optimize the use of fuel sources based on weather availability. Therefore, Enernoc will try to demonstrate that DR concepts may help in winter to solve the same kind of problems that the power system (closely linked to the gas consumption) has during peak periods in summer [63].

Regarding Europe, Spain was a pioneer in the approval of an interruptible program in $2006^{15}$, based on the need of establishing tools and mechanisms so as to make more flexible the natural gas system. By means of this program, the gas system operator has the possibility to interrupt the supply to large customers willing to that in case of emergencies. This advanced mechanism has two types or modes of interruptibility:

- Mode A: This mode can be used between the gas trader and the final consumer so that the consumer may help the trader in case of imbalance due to incidents which may produce the lack of gas in the portfolio of such trader.

- Mode B: Interruptible fee. The agreement is established between the final consumer, the gas trader and the gas system operator, so that the consumer is committed to reduce the consumption under requirement from the system operator due to the lack of gas in the system. In this case, a reduced access fee is applied to the consumer for using the infrastructures of the gas system.

Interruptible customers must be able to completely interrupt their consumption with a notification in advance of 24 hours. The duration of the interruption may vary from 6 hours up to 10 days. However, as mentioned above, only large customers with an annual consumption higher than $10 \mathrm{GWh}$ and a daily consumption higher than $26 \mathrm{MWh}$ and connected to a pipeline with a pressure higher than 4 bar can participate.

Another experience can be found in the United Kingdom, where there is a kind of interruptible program, but just at the distribution level and less developed than in Spain. Just a small group of large industrial consumers can participate, depending upon the commercial arrangements they have agreed to ${ }^{16}$. Interruptible customers receive discounted

\footnotetext{
${ }^{15}$ The interruptibility program is regulated in the Resolution 25 July 2006 from the General Direction of Energy Policy and Mines. https://www.boe.es/diario_boe/txt.php?id=BOE-A-2006-14314

${ }^{16}$ The characteristics of interruptible supplies are described in: http://www2.nationalgrid.com/uk/Industry-information/Gas-transmission-system-operations/Interruptions-to-supply/
} 
transportation charges when reducing their consumption in periods of high demand (especially in winter peaks). In 2010, just 27 customers participated in interruptible gas contracts in UK [64].

In the Netherlands, a consortium of 11 entities called Energy Delta Gas Research (ED$\mathrm{GaR})^{17}$ coordinates the development of different scientific, applied and technological research projects on natural gas. However, even if there are some research lines in the field of smart natural gas systems, none of them is dealing at the moment with DR applications in the natural gas sector. Said that, it is true that for this consortium, customer's flexibility is a key value in smart grids and some ideas have arisen about the utilization of flexibility of electricity consumers for the management of power plants fueled by natural gas [65].

All these experiences demonstrate the promising application of DR resources for a more efficient management of the natural gas systems, similarly to the power grid. However, most of them are just in pilot phase at present or, in the best case, only large industrial customers are enabled to participate.

\subsection{Analogy between power and natural gas systems}

Electricity and natural gas, as energy vectors they are, present significant differences. The main difference is probably the impossibility to store significant amounts of electricity with an acceptable performance. This fact makes that the electricity that consumers demand from the power grid must be produced in real time by generators at the other side of the grid.

Another significant difference is the wave nature of electricity. This nature provides electricity with an intrinsic characteristic such as the frequency, with no equivalency in the case of natural gas. Frequency must be constant through the whole power system, which can be only guaranteed if generation and demand are balanced at any time.

However, in spite of the aforementioned differences, electric and natural gas systems share many other characteristics which make them comparable in many aspects, especially those related to the system operation:

- Logistics of both systems require a robust transmission and distribution system due to the distance between the place where the energy is produced and the place where the energy is consumed. In order to optimize the electricity transmission while minimizing the power losses, this kind of energy is transmitted for long distances by increasing the voltage of the grid. In the case of the natural gas system, this role is played by the pressure of the pipelines. Similarly to the power lines, the pipelines use a high pressure for optimizing the utilization of

\footnotetext{
${ }^{17}$ More information about this consortium is available at: http://www.edgar-program.com. Accessed on 18 April 2017 
the grid when the gas is transmitted, reducing the pressure at the time the energy has to be supplied to the consumers. Therefore, voltage and pressure are two complementary magnitudes with an equivalent behavior when considering either the power or the natural gas system. Electrical substations and compression stations also illustrate this equivalency.

- The capacity that the distribution company gives to customers is also measured in two equivalent magnitudes. In the case of the power system, the contracted power measures this capacity, which is included as a fix term in the electricity billing. In the natural gas system, the equivalent magnitude is the contracted daily flow, which is also billed in the gas bill as a fix term. The equivalence in the consideration of these two magnitudes (both measured in power units) is even more evident in some countries such as Spain, where the fix term in power and natural gas systems is billed according to the same algorithm, just interchanging the concepts of contracted power ${ }^{18}$ or daily flow.

- Electricity and natural gas markets have evolved towards a liberalized structure almost in parallel. While it is true that electricity markets have been always one step ahead, similar structures have been created for electricity and natural gas.

- The type of customers for both resources is the same (industrial, commercial and residential) and in all the cases, factor which influence the consumption (external temperature, seasonality, etc.) are basically the same.

- Both systems have common operational needs, like the solution of physical constraints, the need of adapting the market results to the physical conditions of the transmission and distribution infrastructures or the needs of consistent strategies so as to afford the quick variation of demand, which has to be followed by the energy provision.

- The business model for the negotiation, trading and settlement of electricity and natural gas is basically the same, in a way that energy companies use to offer both resources in a single package with very similar structure.

As indicated by [5], after the proliferation of DR programs in the electricity sector and the acceptance of this kind of mechanisms by the customers, the adoption in the natural gas sector is only a logical step. This adoption may be strongly favored by the advances in recent times about the utilization of smart technologies and standard platforms such as smart meters, which are being massively installed in some countries as will be discussed in section 3.4.2. Thus, tools and techniques successfully used for the exploitation

\footnotetext{
${ }^{18}$ In the case of the electricity market, this is valid for contracts with three periods (peak, shoulder and valley). Either in power and natural gas contracts, the fix term is calculated comparing the contracted and the maximum registered value of these magnitudes, applying a bonus of $15 \%$ if the maximum value is lower than the $85 \%$ of the contracted value, or a penalty in case of an excess higher than 105\% (Royal Decree 1164/2001 for electricity and Royal Decree 949/2001 for gas)
} 
of DR resources in the power sector can be adapted for their utilization on the natural gas side.

\subsection{Barriers to the implementation of demand response strategies in the natural gas system}

As it has been discussed in this chapter, the participation of consumers in the solution of operation issues by modifying their load state is essential for the optimization of the energy systems. However, there are barriers which sometimes make difficult the proper exploitation of these resources.

Barriers and handicaps related to the implementation of DR in power systems has been discussed in many studies. One of the most recent examples can be found in [66], which results from the European project DRIP. Among other results, this project produced a methodology for the systematic evaluation of handicaps which prevent the implementation of DR strategies in the operation of power systems. Considering this work, and based on the similarities previously identified between power and natural gas systems, a preliminary evaluation of barriers can be assessed referred to the gas side.

One of the main barriers is the difficulty for customer's acceptance: customers do not use to be willing to reduce their consumption. The first reason is that consumers are not aware about the potential they may have, and they do not know that someone could be willing to pay in exchange for such flexibility. Another reason is that, when being aware of this potential, customers perceive that the economic incentives they may receive are not attractive enough. This barrier can be faced by providing customers evidences about the economic profitability that DR actions may provide to their energy bill. While this is a difficult task, there are some tools for this purpose (some examples are provided by the aforementioned DRIP project), developed in the last years for the electricity markets that may be used for this purpose but applied to the natural gas sector.

Tools are also necessary so as to jump barriers on the side of retailers or system operators, as the potential offered by customers is difficult to forecast, and the benefits that DR may mean for their business is not easy to assess. However, the benefits of DR have been also proved in power systems for these activities, so that similar results can be expected in the natural gas sector. Retailers can find in DR resources a help for the optimization of their portfolio and the reduction of imbalances, with significant cost savings. Regarding the gas system operators, the most significant barrier for them is probably the utilization of small and medium flexible consumptions. In fact, the few examples that can be found about the utilization of DR in natural gas systems is just related to very large consumers (as discussed in section 2.3). Therefore, the empower of the figure of the aggregator in natural gas systems is essential for the proper integration of DR resources coming from the residential and commercial sectors, as well as medium and small industries. A significant role can be played here by the managers of district heating networks, as they can 
provide the system operator with flexible customers willing to play not with their gas supply, but also their hot water or steam utilization. The system operator can utilize the potential offered by flexible customers so as to solve technical constraints related to the maximum capacity of pipelines in periods of peak demand. Additionally, the usage of natural gas storage can be optimized, allowing the system operator to combine both storage and DR resources so as to guarantee the optimum management of the whole system.

The development of the concept of Smart Energy Systems in recent times, which is providing with a strong metering and communication structure the natural gas network, is definitively enabling energy grids for the easier utilization of customer's flexibility. However, as indicated in [5], the impact of DR programs, most of which would be similar to those existing for power systems, has to be evaluated and validated. At present, except the few examples mentioned in this section, there are not real experiences demonstrating this potential. Therefore, the implementation of pilots arises as one essential step to provide credibility for considering DR.

There are some opinions against the utilization of DR strategies in the natural gas sector since some experts think that DR programs for gas consumers may be alluring but impractical [67]. Nevertheless, this dissertation proves the suitability of DR strategies applied to the natural gas sector, where similar problems to those arising in power systems can be afforded by this media.

\subsection{Conclusions of the chapter}

Demand Response has been used for years in the operation and management of power systems. However, few experiences exist in the natural gas sector, where the application of DR strategies is almost non-existing.

This chapter has highlighted the most significant experiences in DR utilization in the electricity sector in different countries. This kind of mechanisms offers many benefits either for customers and the power system as a whole, as it has been demonstrated in different applications for the electricity sector. Therefore, due to the similarities existing between the power and natural gas systems, the application of similar strategies for the gas sector should be considered as the natural evolution for a more efficient and operative management.

The barriers that may prevent the utilization of DR resources in the natural gas system are also here discussed. However, many of them can be solved thanks to the new structure that today is being given to the energy systems based on the concept of smart grid. It is indeed in energy systems structured according to the smart grid configuration where the application of DR may result more useful and profitable. The structure of natural gas systems according to the smart grid architecture is discussed in the next chapter. 



\section{Chapter 3 \\ Smart grid configura- tion for natural gas systems}

\subsection{Chapter overview}

The purpose of the natural gas system is providing to the customers this resource to satisfy their energetic needs in the required conditions of security and reliability at a reasonable cost. Coming from this basic concept, different agents arise in order to fulfill this objective, considering not only technical, but also economic and environmental implications so as to do it according to the most efficient way,

Natural gas systems, similarly to the rest of energy systems, are evolving towards a highly technified structure where the customer is called to play a starring role. Customers are not anymore those passive actors who had to be supplied in a rigid way. Nowadays, concerned about the need of better handling the energy resources due to economic and environmental issues, customers start to be willing to behave more flexibly so that energy may be consumed differently depending on externalities such as the price of energy, the weather conditions or the situation of the grid.

This new configuration of energy systems, which include a high level of metering, monitoring and communication activities, is the so-called smart grid architecture. The application of this concept to the natural gas system will be discussed in this chapter, including a comparison between the traditional structure of this kind of infrastructures and the level of application of this novel configuration in Europe and the US. 


\subsection{Traditional architecture of the natural gas system}

\subsubsection{The natural gas supply chain}

The natural gas supply chain comprises the different processes through which this resource is extracted from the subsoil and finally delivered to the consumers. The process includes a set of stages, which depend on the manner in that the gas is produced, stored, transmitted and supplied, as it is shown in Figure 3.1. These processes are the following:

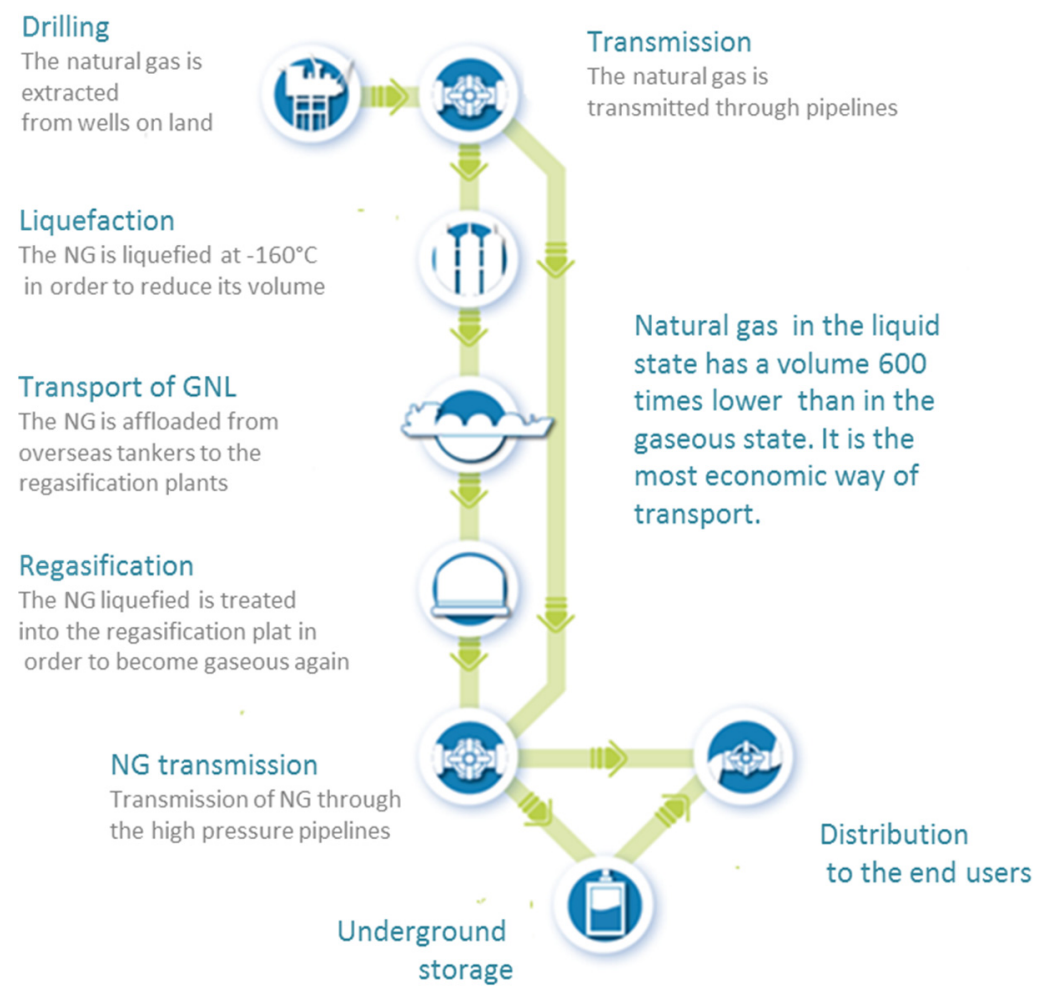

Figure 3.1. Natural gas supply chain. Source: ENAGAS

- Extraction: In this phase of the chain, the natural gas is extracted from wells on land and adapted for its introduction into pipelines. This adaptation includes the chemical homogenization of the gas components, as well as the physical conditions of pressure and temperature. 
- Transmission: Depending on the distance between the gas deposit and the final users, as well as on the existing infrastructures, the natural gas can be transmitted in two forms:

a) In gaseous state. In this case, the gas is directly injected into a transmission pipeline, which will send the resource up to the final consumers through pipelines at a high pressure.

b) In liquid state. When the distance between the deposit and consumers is very large, the natural gas is liquefied at a very low temperature (in the order of $-160^{\circ} \mathrm{C}$ ) and put into liquefied natural gas (LNG) tankers, which transport it by the sea up to a regasification plant. Once on land, the LNG is heated (usually by using sea water) and turned again into gaseous state. Then, the gas is injected into the transmission system (transmission pipelines), or it can be stored in an underground store. Before being re-gasified, the LNG can be also stored in liquid form in external tanks existing at the regasification plant.

- Distribution: The last step in the gas chain is the distribution and delivery of natural gas to the final consumers. So as to do it, the natural gas needs to be adapted to the pressure conditions required by end users, which is done in compression stations located at the end of the grid.

The activities described in the figure above are related to the utilization of the natural gas once the resource is already available. However, there are other tasks that must be performed before and after the exploitation of a gas deposit:

a) Exploration. The first step is the search for hydrocarbons under the ground. It entails the geophysical prospection so as to discover shale formations that hold deposits of oil and natural gas. One of the most used methods of exploration is based on seismology. It is based on the generation of substantial vibrations at the ground surface by means of explosives or machinery. Seismic waves travel through the Earth's mantle, so that when the wave is received back at the surface, it is analyzed in order to identify layers of rock that may trap reservoirs of oil and natural gas.

b) Development/Extraction. After identifying potentially viable fields, the more convenient method of extraction of the liquid hydrocarbons is determined, according to the characteristics of the deposit. An economic evaluation is necessary in order to estimate the construction cost of platforms (offshore or onshore) or any other required infrastructure, and the environmental impact of the proposed solution is also assessed.

c) Production. Liquid hydrocarbons extracted from wells are separated from the non-saleable components such as water and solid residuals. Natural gas is often processed onsite while oil is piped to a refinery before being offered for sale. 
d) Abandonment. Once deposits are deemed unproductive or out of capacity, wells are plug and the areas around are restored to environmental states that existed prior to drilling activities. In many times, old deposits are turned into underground gas stores, so they can keep taking part in the natural gas supply chain by taking a different role.

\subsubsection{The natural gas system in the United States of America}

Natural gas is a very important energy vector in the US, meeting the $24 \%$ of the total energy demand in the country. It is composed of over 500 natural gas processing plants, which adapt the conditions of this resource so as to be injected in the transmission pipelines. In the residential sector, natural gas heats the $51 \%$ of American homes.

The US natural gas system is an efficient structure that produces, stores, and transmits natural gas from the production fields to the end users throughout a deeply interconnected network of interstate and intrastate gas pipelines [7].

The traditional architecture of the natural gas system in US follows the same structure as mentioned in the previous section:

- Productions sites where the natural gas is extracted from the wells

- Processing plants where the physical conditions of the natural gas are adapted to the requirements of the grid

- Storage sites (underground and surface stores)

- Liquefaction plants for the gas shipping (exports) and the regasification plants (imports) for the incorporation of natural gas to the transmission and distribution network

- The transmission and distribution infrastructure, composed of gas pipelines (they include inlet and exit points and market hubs).

- Gas market structures for the trading of this energy vector

- And consumption points, where gas is supplied to the final customers

\subsubsection{Production sites}

Today, the US is recognized as the major producer of natural gas with 28,700 trillion of cubic feet (2016), which corresponds to the $23 \%$ of the global production worldwide. At certain distance, as shown in Figure 3.2, Russia is the second producer in the world with 22,500 trillion of cubic feet [68]. 


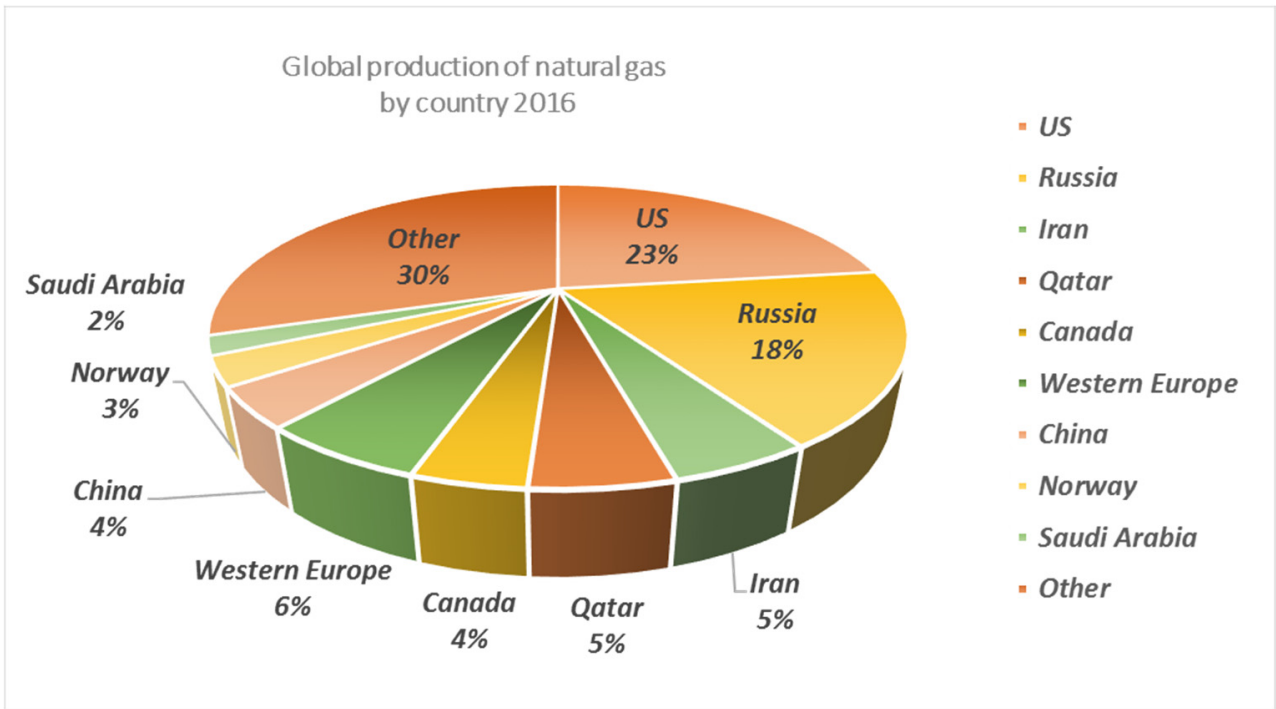

Figure 3.2. Global production of natural gas by country in 2016 (Source: Haver analytics)

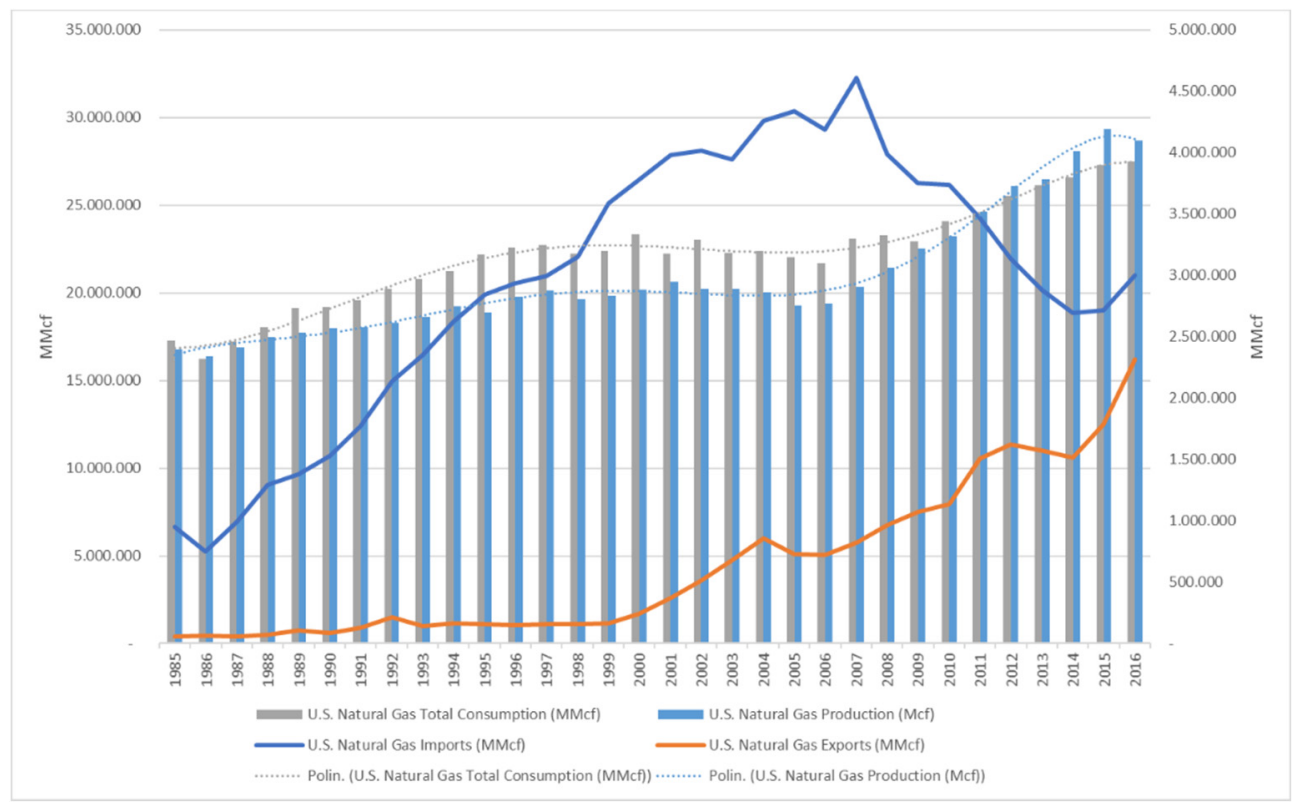

Figure 3.3. US Total Natural gas production and imports, and annual changes in production and imports (1983-2016) (Source: Own elaboration using EIA data) 
At present, thanks to the rise of the shale gas production ${ }^{19}$, the US gas imports have reduced. Simultaneously, the gas self-production exponentially grows, making the US a potential candidate for a worldwide export of natural gas in the future [69].

As shown in the Figure 3.3, the annual production of natural gas in the US increased from 19,259 Tcf/year (545 $\mathrm{Tm}^{3} /$ year) in 2005 to $28,700 \mathrm{Tcf} /$ year $\left(813 \mathrm{Tm}^{3} /\right.$ year $)$ in 2016 . It has been mainly due, as mentioned before, to the intensification of the shale gas production (the so-called "fracking"). As a consequence, gas imports have decreased from 4,608 Tcf/year (130.5 Tm³/year) in 2007 to 3,000 Tcf/year $\left(85 \mathrm{Tm}^{3} /\right.$ year $)$ in 2016 .

With regard to the natural gas demand, it is following a growing tendency, increasing in $5.000 \mathrm{Tcf} /$ year $\left(142 \mathrm{Tm}^{3} /\right.$ year $)$ from the 2015 to 2016 . This growing trend led to an intensification of the shale gas production in order to make the country able to face the national energy needs and become more independent from the foreign imports.

\section{a) Shale gas production}

Shale gas has been a revolutionary discovery for the US energy market and it is currently considered as the most promising source of natural gas worldwide [70]. Actually, shales are fine-grained sedimentary rocks that fracked through a strong water jet release natural gas. The exploitation of the shale rocks started in an intensive way in 2007 in US, after the discovery of large sedimentary rock fields in the oil formation areas of Marcellus (35\%), Haynesville (12\%), Barnett (14\%) and Eagle Ford (12\%) [71].

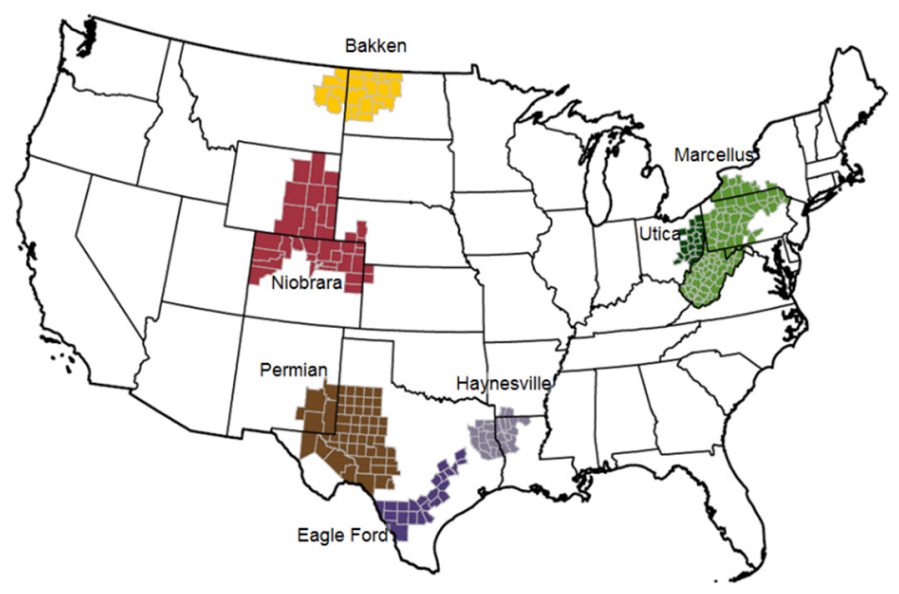

Figure 3.4. Gas production regions in USA (Source: EIA)

${ }^{19}$ Shale gas production, available at https://www.eia.gov/dnav/ng/ng_prod_shalegas_s1_a.htm 
These four areas, located in the map in Figure 3.4, are part of the seven regions with a higher density of gas and oil wells for traditional natural gas and oil extraction in the US: Bakken, Eagle Ford, Haynesville, Marcellus, Niobrara, Permian and Utica. These seven formations accounted for the $92 \%$ of the oil self-production and for all the domestic natural gas production increment from 2011 to 2014.

During the last decade, as it is shown in Figure 3.5, the shale gas exploitation has been constantly increasing. Indeed, shale gas production has not stopped to grow during the last 10 years, starting with a production of just 1,200 billion of cubic feet in 2007 (34 billion of $\mathrm{m}^{3}$ ) and reaching a total production of 15,000 billion of cubic feet (425 billion of $\mathrm{m}^{3}$ ) in 2015 . Nowadays, shale gas production contributes in more than $40 \%$ of the total natural gas production in the country.

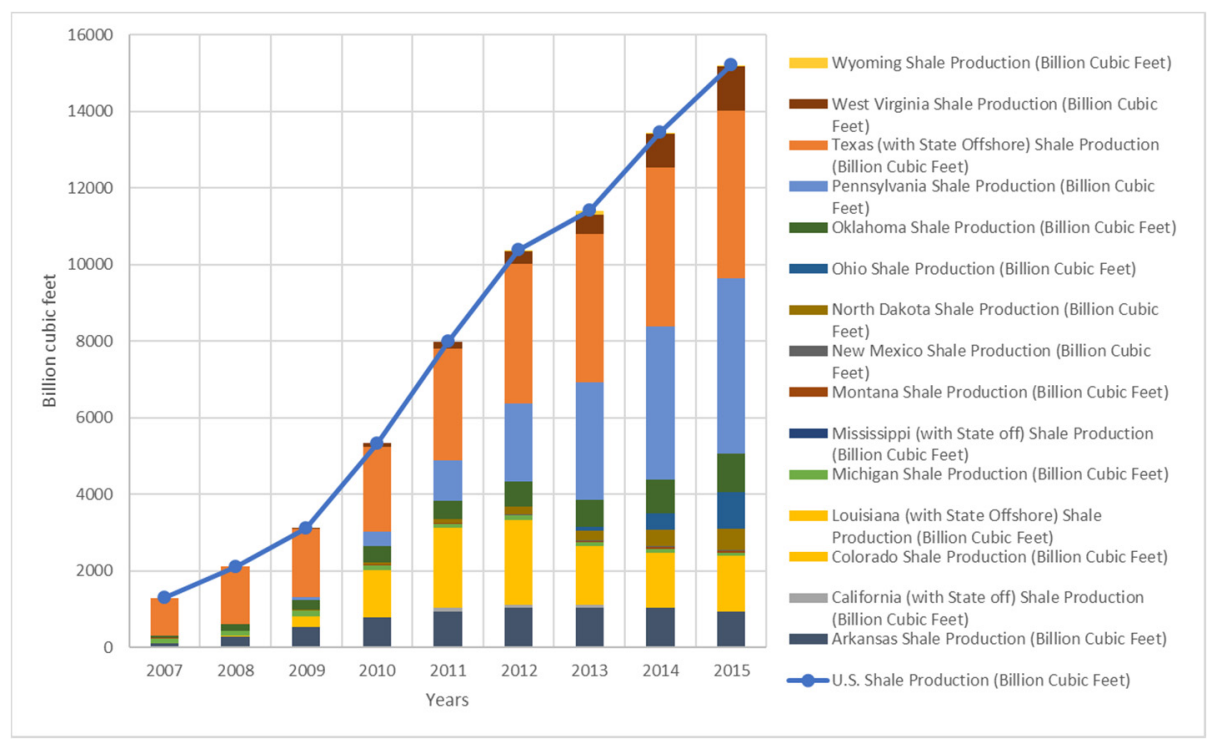

Figure 3.5. Shale gas production in USA (Source: Own production using EIA data base)

Apart from the US, other countries such as Canada, China or Argentina, also have a significant availability of commercial shale gas at the moment, and others like Mexico or Algeria are making interesting efforts on this field. In fact, according to the IEA, it is estimated that these six countries together will account for $70 \%$ of global shale production by 2040 .

\section{b) Natural gas wells}

Today, there are more than 550,000 natural gas producing wells, mainly located in Texas (140.000 wells) and Pennsylvania (70.000 wells), as detailed in Figure 3.6. They contribute for the total NG production for the $42 \%$ and $13 \%$, respectively. 


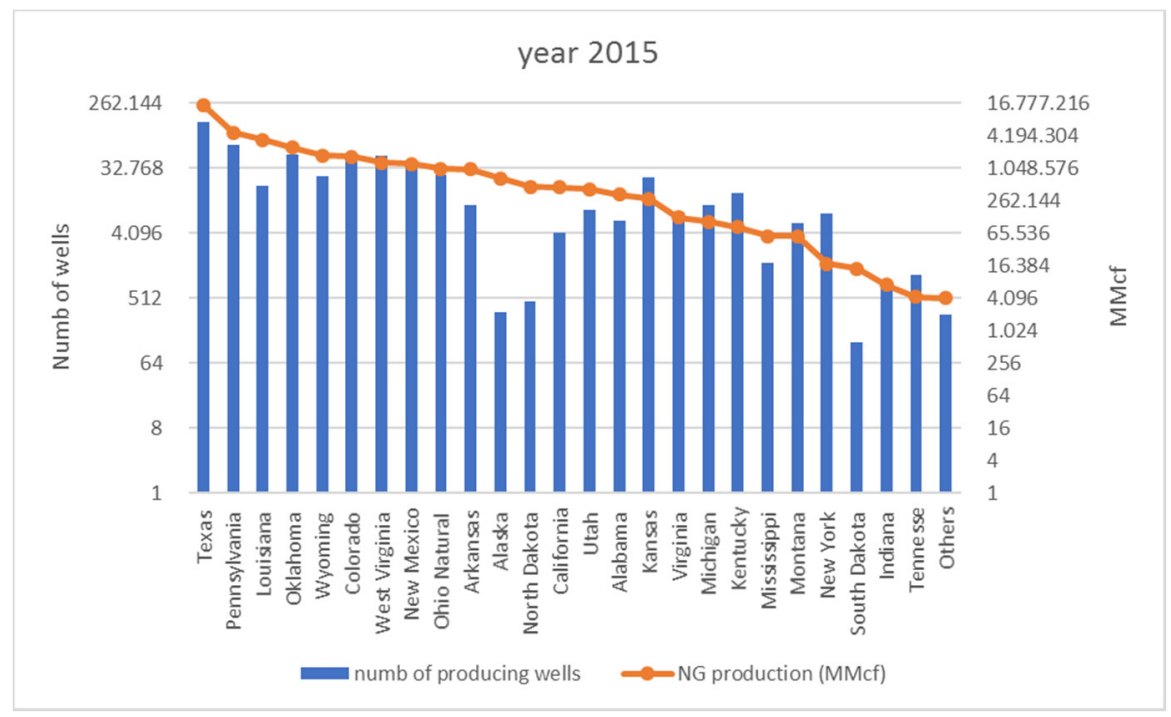

Figure 3.6. Numbers of gas wells for natural gas production in USA (Source: Own production using EIA)

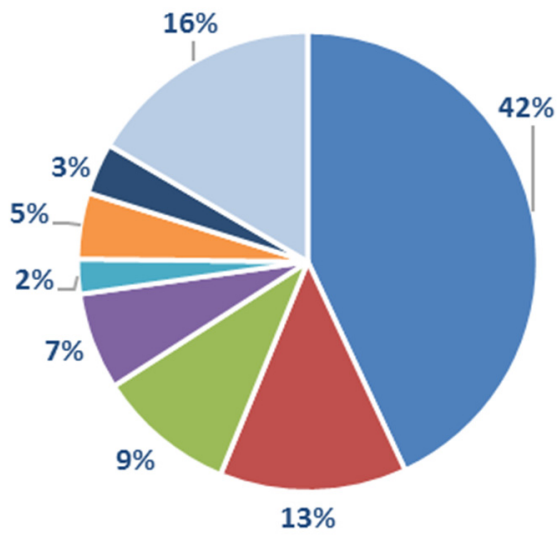

$$
\begin{aligned}
& \text { - Texas } \\
& \text { - Pennysilvania = Lousiana = Oklahoma } \\
& \text { - Wyoming } \\
& \text { - Colorado } \\
& \text { - West Virginia }=\text { Others }
\end{aligned}
$$

Figure 3.7. Natural gas production per State in 2015 (Source: EIA) 


\subsubsection{Processing plants}

Once the natural gas has been extracted, it is processed in processing plants, where impurities are spared. At present, there are more than 500 processing plants distributed all around the country [72]. As shown in the Figure 3.8, Texas had the highest number of processing plants, accounting together with Louisiana a half of the processing capacity of the country.

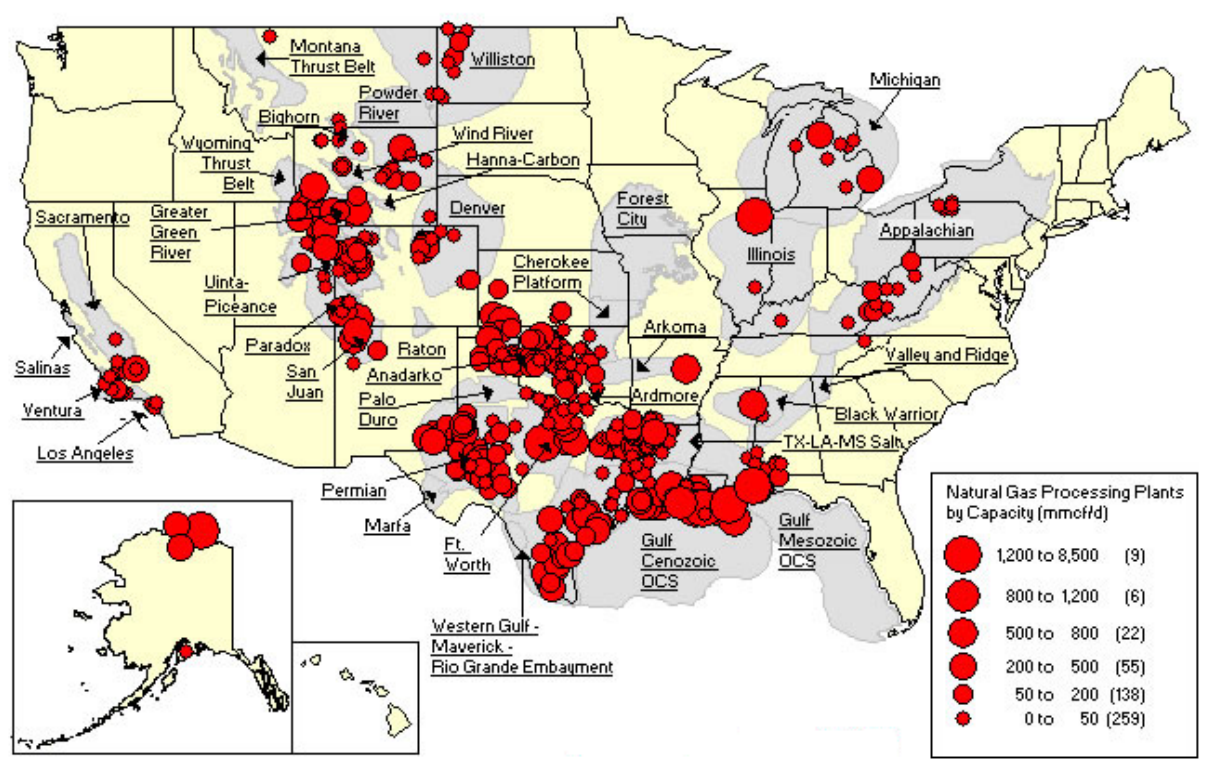

Figure 3.8. Processing plants in US (Source: EIA 2011)

The clean natural gas is later sent through the transmission pipelines to the compression stations, where pressure is reduced so as to inject the gas into the distribution system. There, the gas flows at a pressure range of over 60 pounds per square inch ( 4 bar) to 0.25 pounds per square inch (1.7 bar). Currently, there are more than 1,400 compressor stations that guarantee the pressure on the pipelines. Their location is shown in Figure 3.9. 


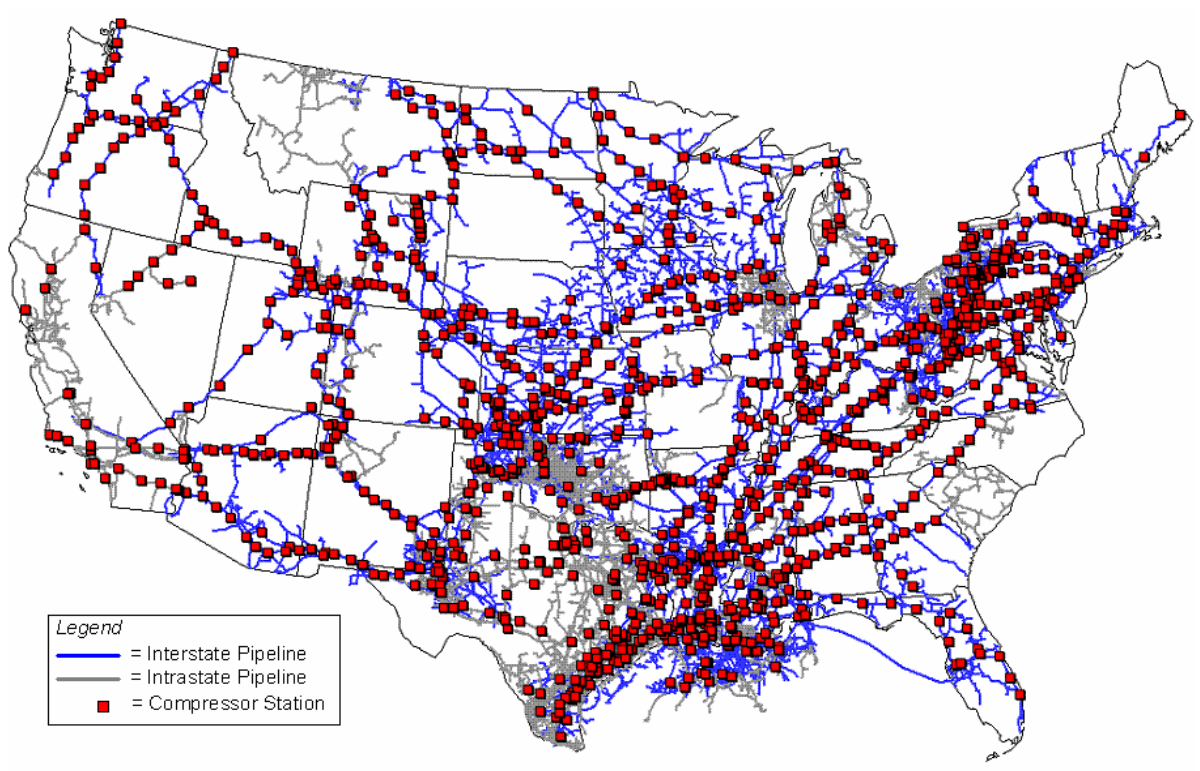

Figure 3.9. Compressor stations on USE (Source: EIA 2008)

\subsubsection{Storage sites}

In the US there are over 400 underground gas storage facilities. Generally speaking, they can be grouped into three groups:

- Exhausted natural gas reservoirs, which represent more than $80 \%$ of natural gas storage capability (329 existing sites in 2015). This kind of storage system is generally located near consumption centers and existing pipeline systems. They are usually wide available ${ }^{20}$.

- Exhausted aquifers, which are water-bearing sands topped by an impermeable cap rock (47 sites in 2010). They constitute almost $10 \%$ of the storage facilities.

- Salt caverns, which represent the $11 \%$ of all facilities (39 sites in 2010). Caverns provide very high withdrawal and injection rates, being mainly located in the Gulf Coast states.

The location of the different natural gas storages, classified according to these three types, is indicated in Figure 3.10.

\footnotetext{
${ }^{20}$ More detailed information can be found at: http://www.energyinfrastructure.org/energy-101/natural-gas-storage
} 


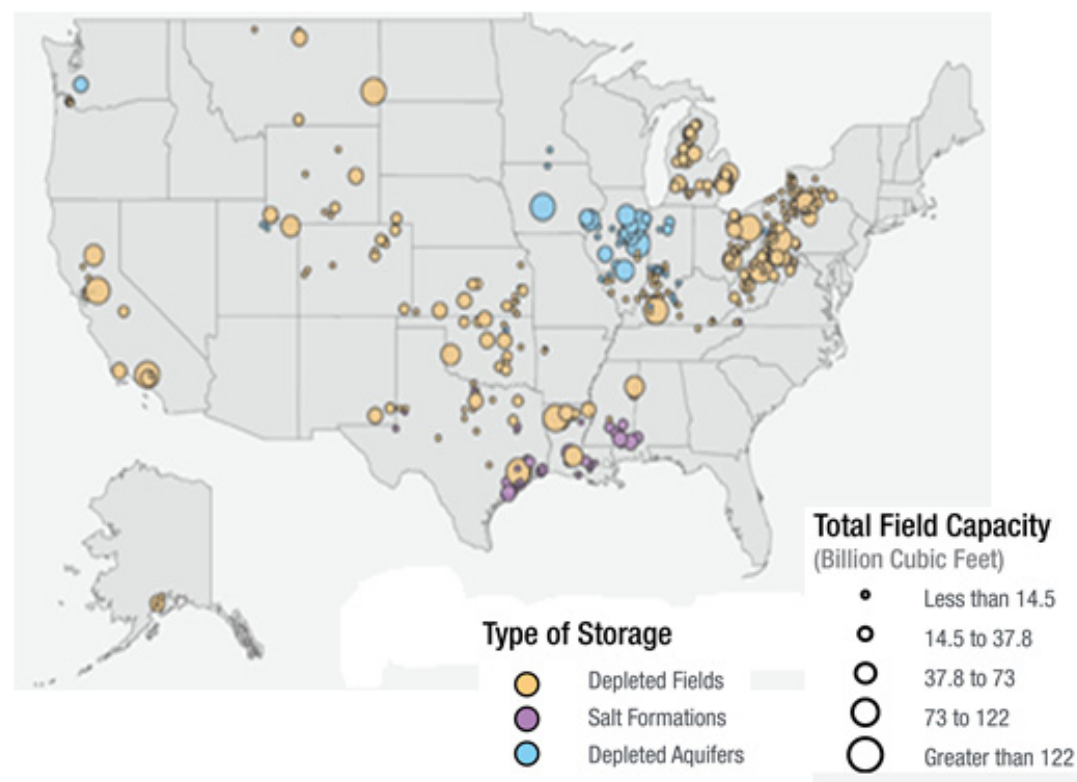

Figure 3.10. Type and total field capacity (Bcf) of the underground storage in the USA (Source: EIA energy mapping system, July 2014)

In 2016, the total storage capacity of working gas was 2,000 billion cubic feet [68]. Most of facilities are located at the South Central region, where there are both salt and non-salt storage facilities. This area represents the $40 \%$ of the total storage capacity, followed by the Midwest region (25\%) and East region (20\%).

Regarding the operation of stores, Figure 3.11 shows the schedule of the storage gas capacity during the last years. As it is shown in the figure, operation is periodical, being the gas generally injected from April to October. Natural gas storage levels are usually maximum at the beginning of November.

Storage facilities are operated by interstate pipeline companies (subject to the jurisdiction of the FERC), intrastate pipeline companies (state-regulated), local distribution companies (LDCs) and independent storage service providers. In addition, some storage facilities might be "open access" operated, which means that the storage can be used by the customers as a backup reservoir where they could store the gas or withdraw it according to the price of energy ${ }^{21}$.

\footnotetext{
${ }^{21}$ More detailed information can be found at: https:/www.eia.gov/naturalgas/storage/basics/
} 


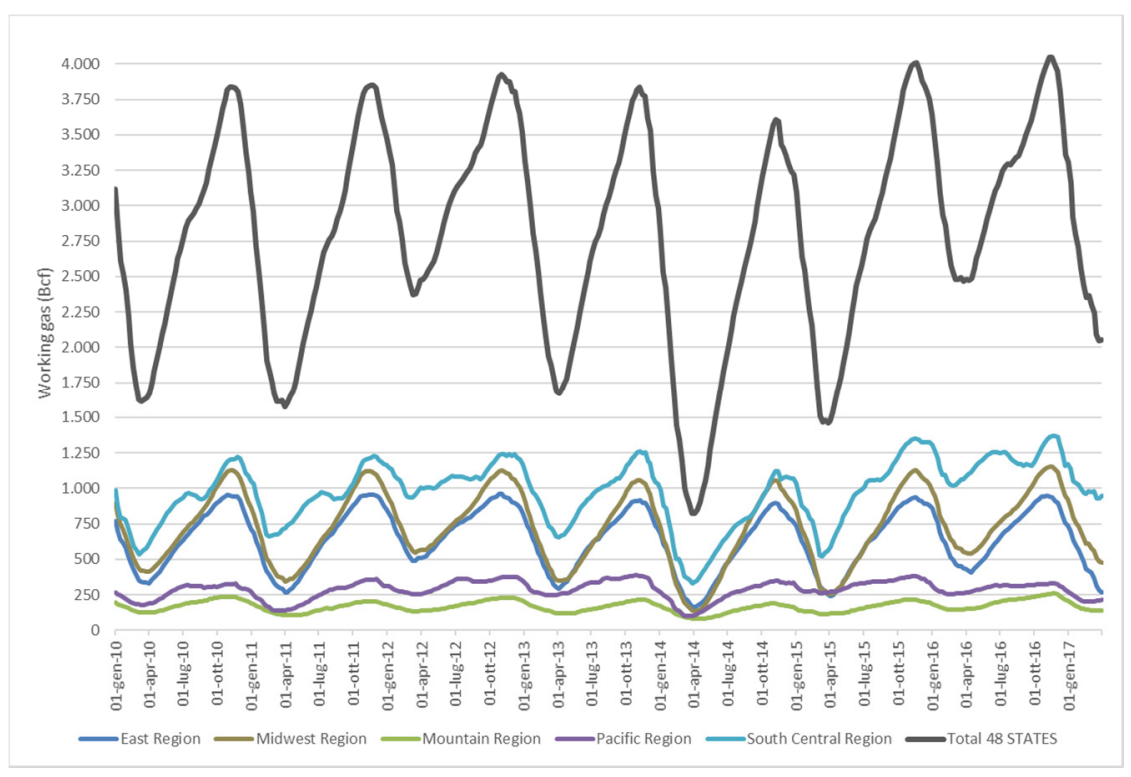

Figure 3.11. Underground gas storage operation schedule in US, in Bcf (Source: EIA database)

\subsubsection{Transmission and distribution infrastructure}

Transmission and distribution of natural gas in the American system takes place according to one of the following alternatives:

- Directly by pipeline when the hydrocarbon is in gaseous state. This infrastructure is composed of interstate pipelines (see Figure 3.12), which cross long distances with a high capacity of gas transmission, and by the intrastate pipelines, which link the end users to the natural gas production sites through the interstate pipelines. Most of the natural as transmitted and distributed in the US do it by means of pipelines, as shown in Figure 3.13.

- By ship as liquefied natural gas (LNG). Around the $3 \%$ of gas is imported by ship through the 9 LNG facilities located in the continental US and Alaska.

- On trucks, as LNG or also as compressed natural gas (CNG). Just a little percentage of the imported natural gas (about 1\%) do it by this mean.

The transmission and distribution infrastructure is composed by 2,7 million $\mathrm{km}$ of interstate and intrastate transmission pipelines, over 11,000 delivery points, 5,000 reception points, 1,400 interconnection points and 58 locations at which natural gas can be exported or imported into USA, including 9 LNG facilities in the continental United States and Alaska. These infrastructures are shown in Figure 3.14. 


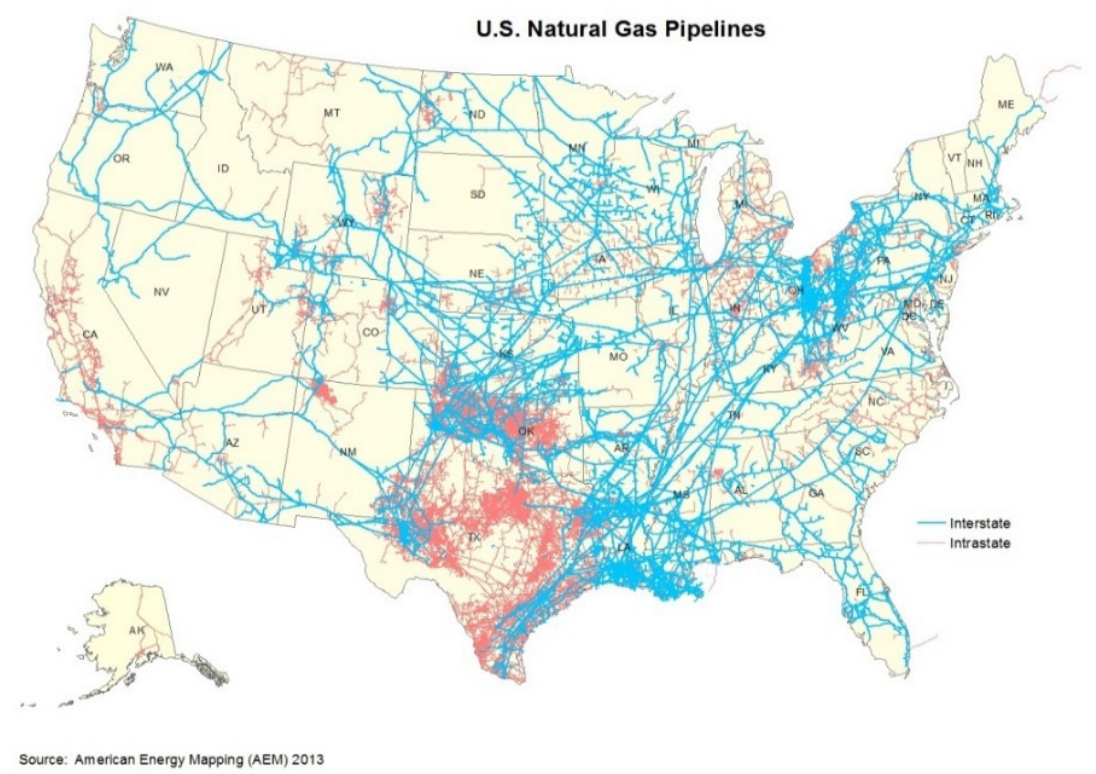

Figure 3.12. Natural gas market centers and hubs in relation to major natural gas transmission corridors (Source: American energy mapping- 2013)
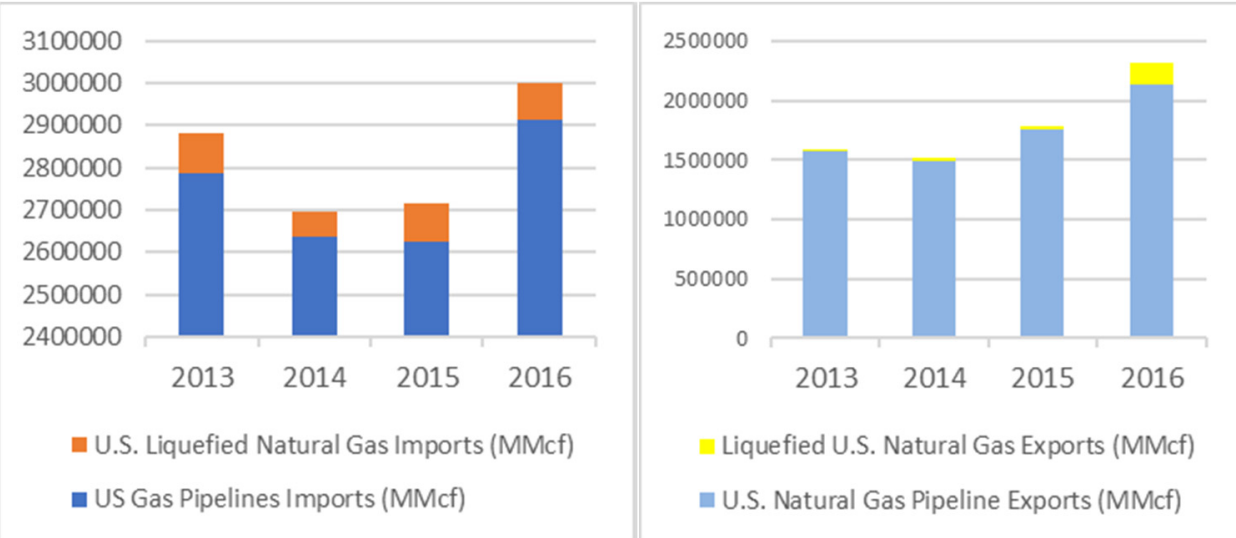

Figure 3.13. Import and export of NG in US (Source: Own elaboration of EIA DATA) 


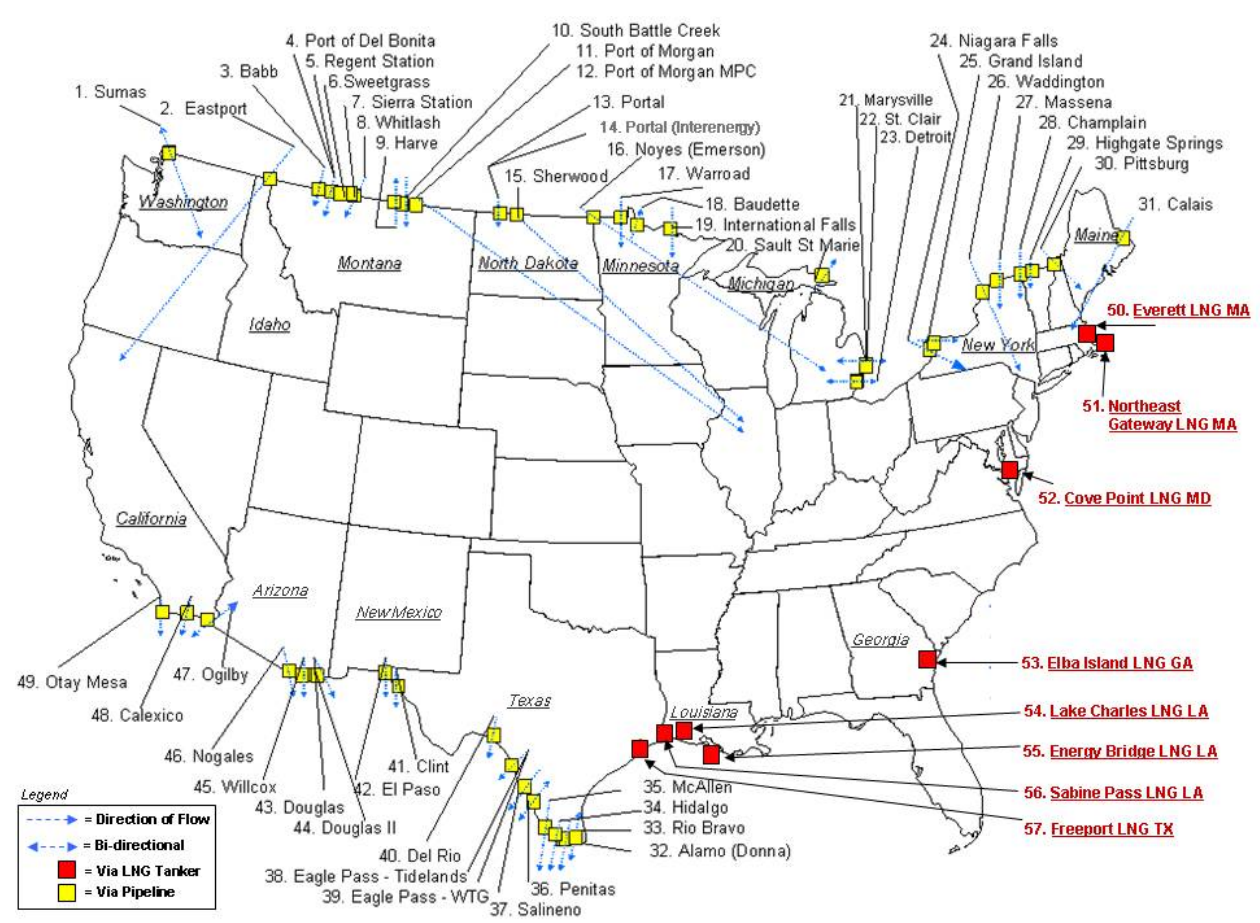

Figure 3.14. U.S. Natural Gas Import/Export Locations, as of the end of 2008 (Source: EIA Energy Information Administration, Office of Oil and Gas, Natural Gas Division, Imports/Export Points Database

In 2016 , the $70 \%$ of the imported natural gas was brought via the following five connection points:

- Port of Morgan, Montana (Northern Border Pipeline)

- Eastport, Idaho (Gas Transmission Northwest)

- Sherwood, North Dakota (Alliance Pipeline Company)

- Noyes, Minnesota (Great Lakes Gas Transmission Company)

- Noyes, Minnesota (Viking Gas Transmission Company)

The net amount of imports, equal to the total imports minus exports reached the peak in 2007. During the following years this figure declined, basically due to the increment of domestic production, as shown in Figure 3.15. In 2016, imports reached about 3.00 trillion cubic feet (Tcf) of natural gas while exports were $2.31 \mathrm{Tcf}$, resulting in net imports of nearly 0.690 Tcf (about $2.5 \%$ of the gas consumption in the country). Most of gas 
was mainly imported by the pipelines connecting to Canada (99\%) and Mexico (just $1 \%)$.

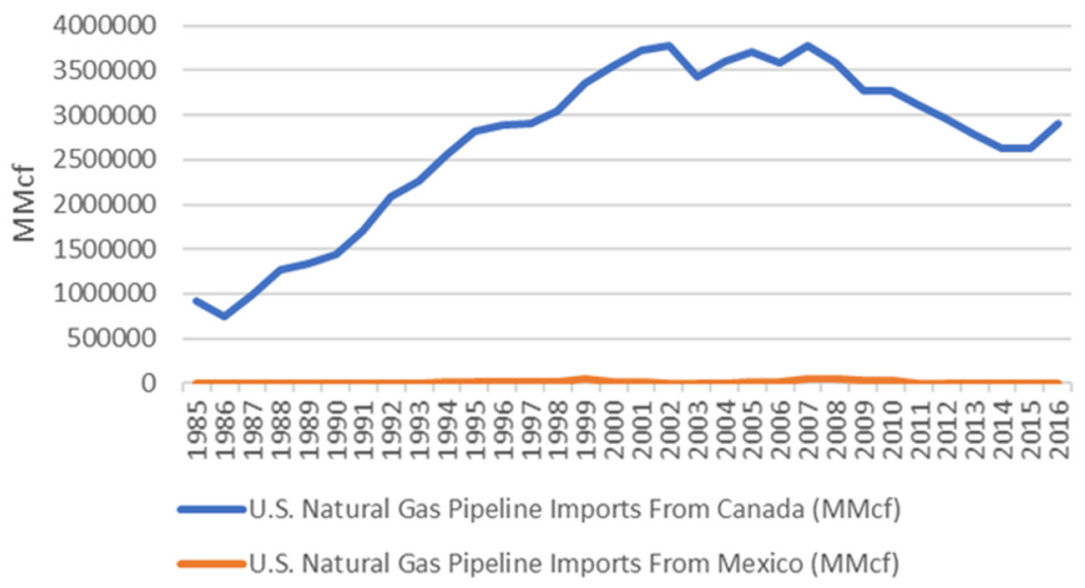

Figure 3.15. Imports from Canada and Mexico (Source: Own elaboration using EIA data)

Regarding the gas exports, they accounted for the $40 \%$ to Canada and the $60 \%$ to Mexico. The evolution of exports is also shown in Figure 3.16.

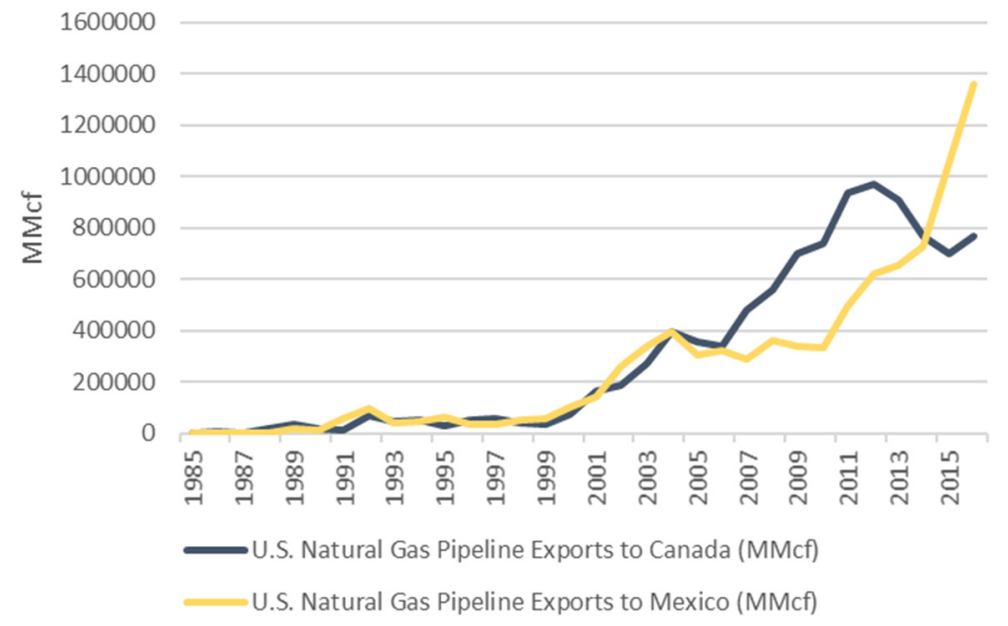

Figure 3.16. Exports from Canada and Mexico (Source: Own elaboration using EIA data)

According to the analysis here carried out, the imported amount of gas is still higher than the exports, so that the country remains predominantly as a net importer, in spite of the 
growing of the domestic production. Imports and exports in form of LNG and CNG represent just a small percentage of the total amount of the total amount of natural gas flowing through the transmission and distribution pipelines. In 2015, exports of LNG and CNG accounted for about $2 \%$ of total, while the imports were the 6\% (Figure 3.17)

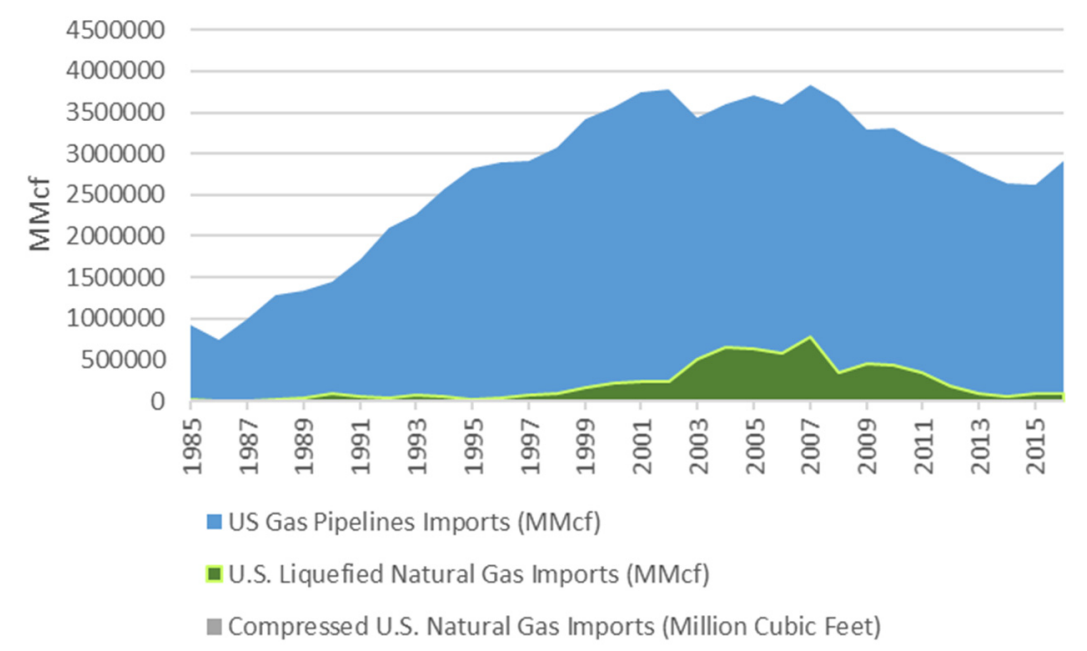

Figure 3.17. Imports by pipelines and by ship [Source: Own production using EIA Data]

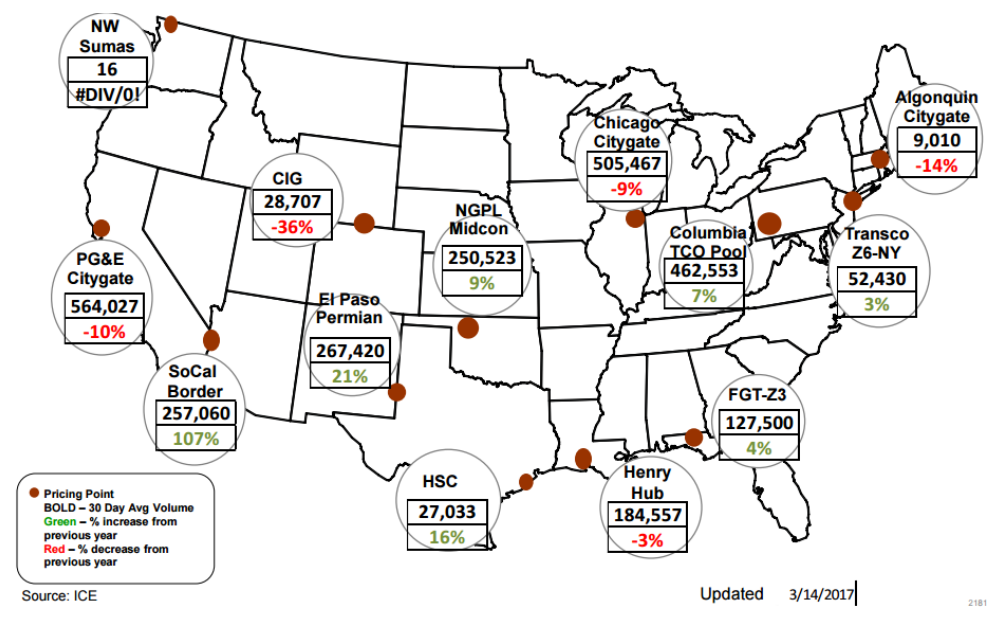

Figure 3.18. Gas trading location and gas volume capacity 
Regarding other infrastructures, there are more than 10 regasification plants where LNG returns to gaseous state, with an additional eight proposed sites. Finally, there are 29 market hubs (Figure 3.18) where natural gas is priced and traded throughout the country by interstate and intrastate pipelines. They provide additional interconnection points, being located at the intersection of major pipeline systems. The Henry Hub in Louisiana is the main one.

\subsubsection{Analysis of the natural gas consumption}

The natural gas delivered to final customers is used for different purposes, depending on the sector to which the final customer belongs (residential, commercial, industrial, transport or power production).

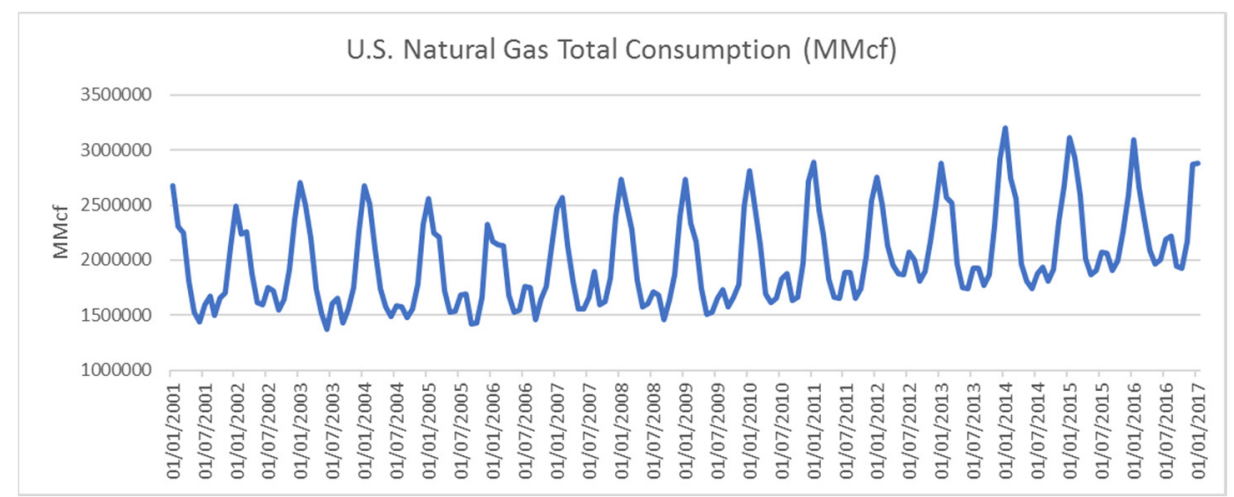

Figure 3.19. Evolution of natural gas consumption in the US, 2001-2017

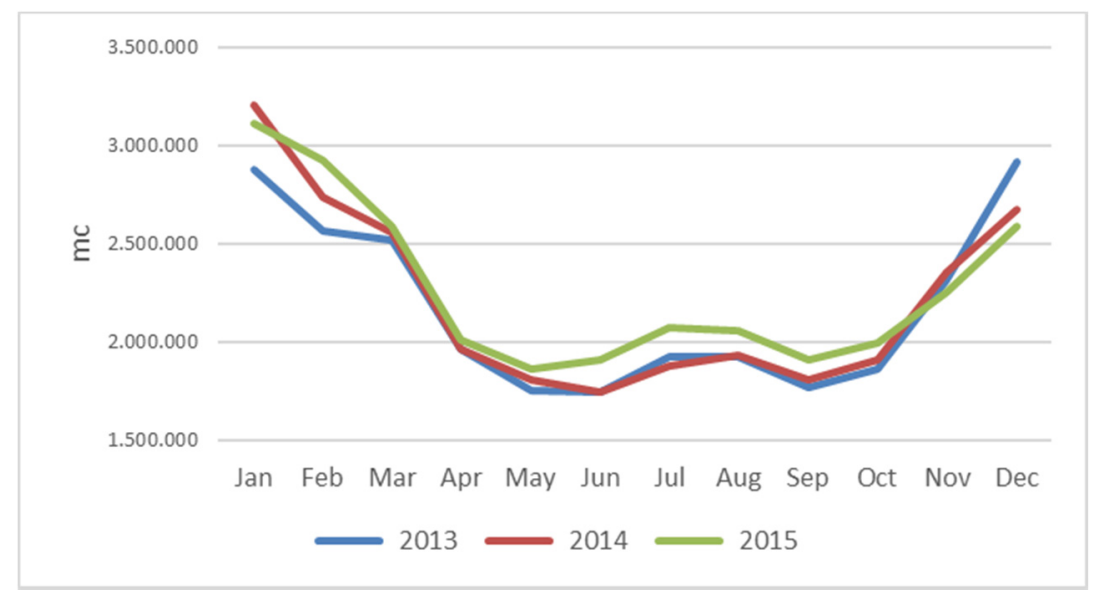

Figure 3.20. Monthly gas consumption in USA, 2013-15 (Source: Own elaboration with EIA data) 
Figure 3.19 shows the natural gas consumption during the last decades, where the high seasonality presented by this energy resource (consumption is generally higher during winter) is clearly presented. Seasonality can be also observed in Figure 3.20, where the load profile of the last three years is represented. Similarly, the growing trend of consumption experimented during the last years, especially due to the high influence of bad weather [73], is also highlighted.

The natural gas consumption can be classified as follows:

- $4 \%$ is used for the gas lease and plant fuel consumption. The gas lease consumption represents the use of the hydrocarbon in wells, field and lease operations. In other words: the gas is used for the extraction activities of the primary resource such as drilling operations and others. On the other hand, the plant fuel consumption refers to the exploitation of the gas as fuel in the processing plants.

- $3 \%$ is used in operation of pipelines and other distribution infrastructures, mainly in compressors. Likewise, the distribution use of natural gas refers to balancing operations.

- $93 \%$ is delivered to the end users. According to the final use given by consumers, this $93 \%$ can be divided into the following blocks (see Figure 3.21 ):

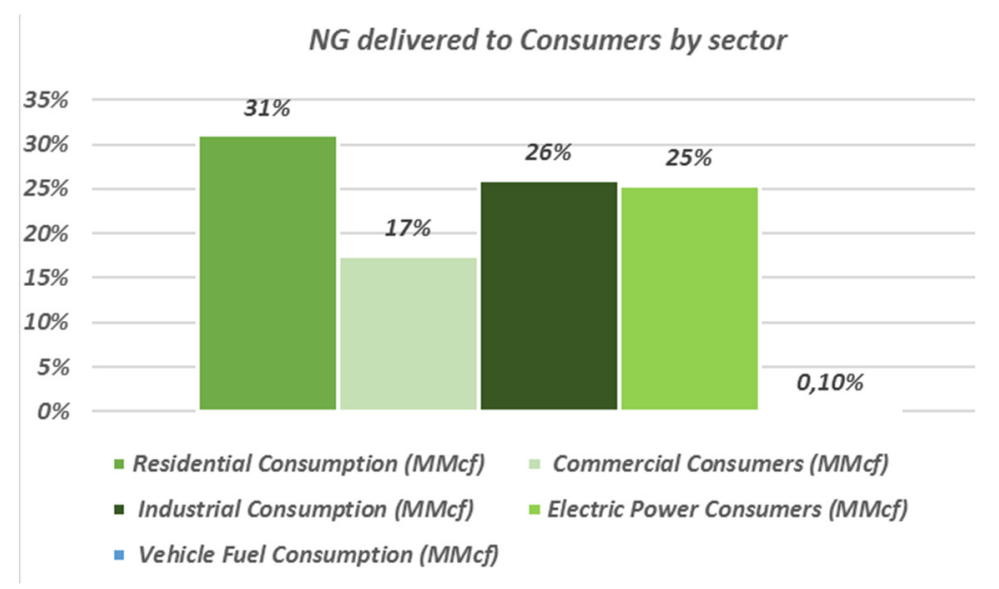

Figure 3.21. Annual consumption of natural gas by final end use

- $31 \%$ is used by residential customers at their homes for such applications as heating, air-conditioning, cooking, water heating, and other household uses.

- $17 \%$ in used by commercial customers for by non-manufacturing establishments or agencies, primarily engaged in the sale of goods or services such as hotels, restaurants, hospitals, etc. In this sector, it is included also the gas used by local, State, and Federal agencies engaged in non-manufacturing activities. 
- $26 \%$ is used by the industry. Natural gas used for heat, power or chemical feedstock, in manufacturing establishments or those engaged activities as agriculture, forestry, and fisheries. Also, power generators that may be used so as to support the abovementioned industrial activities are also included.

- $25 \%$ is used for power production. As it is shown in Figure 3.22, this rate has followed an increasing trend in the las years, also due to the increment of combined heat and power (CHP) plants.

- Finally, $0.1 \%$ represents the quantity of natural gas used as fuel by vehicles. Vehicle fuel consumption is computed as the number of miles traveled by the vehicle divided into the fuel efficiency, reported in miles per gallon (MPG) [74].

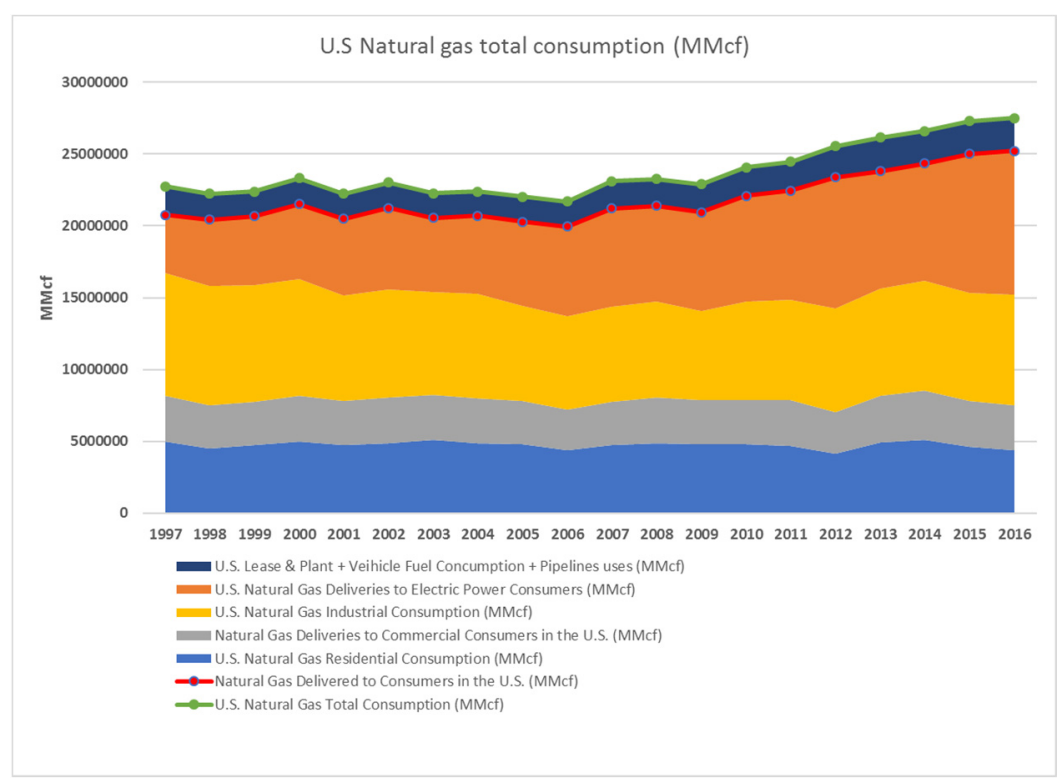

Figure 3.22. Trend of the NG consumption in USA (Source: Own elaboration with EIA Data)

Natural gas for this purpose is more and more used in the last years, existing currently a number of 158,000 vehicles fueled by this resource in the States, and more than 750 natural gas fueling stations [75].

There are two reasons for the success of natural gas as fuel for vehicles:

- It increases energy security. The large availability of this energy resource in US constitute a political guarantee. In addition, the recent discovery of the shale gas, wells have largely increase the natural gas production. 
- It is considered as a "Green Fuel". Due to the low level of greenhouse gas emissions (about $30-40 \%$ ) the natural gas is considered "a public health and environment friendly fuel" [75].

\subsubsection{The natural gas system in Europe}

The European natural gas system is a complex map of inflexible pipelines quite young, gradually established during the last 70 's and so still well-functioning from the operational point of view [76].

As described before for the case of the American network, also the following facilities and activities can be identified within the European natural gas system:

- Production sites, where the natural gas is extracted from the wells.

- Processing plants, compression and liquefaction stations and storage sites, where the natural gas is treated, compressed and stored

- Transmission and distribution pipelines, with entry and exit points and market hubs.

- Gas markets and final consumers, which can be classified according to the sector they belong to.

\subsubsection{Natural gas production and proved reserves}

Production of natural gas began to decline in Europe in 2008 as a consequence of the reduction in consumption due to the economic recession. However, the production is currently taking off again, reaching a rate of $2.2 \%$ in 2015 in $\mathrm{OCDE}^{22}$. In fact, as soon as the production from tight gas, shale gas, and coalbed methane resources start rising, the production forecasts in OECD Europe for 2040 expects an amount of about 1.6 Tcf higher than in 2012.

\footnotetext{
${ }^{22}$ OECD members (Organization For Economic Co-operation and Development) in Europe are Austria, Belgium, Czech Republic, Denmark, Estonia, Finland, France, Germany, Greece, Hungary, Iceland, Ireland, Italy, Luxembourg, Netherlands, Norway, Poland, Portugal, Slovakia, Slovenia, Spain, Sweden, Switzerland, Turkey, United Kingdom. 'Europe and Eurasia' category includes European members of the OECD plus Albania, Bosnia-Herzegovina, Bulgaria, Croatia, Cyprus, The former Yugoslav Republic of Macedonia, Georgia, Gibraltar, Latvia, Lithuania, Malta, Montenegro, Romania and Serbia, as well as the Commonwealth of Independent States (CIS), composed of Armenia, Azerbaijan, Belarus, Kazakhstan, Kyrgyzstan, Moldova, Russian Federation, Tajikistan, Turkmenistan, Ukraine and Uzbekistan.
} 


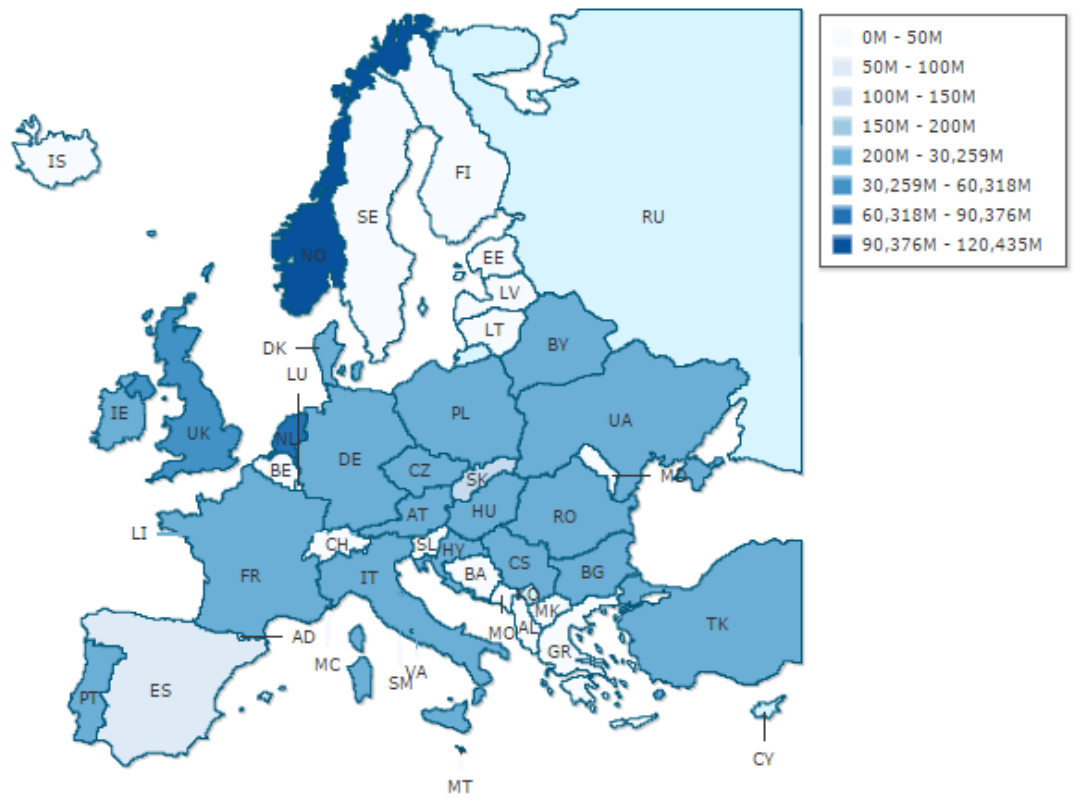

Figure 3.23. Natural gas production in Europe (Source: CIA World Factbook 2014)

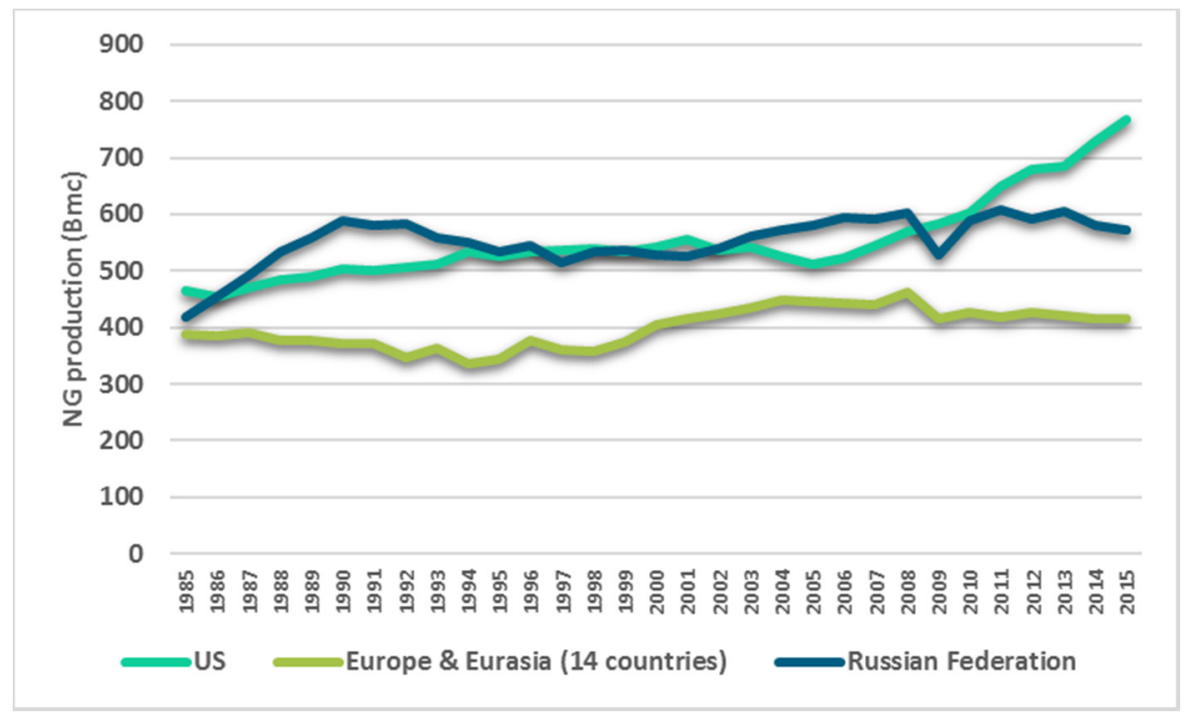

Figure 3.24. Evolution of natural gas production in the last years for different areas in the world (Source: Own elaboration with data from BP plc tools 2016) 
On the contrary, the European domestic production keep decreasing (about 2\% in 2016) but less than the previous year, when the drop was of $6 \%$. Among the OECD European countries, Norway, the Netherlands, and the United Kingdom are the three main producers of natural gas, accounting for more than $80 \%$ of the region's total natural gas production (Figure 3.25). In 2015, even if Norway and UK increased their production $(+7 \%)$ the significant drop of the natural gas production was basically driven by the large reduction in the Netherlands $(-29 \%)$.

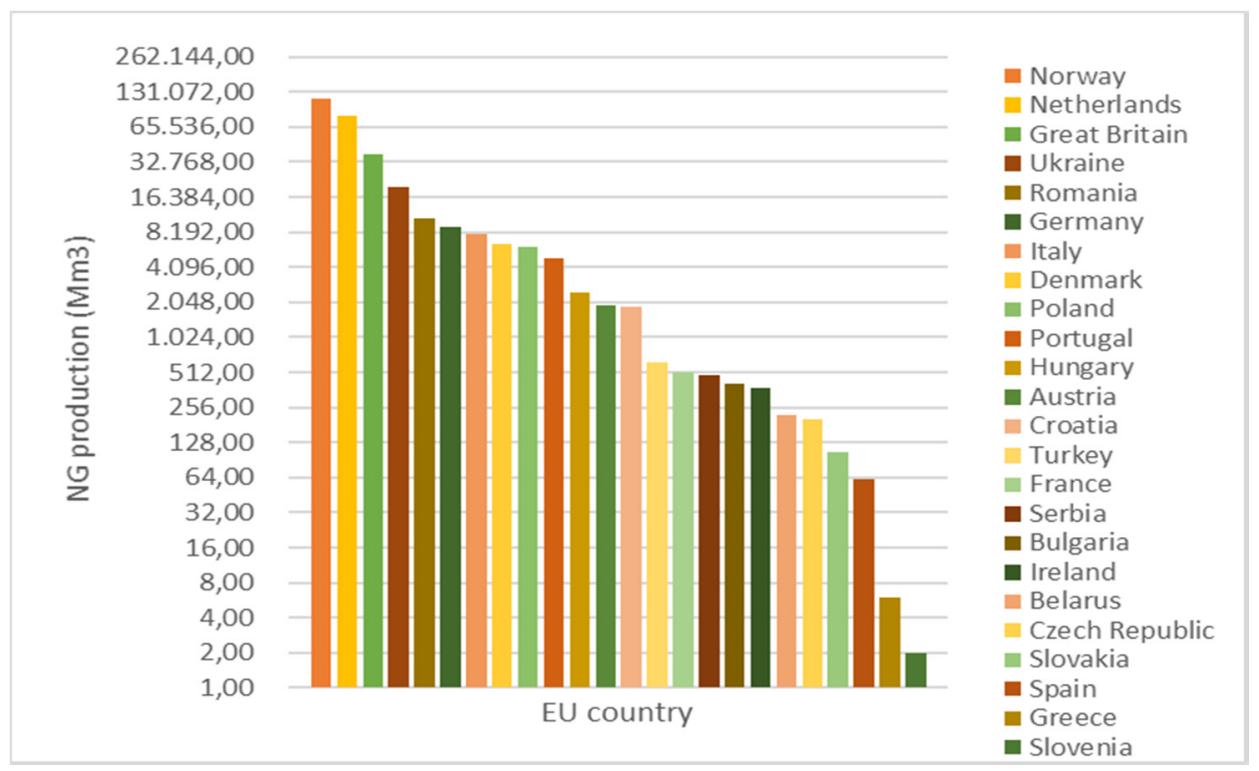

Figure 3.25. Natural gas production in OEDC Europe in 2015, per country (Source: BP Statistical review of world energy, 2016)

With regard to the proved reserves of gas, significant fields are located in the Western Europe. The European Union has the $6.7 \%$ of the total reserves proved in ODCE countries, being mainly located in the Netherlands and Norway, as it is shown in table. The gas proved reserves are deposits of methane currently known which can be exploited economically using currently available technologies [59].

In 2015, the natural gas proved reserves in the world were around 190,000 billion of cubic meters and about $20 \mathrm{Tm} 3$ of proved reserves were located in the ODCE countries. In spite of the significant increase in the world gas proved reserves of about $+18 \%$ from 2005 to 2015, natural gas is an exhaustible source of fossil energy that, sooner or later, will became scarce until arriving at the depletion of the reserves. 
Table 3.1. Total proved reserves of natural gas in Europe

\begin{tabular}{lrrrr}
\hline Total proved reserves & $\mathbf{1 9 9 5}$ & $\mathbf{2 0 0 5}$ & $\mathbf{2 0 1 4}$ & $\mathbf{2 0 1 5}$ \\
Country & $\boldsymbol{T m}^{\mathbf{3}}$ & $\boldsymbol{T m}^{\mathbf{3}}$ & $\mathbf{T m}^{\mathbf{3}}$ & $\mathbf{T m}^{\mathbf{3}}$ \\
\hline Azerbaijan & $\mathrm{n} / \mathrm{a}$ & 0,9 & 1,2 & 1,1 \\
Denmark & 0,1 & 0,1 & - & - \\
Germany & 0,2 & 0,2 & - & - \\
Italy & 0,3 & 0,1 & - & - \\
Kazakhstan & $\mathrm{n} / \mathrm{a}$ & 1,3 & 0,9 & 0,9 \\
Netherlands & 1,6 & 1,3 & 0,7 & 0,7 \\
Norway & 1,4 & 2,4 & 1,9 & 1,9 \\
Poland & 0,1 & 0,1 & 0,1 & 0,1 \\
Romania & 0,4 & 0,6 & 0,1 & 0,1 \\
Russian Federation & 31,1 & 31,2 & 32,4 & 32,3 \\
Turkmenistan & $\mathrm{n} / \mathrm{a}$ & 2,3 & 17,5 & 17,5 \\
Ukraine & $\mathrm{n} / \mathrm{a}$ & 0,7 & 0,6 & 0,6 \\
United Kingdom & 0,7 & 0,5 & 0,2 & 0,2 \\
Uzbekistan & $\mathrm{n} / \mathrm{a}$ & 1,2 & 1,1 & 1,1 \\
Other Europe \& Eurasia & 0,3 & 0,2 & 0,2 & 0,2 \\
\hline Total Europe \& Eurasia & $\mathbf{4 0 , 2}$ & $\mathbf{4 3}$ & $\mathbf{5 7}$ & $\mathbf{5 6 , 8}$ \\
Total World & $\mathbf{1 1 9 , 9}$ & $\mathbf{1 5 7 , 3}$ & $\mathbf{1 8 7}$ & $\mathbf{1 8 6 , 9}$ \\
of which: & & & & \\
OECD & 14,5 & 14,9 & 19,7 & 19,6 \\
Non-OECD & 105,4 & 142,4 & 167,3 & 167,3 \\
European Union & 3,6 & 3 & 1,3 & 1,3 \\
CIS & 31,1 & 37,6 & 53,7 & 53,6 \\
\hline Souce: BP plc data) & & & &
\end{tabular}

(Source: BP plc data)

These findings, together with the awareness of that the $40 \%$ of the natural gas reserves (as well as the oil fields) are concentrated in the Middle East and that countries with more deposits of natural gas are currently Russia, Iran and Qatar, brought up to many concerns about the security of the EU's gas supply.

In 2013, the Ukrainian crisis highlighted the need of increasing energy production and diversifying external supplies in EU in order to face the scarcity of the domestic natural gas reserves and to reduce the dependency on gas imports. 
In this context, shale gas has been also in Europe taken into account with the aim to contribute to guarantee the European energy security. Several researches carried on [77] have identified Poland and France as the major European regions with significant shale gas resources. The recoverable shale gas reserves are estimated to be of 14 trillion cubic meters. In spite of that, shale gas extraction has been not accepted everywhere. Many countries have banned it because of environmental issues, as detailed in Figure 3.26. In addition, shale gas production in EU has been detected to be more expensive than in the US. On the other hand, shale gas is not able to resolve short-term energy security issues as its exploration and development will take from 5 to 15 years and not a guarantee of the independence from the imports from Russia.

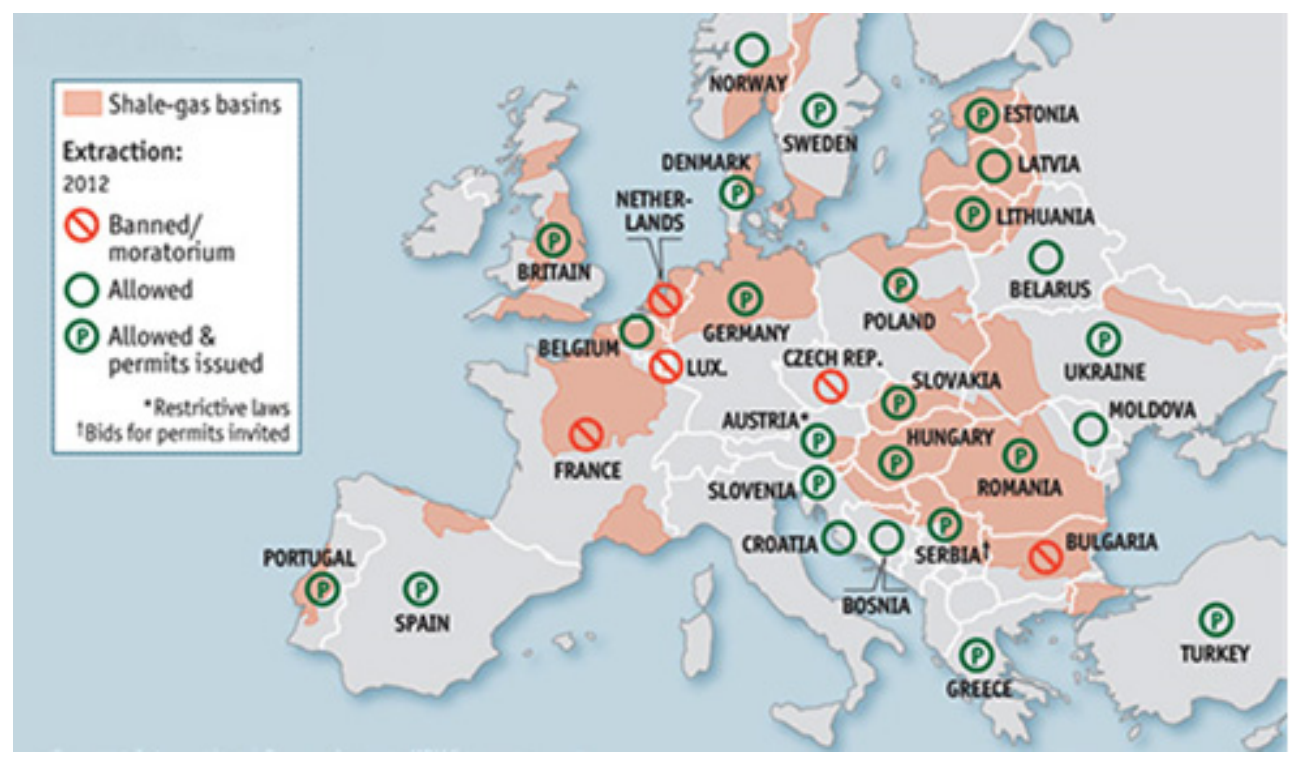

Figure 3.26. Shale gas reserves in Europe (Source: EIA)

\subsubsection{Transmission and distribution infrastructure}

The development of the European transmission and distribution networks took place just over the 1970 [78]. The earliest pipelines only connected the foreign producers to the consumer countries. At present, the natural gas system is a well interconnected network between reserves and different areas of extraction with a large diversification in transport routes and international exchange. It extends from the North Sea and the Baltic Sea to the Mediterranean Sea, and from Eastern Europe and Siberia to the Atlantic Ocean. At present, a dense network of high-pressure pipelines with a total length of about 190,000 $\mathrm{km}$ crosses Europe with more than 100,000 km pipelines concentrated in France, Italy 
and Germany ${ }^{23}$. The major pipelines which import natural gas into the European Union are listed below.

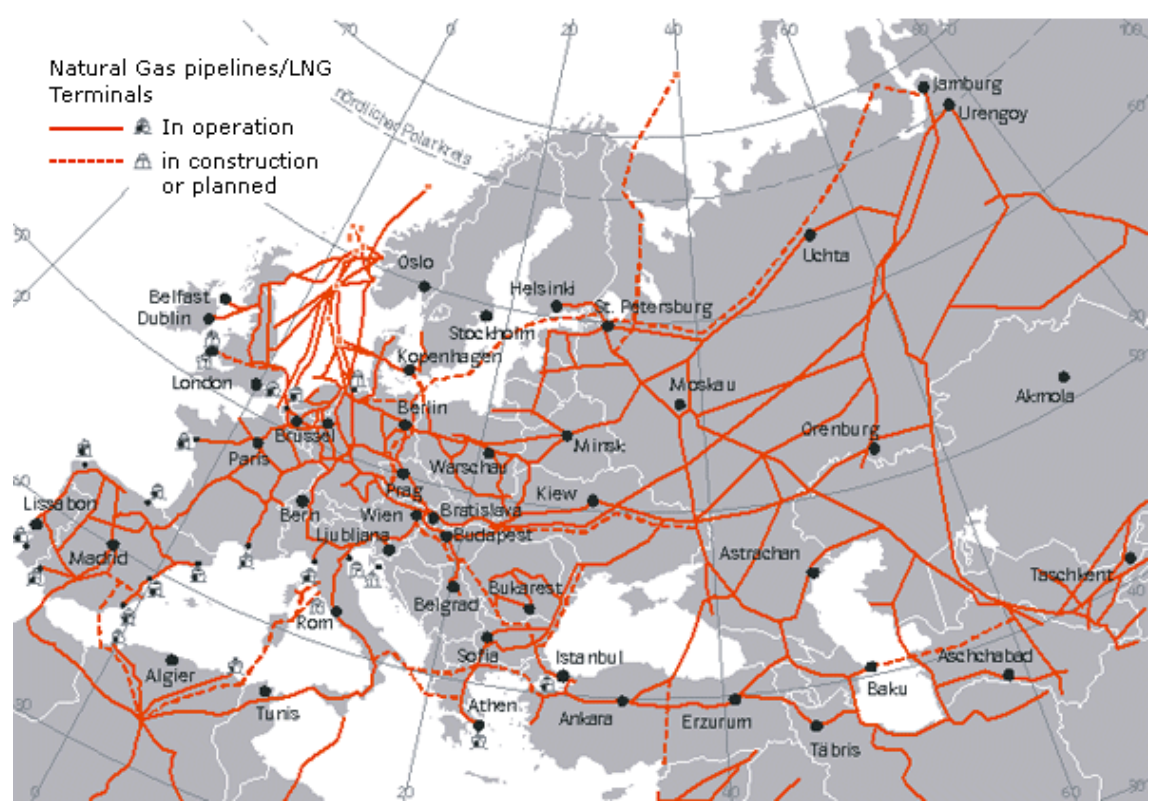

Figure 3.27. Natural gas pipelines and LNG terminals in Europe

- South Caucasus Pipeline (SCP). The aim of the pipeline is to connect the massive Shah Deniz field in Azeri Caspian Sea to Europe via Georgia and Turkey. The South Caucasus Pipeline (SCP) is nearly $692 \mathrm{~km}$ in length and 42-inch in diameter with a capable of daily average throughput of 19.9 million cubic meres of gas per day during $2016^{24}$. The SCP runs parallel to the Baku-Tbilisi-Ceyhan (BTC) crude oil pipeline and travels the same route through Azerbaijan and Georgia to Turkey. As part of the Shah Deniz Full Field Development project, the SCP pipelines will be expanded across Azerbaijan and triple the NG volumes exported ${ }^{25}$.

- Nord Stream is a natural gas pipeline that runs from Russian Federation (Vyborg) to Europe in Germany (Greifswald). It includes two parallel lines with a total length of 1,222 kilometers. Currently, Nord Stream delivers 22.5 billion

\footnotetext{
${ }^{23} \mathrm{http}: / / \mathrm{www} . e n i . c o m$

${ }^{24}$ More information can be found at: http://www.bp.com/en az/caspian/operationsprojects/pipelines/SCP.html

${ }^{25} \mathrm{http}: / /$ azertag.az/en/xeber/Shah_Deniz_2_of_utmost_importance_for_Georgia-1031642
} 
cubic meters ( 790 billion cubic feet) of its total capacity due to political restrictions. It is the longest sub-sea pipeline in the world, surpassing the Langeled pipeline.

- Blue Stream. It links Russia with Europe, and Russia and Turkey with the Black sea (396 Km of pipelines under the sea).It has a total length of 1,207 kilometers and a delivery capacity of 16 billion cubic meters of gas annually ${ }^{26}$.

- Green Stream. It connects Northern Africa with the European market. It is the longest subsea pipeline in the Mediterranean and links Libya with Italy via Sicily. It measures the 520 kilometers long, reaches water depths of 1,127 meters with a yearly delivery capacity of 283 billion cubic feet ( 8 billion cubic meters) of natural gas ${ }^{27}$.

- Langelend. It connects the Norway with the east coast of the UK. It measures 1,200 kilometers long with a capacity to transmission up to 70 million cubic meters of gas a day ${ }^{28}$.

- The Trans-Mediterranean (Transmed) links Algeria to Italy via Tunisia and Sicily. It has a length of $2,475 \mathrm{~km}$-long. It is the longest international gas pipeline and has the capacity to deliver about $33 \mathrm{Bm}^{3} /$ year $^{29}$

- MEDGAZ has been the last European interconnection pipeline to come into operation (2011). It joins the Algerian wells to the south coast of Spain by crossing the Mediterranean Sea at a depth of more than 2,000 m. With a capacity of 8 billion of $\mathrm{m}^{3}$, it supplies almost a half of the total consumption of the Iberian Peninsula.

Through these pipelines the natural gas is imported in EU, even if other projects are going to be carried on in order to improve the infrastructure such as the TANAP, the South Stream pipelines and so on. The transmission and distribution European pipelines transmit the $85 \%$ of the total amount of gas consumed in the EU natural gas consumption [79].

Europe is basically an importer area. Actually all European countries, in a different level, energetically depend from the natural gas imports, mainly from countries outside the European Union. Norway is the only European country that can meet its internal demand for natural gas on the basis of domestic, while Germany and Italy are the countries with the major dependency from foreign countries (Figure 3.28).

\footnotetext{
${ }^{26} \mathrm{http}: / /$ www.gazprom.com/about/production/projects/pipelines/active/blue-stream

${ }^{27} \mathrm{http}: / /$ www.greenstreambv.com/en/pages/home.shtml

${ }^{28} \mathrm{http}$ ://www.rigzone.com/training/insight.asp?insight_id=335

${ }^{29} \mathrm{http}: / /$ www.hydrocarbons-technology.com/projects/trans-med-pipeline
} 


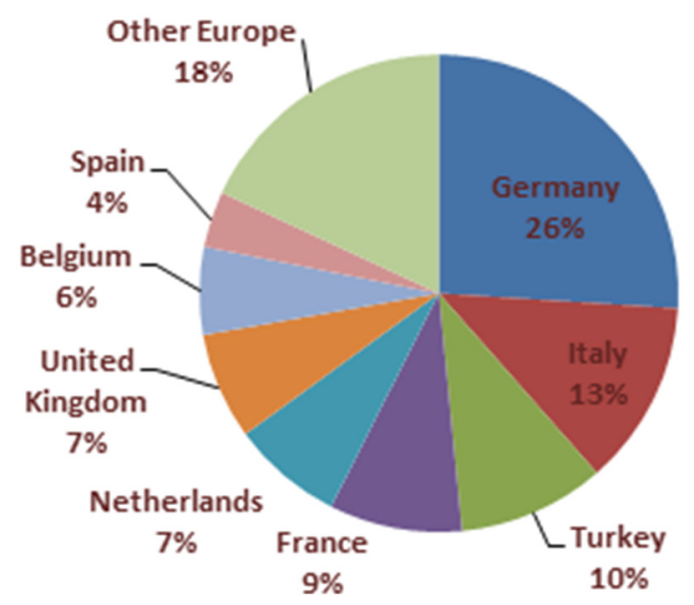

Figure 3.28. Natural gas imports in Europe and Eurasia, per country (source: Own elaboration with data from the BP statistical review of world energy 2016)

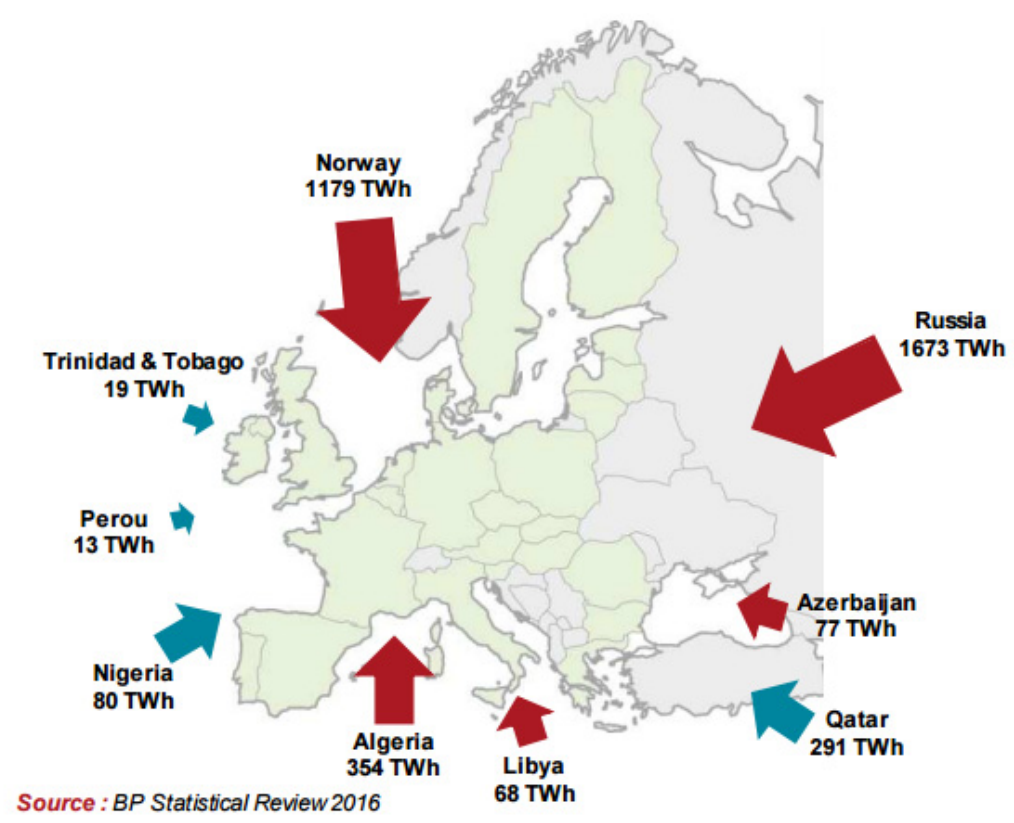

Figure 3.29. Natural imports according the countries of origin (BP Statistical Review 2016) 
Total EU imports of natural gas increased by $6 \%$ to total 401 billion cubic meters. The most significant increase in 2015 compared with 2014 was observed in German, Italy and France [80]. Regarding the EU exports, Norway is the source of $27 \%$ of the natural gas consumed in the EU, while Russia provides $40 \%$.

With regard to supplies from countries outside the OECD area, the main supplier countries in 2015 were Algeria, Nigeria (both with slightly declining exports), Qatar and Russia, which, after the significant drop last years due to the tensions with Ukraine, has increased in $6.3 \%$ exports to Europe.

Regarding imports of liquefied natural gas, the number of operative LNG terminals in operation was 29. There are 6 terminals under construction and other 27 planned (Figure $3.30)$.

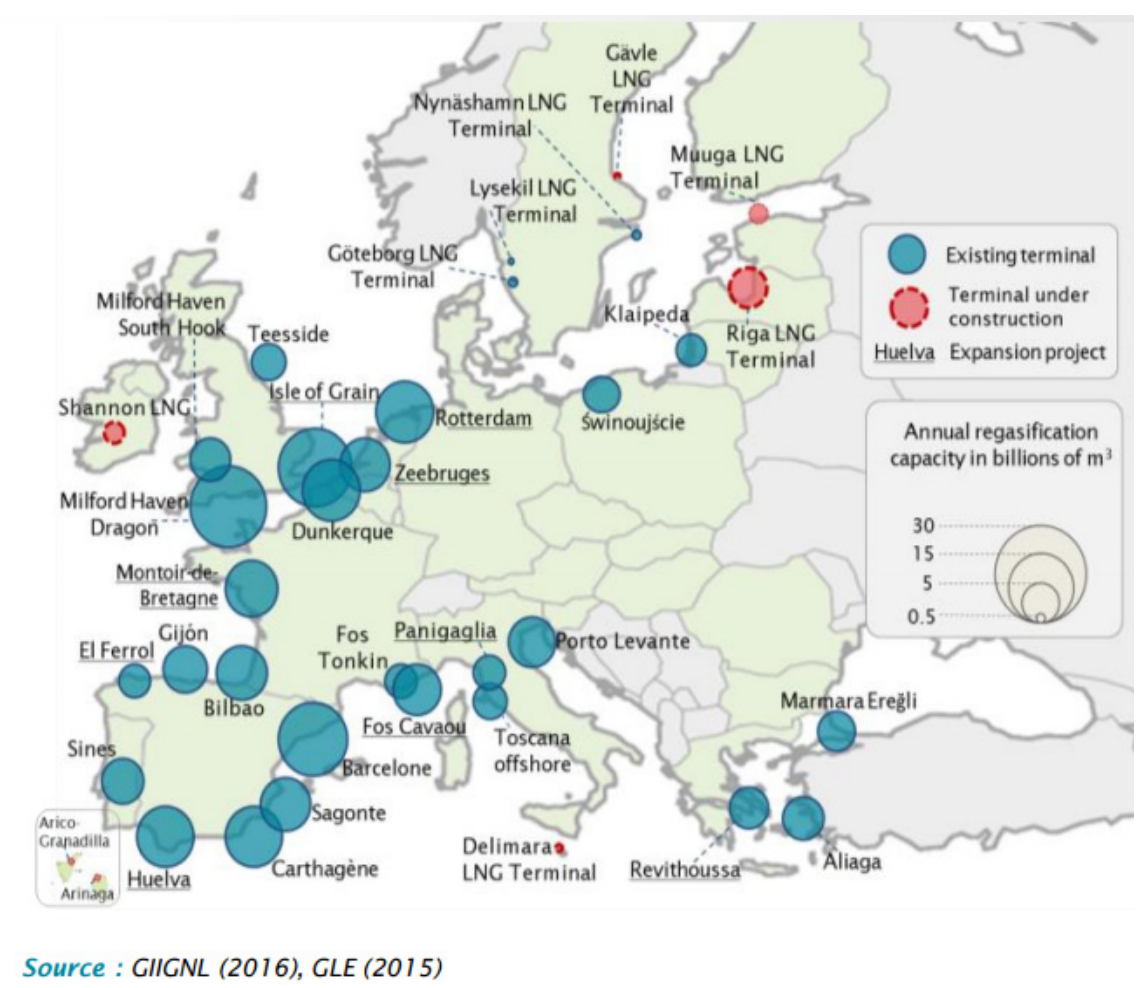

Figure 3.30. Existing and planned LNG terminals in Europe (2016)

In the recent years, there has been a gradual increase in the utilization of LNG. Supply contracts for the acquisition of LNG have similar characteristics to those for the import via pipeline, but they are more flexible. 


\subsubsection{Analysis of the natural gas consumption}

In the last years, Europe has shown a significant reduction in natural gas consumption (about 18\%) due to the financial crisis started in the mid of the 2007 [9]. In spite of that, and even if the level of consumption is still lower than before the crisis, consumption and still strongly influenced by the annual climatic conditions [81].

In 2015 there was an overall increase of about $4.4 \%$ in the natural gas consumption compared to the previous year, as it can be seen in Figure 3.31. This increment is mainly due to the increase in air conditioning demand by using gas [10].

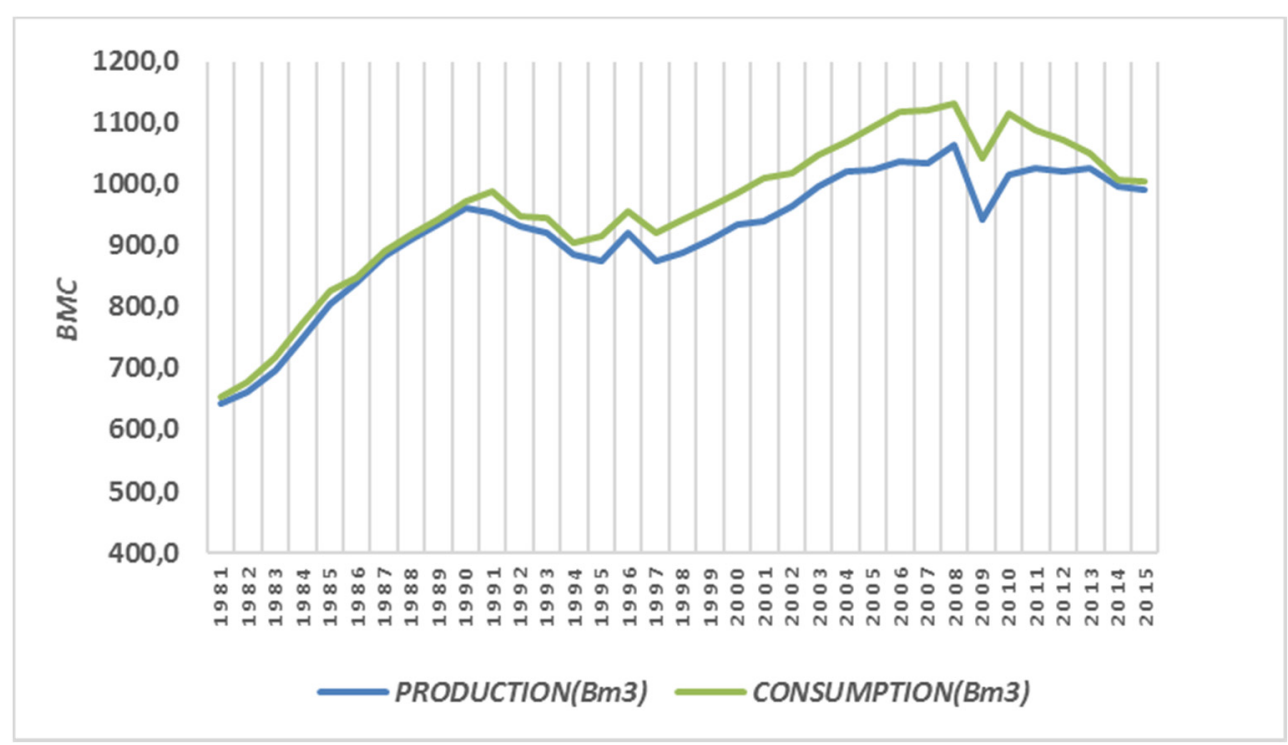

Figure 3.31. Evolution of the natural gas consumption in Europe and Eurasia (Source: Own elaboration with data from EIA)

Among the EU countries, Slovakia (30\%), Portugal (13\%), Croatia (12\%) recorded the most significant increase whereas Finland $(-12.9 \%)$ and Sweden $(-11.1 \%)$ the most significant decrease.

In 2014, Italy and Germany recorded important downturns (-13\% and $-17 \%$ respectively) mainly due to the mild conditions of the winter and cool condition of the summer of that year. In 2015 they also increased their consumption respectively by $8 \%$ and $4 \%$, as shown in Figure 3.32. In spite of these events, Germany is still the main consumer of natural gas in Europe, representing the 19\% of total, followed by the United Kingdom and Italy (17\% and 15\% respectively). France and the Netherlands are the next with $9 \%$, followed by Spain with a $6 \%$ (Figure 3.33). 


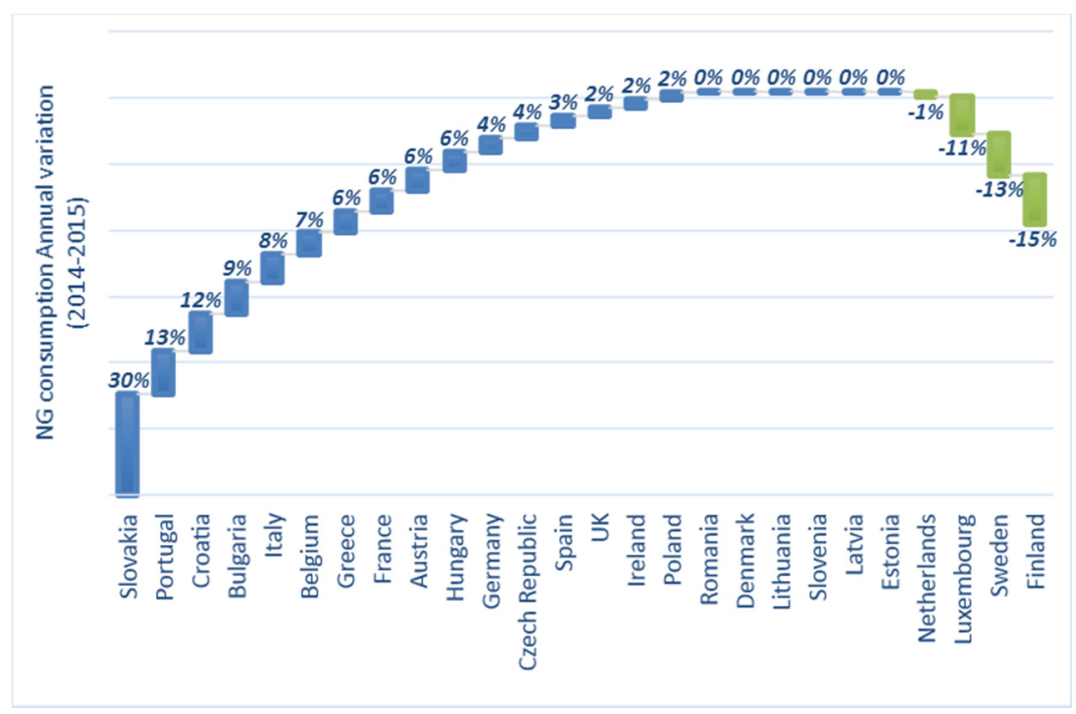

Figure 3.32. Variation of the natural gas consumption in European countries from 2014 to 2015 (Source: Own elaboration with data from EIA)

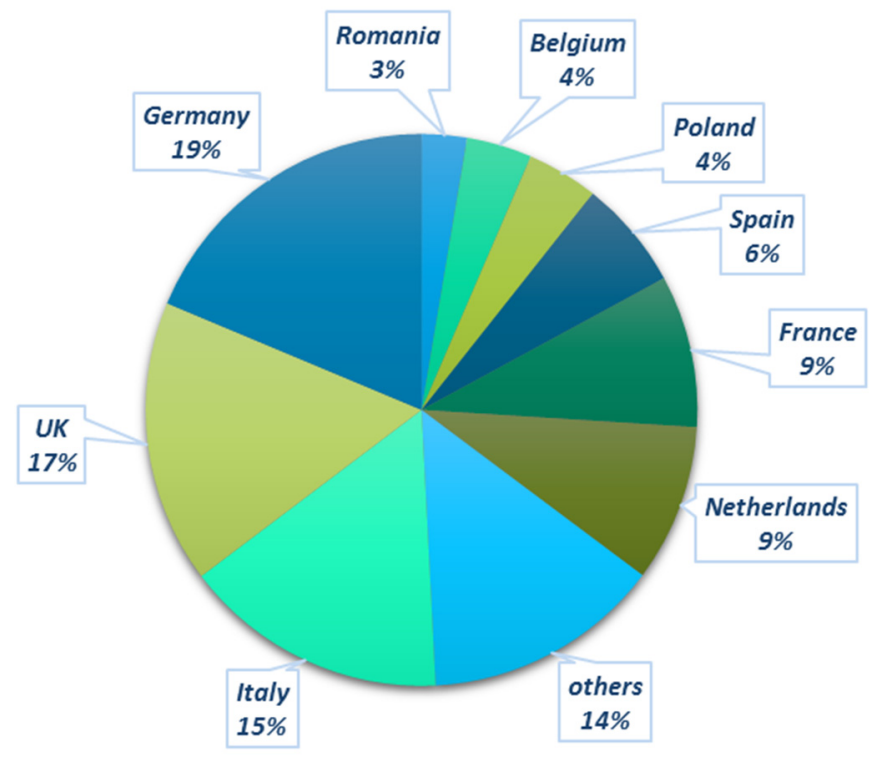

Figure 3.33. Natural gas consumption in European countries, 2015 (Source: Annual report AEEGSI -2016) 
The growing trend of the gas consumption from 1990 to 2013 is shown in Figure 3.34. The consumption by the end users sector show that the $44 \%$ of the total is for the residential use, while the $33 \%$ is for Industry and the $20 \%$ for services sector. The power generation sector represent the $30 \%$ of the total consumption, basically due to the large investments made in the gas-fired power plants and to the green environmental characteristics as gas emits much less $\mathrm{CO}_{2}$ than other fuels because of the low carbon content in methane. This low content in carbon makes that many stakeholders consider the natural gas as the fossil fuel of the future [9].

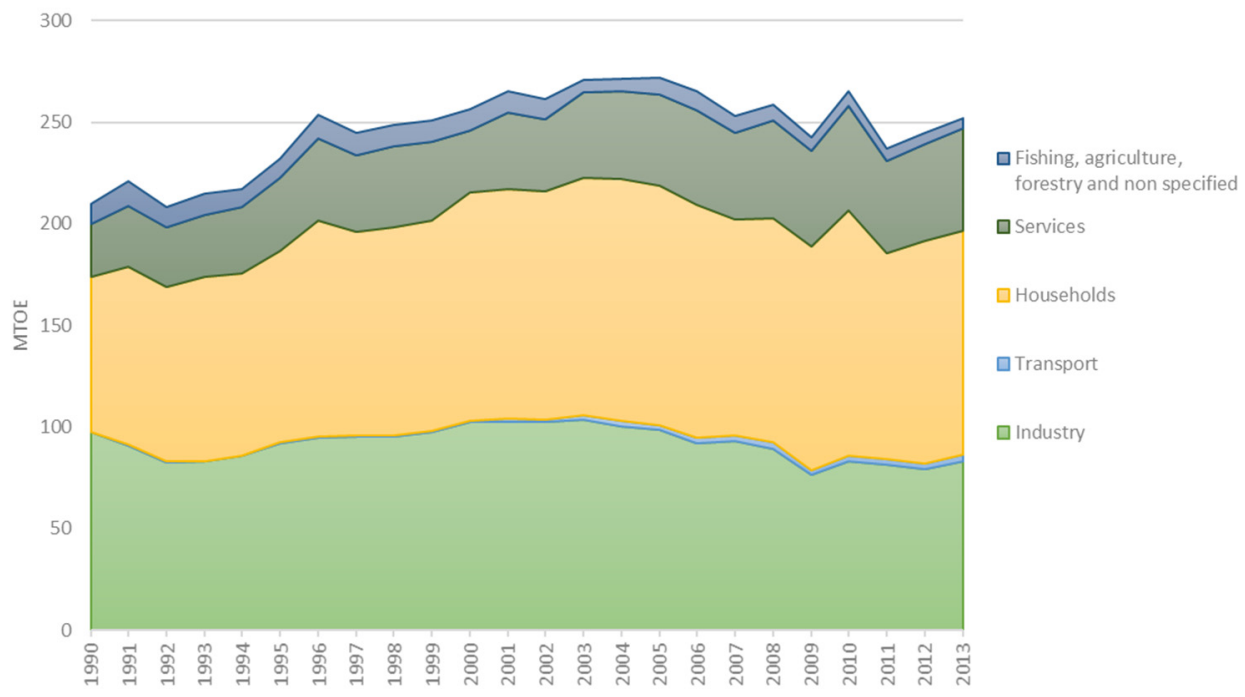

Figure 3.34. Annual evolution of the natural gas consumption in Europe 1990-2013, per sector (Source: European Environmental Agency)

By the 2040, the EIA forecast an increase in natural gas consumption in the OECD European region by $1.3 \%$ year on average, from $17.8 \mathrm{Tcf}$ in 2012 to $25.3 \mathrm{Tcf}$ in 2040 . The energy sector which presents the highest increment will be the electric power sector, accounting for more than one-half of the total increase (4.6 Tcf). Actually, as soon as nuclear and coal-fired are dismissed, the natural gas will be the predominant fuel used for power generation, as shown in Figure 3.35 [59]. These forecasted increments in natural gas are in line with the expectations of the Conference of Parties 21 of the United Nations for the coming years [82] 


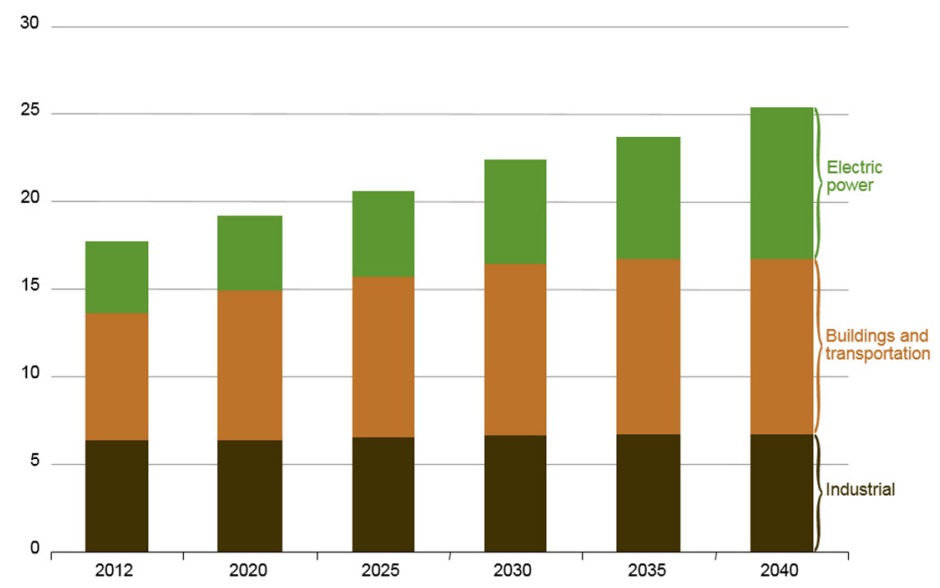

Figure 3.35. Forecast of the OECD Europe natural gas consumption by end users sector, 20122040, in Tef (Source: EIA)

\subsubsection{The Italian natural gas system}

The following paragraphs describe in detail the Italian natural gas system, since the case of application presented in Chapter 6 focuses on this country. In Italy, the production of natural gas is limited and only the $10 \%$ of the national demand is directly met by domestic production [80].

Table 3.2 shows the annual consumption according to the final use given to gas, as well as the coverage of demand which includes the domestic production and the imports from foreign countries.

Table 3.2. Consumption and production of natural gas in Italy, 2016

\begin{tabular}{lrr}
\hline & $\begin{array}{c}\text { 2016, } \\
\text { Billion } \mathbf{~ m}^{\mathbf{3}}\end{array}$ & $\begin{array}{c}\text { Variation rate } \\
\mathbf{2 0 1 5 - 2 0 1 6}\end{array}$ \\
\hline Power production & 23,3 & $12,10 \%$ \\
Non-residential consumers & 13,4 & $4,40 \%$ \\
Residential consumers & 31,4 & $-0,50 \%$ \\
\hline Total consumtpion & 70,4 & $4,90 \%$ \\
Domestic production & 5,6 & $-13,70 \%$ \\
Imports from foreing countries & 65 & $6,60 \%$ \\
\hline (Sorce: Report 'andamenti del mercato italiano-2016 GME)
\end{tabular}

As shown in the table, most of the gas consumed in Italy is destined to the residential sector, followed by power production and, finally, non-residential uses, which includes industrial and commercial sectors. 


\subsubsection{Domestic production}

The evolution of the domestic production and consumption is also shown in Figure 3.36, from the beginning of 1980's to present (2015).

Before the liberalization of the natural gas market (the Letta's Decree $23^{\text {rd }}$ May 2000), the company SNAM (former Eni), monopolistically controlled the $97 \%$ of the all activities of the natural gas chain. Just a small part of the distribution system was handled by municipal utilities. However, this situation changed when the market was liberalized in 2000. After that, production, imports and trading have been liberalized and anyone is free to produce, import and sell gas. However, some limitations have to be taken into account:

- Exploratory activities are still subject to state concessions or permits.

- The trading of natural gas is granted only to operators who have adequate access to storage systems and that are able to carry out the so-called "renegotiation of prices."

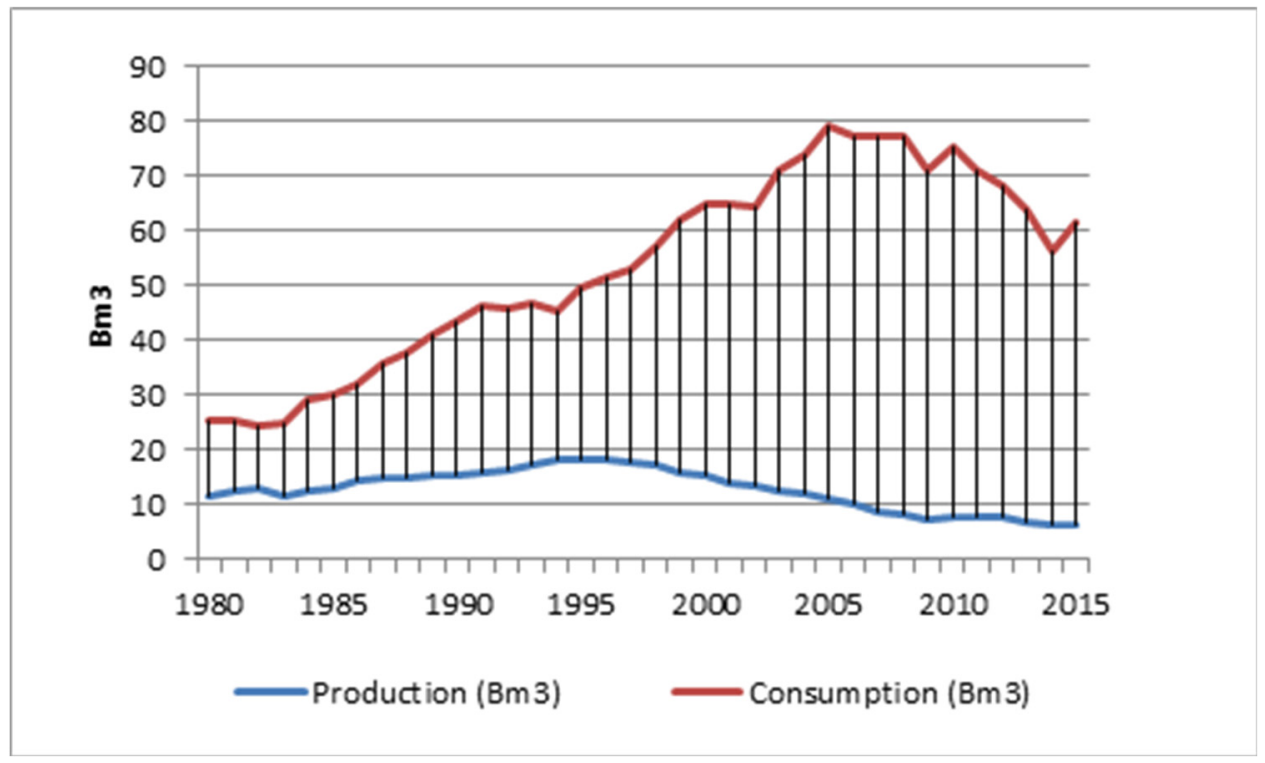

Figure 3.36. Italian annual natural gas production and consumption, 1980-2015 (Source: BP Statistical data)

Based on data collected by the regulator AEEGSI, the total quantity of gas extracted in 2015 was about $6.1 \mathrm{Mm} 3$. About the $85 \%$ of national production is extracted by the Eni Group, which is the dominant player in this segment. The second producer is Royal Dutch Shell with $8.3 \%$ followed by Edison with the 4.9\% [83]. 


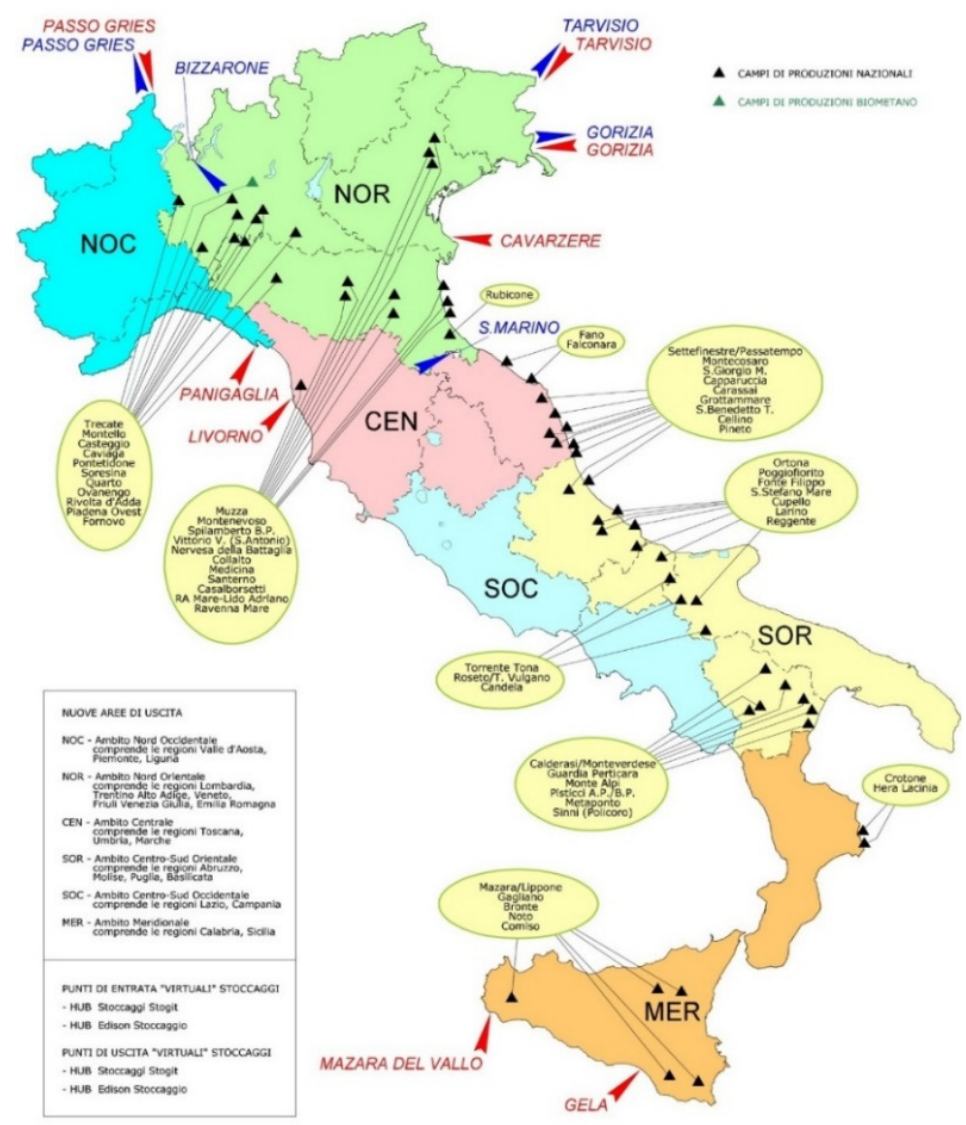

Figure 3.37. Natural gas production sites in Italy and national entry and exit points (Source: SNAM rete gas)

In 2015, domestic production felt by $5.3 \%$ compared to the previous year to $6.5 \mathrm{Mm}^{3}$. The amount of gas extracted from mainland deposits, which was $2,351 \mathrm{Mm}^{3}$, decreased lower than the NG reserves at sea compared to 2014 (-2.9\%), which instead decreased $6.9 \%$, reaching the $4.526 \mathrm{Mm}^{3}$. The Italian oil fields are distributed on the all Italian peninsula, but they are largely depleted (Figure 3.37). Additionally there are 10 large storage reservoirs, eight of which are located in an area between Lombardy and Emilia Romagna.

On date $31^{\text {st }}$ December, 2015 the proved gas reserves were $49.1 \mathrm{Gm}^{3}$, while the probable gas reserves reached $52.4 \mathrm{Gm}^{3}$. Compared to the data collected one year before (2014) 
they have overall declined in $-8.5 \%$ for proved, $-12.4 \%$ for probable and $-10.1 \%$ possible natural gas reserves. Just considering proved reserves, natural gas production would be extinguished in about seven years, although some of the currently probable or possible ones could turn into certain reserves thanks to the utilization of new technologies or new investments.

\subsubsection{Gas imports}

As mentioned before, the domestic production $(10 \%)$ is not able to satisfy the internal needs, so that imports from foreign countries are fundamental for the coverage of the domestic energy needs. Hence, the remaining $90 \%$ is imported through large international pipelines or, minimally, by sea, in large LNG carriers where it is transported in liquid form and is then returned to its gaseous state at the regasification plants. Regarding the origin of imports, $43 \%$ comes from Russia, $12 \%$ from Algeria, $23 \%$ from Norway and the Netherlands, $12 \%$ from Libya. The remaining $10 \%$ is imported as LNG mainly from Qatar, as shown in Figure 3.38

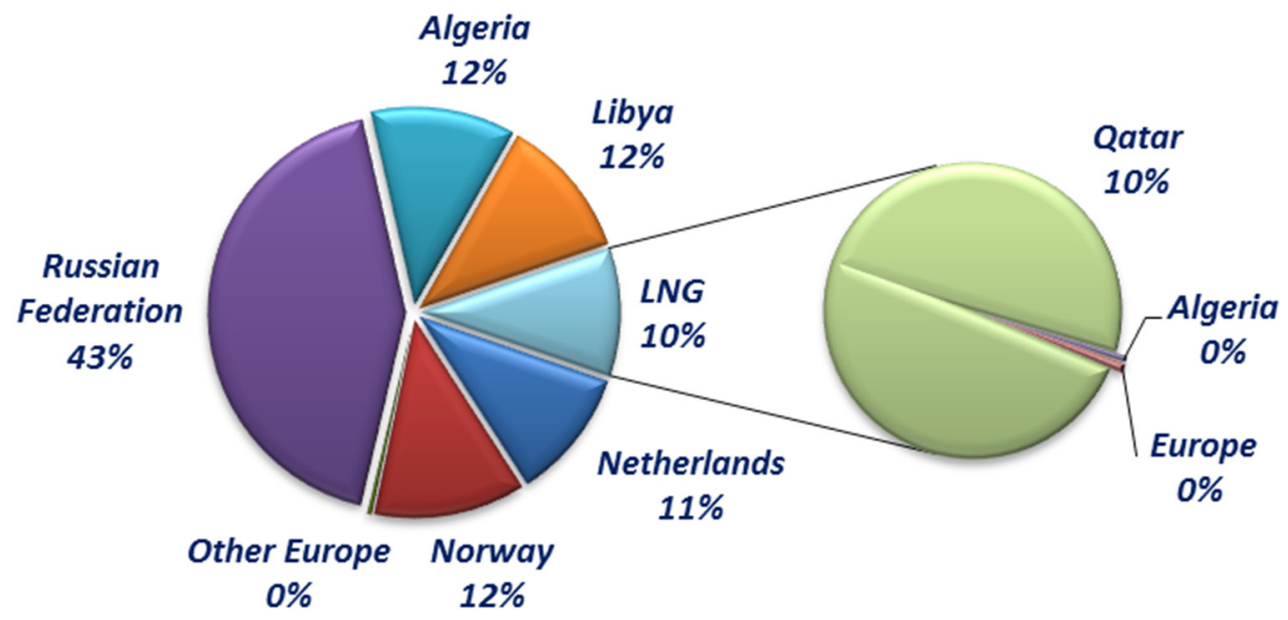

Figure 3.38. Natural gas imports in Italy in 2015 per country of origin (Source: Own elaboration with data from the BP statistics)

From 2014 to 2015, Italian imports via pipelines increased in 7\% while the imports via LNG got an increment of 3\% (Table 3.3). The dependency from Russia is still predominant of about the $43 \%$, which emphasizes the risk of supply due to potential sudden interruptions ${ }^{30}$.

\footnotetext{
${ }^{30} \mathrm{http}: / /$ www.utilita.com/gas/mercato/mercato-gas.html
} 
Table 3.3. Natural gas imports and exports in Italy in billions of $\mathbf{m}^{3}$, 2014-2015

\begin{tabular}{ccc|cc} 
& \multicolumn{2}{c|}{ IMPORTS } & \multicolumn{2}{c}{ EXPORTS } \\
\cline { 2 - 5 } & $\begin{array}{c}\text { Pipeline } \\
\mathrm{Bm}^{3}\end{array}$ & $\begin{array}{c}\text { LNG } \\
\mathrm{Bm}^{3}\end{array}$ & $\begin{array}{c}\text { Pipeline } \\
\mathrm{Bm}^{3}\end{array}$ & $\begin{array}{c}\text { LNG } \\
\mathrm{Bm}^{3}\end{array}$ \\
\hline 2014 & 46,6 & 4,6 & 0,2 & - \\
2015 & 50,2 & 6,0 & 0,2 & - \\
\hline
\end{tabular}

(Source: BP Statistical Data)

\subsubsection{Transmission and distribution infrastructures}

The Italian transmission gas system is managed by 10 companies, the largest of which is Snam Rete Gas, handling more than $90 \%$ of the transmission network and being also the only intermediary with foreign carriers.

Table 3.4. Characteristics of the entry points into the Italian gas network

\begin{tabular}{llrrrrr}
\hline Location & $\begin{array}{c}\text { Nominal } \\
\text { capacity } \\
\mathrm{Mm}^{3}\end{array}$ & $\begin{array}{c}\text { Actual } \\
\text { capacity } \\
\mathrm{Mm}^{3}\end{array}$ & $\begin{array}{c}\text { Available } \\
\text { capacity } \\
\mathrm{Mm}^{3}\end{array}$ & $\begin{array}{c}\text { Saturation } \\
\text { \% }\end{array}$ & $\begin{array}{c}\text { Stake- } \\
\text { holders }\end{array}$ \\
\hline \multirow{4}{*}{$\begin{array}{l}\text { Entry point } \\
\text { of pipeline }\end{array}$} & Passo Gries & 59.0 & 35.1 & 23.9 & 59.6 & 23 \\
& Tarvisio & 107.0 & 94.6 & 12.4 & 88.4 & 38 \\
& Vallo & 96.6 & 86.5 & 10.1 & 89.6 & 8 \\
& Gorizia & 2.0 & 0.0 & 2.0 & 0.0 & 0 \\
\cline { 2 - 7 } GNL & TOTAL & 29.2 & 29.2 & 0.0 & 100.0 & 3 \\
\hline \multirow{2}{*}{ Terminals } & Panigaglia & $\mathbf{2 9 3 . 8}$ & $\mathbf{2 4 5 . 5}$ & $\mathbf{4 8 . 3}$ & $\mathbf{8 3 . 6}$ & $\mathbf{5 0}$ \\
& Cavarzere & 26.4 & 24.4 & 2.0 & 92.5 & - \\
& Livorno & 15.0 & 2.5 & 12.5 & 16.7 & - \\
\cline { 2 - 7 } & TOTAL & $\mathbf{5 2 . 4}$ & $\mathbf{3 1 . 7}$ & $\mathbf{2 2 . 7}$ & $\mathbf{6 0 . 5}$ & - \\
\hline
\end{tabular}

Source: AEEGSI

The Italian transmission network is divided into a primary network (better known as 'National Gas Pipeline Network') that guarantee the connection from the place of production or import; and the secondary network, connecting the primary network to the final points of consumption. The primary network has a length of about $30,000 \mathrm{~km}$ and it is widely extended through all the nation except the island of Sardinia.

The gas imported abroad is injected into the national network through eight entrance points: the interconnections with the import pipelines (Tarvisio, Gorizia, Gries Pass, Mazara del Vallo, Gela) and regasification plants (Panigaglia, Cavarzere and Livorno), 
where gas is received in liquid state. The capacity and availability of each of these points is summarized in table Table 3.4.

Table 3.5. Five top gas importers in Italy, 2014

\begin{tabular}{lcc}
\hline COMPANY & $\begin{array}{c}\text { Imported } \\
\text { annual flow } \\
\mathrm{Mm}^{3}\end{array}$ & $\begin{array}{c}\text { Rate } \\
\%\end{array}$ \\
\hline Eni & 31,052 & $58.0 \%$ \\
Edison & 9,723 & $18.2 \%$ \\
Enel Trade & 4,934 & $9.2 \%$ \\
Gunvor International B.V. & 572 & $1.1 \%$ \\
Axpo Italia & 561 & $1.0 \%$ \\
Altri & 6,714 & $12.5 \%$ \\
\hline TOTAL & 53,556 & $100 \%$ \\
\hline Imports from the European stock Exchange & 2,953 & $5.50 \%$ \\
Imports (Ministero dello sviluppo economico) & 55,757 & - \\
\hline
\end{tabular}

Source: Indagine annuale sui settori regolati

The natural gas infrastructure has also two entry points from storage sites, which are managed by the companies STOGIT and Edison Storage S.p.A. Finally there are the 57 points of entry by major domestic production fields or their collection and treatment centers (in high and low pressure), which have been shown in Figure 3.37.

The gas is purchased in international markets by the energy traders, which use the transmission and distribution infrastructures so as to deliver such energy to the final customers. The most significant traders according to their market quote are included in Table 3.5.

The distribution infrastructure is composed of $258,270 \mathrm{~km}$ of pipelines (of which 426 are inactive), $58 \%$ at low pressure, $41 \%$ at medium pressure and $1 \%$ at high pressure.

The $59 \%$ of the network $(151,100 \mathrm{~km})$ is located in the North, $23 \%(58,900 \mathrm{~km})$ in the Center and the remaining $19 \%(48,100 \mathrm{~km})$ is located in the South and Sicily. The distribution infrastructure connects the local pipelines to end customers, being the access to the grid regulated by the local government concession. There are around 560 operators of the distribution grid. 2i Rete Gas S.p.A, which has been considered for the application case in Chapter 6, is the second distributor of the country with approximately $57,000 \mathrm{~km}$ 
of network and over 3.8 million end users ${ }^{31}$. The most significant distributors according to their volume of distributed gas are listed in Table 3.6.

Table 3.6. First twenty gas distributors in 2014

\begin{tabular}{lcc}
\hline COMPANY & $\begin{array}{c}\text { Share } \% \\
\%\end{array}$ & $\begin{array}{c}\text { Ranking } \\
\text { position }\end{array}$ \\
\hline Snam & 24.7 & $1^{\circ}$ \\
2i Rete Gas & 16.6 & $2^{\circ}$ \\
Hera & 8.9 & $3^{\circ}$ \\
A2A & 5.9 & $4^{\circ}$ \\
Iren & 4.2 & $5^{\circ}$ \\
Toscana Energia & 3.1 & $6^{\mathrm{o}}$ \\
E.S.TR.A. & 2.3 & $7^{\circ}$ \\
Asco Holding & 2.2 & $8^{\circ}$ \\
Linea Group Holding & 2.0 & $9^{\circ}$ \\
Erogasmet & 1.2 & $10^{\circ}$ \\
Acsm-Agam & 1.2 & $11^{\circ}$ \\
Agsm Verona & 1.1 & $12^{\circ}$ \\
Ambiente Energia Brianza & 1.1 & $13^{\circ}$ \\
Unión Fenosa Internacional & 1.0 & $15^{\circ}$ \\
Energei & 1.0 & $14^{\circ}$ \\
Dolomiti Energia & 0.9 & $17^{\circ}$ \\
Gas Rimini & 0.9 & $16^{\circ}$ \\
Edison & 0.9 & $18^{\circ}$ \\
Aimag & 0.8 & $19^{\circ}$ \\
Aim Vicenza & 0.8 & $20^{\circ}$ \\
Altri & 19.6 & - \\
\hline TOTALE & $\mathbf{1 0 0 . 0}$ & - \\
\hline Source: Indagine annuale sui settori regolati & &
\end{tabular}

\subsubsection{Analysis of the natural gas consumption}

According to the Italian regulation [84], consumers are divided into the following categories depending on the final use for which the energy is used:

- C1: Natural gas is mainly used for space heating

- C2: Natural gas is mainly used for cooking and hot water production

${ }^{31}$ More information can be found at; http://www.2iretegas.it 
- C3: Natural gas is mainly used for space heating, cooking and hot water production

- C4: Natural gas is mainly used for space cooling

- C5: Natural gas is mainly used for space heating and cooling

- T1: Natural gas is mainly used for industrial processes

- T2: Natural gas is mainly used for industrial processes and space heating

Table 3.7. Characteristics of the gas consumption per category, 2015

\begin{tabular}{cccc}
\hline Category & $\begin{array}{c}\text { Number of } \\
\text { clients rate }\end{array}$ & $\begin{array}{c}\text { Annual } \\
\text { consumption } \\
\text { rate }\end{array}$ & $\begin{array}{c}\text { Average annual } \\
\text { consumption per } \\
\text { consumer } \\
\mathrm{m}^{3} / \text { year }\end{array}$ \\
\hline C1 & 2.0 & 21.8 & 14,393 \\
C2 & 41.8 & 6.3 & 200 \\
C3 & 54.5 & 45.7 & 1,110 \\
C4 & 0.0 & 0.0 & 1,160 \\
C5 & 0.1 & 0.3 & 6,623 \\
T1 & 0.2 & 3.5 & 28,120 \\
T2 & 1.5 & 22.4 & 20,332 \\
\hline TOTAL & $\mathbf{1 0 0}$ & $\mathbf{1 0 0}$ & $\mathbf{1 , 3 2 5}$ \\
\hline Sour
\end{tabular}

Source: Indagine annual sui settori regolati

According to the number of customers under each category, as summarized in Table 3.7, more than a half of customers (54.5\%) use gas at the same time for heating, cooking and hot water production (Code C3) with a $45.7 \%$ of the total gas distributed in Italy $(1,110$ $\mathrm{m}^{3}$ per year). The second most frequent use among customers (41.8\%) is the use of gas for cooking and hot water production (code $\mathrm{C} 2$ ), corresponding to the $6.3 \%$ of the total $\left(200 \mathrm{~m}^{3} /\right.$ year). However, the second position in the ranking according to the consumed volume corresponds to heating space (code C1) with $21.8 \%$ of total $\left(14,393 \mathrm{~m}^{3} /\right.$ year). The first position according to the gas consumption is for category $\mathrm{T} 2$ with an average of around $20,300 \mathrm{~m}^{3} /$ year.

If the total consumption is divided into residential (including small business), industrial (including large commercial consumers) and power generation, as shown in Figure 3.39, the residential sector experimented an increase in 2015 with an annual consumption of $30,600 \mathrm{Mm}^{3}$ corresponding to a $+9 \%$ compared to the previous year. The most significant increase in national consumption was the power generation sector (thermoelectric), which consumed $20,200 \mathrm{Mm}^{3}$, more than the $17 \%$ compared to 2014 . On the contrary, the industrial sector reduced the consumption in $12,400 \mathrm{Mm}^{3}$ compared to $2014(-3 \%)$. 
Geographically, the consumption in the north of Italy is almost the double than for the rest of the Apennine peninsula.

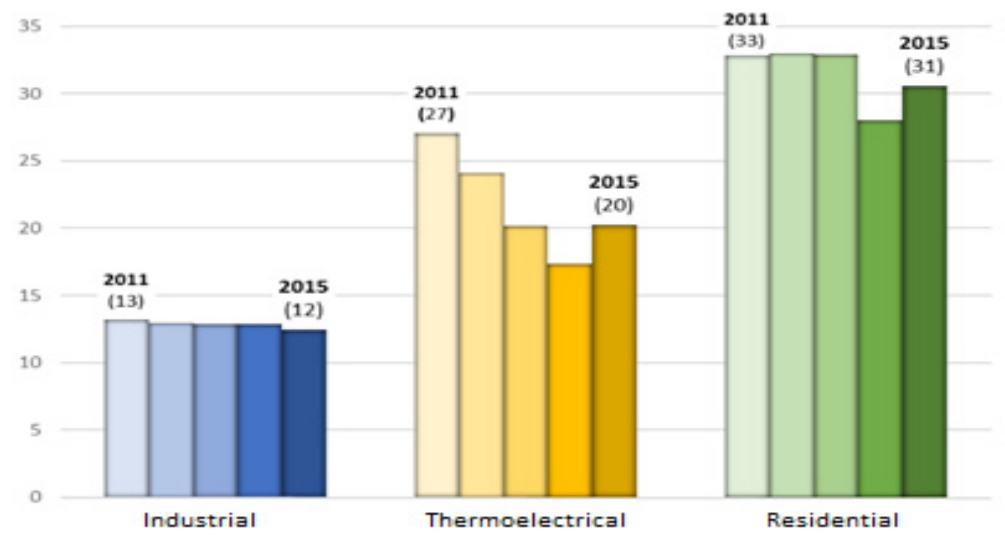

Figure 3.39. Natural gas consumption in Italy per sector, in $\mathbf{G m}^{3}$ (Source: SRG data ${ }^{32}$ )

The growing trend of consumption in the power production sector is mainly due to the reduction in the national share of renewable energies and the decrease in the import of nuclear electricity from France due to the stop of the transalpine reactors. This fact, together with the fall in hydroelectric production, has boosted the power production by natural gas-fired power plants [85].

For the ten year period 2014-2023, the gas system operator Snam estimates a growing trend for the use of natural gas for power generation at a rate of $+2.6 \%$, together with an increase in imports at an average annual rate of $2.2 \%$. Moreover, it is forecasted a decrease in national production at an average annual rate of $1.4 \%$.

Regarding the other sectors, import development projects will allow industrial consumers to increment the gas consumption at a rate of $+0.2 \%$. However, it would be partially balanced by a reduction in the consumption of the residential and commercial sectors $(-1.2 \%)$ reflecting the impact of energy saving and efficiency measures [86].

\subsubsection{Energy trading}

The trading of natural gas, like in the rest of European countries, is a competitive activity that is liberalized. The major players are about 380 companies, including the retailer branch of traditional utilities S.p.A. However, although the price is freely agreed between buyers and seller, the Authority defines a benchmark pricing as reference.

${ }^{32} \mathrm{http} / /$ www.sicurezzaenergetica.it/2016/01/consumi-di-gas-in-italia-2015-di-nuovo-in-positivo 
Before liberalization, end users could buy the gas exclusively from their local distributor. Then the distributor was responsible for all aspects related to energy supply, both technical (maintenance of the network, connection, intervention in case of failure, etc.) and commercial (price, bills management, collecting payments, etc.). End users, in short, had no chance to make any choice with respect to its gas supply.

With the liberalization of the gas sector in 2003, all customers are eligible and, therefore, they can freely choose their supplier.

\subsection{Constraints in the natural gas system}

The present section has the aim to describe the technical constraints that may affect the natural gas system, highlighting the potential of demand response so as to overcome these limits and promote the development of a reliable natural gas system, able to quickly face sudden network failures.

The core of a natural gas system is an extensive frame of pipelines that transmit the gas from the production site to the consumption site. These pipelines are essential for the management of the natural gas system and their technical characteristics deeply influence its operation.

A constraint can be defined as a physical or commercial barriers that prevent the normal operation of the natural gas system, lowering the reliability of the continuity of the gas service. A constraint could result in:

- A total interruption of the gas supply, if it is totally interrupted and the gas demand of the end user is not satisfied.

- A reduction of the gas supply, when the end user still receives gas but in a lower quantity compared to its actual needs.

In terms of lack of supply due to technical constraints, the concept of end user is applied to a significant consumption of gas from the grid (e.g. $40 \mathrm{~m}^{3} / \mathrm{h}$ ) which may be consumed by a district heating system, one or several industries or an entire town.

Generally speaking, the physical/technical constraints of a gas network system are set by one or more of the following parameters:

- The capacity of the pipelines, that limits the quantity of gas that can be transmitted between two points.

- The pressure of the gas supply. Actually, a different reliability issue can derive from the natural gas operation. The gas network is characterized by variable flow for each arc, which determines a variable pressure at every node [87].

- The extension and meshing complexity of the network -areas not served by the pipelines cannot be supplied by gas.

Regarding the commercial constraints, they may be set by: 
- Energy regulations. The energy regulations should be addressed to implement the efficiency of the gas network by providing incentives.

- Political stability. Sometimes, the presence of a large gas storage site or gas availability in countries defined as politically instable could affect the trend of the natural gas market.

- Geographical position of a country. The geographical position of a country may facilitate more or less the connections with large gas reserves or with strategic gas transit hubs.

- Availability of other energy resources for thermal production. The presence of other energy resource guaranties the energy independence from the natural gas network failure

Interruptions of gas supply that could occur in the gas system determine a not continuity of the service. Traditionally, interruptions have been divided into short and long. Short interruptions, are those whose duration is shorter than a standard value defined in regulation. For example, the Italian regulation defines an interruption as short when the duration is less than or equal to 120 minutes. On the other hand, interruptions are considered as long when exceed such standard duration.

According to its nature, interruptions could be also classified in:

- Scheduled interruptions (also called interruptions with notice), which take place due to scheduled operations of maintenance of the system (transmission and distribution). Usually, operators notify the customers at least 24 hours before a planned interruption occurs, specifying the date, time and duration for the scheduled activities. Generally, among the activities considered as scheduled interruptions, the more relevant are:

a) Ordinary/planned system maintenance, scheduled by the network operator (replacements of working parts of valves, of piping, etc.)

b) Extraordinary maintenance, scheduled by the network operator (the roll-out of the meters replacing)

c) Extraordinary maintenance, requested by the customers (request for a metrological test, leakage test, etc.)

- Unscheduled interruptions (or without notice), which are unexpected events that occur on the gas system network and cannot be forecasted by the network operators. Among the reason which can motivate an interruption without notice can be considered:

a) Congestion of the pipelines in specific nodes of the network, defined as the impossibility of the system to meet the energy needs of end users. It could be of two types: 
- Commercial congestion, due to the not commercial availability of the gas on the wholesale market

- Technical congestion, due to the non-physical presence of sufficient quantity of gas to meet the energy needs

b) Extraordinary maintenance operations because one of the following events occurs:

- Detection of gas leakage from any part of the supply system (meters, pipelines, compression cabin, valves, etc.)

- Presence of water into the gas pipelines or into the meters

- Tampering of the network system (vandalism act, close of the meter valve, damage)

- Blocking of the pressure regulator in the compression cabin

- Pressure level out of the range of the proper operation of the system

c) Political issue that determines unpredictable events such as acts of public authorities, or such as the gas crisis of 2014 because of the political instability in the relationship with Russia.

d) Natural catastrophe, unusual natural events for which has been declared a state of emergency by the competent authority, such the heart quake in the center of Italy happened in the summer of 2016, which determined the damage of several pipelines and compression cabins.

e) Strikes or rejection of the authorization documents by the competent Authority (not taken into account in this dissertation)

f) A gas accident, defined as an event involving any apparatus of the gas network that determines serious injuries or deaths of people, or damage to people's goods not lower than an economic value established by the law. For example, in Italy, this economic value is 1000 euros (Article 28, paragraph 28.1). The causes of a gas accident could be multiple, such as gas leakage (voluntary or not); an uncontrolled combustion caused by insufficient ventilation, etc.

g) An emergency, defined as an event that can put into risk the safety and the continuity of supply in large proportions of the distribution/transmission network. An emergency can be caused by:

- Unplanned unavailability of service at delivery points or interconnection points. 
- Unplanned out of service at the high, medium or low pressure networks that results in the interruption of the gas distribution without notice to one or more end users.

- Gas leakage on the pipelines.

- Damage caused by excess or defect of pressure in the network compared to the values provided by the current technical standards.

Depending on country specific regulation, an emergency could be defined in different way. For example in Italy, and according to the Article 27, paragraph 27.1, an emergency is considered an event that causes the interruption of the gas distribution without notice to at least a number of 250 end users and for the duration of 24 hours.

\subsubsection{Gas network constraints in the United States of America}

The analysis of the US natural gas system carried on in section 3.2.2 has highlighted the main characteristic of the transmission and distribution system, as well as the main characteristics of the system exploitation.

In spite of the wide network of interstate and intrastate pipelines that run throughout the country, there are still several open issues to solve in order to strengthen the stability and reliability of the American gas network:

- Implementation of existing pipelines and infrastructure. In spite of the growth in consumption, the US transmission infrastructure does not properly cover all the country and large areas suffer the lack of sufficient pipelines with the adequate capacity for the gas delivery, such as the Northwest and New England [88]. In order to face this constraint, new upcoming projects are expected to increase the number and capacity of the existing pipelines in order to transmit natural gas from production centers to consuming markets or exports terminals. Recent projects intended to increase the reach of natural gas produced in the Marcellus and Utica regions of the Northeastern United States (see Figure 3.40). New infrastructures are expected to be built from the Appalachia production between 2015 and 2025.

- Implementation of new pipelines and processing infrastructure. Forecast of energy needs beyond 2025 expects a significant impact of the growth in demand for gas-fired power generation on the existing pipeline system. In particular, to face the growth in electric demand, additional pipelines are needed in order to ensure the system reliability. The gas demand for power generation will increase by $73 \%$ between 2014 and 2025 , in comparison to the $39 \%$ increase between 2005 and 2014. New pipelines and processing infrastructure are required to face this growing in demand and to connect the end user to new supply source [89]. 


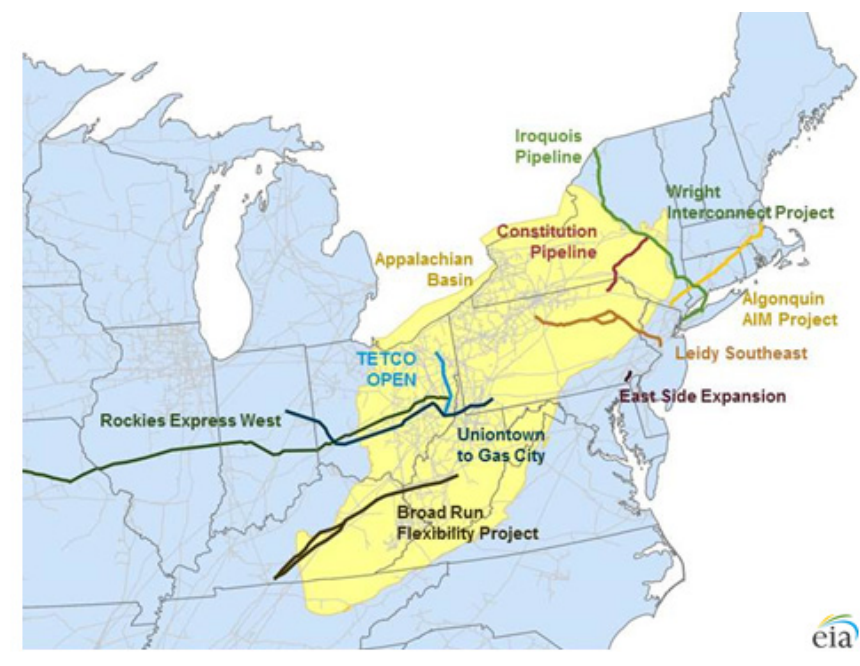

Figure 3.40. Implementation of new pipelines in USA (Source: New pipeline projects increase Northeast natural gas takeaway capacity, January 28, 2016)

- Reduction of natural gas losses. Local distribution companies (LDCs) have been pursuing the replacement of leak-prone pipes in order to reduce natural gas losses from infrastructure systems, contributing to the growing of the safety of the transmission system. Now, the mileage of cast iron distribution pipes has been reduced just for the $25 \%$ between 2005 and 2014 [90].

- Increment in state incentives. New capital expenditures have to be provided by State legislators for building new pipelines and expanding or repurposing existing ones. Such investments should be applied also to other infrastructures, such as compressor and pumping stations [91]. In spite of the growing awareness of the stakeholders about the potential environmental benefits of reducing natural gas losses, many reforms are required on the natural gas infrastructure.

- Introduction of DR programs. The introduction of new DR programs for the management of the consumption could help to face the temporary the lack of sufficient pipelines with the adequate capacity for the NG delivery (such as Northwest and New England). Indeed, putting in evidence the advantage of this kind of strategies is one of the main objectives of this dissertation.

\subsubsection{Gas network constraints in Europe}

The analysis of the natural gas system carried on until now highlights that the recent gas supply disruptions as a result of the political turbulence between Russia and Ukraine, increasing EU dependency on gas imports and the risks of the security supply. A reliable 
and interconnected system able to face the EU domestic energy needs should be implemented. Depending on the duration and on the level of the demand, ENTSOG ${ }^{33}$ shows that potential disruptions may directly affect the majority of EU Member States except France, Spain and Portugal, which may be supplied from the south interconnections. Indirect effects would include increases in the prices of LNG for the entire EU. The resilience of the gas infrastructure needs to get improved, carrying on the following implementations:

- Improvement of the existing pipelines._The increasing dependence of imports need the improvement of the existing pipelines. The major issue is the limited connections between the Western pipeline and the Eastern infrastructures. In order to facilitate the creation of a reliable and robust gas system throughout Europe, the European Network of Transmission System Operators for Gas (ENTSOG), in cooperation with Gas Infrastructure Europe (GIE) implemented the Gas Infrastructure Map, which provides an overview of the existing gas infrastructures and establishes a reference for information of their trends over time.

- Diversification of supply routes. In order to reduce the dependency of imports from Russia (the owner of the $23 \%$ of the total proved reserves of natural worldwide, as show in Figure 3.41) and unstable transit countries, new pipelines need to be built re-routing the Russian imports (i.e. Nord Stream, Yamal and Blue Stream)

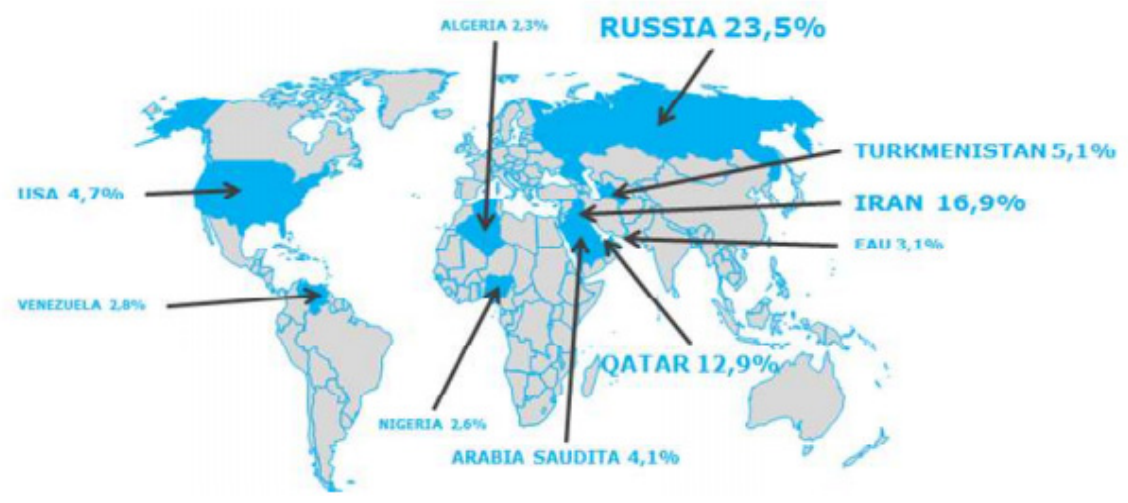

Figure 3.41. Proved reserves of natural gas worldwide (Source: Eni 2012)

- Implementation of reverse flow pipelines. Even if establishing a reverse flow is relatively easy since a technical point of view, there are still many restrictions

${ }^{33}$ ENTSOG is the European Network of Transmission System Operators for gas. More information ca be found at: http://www.entsog.eu 
in the main pipelines, which both hinder competition and decrease the security of supply. The potential to operate pipelines in two directions increases the resilience in case of a supply disruption [76].

- Improvement of the energy efficiency. It should be considered a potential in the energy efficient design of the transmission system. These days, the $5 \%$ of the energy is lost in the transmission grid.

- Harmonization of the Standards. The diversification and non-integration of the standards adopted by the different countries for technical building and daily operations do not favor the system management across the system borders. A higher degree of standardization is required. Efforts are required so as to regulate the three party access to the grid (TPA) in free conditions, as well as to improve information requirements to ensure transparency.

- Improvement of the security of supply. After the physical breakdowns of energy transmission networks following the crises with transit countries (Ukraine in 2006 and 2008 and Belarus in 2007) EU has been forced to adopt the strategy of diversifying supply routes which would gradually reduce its dependence on such transit countries. An improvement in the energy network and a strictly cooperation between states is essential so as to ensure a timely response in case of crises.

- Introduction of DR programs. The implementation of the DR programs could reduce the vulnerability to gas supply shocks, facilitating the development of an integrated gas market, reducing the import dependency and the variation of natural consumption due to the climate change issue. Some of the most significant benefits of DR programs on the short term in European countries may be:

- Management of sudden supply disruption due to catastrophic event (heart quake) and/or to political issue such as in the case of disruption of all supplies from Russia

- Management of the seasonal storage. The EU's gas storage, together with increased scope for reverse flows, can play a mitigating role in the event of supply disruption.

- Management of the growing variable trend of the natural gas consumption and network congestion. The demand of natural gas has traditionally been characterized by a highly cyclic trend depending on the season and on the climatic changes. Generally speaking, gas demand is expected to be higher in January and February, and lower during the months of July and August. Correspondently, and in order to meet the cyclical demand, the base-load storage capacity is typically withdrawn in winter (to meet increased demand, while storage injection typically takes place in summer (to store excess gas in preparation for the next up cycle). The recent grow in the use of gas for power generation has 
resulted in an anomalous and variable behavior of the gas demand. Hence, the increasing use of natural gas so as to generate electricity results in a peak of demand during the warmest months, whose magnitude is as pronounced as the peak in electricity consumption for air conditioning and lighting systems.

\subsubsection{Gas network constraints in Italy}

Beyond the usual utilization of natural gas as fuel to for heating space or producing hot water, it is in Italy the main fossil fuel used in power production [92]. A global increase in the production of electricity from natural gas equal to $75 \%$ was produced from 2002 to 2008 [93] mainly as a consequence of the introduction of the "Unlock Centers" Decree in 2002. That decree simplified the authorization procedures for the construction of thermoelectric power plants in order to avoid the danger of interruption of the electricity supply and to ensure the necessary coverage of the electrical demand. In the latest years, the energy dependency from the foreign imports of energy further contributed so as to increase the domestic natural gas consumption for electrical production.

In 2016 the drastic reduction of power imports from France and Switzerland due to the blockade of two nuclear power plants for maintenance has led to a sharp rise in the cost of electricity and brought to an intensification of the use of the natural gas for power production. In spite of that, the main advantages that have favored this extensive usage and the growing interest in the exploitation of the fossil fuel resources above the others are:

- The easy of transmission and distribution

- The limited cost

- The low emissions even in small installations without fumes treatment.

Although the Italian natural gas network is quite well developed in terms of technology (smart metering roll-out is in progress) and branching on the territory (actually the only Italian region that is not provided with gas is Sardinia), there are still some techno-economic constraints to face [86].

Despite the good degree of flexibility and meshing of the Italian gas transmission and distribution network, it is possible that supply is not guaranteed on peak periods. As documented by SNAM [86], congestions of the natural gas network system have affected the reliability of the system in the North-West area of Italy in the over past ten years. In fact, the combination of gas demand peaks together with an insufficient availability of gas stocks (gas wells or GLP tanks) brought into the interruption of the gas service in 2004-2005 and 2005-2006.

Similarly, political issues demonstrated to affect the continuity and safety of the gas service. Italy is one of the most affected countries by a sudden interruption of the imports from Russia. At present, the TAG pipeline (which belongs to Russia and passes through the territory of Ukraine) is one of the major connections for the Italian gas supply and 
contributes for the $45 \%$ of the total gas imported [79]. The gas crisis between Ukraine and Russia that occurred in 2014 with the risk of a possible gas service interruption highlighted the weakness of the system and the need to implement new transits for the supply in order to gain the energy independence. A consequence of the 2014 gas crisis was also the closure of the international project for the building of the South Stream, a gas pipeline under the Black Sea to Austria for the gas transmission to Europe $e^{34},{ }^{35}$.

Beyond that the recurring natural catastrophic events usually affect the Apennine peninsula due to its geographical position, Italy is a country widely hit by heart quakes. Actually, Italy is located in a convergence zone between two large tectonic plates, the African and Eurasian plates. The movement between these two plates determines an accumulation of energy in the ground which is released in the form of earthquakes ${ }^{36}$. In the last two years, there were 3,690 earthquakes of magnitude 2.5 and, as shown in Table 3.8, there were 16 earthquakes with a magnitude greater than 4.0 in just the first 4 months of 2017. In 2016, these natural disasters turned out into serious damages not only to people, but especially to the supply infrastructure, resulting in sudden blackouts and interruptions of the energy services [94].

In order to face the possible disruptions of the gas service and the constraints highlighted above, the following amendments should be performed:

- Creating new transmission capacity in order to sustain increases in demand for natural gas, registered in a given area over the medium - long term

- Improvement of the existing pipelines. In the framework of the project 'Support to the north-west market and bidirectional cross-border flows' the Transmission Operator is going to create new transmission capacity (project of Galsi and Adriatic Line) to satisfy the long and medium term demand and strengthen and eventually extend the existing network [86]. In that framework, there is another project for the building of the Trans Adriatic Pipeline (TAP) currently in progress. The TAP will transmit natural gas from the Caspian Sea region to Europe, connecting the Trans Anatolian Pipeline (TANAP) at the border between Greece and Turkey ${ }^{37}$. The pipeline will pass through northern Greece, Albania and the Adriatic Sea to land on the coast of Salento San Foca Melendugno to the Italian network. Once completed, TAP will constitute the most direct link and economically advantageous passage to the new area of the Caspian Sea gas resources. The pipeline will have an initial capacity of 10 billion $\mathrm{m}^{3}$ of natural gas per year, equivalent to the energy consumption of about seven million

\footnotetext{
34 "Putin: Russia Cannot Continue South Stream Construction in Current Situation". RIA Novosti. 1 December 2014, accessed on 12 January 2016

35 "Russia drops South Stream gas pipeline plan”. BBC News. 1st December 014, accessed on 12 January 2016.

${ }^{36}$ More information can be found at the website of the Italian Center for Earthquakes: http:/cnt.rm.ingv.it/

${ }^{37}$ More information can be found at: http://www.tanap.com/tanap-project/why-tanap
} 
households in Europe. In addition, Italy will gain in terms of transit fees to be paid by the different operator. In the future, with the addition of two compression stations, the delivery rate can reach up to 20 billion cubic meters [95].

Table 3.8. Earthquake in Italy between the $1^{\text {st }}$ January 2017 and the $1^{\text {st }}$ April 2017

\begin{tabular}{|c|c|c|c|c|c|}
\hline $\begin{array}{l}\text { Date and } \\
\text { Time }\end{array}$ & $\begin{array}{l}\text { Magni- } \\
\text { tude }\end{array}$ & Area & Depth & Latitude & $\begin{array}{l}\text { Longi- } \\
\text { tude }\end{array}$ \\
\hline $\begin{array}{l}\text { 2017-02-03 } \\
05: 10: 05\end{array}$ & Mw 4.2 & $\begin{array}{l}2 \mathrm{~km} \text { E Monte } \\
\text { Cavallo (MC) }\end{array}$ & 6 & 42.99 & 13.03 \\
\hline $\begin{array}{l}2017-02-03 \\
04: 47: 55\end{array}$ & Mw 4.0 & $\begin{array}{l}2 \mathrm{~km} \text { E Monte } \\
\text { Cavallo (MC) }\end{array}$ & 6 & 42.99 & 13.02 \\
\hline $\begin{array}{l}2017-01-18 \\
20: 32: 31\end{array}$ & Mw 4.2 & $\begin{array}{l}6 \mathrm{~km} \mathrm{~N} \text { Monte- } \\
\text { reale (AQ) }\end{array}$ & 13 & 42.58 & 13.24 \\
\hline $\begin{array}{l}2017-01-18 \\
16: 16: 10\end{array}$ & Mw 4.3 & $\begin{array}{l}2 \mathrm{~km} \mathrm{SE} \mathrm{Ama-} \\
\text { trice (RI) }\end{array}$ & 10 & 42.61 & 13.30 \\
\hline $\begin{array}{l}2017-01-18 \\
14: 33: 36\end{array}$ & Mw 5.0 & $\begin{array}{l}3 \mathrm{~km} \text { N Barete } \\
\text { (AQ) }\end{array}$ & 10 & 42.48 & 13.28 \\
\hline $\begin{array}{l}2017-01-18 \\
12: 07: 37\end{array}$ & Mw 4.1 & $\begin{array}{l}4 \mathrm{~km} \mathrm{~W} \text { Amatrice } \\
\text { (RI) }\end{array}$ & 10 & 42.62 & 13.24 \\
\hline $\begin{array}{l}2017-01-18 \\
11: 39: 24\end{array}$ & ML 4.1 & $\begin{array}{l}2 \text { km NW Capiti- } \\
\text { gnano (AQ) }\end{array}$ & 11 & 42.54 & 13.29 \\
\hline $\begin{array}{l}2017-01-18 \\
11: 25: 23\end{array}$ & Mw 5.4 & $\begin{array}{l}3 \mathrm{~km} \text { S Capiti- } \\
\text { gnano (AQ) }\end{array}$ & 9 & 42.49 & 13.31 \\
\hline $\begin{array}{l}2017-01-18 \\
11: 24: 14\end{array}$ & ML 4.0 & $\begin{array}{l}6 \mathrm{~km} \mathrm{~W} \\
\text { Campotosto (AQ) }\end{array}$ & 10 & 42.58 & 13.31 \\
\hline $\begin{array}{l}2017-01-18 \\
11: 16: 39\end{array}$ & ML 4.6 & $\begin{array}{l}3 \mathrm{~km} \text { NE Monte- } \\
\text { reale (AQ) }\end{array}$ & 11 & 42.55 & 13.28 \\
\hline $\begin{array}{l}2017-01-18 \\
11: 15: 33\end{array}$ & ML 4.7 & $\begin{array}{l}1 \mathrm{~km} \text { W Capiti- } \\
\text { gnano (AQ) }\end{array}$ & 10 & 42.53 & 13.29 \\
\hline $\begin{array}{l}2017-01-18 \\
11: 14: 09\end{array}$ & Mw 5.5 & $\begin{array}{l}2 \text { km W Capiti- } \\
\text { gnano (AQ) }\end{array}$ & 9 & 42.53 & 13.28 \\
\hline $\begin{array}{l}2017-01-18 \\
10: 25: 40\end{array}$ & Mw 5.1 & $\begin{array}{l}3 \mathrm{~km} \text { NE Monte- } \\
\text { reale (AQ) }\end{array}$ & 9 & 42.55 & 13.26 \\
\hline
\end{tabular}

- Identification of new storage sites. Considering the currently available stock $(15-20 \%)$ and the rate of utilization of the infrastructure, that is about $90 \%$ of its capacity, the prolonged interruption of an important artery (i.e such as Transitgas pipelines) leads to strong supply problems with a significant increase in gas prices. Previous research establishes a needs of additional $80 \mathrm{Mm}^{3} /$ day to respond to the actual Italian demand [96]. Gas storage represents the security of supply of a country preventing emergency situations during peak demand conditions and supply interruptions. In the Italian market, which is so dependent on imports, it plays a fundamental role and increase the flexibility of the system. 
Nowadays, when the price of gas is low, it cannot be bought because there are not enough storage sites available in Italy. On the other hand, when the price is high, there are only two options: paying a higher price for the gas to be consumed or reducing consumption.

Different projects on the expansions of the existing storage facilities are in progress in Fiume Treste, Minerbio, Ripalta, Sabbioncello, Sergnano and Settala, and others are expected in Lombardy, Emilia Romagna and Marche [86].

- Diversification of the supply. In order to contribute to the supply diversification, the MiSE (Ministero dello Sviluppo Economico) has authorized the construction of other three LNG terminals, and other project for a new terminal proposed by Gas Natural will be carried by the 2015-2024. It is expected that such efforts will ensure diversification and hence the security of energy supply, reducing the current dependency on Russia [86]. In addition, European regulation has defined priority transmission corridor for electricity, gas and oil for the Member States:

- South-North interconnection in Western Europe ("NSI West Gas") for the transmission of gas between Northern and Southern Europe.

- South-North interconnection in Central and Eastern Europe and Southern Eastern Europe ("NSI East Gas")

○ South Corridor ("Southern Gas Corridor - SGC")

- Baltic Energy Market Interconnection Plan ("BEMIP Gas).

Italy is involved in three regional groups: NSI West Gas, NSI East Gas and SGC. These corridors have the aim to reduce Russia's imports dependency and increase the diversity and security of supply.

- Development of DR programs. In this complex scenario of agitated political issue, natural catastrophic events and experienced congestions of the gas supply system, the potential benefits of the introduction of demand response program is huge. The introduction of DR programs should contribute in facing the natural emergencies and to guarantee the continuity of the energy supply especially for the primary sanitary service (such as hospital, fire department, etc.). In addition, DR programs could contribute to the management of the gas demand during the refilling period of the storage reserves. At present, during a possible interruption, the gas stored is the primary resource that the operator has available in order to face the breakdown of the system. In case of the storage is not sufficient to cover the gas demand (e.g. due to the severe weather conditions of the previous winter), DR resources could give to the operator the possibility to still keep the continuity of the gas supply by managing the demand. Indeed, one of the main objectives of this dissertation is precisely the enhancement of the role of 
demand flexibility so as to overcome the constraints that may appear in the gas system.

\subsection{Smart metering and smart cities in the European Union}

The Smart metering and Smart city are phenomenons rapidly expanding worldwilde with the objective to raise sustainability standards, quality of life and economic dynamism of future cities [97]. At the present time, cities are responsible for more than $75 \%$ of waste, $70 \%$ of greenhouse gas emissions and $75 \%$ of energy consumption [98]. This trend is going to be more and more important due to the expected increase in the number of population living into urban area. By 2045 , according to the World bank ${ }^{38}$, the number of people living in cities will increase by 1.5 times to 6 billion. This figure emphatizes the importance of increasing the sustainability, the reduction of waste and the 'smart' management of the available energy resources.

The implementation of a smart city requires the proper development of a smart metering infrastructure, a system for the intelligent measurement of the energy consumption of each user, through smart meters able to give real time and remote consumption readings of different services (electricity, water, gas, district heating), providing advanced services to the users ${ }^{39}$.

In order to reach the proper integration of different energy supplies such as electricity, gas, water, district heating and energy produced by waste ${ }^{40}$ and service system such as internet, video terminal, e-cars, and so on, it is necessary to promote the use of different electronic meters (e.g. electric, water, heating and gas meters) and different sensors integrated into a distributed architecture, able to gather and analyses heterogeneous data. So as to achieve this objective, the following sub-sistems should be implemented:

- Smart Grids: intelligent interconnected networks, which have a bidirectional data flow between the service center and the end user.

- Smart Buildings: commercial and residential buildings that respect the environment and have integrated energy production systems.

- Smart Sensors: sensors with the function of collecting data from the necessary variables at the smart city. They are fundamental to manage the energy and avoid waste.

- Information and Communication Technology Infrastructure (ICT): ICT infrastructure must be able to control the different subsystems of the smart city,

\footnotetext{
${ }^{38}$ http://www.worldbank.org/en/topic/urbandevelopment

${ }^{39} \mathrm{https}$ ://www.endesaeduca.com/Endesa_educa/recursos-interactivos/smart-city

${ }^{40} \mathrm{http}: / /$ www.autorita.energia.it/it/com_stampa/14/140908cs.htm
} 
through which citizens and administrative operators can actively participate in the management of the different facilities and uses [99].

- Smart Citizen: they have to active participate into the smart solutions and smart programs. From the enery perspective, it is the energy consumer.

\subsubsection{Pilots and examples of applications}

Smart city pilot projects have largely spreaded out in Europe (Spain, Germany, France, Finland, Italy). In 2010, the Association "Genova Smart City" drew up a project to turn the capital of Liguria into a smart city, meeting the requirements of the European Commission [100]. In 2015, into the framework of "Flexemeter project- "Flexible smart metering for multiple energy vector with active prosumers", two pilot applications have been performed in Turin (Italy) and Malmo (Sweden) ${ }^{41}$. Both projects involve the local DSOs and volunteer "prosumers" 42 on real systems and are predoninantly focused on the integration of the elecrity and heating district supply. By the 2030, supported by the European Commission, also Geneva (Switzerland) will become a smart city for the electric, heating and cooling networks, with the integration of renewable energies (wind turbines).

The diffusion of flexible multi-utilities and multiservice system is the crucial step to improve energy and market efficiency, to optimize the energy management during the peak periods and to promote the integration of DR programs profiled on more efficient energy demand prediction [101]. In that framework, a fondamental role is played by the smart meters. At present, a smart metering infrastructure able to collect, aggregate, and analyze real-time data is esssential to properly manage the different energy resources and to reduce greenhouse emissions as required by the COP.21 [82].

The European Smart Metering Landscape report [102] has presented the best practices in the smart metering field. Different smart metering pilot projects have been successfully carried out in Europe: in Finland, the smart metering project was based on the monitoring in real time the cottage's electricity consumption and its impact on the carbon footprint. Other example was carried out in Spain, where consumers equipped with smart meters received specific information to allow an evaluation on how reducing their average electrical consumption. In Germany, a German start-up company created a Social Metering App that allows users to view and share smart metering data in terms of carbon emissions, $\mathrm{kWh}$, or monetary costs for all energy carriers (electricity, gas, oil) and water meters.

\footnotetext{
${ }^{41} \mathrm{http}: / /$ flexmeter.polito.it/index.php/project

${ }^{42}$ Prosumer is a neologism applied to consumers which also are able to produce electricity that can be delivered to the grid.
} 
Under the Third Energy Package ${ }^{43}$, Member States are required to ensure the implementation of smart metering for electricity, gas, water and heating. In this framework, long term cost benefits analysis (CBA) have been carried out so as to decide the implementation of a smart metering infrastructure [103].

In contrast with the Electricity Directive, which requires that $80 \%$ of consumers should have smart electricity meters by 2020 , the Gas Directive does not specify how many consumers should have smart meters or provide a deadline for deployments following a positive CBA. This lack of enforceable EU regulations has contributed to the slower approach in gas, and several EU member states have yet to submit their CBAs for gas. In spite of that, as it has been done into the electrical field by Enel ${ }^{44}$, also the smart meter gas roll out has spread out in Europe, as it will be detailed in the next section. By 2020, it is expected that almost $40 \%$ of European consumers will have a smart meter for natural gas $^{45}$. The following paragraphs will show the state of art of the roll out of smart meter gas in Europe and, with a particular focus, on the state of art of the district heating fueled by natural gas.

\subsubsection{Massive roll-out of smart gas meters in Europe}

In the recent years, the European Union has played a leading role in promoting the reduction of greenhouse gas emissions in line with the ambitious targets of the 2020 regulation to reduce the GHG emissions at least of a $20 \%$. In accordance to this de-carbonization process, the natural gas retail market is today affected by deep changes.

In order to enforce the transition to a more efficient organization for the gas system, the introduction of gas smart meters and smart metering network concepts have to be promoted as it has been already done in the electrical sector. In order to support these innovative changes, a new concept of consumer like a more aware and active participant in the marketplace needs to be promoted [104]. Similarly, the role of aggregators needs also to be empowered as an intermediary between small customers and network operators willing to use customers' services (DR resources) so as to manage their infrastructures more efficiently. With regard to the metering instruments and in prospective to the development of multiservice smart cities, the European Directive MID 2014/32/UE defines the functionality of measuring instruments for the promotion of efficient consumer behavior and for their active participation in the energy market. In spite of that, as previously stated, the Directives on the Internal Market for Electricity and Gas (Directives 2009/72/EC and 2009/73/EC) included in the Third Energy Package does not oblige European countries to participate in the roll out of the smart meter gas and does not state a

\footnotetext{
${ }^{43} \mathrm{http}: / /$ eur-lex.europa.eu/legal-content/EN/TXT/PDF/?uri=CELEX:32009L0072\&from=en

${ }^{44}$ Enel has invested 2 billion euros ( $\$ 2.6$ billion) and placed 40 million meters worldwide since 2001

${ }^{45} \mathrm{http} / / /$ ses.jrc.ec.europa.eu/smart-metering-deployment-european-union 
deadline to complete the roll out neither. This lack of a mandatory regulation on this matter derives into different behavior on each European countries.

As previously done for the electrical sector, European countries carried out a cost-benefit analysis (CBA) for the participation into the smart meter gas roll-out [105].

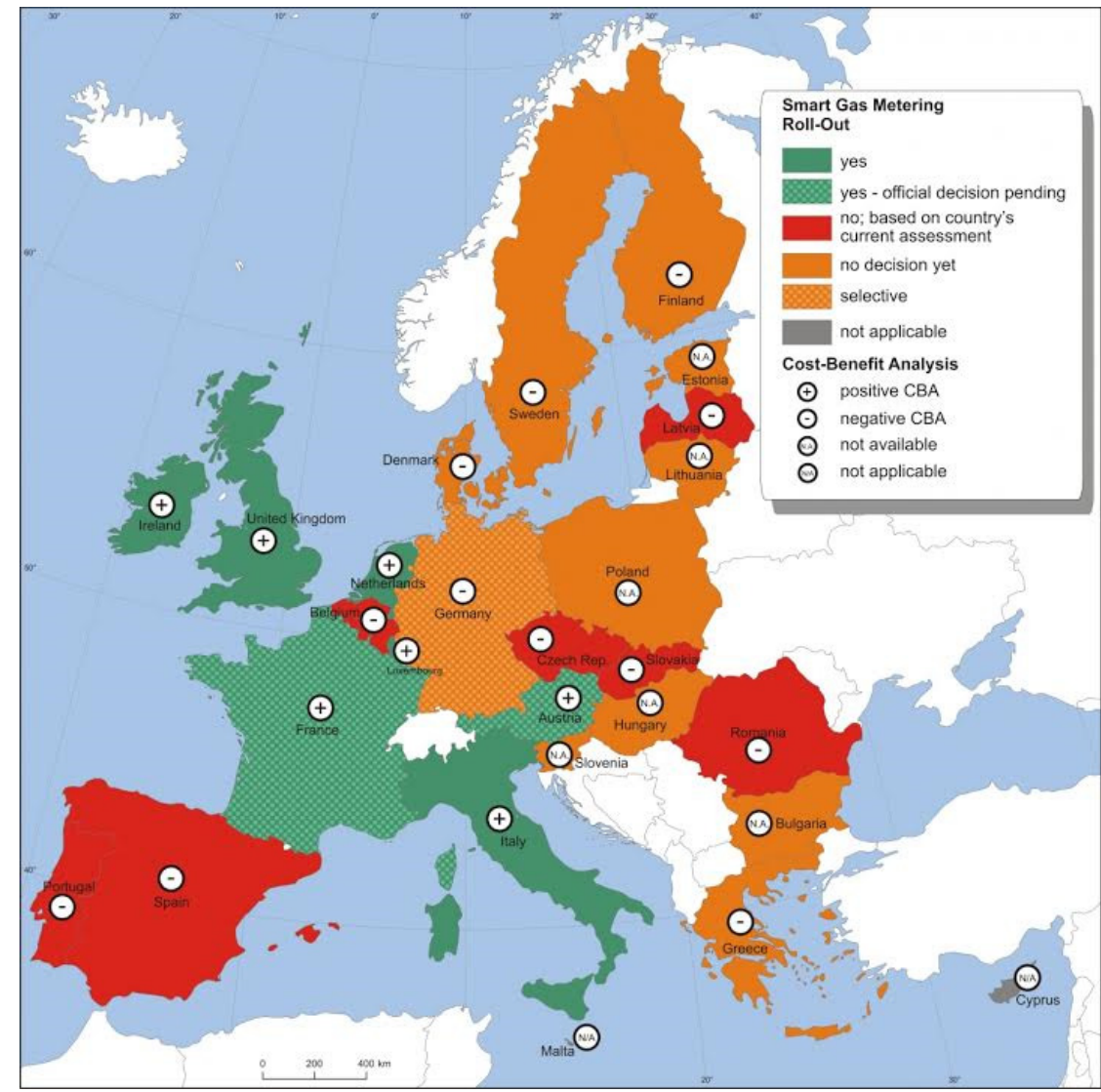

Figure 3.42. Smart metering roll-out in Europe (Source: Smart Metering deployment in the European Union-2017)

As shown in Figure 3.42, the results were dissimilar and a slower approach to the smart meters gas introduction was registered:

- Four Member States (Ireland, Italy, Netherlands, Luxembourg and the United Kingdom) have decided to introduce smart meters by 2020 or before.

- France and Austria, in spite of the positive results of the national CBA, have not started officially the roll out yet. In France, Electricité Réseau Distribution 
France (ErDF) carried out in 2011 an initial gas smart meter pilot project in around 18,500 facilities. In spite of that, the complete rollout is still being discussed $^{46}$.

Globally, 19 European countries have conducted a cost benefit analysis (CBA) so far, with twelve countries showing negative CBA results (Germany, Spain, Portugal, Romania, Finland, Sweden, Poland, Czech Rep, Belgium, Greece, Latvia).

The main benefit provided by the gas smart metering is probably the reduction in operating costs through savings in manual meter readings, theft protection, process improvement, better scheduling and balancing processes, and consumer engagement opportunities. However, the participation into the massive roll out and the results of the CBA are influenced by different factors, such as density of gas customers, gas customer expenditure, and competitiveness of supply market and need for consumer engagement, meter location, and meter ownership [105]. Currently, countries with a high density of gas customers and significant share of gas bills such as UK and Italy were more favorable to the smart metering roll out. Additional benefits to take part into the roll out of gas smart meters could derive from the higher transparency and awareness about the gas consumption and from the reduction of GHG emissions improving energy efficiency. These social benefits, together with the introduction of DR programs, should be driving factors to enlarge the number of EU countries enrolled into this program.

Germany is the largest gas consumer country in EU. However, it does not accept the mandatory roll out due to unclear costs-benefit ratio of the smart metering gas implementation [106]. In addition, the saving costs derived from the theft protection were not as high in Germany as in the other countries, as this is not a frequent problem in that country. Similarly, Sweden rejected the participation into the roll out because the low number of gas consumers (around 40.000) made it not attractive [107]. On the other side, Spain has a much higher amount of gas customers (over 7 million) but, in spite of that, the CBA had negative results.

The most significant results obtained in the countries which have adopted the rollout are described in the following sections.

\subsubsection{Italy}

The mass-market stage of the rollout will end at the end of the 2018. This gas smart meter deployment target is more ambitious than those set by other European countries. For example, the UK will complete the program in 2020.

The Italian CBA showed a positive net benefit, coming from the reduction of the operation costs mainly due to two reasons: the lower cost of metering compared to the manual

${ }^{46} \mathrm{https}: / /$ www.metering.com/erdf-begins-linky-smart-meter-rollout/ 
reading and the reduction of energy theft. The CBA does not consider the installation of In-Home Display (IHD) [108].

According to the Plan of the Authority for the Electric, Gas and Water, the mass market roll out started in Italy in 2013. When the program finishes by the end of 2018, around 12 million of gas customers will have a smart meter gas.

Between 2014 and 2015 (Figure 3.43), the number of electronic meters in operation has almost tripled. Approximately 1.5 million of units were installed during the last year, $92 \%$ of which concerned the meters up to G6 class. The proportion of households (household measurement groups) with electronic meters has risen to 7\%. By the end of 2015, about half of the condominiums with household use were provided with electronic gas meters, just over a third of the public service activities and $15 \%$ of the other measurement units [83].

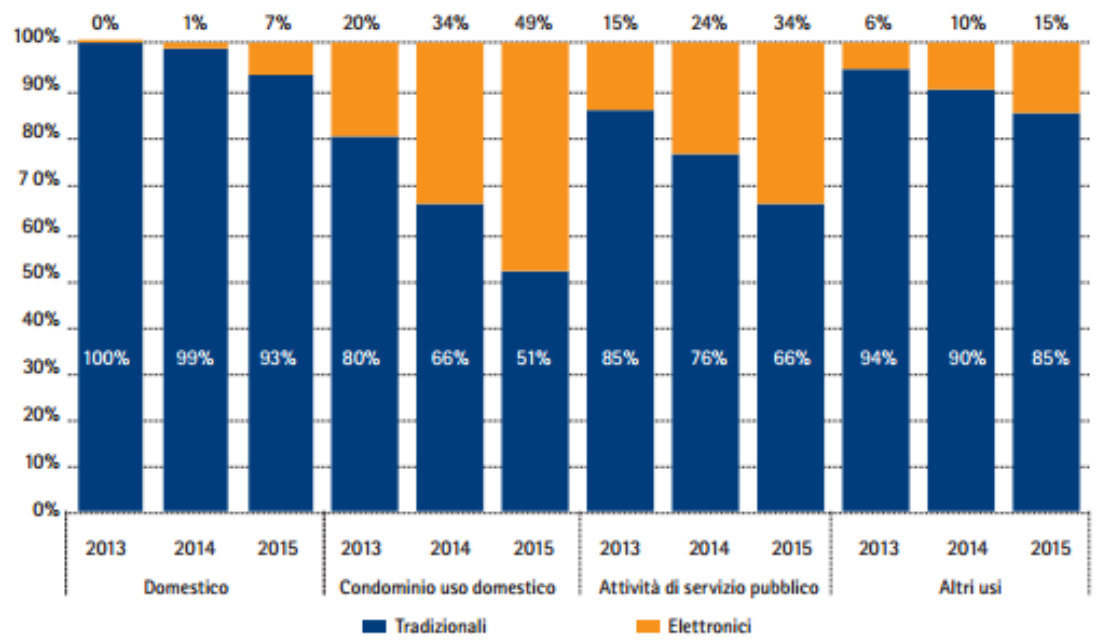

Figure 3.43. Percentage of smart meter gas installed in Italy in 2013-2015 (Source: RAV2015 AEEGSI)

Regarding the telecommunication architecture, the Italian standard technical rule for smart gas metering [109] currently restricts the choice to:

- Point-to-multipoint (PM) radio frequency (RF) communication between meters and gateways (Data concentrator) leveraging the Wireless M-Bus standard at $169 \mathrm{MHz}$

- Direct point-to-point (PP) GPRS links between meters and Central acquisition system (SAC)

The pros and cons of each of them will be well be discussed in Chapter 4 . 


\subsubsection{Luxembourg}

Luxembourg is one of the EU countries which had a positive cost-benefits analysis (CBA) regarding the smart meters gas roll-out. As a consequence, the government chose to start a mandatory roll out with the introduction of gas smart meters and electrical smart meters by 2020 for at least the $95 \%$. The smart metering roll out started in 2015 and it will include the development of an energy grid for the integration not just of electricity and natural gas consumptions but also distributed energy resources such as solar, wind, biogas, and heat pumps [102].

\subsubsection{Ireland}

The CBA had in Ireland the strongest positive result, especially for the fast rollout scenario with the combination of energy statement with In-Home display (IHD) and variable tariff. Regarding the additional benefits from reduced emissions of greenhouse gases, all the considered scenarios were positive [110]. Gas Networks Ireland (GNI) currently supports the National Smart Metering program, which is focused on both gas and electricity metering devices ${ }^{47}$. The program includes the use of smart metering technology, variable time of use and in-home displays according to the CBA results. A share communication infrastructure has been implemented for gas meter and electricity meters in order to leverage the costs. In future, the same infrastructure could be used also for water smart meters.

\subsubsection{Netherlands}

In 2009, due privacy concerns, the mandatory roll out was not accepted by the Dutch Senate, so that a voluntary roll out of 7 million consumers started. During 2012, installations of smart meters were performed on a small scale and the company Oxxio (former Eneco Energie) provided over 200,000 smart meters using GPRS as the communication technology [111]. Considering that almost $100 \%$ of the households accepted the smart meter (with almost $100 \%$ standard readings), it would be expected a benefit of approximately 770 million of euro, which is equivalent to $50 €$ per metering point according the positive results of the CBA [112]. The rollout of smart meters in the Netherlands will continue with a small scale rollout from 2013. In 2015 approximately 1.5 million Dutch households had smart meters, so far with the objective to get smart meters in at least $40 \%$ of households for the gas sector and at least $80 \%$ for the electrical sector by the 2020 .

\subsubsection{United Kingdom}

The Impact Assessment (CBA) carried on by the UK Department of Energy and Climate Change in 2014 on the smart meters roll out was positive with an estimation of net benefits equal to $£ 6.2$ billion [113]. UK's rollout is the largest project in the gas market and involves 30 million customers with a gas consumption equal to the $50 \%$ of the household

\footnotetext{
${ }^{47}$ http://www.gasnetworks.ie/en-IE/About-Us/Our-commitment/Marketplace/Smart-meters
} 
energy costs [109]. Households can freely choose if applying or not for a smart meters of new generation, for the gas and electricity with an in-home display screen that show in real time the exactly amount of the energy consumption ${ }^{48}$.

At the end of 2013 there were 295,700 smart meters already installed in domestic properties in Great Britain. By the end of 2020, around 53 million smart meters will be fitted in more than 30 million premises (households and businesses) across Wales, Scotland and England ${ }^{49}$.

The Home Area Network (HAN) implemented in UK for the smart meters' remote reading uses a ZigBee Energy network. ZigBee Smart Energy is the network solution for both electric meters, gas meters and in-home displays due to its maturity and popularity in Smart Energy application profile and its capability of ensuring robust communications architecture of a smart natural gas system [114].

\subsection{Architecture of a smart natural gas system}

The main purpose of the gas system is to supply gas to consumers with the required safety and quality characteristics at a reasonable cost. In order to fulfill this target in a cost-effective manner, different agents are necessary, each of them will be assigned some specific role.

The gas transmission network is the physical medium through which consumers can obtain the amount of gas they need. Depending on the type of network (characterized, among other parameters, by the pressure level and its capacity), there are transmission and distribution networks. Distribution networks are structures connected to the transmission network and carry the gas to the final consumers. The owners of the network, which are in charge of maintenance and development of those infrastructures, will therefore be transmitters and distributors.

Distribution (low and medium pressure network) is the final link of the chain in delivering natural gas to customers. While some large industrial or commercial customers, as well as power generators fueled by gas, receive natural gas directly from high capacity interstate and intrastate pipelines, most of users receive natural gas from their local gas utility, also called local distribution company (LDC).

Unlike other energy sources, the gas can be stored in large amounts at different points of the grid. The network operator, whose mission is to ensure that the gas system remains balanced and stable so that energy transactions can be performed safely and reliably, can use these gas stores.

\footnotetext{
${ }^{48}$ https://www.smartenergygb.org/en/about-smart-meters/what-is-a-smart-meter

${ }^{49}$ https://www.smartenergygb.org/en/resources/resource-centre
} 
Depending on the type of network they manage, these operators may be transmission or distribution operators. The operation of the network is an activity that could be developed by agents different from the owners of the infrastructures, so that these operators would be different from the transmitters and distributors previously defined.

Other agents that should be established according to size and characteristics of the gas system, as well as the configurations that the network can adopt, are the aggregators, whose mission is grouping small distributed demand resources into larger packages that can provide significant value to the system as a whole.

Finally, the figure of the gas retailer appears as intermediary of the retail market between the final consumers (small amounts of energy) and the mechanisms of the wholesale market and gas production (large amounts of energy).

The different agents and the activities they would carry out within the new framework that smart grids offer to the natural gas market are further discussed below.

\subsubsection{Agents in a smart natural gas system}

With the liberalization of the natural gas market which has taken place in different part of the world, final consumers are free to purchase gas by competitive mechanisms, directly participating into the market (large customers) or freely choosing a retail supplier. In Europe it started in 2003 and, from that year, a new liberalized market with new companies competing with each other has originated more competitive and profitable services and offers.

Market rules have been established in these competitive markets so as to guarantee the free competence between participants. For example, in Italy, a new Gas Network Code was approved by the Authority for Electricity and Gas (Acronym CRDG - with resolution no. 108/06) as the contractual instrument between the companies that manage the distribution systems, the retailers and wholesalers.

The development of this competitive market brought to the formal separation between the different actors in the gas market. At this moment, the application of the concept of smart grid to the natural gas system enhances the need to define new roles in order to satisfy new arising necessities, or to redefine existing activities so as to adapt the to this novel configuration.

According to previous research developed in this field, applied to the power sector [115], the following agents have been identified for this smart natural gas network: 
- End users: They consume the natural gas and pay the prices established by the supplier (wholesaler for larger consumers, or retailer). In this smart infrastructure, the end user is also able to provide the operator of the grid with demand response services, based on the flexibility that end users may have.

- Producers: They explore, investigate and exploit the gas deposits.

- Gas Storage Manager: It is the responsible body for the management of the gas storage facilities.

- Aggregator: It creates blocks of flexible demand which may be used by the operator of the grid (or any other stakeholder) by grouping smaller end users.

- Transmitter: It is who owns and manages the infrastructures related to the transmission of gas at high pressure and the international interconnections.

- Distributor: It is the manager of the distribution network, which carries the natural gas from the transmission grid to the end users.

- Retailers: They buy large amounts of natural gas in the wholesale market and resell it in smaller packages to the end users.

- Wholesale energy traders: They incorporate natural gas to the system, buying this gas in international markets, to other wholesale energy traders or directly to producers, and resell it to retailers or large end users. Diversely to the case of the power grid, transmitters and distributors, together with network operators (at transmission and distribution levels) also buy natural gas for operation purposes (balancing, refilling of tanks, maintenance of the pressure in the pipelines, etc.)

- Transmission System Operator (GSO): It operates the national and regional transmission network, guaranteeing the security of the whole system and the supply to end users according to the technical conditions established by regulation.

- Distribution network operator: This role is similar to that for the GSO, but just applicable to a region of the gas network at the distribution level.

- Market operator: It is the body responsible for managing the mechanisms for the energy exchange between the parties (energy traders, producers, retailers, large end users) in the wholesale market.

The activities stated before are roles that can be independently performed under a smart grid configuration, but not entities. It means that it may be possible that the same body could performed more than one of the identified roles (e.g. the distributor may be also play the role of distribution operator, but not necessarily).

Each of the identified roles are further explained in the following sections. 


\subsubsection{End user}

Traditionally, end users have been the agents consuming natural gas from the grid. However, end users acquire a starring role in the new configuration of smart systems as their behavior becomes more dynamic. Thus, the flow stops being just from the grid to the end user, as end users may be able to provide with operation services to the network operators by using its flexibility. Actually, the word "smart" takes at the end user side its real meaning as smart users are who, according to this new behavior, transform the concept under which the whole system works.

End users are usually connected to the distribution network. However, there are larger industrial or commercial end users who may be connected directly to the transmission network.

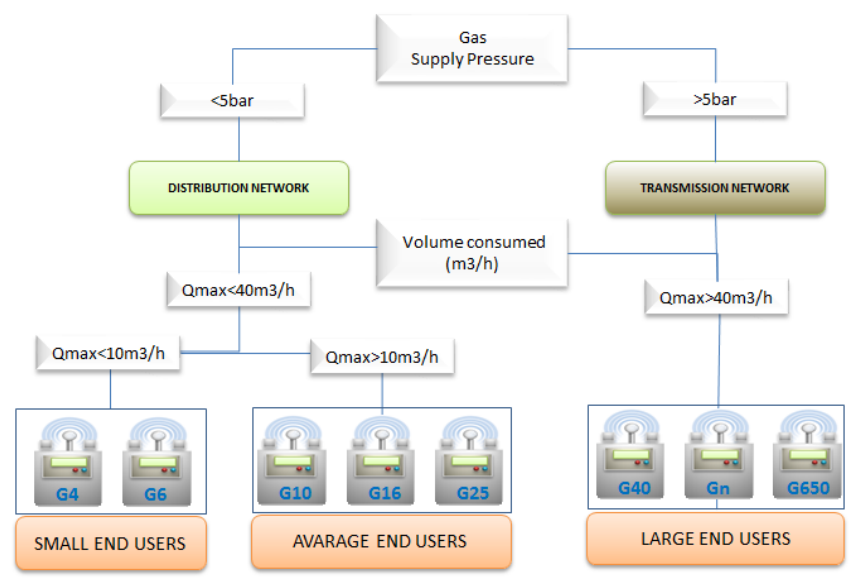

Figure 3.44. Activities of the end user

Depending on the supply pressure at which they are connected to, end users can be classified into different groups. For example, according to the Italian regulation [116], users may be divided into the two following groups:

- End users supplied from gas pipelines operated at low pressure (max 5 bar) are connected to the distribution system.

- End users supplied from gas pipelines operated at high pressure (above 5 bar) are connected to the transmission system.

According to the consumed volume of gas, end users can be also classified according to de main activity they perform, as included in Directive 2008/92/CE:

- Industrial consumers (including large commercial facilities)

- Domestic or residential consumers (including small businesses)

- Thermo-electrical consumers 


\subsubsection{Producer}

The natural gas as energy resource cannot be generated but there are many reserves of this resource worldwide. The world's reserves are estimated in 190.878 billion $\mathrm{m}^{3}$. The major producers are:

- Russia $19.3 \%$

- $\operatorname{Iran} 4.5 \%$

- Qatar $4.0 \%$

- Saudi Arabia 2.5\%

- USA $18.6 \%$

- Canada $2.7 \%$

- Algeria $4.9 \%$

- China $3.0 \%$

- Indonesia $2.8 \%$

- Norway $3.4 \%$

While and the rest of the world accounts for the 34.4\%.

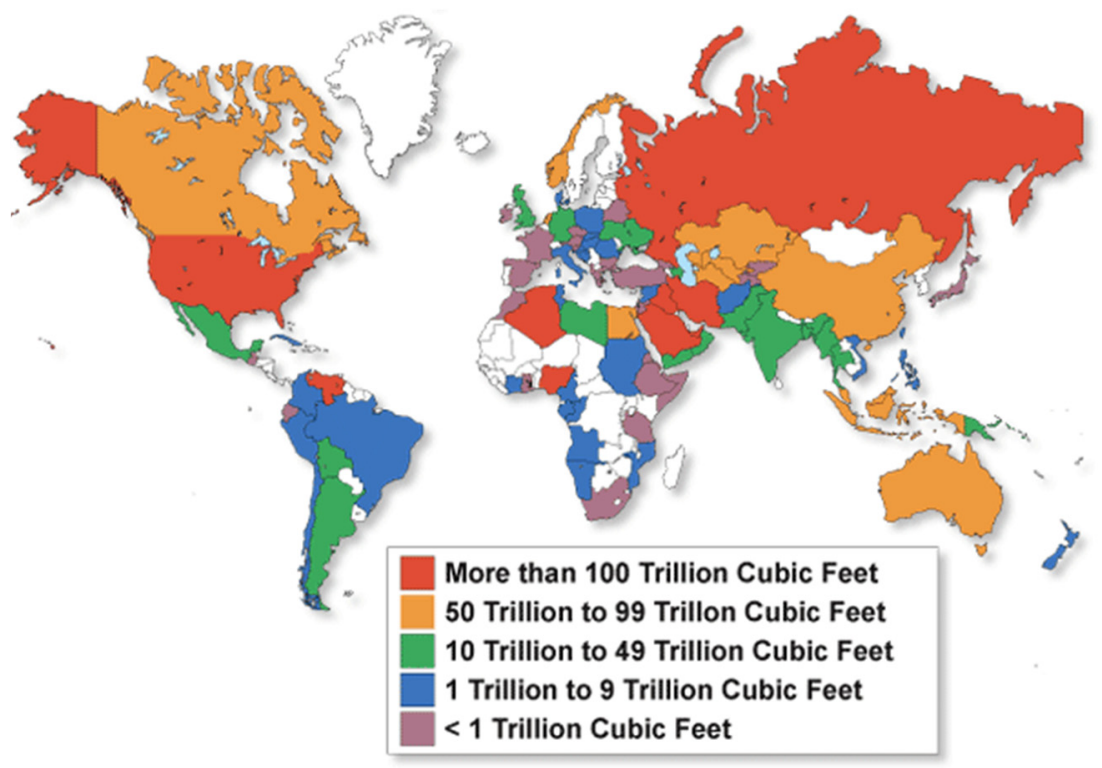

Figure 3.45. World gas reserves (Source: Oil \& Gas journal, “Worldwide report 2003) 


\subsubsection{Gas store operator}

A gas storage system is essentially based on the exploitation of depleted reservoirs of gas. The gas is injected into underground structures when it is cheap or demand is low. Later, the stored gas can be fed back to the network as required by demand or the market. In terms of operation, the storage of natural gas has to satisfy different requirements:

- It has to respond quickly to market demand.

- It ensures a high elasticity to the management of production and transmission facilities.

- It ensures the maintenance of "strategic" reserves, which can be exclusively used to handle exceptional situations (extreme weather conditions such as abnormal spikes of intense cold, or international crisis that block part of the supply from foreign countries which, in the case of such countries as Italy, is highly critical as it means over the $90 \%$ of the gas used in the country).

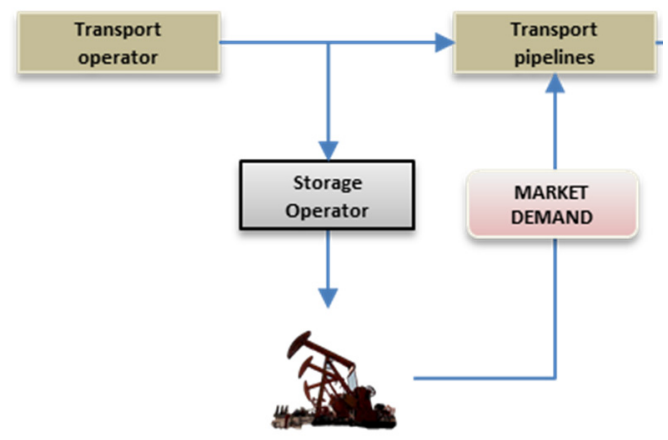

Figure 3.46. Activities of the gas storage operator

\subsubsection{Aggregator}

Aggregators are agents that act as intermediaries between small/middle consumers (who behave as DR providers) and the stakeholders interested in using such flexibility. These stakeholders could be transmission system operators, distribution network operators, retailers or other. For the scope of this dissertation, the gas system operator (GSO) will be the user of DR resources and, therefore, the only DR requester considered.

The aggregator is able to manage flexible gas demand packages of groups of customers, which once aggregated, may be offered in significant amounts to the GSO for operation purposes (balancing of the gas network, solution of technical constraints, etc.). This flexible package could be the result of reductions in the gas consumption of customers, but also increments in consumption during periods when the gas system is in surplus. In any 
case, this management implies the modulation of the gas load consumption but never determines a gas injection into the network.

Aggregators must have the appropriate measurement and management equipment to be able to offer safe and reliable operating services to the GSO. Here, the massive deployment of gas smart meters which is taking place in some countries, as mentioned in section 3.4.2, may be a very positive point so as to help in the further development of the role of aggregator in the natural gas system.

While the GSO can balance the gas in the grid in the wholesale market, aggregators would offer the same service through the increase or the reduction in the demand. In this way, the use of demand resources offered by the aggregators would provide more efficient services than those offered by the wholesaler, since before an event that required a gas increase, the aggregator would manage the demand, which implies a reduction of the gas consumed, a lower load level of the network (which reduces the risk of congestion) and greater efficiency of the system as a whole. Moreover, DR may imply a reduction in the greenhouse emissions when reducing but not shifting the net gas consumption.

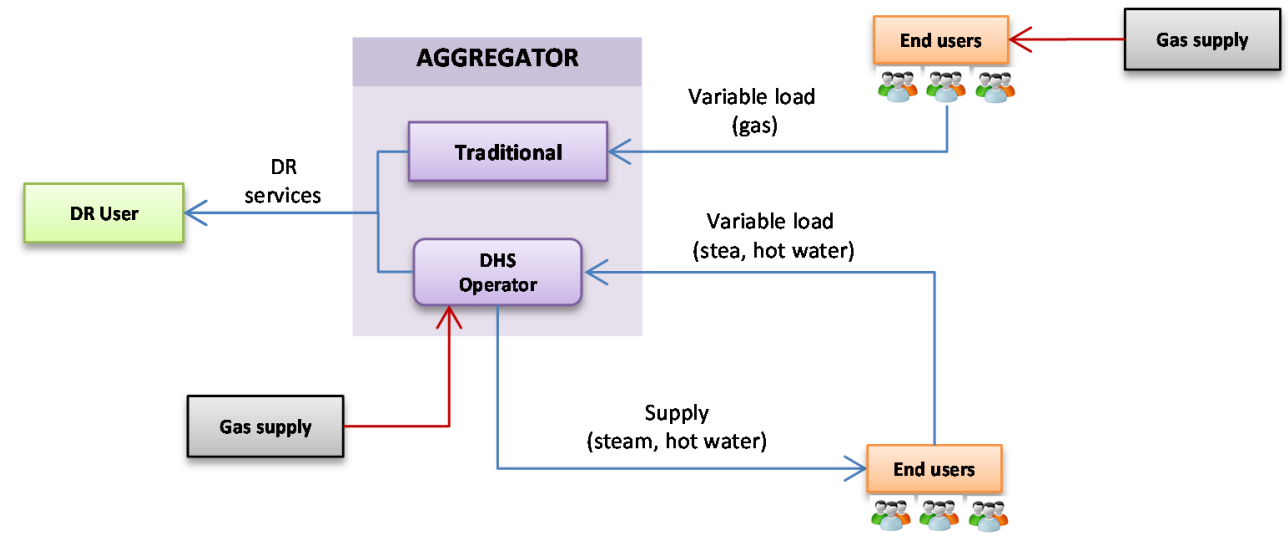

Figure 3.47. Activities of the aggregator

The aggregator of DR resources in the natural gas system has in this dissertation a novel approach. Indeed, together with the traditional aggregator, who represents and manage the flexibility of medium and small customers in order to create more significant DR packages so as to be offered to the GSO, the manager of district heating systems (DHS) arises here as a potential aggregator of thermal energy consumers. Customers aggregated under the traditional aggregator are natural gas consumers, which directly use this fuel in a boiler or a burning system for heating purposes. However, the DHS can also play the role of aggregator not by managing directly the use the natural gas, but steam or hot water supplied to final consumers by the DHS, who is the actual consumer of the fuel. Therefore, and diversely to the traditional one, this aggregator would be simultaneously 
the thermal energy supplier and the manager of the DR resources that may be offered by the supplied customers within its portfolio.

In both cases, the objective is the same: using the ability of customers to modify their usual pattern of consumption (consuming natural gas or any other thermal fluid) as a response to the aggregator.

\subsubsection{Transmitter}

The transmitter is the owner of the gas infrastructures including transmission pipelines in high and medium pressure, regulation and measurement plants (in Italy called REMI -impianto di regolazione e misura-), etc. As the owner of the transmission network, the transmitter has the following responsibilities:

- The development and implementation of the network, making annual forecasts of the increase/decrease in the gas demand in the medium and long term, as well as its demand supply. They are essential for the development of the transmission system for the coming years.

- The evaluation and analysis of the natural gas that is incorporated to the system in terms of composition, heat value and physic-chemical characteristics in order to guarantee that it fits within the applicable standards.

- The analysis of new requests for connection to the transmission network, limiting the access to network when there is insufficient capacity or there are risks to the security of supply.

- The correct maintenance of the transmission infrastructures.

- Guaranteeing of the access to the transmission network to third parties on equality conditions.

For its services, the transmitter receives a fee according the regulation (e.g. fees for the Italian gas transmission system are defined in 514/2013/R/GAS). This fee should be paid by all consumers connected to the transmission network based on their level of pressure, consumption, volume capacity and utilization of additional services (regasification, storage, LNG ships unloading, etc.). Whereas other agents also benefit of the access to the network, such as producer, distributors, retailers, etc., the final payer of this fee is always the end users as any intermediate payment is finally charted to the price of gas.

Given its nature, and considering that from the financial point of view is economically more efficient to maintain a monopolistic structure in this kind of activity than opening it up to competition, the transmission network should function as a natural monopoly with freely accessible to third parties through the payment of a fee. Therefore, a strong regulation would be necessary in order to protect consumers from potential abuse derived from a monopolistic activity. 


\subsubsection{Distributor}

The distributor is the owner of the infrastructures of the gas distribution network, whose main purpose is the conduction of gas from the transmission network to the points of consumption (end users). These infrastructures include medium and low pressure pipelines, regulation and measurement plants, cathodic protection systems (so as to avoid corrosion of pipelines), measurement equipment, and so on.

As the owner of the distribution network, the distributor would have following functions:

- The development and the expansion of the gas distribution network, as well as its interconnections to other networks.

- Carrying out studies and load/supply forecasts to ensure an adequate capacity of the network, able to satisfy the gas demand.

- Performing the necessary control at the specific points of connection to evaluate the odorization level of the distributed gas according to the current regulation.

- Monitoring the gas capacity of the pipelines in order to prevent the congestion of the distribution system.

- Analyzing all new requests for connection to the distribution network and limit access when there is insufficient capacity or there are risks to the security of gas supply.

- Taking care of the maintenance of the gas distribution network and relative infrastructures and preventing and facing the failure of the gas system.

- Guaranteeing the access to third parties to the distribution network on equality conditions.

The distributor can acquire also a new role as manager of the measurements taken at the connection points of end consumers. These measurements are essential for the well-functioning of a smart energy system for different purposes (demand forecast, real time operation, settlement, etc.) so that the distributor would be able to provide with this information to the interested stakeholders in exchange for a fee, under the conditions of confidentiality and data protection required by current legislation. Data ownership should be shared between the customer (as the "data generator") and the distributor (as the "data registrator"). Some kind of agreement related to data ownership should be established between them when a third party may (e.g. an aggregator) may need some of this information for its own purposes. According to the proposed configuration, it is the distributor who should handle the provision of data in exchange for a fee, but without prejudice of confidentiality interests of customers. Moreover, customers should be freely provided with their own data as they already pay a fee for the rental of the metering equipment. Also the Authority would have free access to any kind of data for supervision purposes. 
Similarly to the transmission system, the distribution networks should be managed as a natural monopoly, being strongly regulated to protect consumers from potential abuse. The access to distribution networks should be free to third parties. In return for their services, distributors should receive a fee, which would be paid by all the connected end users.

\subsubsection{Retailer}

The retailer purchases natural gas in large amounts in the wholesale market and sells the gas to end users by retail mechanisms. Unlike the transmission and distribution, the trading of natural gas is not a public service anymore, but rather a liberalized activity. It means that customers would receive an amount of natural gas according to how much they were willing to pay for.

The end user signs a supply contract with the retailer under conditions freely agreed between both parties, and receives the supply of natural gas in exchange for a price negotiated in the contract.

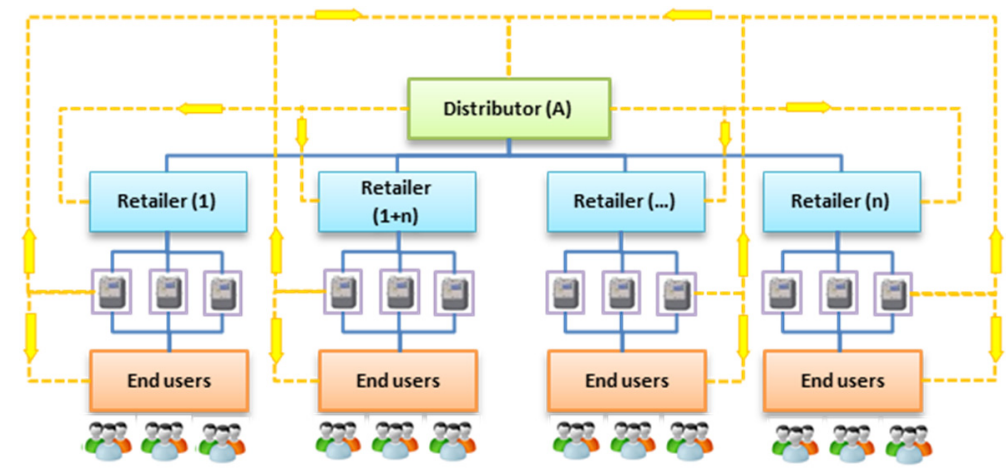

Figure 3.48. Activities of the retailer

Retailers, as the companies that supply and sell gas to the final customers, constitute the first point of contact between the end user and the distributor when a gas supply is contracted. For this reason, the retailers purchase large gas packages in the wholesale market or through bilateral contracts with producers and then supply this energy to final customers through the retail market mechanisms, acting as a bridge between the two markets. It means that retailers must have enough financial capacity as required by their activity, in order to be able to buy large quantities of energy in advance.

To carry out the purchases in the wholesale market, retailers must make forecasts regarding the gas demand. There are always differences between the gas purchased and the gas supplied, whereby retailers must usually pay a higher price to the wholesale market for 
imbalances. To better adjust its consumption in real time with the energy previously acquired in the wholesale market, the retailer may use demand resources provided by its own consumers or by the aggregators. Said that, this aspect is not further explored in this dissertation as the only DR requester here considered will be the GSO. However, this approach constitutes a research line to be taken into account for future developments.

Retailers should have detailed measures of consumption and consumption-generation balance regarding the customers they are supplying. Corresponding measures must be provided by the distributor, who is responsible for the measurements in the distribution network and therefore to determine the volumes of incoming and outgoing gas in the network.

The profit obtained by the retailers from their activity would be based on fee applied to the prices paid by end users for the gas pre-purchased by retailers in the wholesale market, once all the costs incurred by the retailer due to its activity (gas losses, adjustment services, fees for use of the network, payments to operators, etc.) is covered.

\subsubsection{Wholesale traders}

Wholesale traders are agents that incorporate large amounts of natural gas to the system, buying this gas in international markets, to other wholesale energy traders or directly to producers, and resell it to retailers or large end users. Diversely to the case of the power grid, transmitters and distributors, together with network operators (at transmission and distribution levels) also buy natural gas for operation purposes (balancing, refilling of tanks, maintenance of the pressure in the pipelines, etc.)

Wholesale traders can incorporate the gas by two different means:

- In gaseous state, directly imported by the pipelines connecting the considered market to the international suppliers.

- In liquid state as LNG. In this case, the gas must be transported in tankers through the ocean from the production sites to a regasification plant. Hence, the role of regasification plant manager arises, although it may be also played by the wholesale trader that incorporates the LNG into the market as a complementary activity.

\subsubsection{Transmission system operator}

The operator of the transmission system is an entity that carries out the necessary activities to guarantee the security and continuity of the gas supply throughout the national gas system, as well as the correct coordination between the production system and the transmission network, ensuring that the gas produced or imported is transmitted to the distribution networks with the quality conditions required by the current regulation.

The transmission system operator must be a neutral agent in the gas business whose mission is to manage the gas network and, therefore, neither buying nor selling energy. 
In exchange for this service, the network operator would receive a fee payed by the consumers based on their level of pressure, gas consumption and capacity of the transmission network.

The functions of the transmission system operator would be the following:

- Ensuring the safety and continuity of the gas supply under the current regulation

- Ensuring the proper value of pressure in all the pipelines of the transmission network, within the margins of variation allowed by current regulation.

- Coordinating the different distribution network operators (see section 3.5.1.10) for the correct functioning of the whole gas system.

- Managing international exchanges with foreign countries and coordinating the necessary activities to guarantee these exchanges with their respective operators.

- Guaranteeing the coordination among the different agents of the gas system so as to ensure service settlement in case of interruptions.

In order to perform this functions, the transmission system operator would manage the required complementary actions for the control of the pressure and the quantity of gas flowing into the pipelines, which may be provided either by producers or by consumers, either directly or through aggregators.

In addition, the network operator would manage the required operation services for the solution of technical constraints and for the balancing of the level of gas in the pipelines and other facilities.

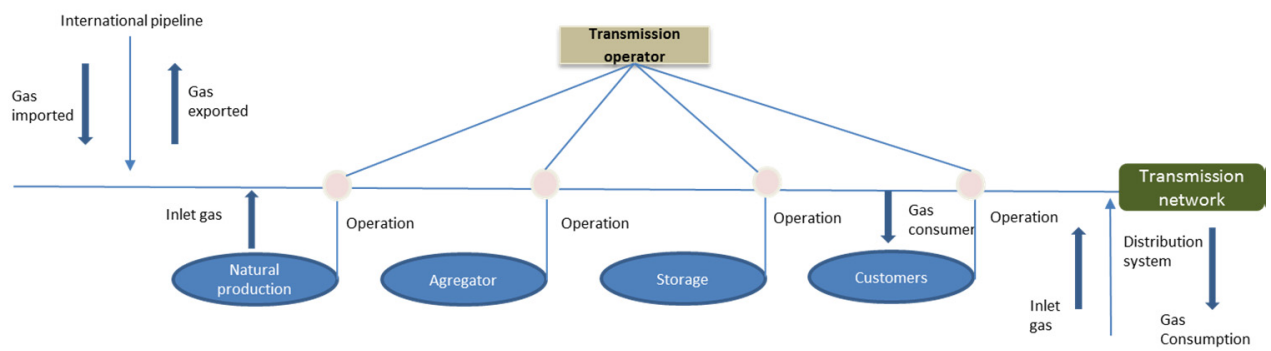

Figure 3.49. Activities of the transmission system operator

\subsubsection{Distribution network operators}

Similarly to the transmission system operator, the distribution network operators manage the distribution grid of the area under their responsibility in order to guarantee the gas 
supply to the final consumers connected to the distribution pipelines under the conditions of security and quality of supply established by the current regulation.

As mentioned before, operators of distribution networks do not buy or sell gas, since this activity will be developed by other agents (retailers and wholesalers), who make use of the distribution network so as to carry the gas from the points where it enters the grid to the points where gas is supplied to the end users.

Their services, like those of the owners of the network, would be compensated by all the consumers connected to the distribution network by means of a fee, calculated according to pressure, consumption and capacity of the network they are connected.

Unlike the transmission network, where it has been considered a single system operator, the existence of different distribution network operators is here considered, depending on the number of distribution areas taking part in the whole system for its best management.

The functions given to the distribution network operators are:

- Ensuring the safety and continuity of the gas supply that flows from the points of connection through the transmission network to the end users.

- Ensuring the proper value of pressure in all the nodes of the distribution network, within the margins of variation allowed in the current legislation.

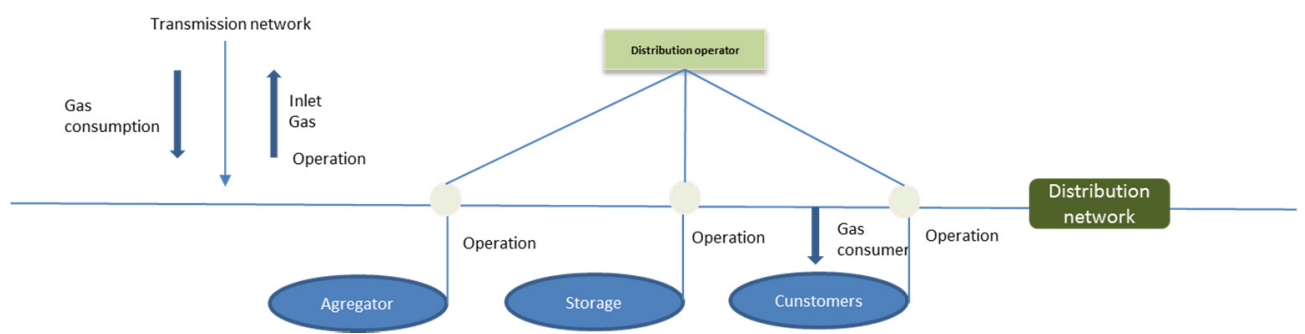

Figure 3.50. Activities of the distribution network operator

\subsubsection{Wholesale market operator}

The wholesale market operator has the purpose to provide the necessary mechanisms for buying and selling gas in a short term (typically one day).

According to the market operator's mechanisms, the different agents can purchase and sell the gas according their bilateral supply contracts and eventually take advantage of the instantaneous adjustment of the consumption according to the available gas capacity of the system. 
In the proposed market model, the daily capacity available for gas production and storage (excluded the technical capacity which may be reserved for the operation of the network) would be determined through different mechanisms managed by wholesale transactions. These wholesale transactions may be performed according to one of the following mechanisms:

- Trading on the gas stock exchange managed by the wholesale market operator, through daily or intraday markets through an electronic platform.

- Signing bilateral contracts (long-term or short-term), based on negotiations between two private parties that take place outside the gas stock exchange.

Through the gas stock exchange which may manage the wholesale market operator, gas sellers could daily communicate the volume capacity and the price of gas flowing they are willing to provide. In the first instance, the market operator could determine the quantities of gas required in the market considering both the bids and the offers for gas purchase and sale.

According to the market results, the gas transmission system operator would determine the gas quantities required, once the market result has been adapted to the physical conditions of the network.

In this configuration, the main functions of wholesale market operator would be the following:

- The collection and approval of the offers for the gas purchase and gas sale, as well as the determination of the gas price in the short-term market.

- Communication with the gas transmission system operator about the data related to the evaluation of the offers in the short-term market or in the other possible markets and communication of the possible market changes in order to adapt the results of the market to the real situation of the gas network.

- The settlement and the communication of the payments and charges due to the final price of the gas resulting from these mechanisms.

- The requirement to market agents to prove their correct performance with compliance with the Market Operating Rules, which should be established to regulate the proper functioning of the market.

- To be responsible and take care of the economic management of the wholesale gas market.

Another way to organize this adjustment for the gas market could be through short-term bilateral contracts. The contracts would be freely negotiated between buyers and sellers, or through an exchange platform where the operator should publish indexes related to the types of products and average prices that are traded. In the latter case, it would be 
also necessary to create short-term mechanism (hours before the dispatching) with the objective of obtaining resources to balance production and distribution.

\subsection{The district heating operator as Demand Response aggregator}

A district heating system is based on the central production of steam, hot water or any other thermal supply that is later supplied to the final consumers of thermal energy, avoiding such consumers to have to perform the energetic transformation in their own facilities.

The working scheme of a district heating system is relatively simple, as highlighted in Figure 3.51. The thermal fluid (steam, hot water and so on) is produced by a thermal plant, usually located at certain distance from the consumers (e.g. for urban supply, the district heating plant is usually outside of the city). Then, the thermal fluid is sent through underground pipelines from the thermal plant to each individual buildings connected to the district heating network. There, thanks to a heat exchanger, hot water produced at the secondary side of the exchanger is distributed to the facilities using the thermal energy. For example, the hot water can be used to feed radiators or to produce sanitary hot water [117]. When the district heating is coupled to a cogeneration plant, electricity can be also produced, which increases the efficiency of the whole system.

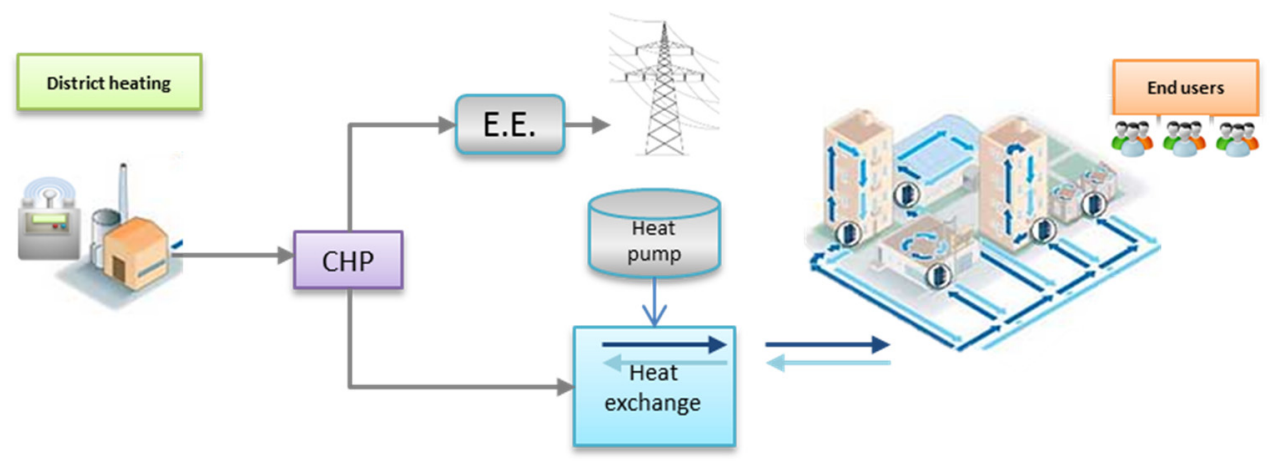

Figure 3.51. District heating scheme

The district heating thermal plant can be fueled by different kinds of fuels such as natural gas/fossil fuels but also biomass [118] or heat resulting from the incineration of solid urban waste. In some countries such as Russia, Ukraine, Sweden or Switzerland, where the head needs are extremely high, the district heating can be fueled by nuclear power [119], [120]. On the other hand, renwable energy sources are more and more used as primary energy sources for the district heating production, such as geothermal and solar 
thermal energy (solar district heating ${ }^{50}$ ). Another source of primary energy "at no cost" is the use of waste heat from industrial processes ${ }^{51}$. The work presented in this dissertation put emphasis in valorizing the role that district heating system managers could play as aggregators of DR resources. Indeed, district heating plants using natural gas as primary fuel may be used so as to provide DR services to the natural gas system if managers reduce or increase their gas consumption when requested by the gas system operator (GSO). Therefore, this flexibility would be finally given by customers supplied not by gas, but by the thermal fluid produced by the district heating plant. This is actually a very interesting approach which constitutes a significant contribution of this dissertation as it may entail a new business opportunity for this kind of companies, at the same time that they help in the operation of the natural gas system under a smartgrid configuration.

\subsubsection{District heating system in the United States of America}

North America has more than 700 District energy systems, located in the places indicated in Figure 3.52 and held the dominant share of the global district cooling (DC) market in 2014 [121]. The Holly Steam Combination Company was the first steam heating enterprise to commercially distribute district heating from a central steam heating system [122]. Three types of district heating systems have been developed in the U.S. [123]:

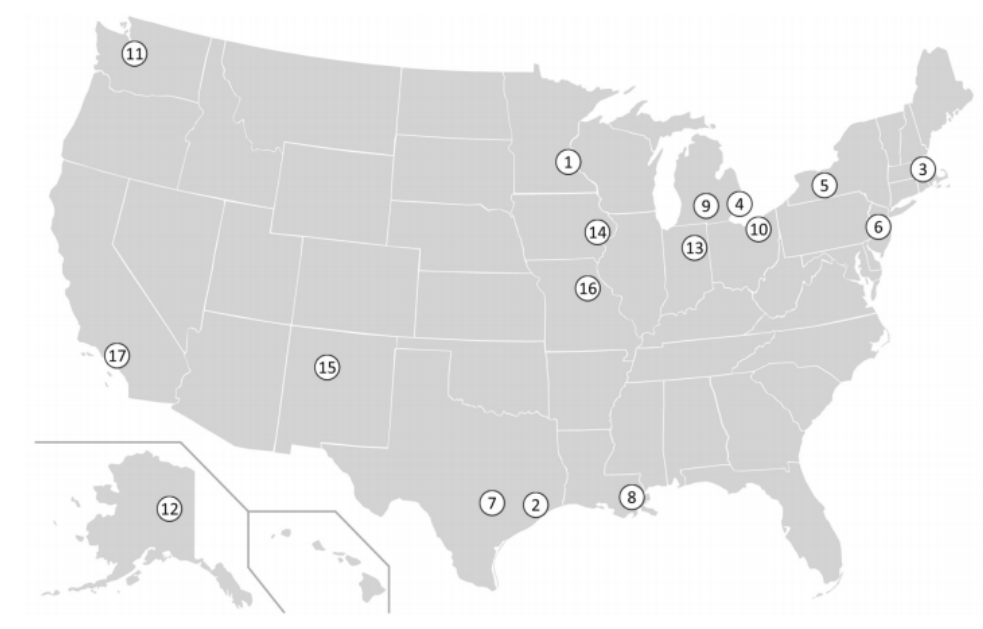

Figure 3.52. The district heating in USA (Source: Environmental and Energy Study Institute - 'What is District Energy?' September 2011)

\footnotetext{
${ }^{50} \mathrm{http} / / /$ solar-district-heating.eu

${ }^{51} \mathrm{http}: / / \mathrm{www} . e c o d a l l e c i t t a . i t / n o t i z i e / 377390 /$ teleriscaldamento-come-si-regola-la-temperatura-dei-termosifoni
} 
- Steam heating systems owned and operated by local electric utilities and developed in the late nineteenth century

- Non-profit systems (usually municipally incorporated or owned) which serves many urban users.

- Finally, and significantly grown in the last two decades, district heating systems for institutional users such as university campuses, military bases, etc. [124].

Some of the most significant DHC facilities, according to the numbered locations indicated in Figure 3.52, are shown in Table 3.9:

Table 3.9. Most significant district heating facilities in the U.S.

\begin{tabular}{|c|c|c|}
\hline Location & $\begin{array}{l}\text { DHC } \\
\text { facilities }\end{array}$ & Characteristics \\
\hline $\begin{array}{l}\text { 1. St. Paul, } \\
\text { MN }\end{array}$ & $\begin{array}{l}\text { Central Busi- } \\
\text { ness District }\end{array}$ & $\begin{array}{l}\text { It provides heating to more than } 80 \% \text { of St. } \\
\text { Paul's central business district and cooling to } \\
\text { more than } 60 \% \text { of the central business district. }\end{array}$ \\
\hline $\begin{array}{l}\text { 2. Houston, } \\
\text { TX }\end{array}$ & $\begin{array}{l}\text { Texas Medical } \\
\text { Center }\end{array}$ & $\begin{array}{l}\text { The largest campus district energy system in the } \\
\text { United States that serves the largest medical } \\
\text { complex with } 6800 \text { patients }\end{array}$ \\
\hline $\begin{array}{l}\text { 3. Boston, } \\
\text { MA }\end{array}$ & $\begin{array}{l}\text { Downtown } \\
\text { Boston }\end{array}$ & $\begin{array}{l}\text { DH that uses the steam from a Cambridge power } \\
\text { plant to downtown Boston }\end{array}$ \\
\hline $\begin{array}{l}\text { 4. Detroit, } \\
\text { MI }\end{array}$ & $\begin{array}{l}\text { Downtown } \\
\text { Detroit }\end{array}$ & $\begin{array}{l}\text { The CHP facility that can generate up to } 68 \text { meg- } \\
\text { awatts of electricity and heat over } 140 \text { businesses } \\
\text { from-waste }(3,300 \text { tons of municipal solid waste } \\
\text { per day) }\end{array}$ \\
\hline $\begin{array}{l}\text { 5. Ithaca, } \\
\text { NY }\end{array}$ & $\begin{array}{l}\text { Cornell } \\
\text { University }\end{array}$ & $\begin{array}{l}\text { In December } 2009 \text {, Cornell University upgraded } \\
\text { its central heating plant with a cogeneration sys- } \\
\text { tem that cut its greenhouse gas emissions by over } \\
20 \% \text {. }\end{array}$ \\
\hline $\begin{array}{l}\text { 6. Princeton, } \\
\text { NJ }\end{array}$ & $\begin{array}{l}\text { Princeton } \\
\text { University }\end{array}$ & $\begin{array}{l}\text { A district energy to provide electricity, steam, } \\
\text { and chilled water to power, heat, and cool the } \\
150+\text { buildings on the Princeton University cam- } \\
\text { pus. Princeton's plant reaches about } 80 \% \text { effi- } \\
\text { ciency. The plant can switch from natural gas to } \\
\text { biodiesel when natural gas demand and prices } \\
\text { are high. }\end{array}$ \\
\hline $\begin{array}{l}\text { 7. Austin, } \\
\text { TX }\end{array}$ & $\begin{array}{l}\text { University } \\
\text { of Texas }\end{array}$ & $\begin{array}{l}\text { UT Austin uses CHP and district energy to pro- } \\
\text { vide } 100 \text { percent of power, heating, and cooling } \\
\text { for the } 200 \text { buildings on its campus. The campus } \\
\text { has not been a load to the Texas electrical grid } \\
\text { since } 1929 \text {. }\end{array}$ \\
\hline
\end{tabular}




\begin{tabular}{|c|c|c|}
\hline Location & $\begin{array}{l}\text { DHC } \\
\text { facilities }\end{array}$ & Characteristics \\
\hline $\begin{array}{l}\text { 8. New Orleans, } \\
\text { LA }\end{array}$ & $\begin{array}{l}\text { New Orleans } \\
\text { Medical Cen- } \\
\text { ter and Down- } \\
\text { town }\end{array}$ & $\begin{array}{l}\text { At full build-out, the NORMC District Energy } \\
\text { Center will have the capability to produce } 33,000 \\
\text { tons of chilled water and provide air conditioning } \\
\text { to over } 12 \text { million square feet of commercial } \\
\text { property in the NORMC district and downtown } \\
\text { New Orleans. }\end{array}$ \\
\hline $\begin{array}{l}\text { 9. Battle Creek, } \\
\text { MI }\end{array}$ & $\begin{array}{l}\text { Battle Creek } \\
\text { Veteran's } \\
\text { Affairs } \\
\text { Medical Cen- } \\
\text { ter }\end{array}$ & $\begin{array}{l}\text { Nexterra Systems Corp. announced in September } \\
2011 \text { that it signed a } \$ 6.9 \text { million contract to de- } \\
\text { liver a biomass gasification system that will pro- } \\
\text { vide heat and power for the U.S. Department of } \\
\text { Veterans Affairs Medical Center (VAMC) in } \\
\text { Battle Creek, Michigan. }\end{array}$ \\
\hline $\begin{array}{l}\text { 10. Cleveland, } \\
\text { OH }\end{array}$ & $\begin{array}{l}\text { Downtown } \\
\text { Cleveland }\end{array}$ & $\begin{array}{l}\text { Cleveland Thermal's district energy network in- } \\
\text { cludes two plants on opposite ends of Downtown } \\
\text { Cleveland, which provide } 30 \text { percent of the heat- } \\
\text { ing and cooling needs of the city's business dis- } \\
\text { trict. }\end{array}$ \\
\hline $\begin{array}{l}\text { 11. Seattle, } \\
\text { WA }\end{array}$ & $\begin{array}{l}\text { Central } \\
\text { Business } \\
\text { District - }\end{array}$ & $\begin{array}{l}\text { Seattle Steam, a privately-owned utility, pro- } \\
\text { vides district heat to approximately } 200 \text { build- } \\
\text { ings in Seattle's Central Business District and } \\
\text { First Hill neighborhoods. }\end{array}$ \\
\hline $\begin{array}{l}\text { 12. Fairbanks, } \\
\text { AK }\end{array}$ & $\begin{array}{l}\text { University } \\
\text { of Alaska } \\
\text { Fairbanks }\end{array}$ & $\begin{array}{l}\text { The central utilities system at the University of } \\
\text { Alaska Fairbanks provides steam, electricity, and } \\
\text { chilled water to } 7,000 \text { students and over } 3 \text { mil- } \\
\text { lion square feet of facilities. }\end{array}$ \\
\hline $\begin{array}{l}\text { 13. Muncie, } \\
\text { IN }\end{array}$ & $\begin{array}{l}\text { Ball State } \\
\text { University }\end{array}$ & $\begin{array}{l}\text { Ball State University is in the process of building } \\
\text { the nation's largest closed-loop geothermal en- } \\
\text { ergy system to replace its four aging coal-fired } \\
\text { boilers. }\end{array}$ \\
\hline $\begin{array}{l}\text { 14. Iowa City, } \\
\text { IA }\end{array}$ & $\begin{array}{l}\text { University } \\
\text { of Iowa }\end{array}$ & $\begin{array}{l}\text { The University of Iowa fuels its district energy } \\
\text { system with oat hulls (a by-product of cereal- } \\
\text { making from the neighboring Quaker Oat facil- } \\
\text { ity) that are co-fired with coal and natural gas }\end{array}$ \\
\hline $\begin{array}{l}\text { 15. Albuquerque, } \\
\text { NM }\end{array}$ & $\begin{array}{l}\text { University of } \\
\text { New Mexico }\end{array}$ & $\begin{array}{l}\text { The University of New Mexico uses CHP and } \\
\text { district energy to provide power, heating, and } \\
\text { cooling for its } 8 \text { million square feet of facilities. }\end{array}$ \\
\hline $\begin{array}{l}\text { 16. Columbia, } \\
\text { MO }\end{array}$ & $\begin{array}{l}\text { University } \\
\text { of Missouri }\end{array}$ & $\begin{array}{l}\text { In mid-2012, the University of Missouri com- } \\
\text { pleted a large biomass district energy system } \\
\text { project that will use } 100,000 \text { tons of regionally } \\
\text { supplied biomass per year. }\end{array}$ \\
\hline $\begin{array}{l}\text { 17. Los Angeles, } \\
\text { CA }\end{array}$ & $\begin{array}{l}\text { University of } \\
\text { California LA }\end{array}$ & $\begin{array}{l}\text { The UCLA cogeneration plant is fueled by natu- } \\
\text { ral gas and seven percent landfill gas. }\end{array}$ \\
\hline
\end{tabular}




\subsubsection{District heating systems in Europe}

Among the European countries, Denmark has a remarkable experience with district heating, since the first Danish district heating plant was put into regular operation and inaugurated in Copenhagen in 1903. Between the 1920s and 1930s, regular district heating substations appeared in connection with the development of large adjoining housing areas. Already in the beginning of the 1960s, Denmark had more than 50 years of experience using district heating. Today approximately the $65 \%$ of total energy used for heating in this country comes from a district heating plant [125].

With the exception of Iceland, where the $95 \%$ of homes receive district heating supply produced by geothermal energy, most of district heating facilities in Europe operate under a cogeneration (CHP) configuration, so that heat and electricity are jointly produced. Thus, the prevalence of the district heating is produced mainly through cogeneration. CHP is a high energy system that allows the combined production of electricity and heat [126]. In total, there are over 5,000 district heating networks across Europe and, nowadays, this technology covers $10 \%$ of the energy market. In addition to the aforementioned countries, Netherlands and Finland followed by Poland, Czech Republic, Finland and Romania use district heating so as to cover more than $60 \%$ of their thermal needs.

The Dutch district heating network has 30 large scale grids, supplying the heat produced by such companies as Eneco, Essent or Nuon to approximately 227,000 consumers. In addition, these suppliers deliver heat to around 6,900 small scale grids owned and operated by housing corporations, supplying to approximately 336,000 homes [127] .

The main type of fuel used for heat production in district heating plants is natural gas and coal, with a small fraction from renewables. However, small scale grids use a wider variety of energy sources, using cogeneration and conventional boilers, as well as boilers that use solar thermal energy.

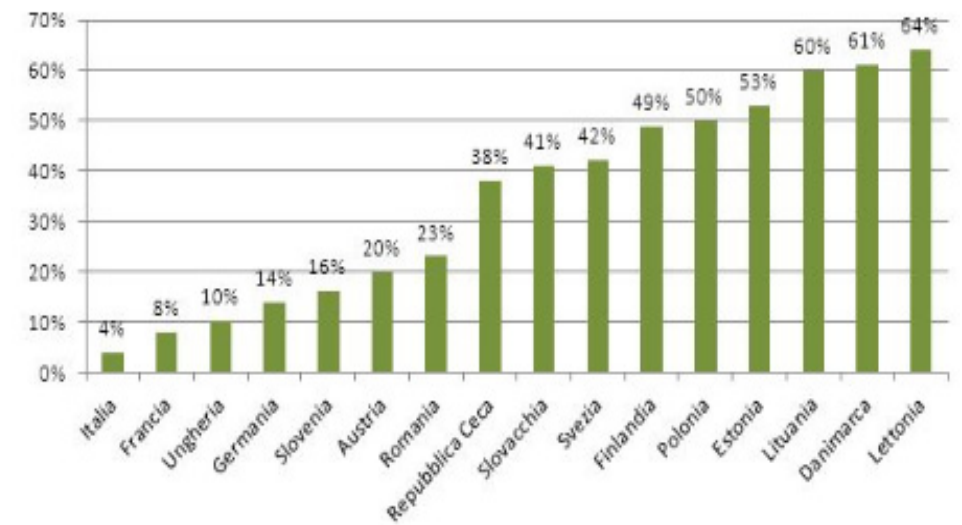

Figure 3.53. Rate of thermal energy produced by district heating in Europe, per country (Source: Potenziale del teleriscaldamento in Italia, FIPER 2013) 
The Technical Research Centre of Finland VTT states that district heating is the most popular form of heating in Finland, with and estimated coverage between 50\% and 75\% of the heating demand in new buildings. The current demand supplied by district heating is in $33 \mathrm{TWh}$ per year, mainly produced by cogeneration (74\% of total) [128]. At present, the thermal demand covered by district heating is still growing, being forecasted a total supply of 42 TWh by 2020 [129].

\subsubsection{District heating systems in Italy}

The Italian district heating network took off in 1972 and from this year, the system has constantly grown. This trend has been even more intense in the last years, from 150 million $\mathrm{m}^{3}$ of steam supplied in 2010 to almost 200 million $\mathrm{m}^{3}$ in 2013 [130]. This growing trend has been mainly motivated to the higher utilization of natural gas as energy source in the last decade, being at this moment the most significant energy vector of the country.

In 2015 , the $73 \%$ of energy consumed by the residential sector was used for space heating, about the $11 \%$ for electric appliances and lighting, almost $8 \%$ for water heating, and a small part for cooking $(6 \%)$ and air cooling $(2 \%)$. The main primary energy source used for space heating is gas (53\%), followed by wood (30\%), oil (9\%) and electricity $(5 \%)$. Natural gas was also the main energy source for water heating $(63 \%)$ while more than a half of the total amount of energy consumed for cooking came also from gas [131].

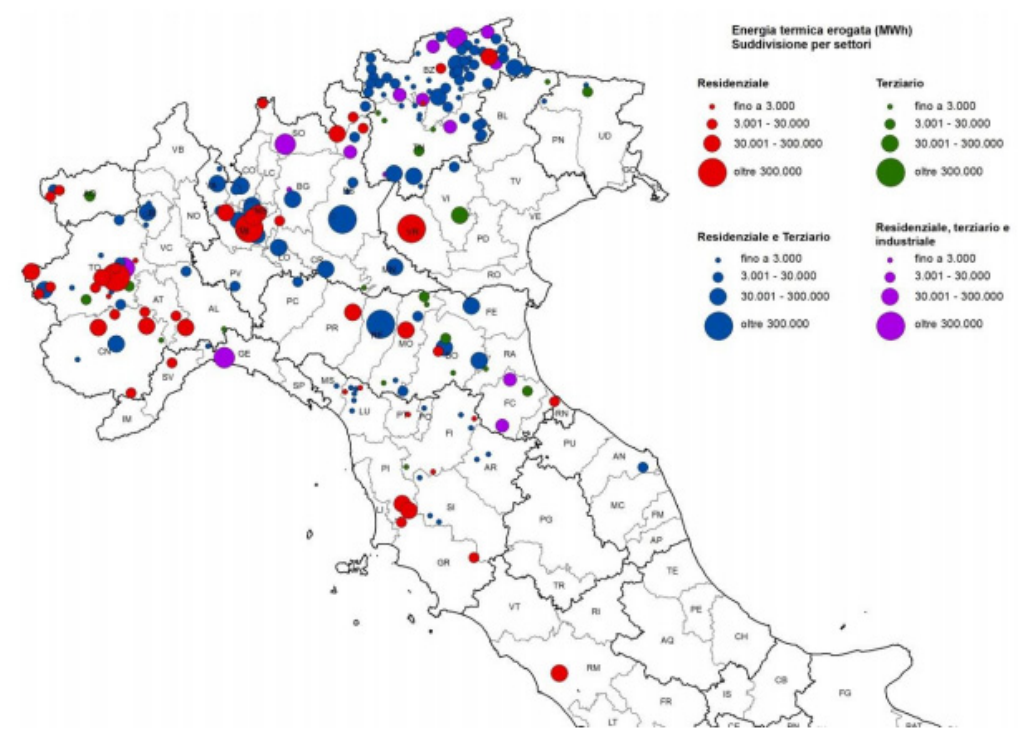

Figure 3.54. Geographical distribution of the thermal energy supplied by district heating systems in Italy (Source: GSE, 2015) 
In Italy, the $95 \%$ of the energy supplied through the district heating networks is used for space heating and for the production of domestic hot water (DHW), while only $5 \%$ is supplied for production processes in the industrial sector. The use of the thermal energy for the residential sector is the highest one, with about $67 \%$ of total [132].

The $63 \%$ of the Italian district heating networks are located in the regions of Piedmont (especially around Turin), Lombardy (metropolitan area of Milan), Trentino and Alto Adige. Regarding the Central Italy, district heating networks are just present in the city of Osimo (Ancona) and in a district near Rome. In any case, the most significant presence of district heating systems is in Tuscany, where heat is produced with geothermal energy [133].

In the town of Osimo, the company Astea S.p.A. operates the district heating network. This network is powered by superheated hot water, kept hot by a cogeneration power plant and boilers fueled by natural gas. The supply contracts carried on for district heating services are of two types: residential and other use. In 2012, the number of customers supplied from the district heating network was of 1,238 , with a total thermal energy supplied of $14,487 \mathrm{MWh}^{52}$.

The largest company in district heating in Italy the Iren Group, headquartered in Turin, that manages 800 kilometers of transmission and distribution networks that supplies a population of 700,000 inhabitants and heats a volume of about 80 million $\mathrm{m}^{3}$ in the following towns [134]:

- In Turin (Piedmont), the transmission and heat distribution networks operated by AES Torino extends for about $500 \mathrm{~km}$ and serves a volume of 54 million $\mathrm{m}^{3}$ of hot water, corresponding to 550,000 inhabitants. With the implementation of a cogeneration plant at Torino North, an additional amount of 15 million $\mathrm{m}^{3}$ of water can be heated. Today, Turin has established its primacy as the first Italian city served by district heating

- In the region of Emilia-Romagna, the district heating network at the town of Reggio Emilia extends for $215 \mathrm{~km}$ and serves a volume of almost 13 million $\mathrm{m}^{3}$ of hot water. In Parma, the network extends for 81 kilometers and provides district heating a volume of 4.8 million cubic meters. The third district heating network of the region if located in Piacenza, with a length of 18 kilometers and a served volume of water equals to 1 million cubic meters.

- Finally in Genoa, capital of the region of Liguria, the district heating network extends for nearly 10 kilometers and serves a volume of 3.5 million $\mathrm{m}^{3}$.

\footnotetext{
${ }^{52} \mathrm{http}: / /$ www.asteaspa.it/servizi-2/servizi-ai-clienti-consumatori/teleriscaldamento/
} 


\subsubsection{Cost-benefit assessment of district heating systems}

District heating systems provide different benefits both to customers and the environment. The relative simple equipment of the district heating substation minimizes the maintenance costs and distributing directly the hot water all year in a continuous way makes not required to customers the installation of heating systems. Therefore, such equipment as boilers, burners, fuel tanks or chimneys are not needed anymore, which implies the recovery of spaces inside the buildings.

As a consequence, the elimination of noise and pollution linked to boilers and burners, located closely to houses, provides the citizens a higher comfort and life quality. Additionally, the elimination of local thermal plant reduces the risks of explosion and poisoning, as well as the reduction in $\mathrm{CO}_{2}$ emissions with the subsequent environmental benefit.

Modern district heating systems may have linked to different devices for time and temperature control, installed inside the end users facilities. This characteristic facilitates enabling final customers for the provision of DR services centrally managed by the district heating system operator.

A cost-benefits evaluation is necessary before taking the decision to install a district heating network, as despite the many benefits entailed, it may not be appropriate in some cases. Several factors determine the feasibility of a district heating project, such as the density of population of the considered area or the presence of aggregated thermal loads. Actually despite its benefits, district energy is not an appropriate investment for every project [135]. The inadequate customer density or the lack of aggregated thermal loads affect negatively the feasibility of the project.

One of the main economic disadvantages of district heating systems is their longer payback (15 years) compared to self-generated heating and cooling plants. District energy systems require substantial investments in the initial stages of a project, not only for the building of the production plant and the distribution network, but also for the business development, design, and contract negotiation. In addition, there is a lack of knowledge on building owners, who do not have a real awareness about the actual costs of heating and cooling their buildings because of the high numbers of the factors that affect this calculation [124], such as:

- The energy required for chilled-water and condenser-water pumps or coolingtower energy

- Make-up water and water-treatment costs

- Operations staff cost

- Cooling equipment cost

- The cost and opportunity-cost value of the occupied space

- The cost of maintaining, cleaning, repairing, and replacing equipment throughout the life of the plant 
- Utility costs and salaries over the life of the equipment

Finally, it is important to keep in mind that in most of countries there is not a welldefined energy policy that regulates the district heating system. The connection to district heating system often oblige the users to sign binding contracts with operators that manage the network as a monopoly with non-regulated prices that sometimes could result not economic convenient for the end users.

However, district heating systems have a highly valuable characteristic that is highlighted in this dissertation: they have the ability to centrally manage the fuel consumption (in particular, natural gas) based on the flexibility that end users may apply on their thermal consumptions. Therefore, the managers of this kind of facility would acquire the role of aggregator of thermal loads that, properly used, may entail significant benefits for customers and the whole system in terms of operability and efficiency.

\subsection{Conclusions of the chapter}

The main characteristics of the traditional structure of natural gas systems around the world are presented in this chapter, paying special attention to the cases of Europe and the United States of America. Moreover, the natural gas system of Italy is presented in detail due to the special significance it has for the scope of this dissertation.

In the second part of the chapter, the re-configuration of natural gas systems according to the smartgrid principles is proposed as one of the most significant contributions of the dissertation. Thus, the activities related to the functioning of the natural gas system according to a smart grid architecture are identified and analyzed. Within those activities, the role of the operator of district heating network as aggregator and provider of DR services base on the flexibility of customers of its portfolio arises as one of the main novel approaches of the dissertation. This interesting approach may entail a new business opportunity for this kind of companies, whose contribution may help for a more efficient operation of the natural gas system under a smartgrid configuration.

Traditional structures and facilities of the natural gas system has been studied and analyzed, and the application of smart energy systems to the natural gas network has been evaluated. The re-configuration of the gas system according to the smart system concept requires the utilization of suited equipment for metering and management of the grid and the different elements connected to it. Therefore, the existing technologies related to smart metering, communication and control will be analyzed in the next chapter, as well as the most appropriate equipment for DR applications. 



\section{Chapter 4 Metering and commu- nication technology: smart gas meters}

\subsection{Chapter overview}

In the transition from traditional energy systems to the smart grid configuration, as discussed in the previous chapter, it is essential a robust metering and communication architecture. Detailed information about how the natural gas flows through the grid and how it is consumed in end user facilities is the key for the adequate operation of the smart grid, where the customer has to take a principal role. Additionally, this information must flow fast, allowing the communication between the different system agents and providing to the system operator the possibility to use the ability of customer so as to be used for operation purposes.

This chapter is focused on the technology of smart gas meters. Such devices are being massively installed in some European countries to facilitate the data registration for billing purposes. However, the potential of these devices is much higher as they can be used for enabling customers to provide DR services by using the flexibility they may have. The evolution of smart gas meters is here discussed, putting special emphasis in such characteristics that this kind of device should include for DR purposes. Moreover, a complete review about the degree of installation of smart gas meters in different countries in Europe and the United States I also analyzed. 


\subsection{Smart metering system and smart devices}

In order to deploy the proposed model by applying DR management for the gas smart metering system it is necessary to identify the fundamental devices that have to be implemented or that, for other purposes, may be already available in the market. The diffusion and implementation of smart devices is fundamental so as to give support to smart consumers, for an aware energy consumption, as well as to aggregators, for the aggregation and provision of DR resources.

As discussed in section 3.4.2, some EU countries have already started the replacement of the traditional gas meters with smart gas devices. In this section, a detailed description of smart meter devices for the gas sector which are already available in the market is provided, highlighting their peculiarities and technical characteristics that need to be implemented to make them suitable for DR applications.

For the enforcement and deployment of gas DR, the smart grid infrastructure should be equipped with the following devices:

- Smart measurement meters (gas smart meter and heat smart meters). Gas smart meters have to be available at end users' facilities in order to register the gas consumption of customers, as well as in the high pressure (HP) and medium pressure (MP) cabins. In the case of district heating users, heating smart meters would be required.

- The Central Acquisition System (SAC) with a high degree of interoperability between different energy services (water, gas, electricity and heat). The SAC is a system able to remotely receive and transmit information registered by the smart meter, as well as to upgrade their firmware.

- The Gas Demand Response Software (GDRSW), which helps in the management of the gas demand, taking into account such technical factors as pipelines capacity, balancing prices or climatic factors. The GDRSW should be also able to make forecast on the probability of interruptions or other events on the natural gas system.

- The Remote Gas Storage Database (GSD), which collects the key data for the proper management of the gas system and stores information for a long period of time (e.g. 10 years). The GSD has to collect the maps of the gas pipelines, the daily balancing data, the daily volume of consumed gas and all the sensitivity parameters that may be of interest for the management of the system, providing with algorithms for monitoring purposes.

- Smart sensors, which would provide to the aggregator the real consumption of gas per customer, allowing the remote control of gas consuming devices.

- End users interface, such as the In-Home display (IHD) for residential applications. It consists of an informative display that communicates customers with 
smart meters, making more aware consumers of their energy consumption on a real-time base. Considering the utilization of interfaces for DR applications, they would mean the connection between the aggregator and the consumer. It represents a low-cost and reliable way for the aggregator to send messages and alerts to customers on upcoming demand response events and, at the same time, to receive confirmation and feedback from the customer side.

In addition to the elements mentioned in the previous paragraphs, a reliable communication infrastructure with interoperable communication standard and interchangeable communication protocol for the smart devices is also necessary.

\subsection{Gas metering: in the beginning}

The gas meter is an instrument that measures the total volume of gas flowing through the pipelines on which it is installed. Gas meters are universally employed and they can be installed at every domestic, commercial or industrial end user.

Gas meters register the "geometric" volume of the gas at the working temperature and pressure. Then, the measured volume (so-called "un-adjusted") is corrected to the standard conditions of temperature and pressure $\left(15^{\circ} \mathrm{C}\right.$ and 1 bar). The invention of the gas meter is attributed to the British engineer Samuel Clegg in the 1816 [136].
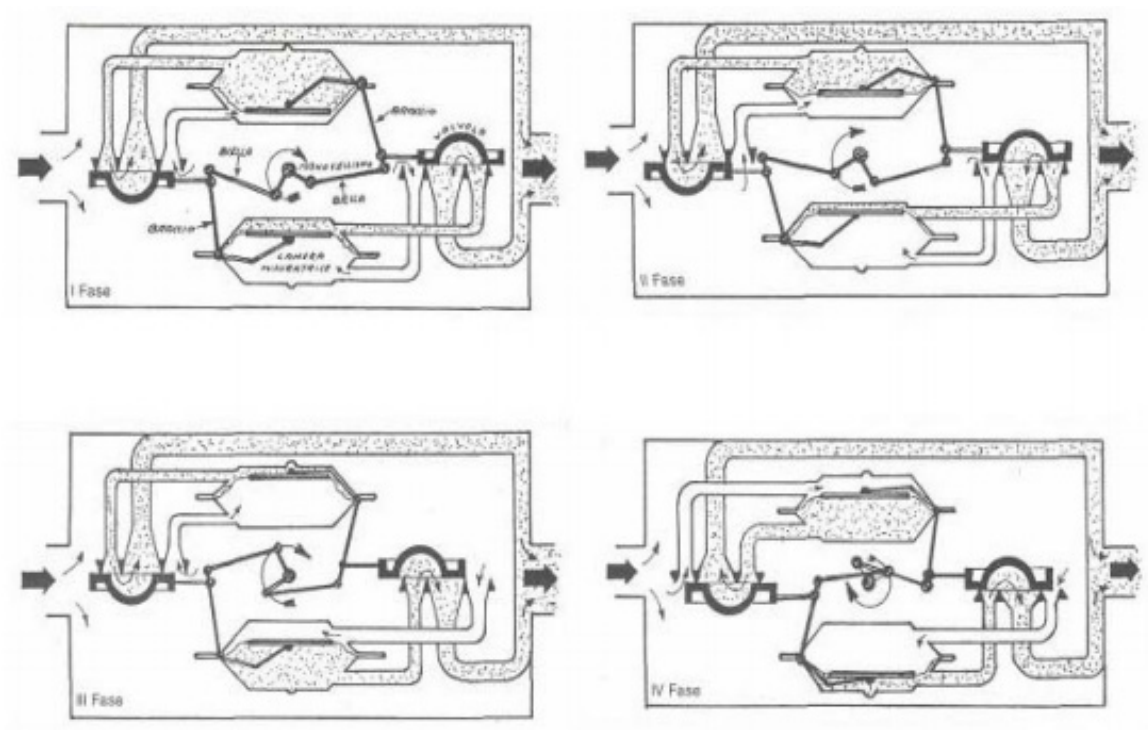

Figure 4.1. Operation of a diaphragm mete gas (Source: http://incoedile.altervista.org) 
Until 1992, gas meters were based on a diaphragm with membranes made of animal skin, usually lamb for domestic meters and leather for industrial devices (Figure 4.1). A diaphragm meter, also known as membrane meter, is a measurement device equipped with a membrane that separates two containers. The volume of gas (measurement volume) flows between these two containers, which constitute the measurement chamber. The measurement chamber is separated by the diaphragm, so that the two derived sub-chambers are alternatively filled and emptied. The movement of the diaphragm is transferred ten to a crank shaft via a linkage. The crank shaft drives two gates, which control the gas flow. Therefore, the gas flow is alternatingly routed through a bellows (tipping bucket). The rotary movement of the gear is transferred to a counter (totalizer) by means of a magnetic coupling.

When that kind of meter was used, humidifying the natural gas injected into the distribution networks was particularly important in order to minimize the oil evaporation. Therefore, impregnated animal's skins were used as membrane of the meter chamber [137]. Otherwise, the walls of the meter chamber would get dried out over the years, changing their physical and geometrical characteristics and, in severe cases, reaching even the breakage.

After 1992, meter chambers were equipped with synthetic membrane, primarily consisting of cotton or nylon with vulcanized rubbers (nitrile rubber, neoprene, Viton, etc.) [138] . Similarly to the animal skins, the synthetic membranes also have some disadvantages, such as they may be chemically destroyed by hydrocarbons. Additionally, they have a low mechanical strength at temperatures below $-5^{\circ} \mathrm{C}$. Besides, the use of synthetic material contributed to the reduction of deviations of the measured volume for diaphragm meters (Maximum Permissible Error - MPE), providing a higher compliance with the standard MPE (Table 4.1) and pressure drop (Table 4.2) defined by the EU regulation [138].
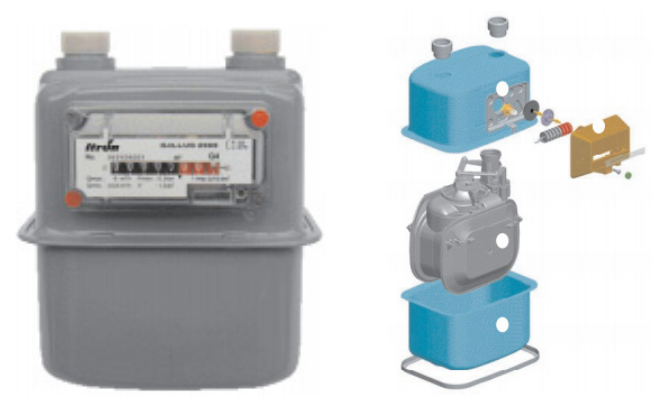

Figure 4.2. Traditional diaphragm gas meter (Source: http://www.autometers.co.uk) 
Table 4.1. Maximum permissible Error - MPE

\begin{tabular}{ccc}
\hline $\mathbf{Q}\left(\mathbf{N m}^{\mathbf{3}} / \mathbf{h}\right)$ & Initial & On working \\
\hline $\mathrm{Q}_{\min } \leq \mathrm{Q}<0,1 \cdot \mathrm{Q}_{\max }$ & $\pm 3 \%$ & From $-6 \%$ to $+3 \%$ \\
$0,1 \cdot \mathrm{Q}_{\max } \leq \mathrm{Q} \leq \mathrm{Q}_{\max }$ & $\pm 1,5 \%$ & $\pm 3 \%$ \\
\hline & Source: European standard EN 1359
\end{tabular}

The flow rate of a gas meter, expressed in $\mathrm{Nm}^{3} / \mathrm{h}$, represents the range within the device has to be able to work in a continuous regime, fulfilling the metrological requirements and without any failure. This parameter is delimited between the minimum flow $\left(\mathrm{Q}_{\mathrm{min}}\right)$ and the maximum flow rate $\left(\mathrm{Q}_{\max }\right)$, as shown in Figure 4.3.

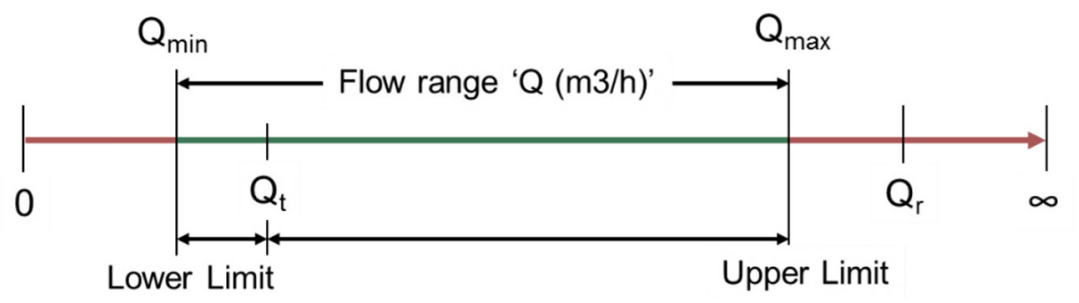

Figure 4.3. The working flow range $\left(\mathrm{Nm}^{3} / \mathrm{h}\right)$ of a gas meters

The maximum permissible measurements error (MPE) must be framed within the limits prescribed by the European standard EN 1359 are shown in Table 4.1:

- $\quad \pm 3 \%$ when the flow rate is between the minimum flow $\left(\mathrm{Q}_{\min }\right)$ and the transitional flow $\left(\mathrm{Q}_{\mathrm{t}}\right)$;

- $\pm 1.5 \%$ when the flow rate is between the transition flow rate $\left(\mathrm{Q}_{\mathrm{t}}\right)$ and the maximum flow $\left(\mathrm{Q}_{\max }\right)$.

where:

- The transitional flow rate $\left(\mathrm{Q}_{\mathrm{t}}\right)$ is the vale at which the flow rate range is divided into an upper zone and a lower one. Each one of these zones is characterized by its own specific maximum permissible error, calculated as follows:

$$
Q_{t}=\frac{1}{10} \cdot Q_{\max } \quad\left(\mathrm{Nm}^{3} / \mathrm{h}\right)
$$

- The overload flow rate $\left(\mathrm{Q}_{\mathrm{r}}\right)$ is the value at which the meter must be able to work for short periods without deterioration. It is calculated as follows:

$$
Q_{r}=1.2 \cdot Q_{\max }\left(\mathrm{Nm}^{3} / \mathrm{h}\right)
$$


Table 4.2. Permissible Pressure drop

\begin{tabular}{ccc}
\hline $\begin{array}{c}\mathbf{Q}_{\mathbf{m a x}} \\
\left(\mathbf{m}^{\mathbf{3}} / \mathbf{h}\right)\end{array}$ & \multicolumn{2}{c}{ Maximum Permissible pressure drop $(\boldsymbol{\Delta P})$} \\
\cline { 2 - 3 } & $\begin{array}{c}\Delta \mathbf{P} \text { initial } \\
(\mathbf{m b a r})\end{array}$ & $\begin{array}{c}\Delta \mathbf{P} \text { on working } \\
(\mathbf{m b a r})\end{array}$ \\
\hline from 2,5 to 16 & 2 & 2,2 \\
from 25 to 65 & 3 & 3,3 \\
from 100 to 160 & 4 & 4,4 \\
\hline Source: European standard EN 1359 & & $\left(^{*}\right) \Delta \mathrm{P}-$ Pressure drop $\left(\mathrm{Q}=\mathrm{Q}_{\max }\right.$ and $\left.\rho=1,2 \mathrm{~kg} / \mathrm{m}^{3}\right)$
\end{tabular}

On the other hand, the maximum pressure drop of a gas meter must remain in the range of values shows in Table 4.2. The pressure drop is a very significant parameter for the gas transmission and distribution system. It indicates that an interruption of the gas service has happened and that high gas flow losses are eventually taking place along the distribution pipelines. On the contrary, this parameter can be also used so as to identify a failure in the working of the instruments.

Gas meters are usually identified by their maximum working flow rate $\left(\mathrm{Q}_{\max }\right)$ that is indicative of the sector where the device would be used. Generally, gas meters under Class 'G6' are used for residential customers, while the classes over 'G6' are used for commercial and industrial supplies. The classification of gas meters by flow rate is indicated in Table 4.3.

Table 4.3. Classification of meters' class by flow rate

\begin{tabular}{lcccc}
\hline Class & $\begin{array}{c}\mathbf{Q}_{\max } \\
\left(\mathbf{m}^{3} / \mathbf{h}\right)\end{array}$ & $\begin{array}{c}\mathbf{Q}_{\min } \\
\left(\mathbf{m}^{3} / \mathbf{h}\right)\end{array}$ & $\begin{array}{c}\mathbf{Q}_{\mathbf{t}} \\
\left(\mathbf{m}^{3} / \mathbf{h}\right)\end{array}$ & $\begin{array}{c}\mathbf{\mathbf { Q } _ { \mathbf { r } }} \\
\left(\mathbf{m}^{3} / \mathbf{h}\right)\end{array}$ \\
\hline G2.5 & 4 & 0.025 & 0.4 & 4.8 \\
G4 & 6 & 0.040 & 0.6 & 7.2 \\
G6 & 10 & 0.060 & 0.8 & 9.6 \\
G10 & 16 & 0.100 & 1.2 & 14.4 \\
G16 & 25 & 0.160 & 2.5 & 30.0 \\
G25 & 40 & 0.250 & 4.0 & 48.0 \\
G40 & 65 & 0.400 & 6.5 & 78.0 \\
G65 & 100 & 0.650 & 10.0 & 120.0 \\
G100 & 160 & 1.000 & 16.0 & 192.0 \\
\hline
\end{tabular}

The standard metrological requirements here shown for traditional gas meters remain being valid for the new generation of gas meters. Said that, large progress has occurred in the gas transmission and distribution network, similarly to the trend observed in electrical systems. As a result, a new generation of gas meters with new measurement technologies have been implemented. The mechanical rotating totalizers based on the diaphragm movements have been replaced by new electronic displays and remote control 
sensors have been added. The following section will show the new gas measurement technologies, as well as the components introduced to gas meter in order to turn it into "smart".

\subsection{Smart meters: the new challenge of the gas supply system}

A gas smart meter is an electronic device that register the gas volume consumed during a period of time. A smart metering device has to allow a remote management and a remote reading of the registered variables. The remote reading improves data collection accuracy and reduces the cost of the readings and metering management operations (e.g., vendor change, deactivation, etc.). On the other side, it increases the security of supply due to the remote control and collection of diagnosis. The remote control reduces the onsite operation costs and it allows the deactivation of the gas supply without an on-site intervention.

During the latest years, new gas meter devices with an electronic communication module and electronic components have appeared in the market. Not being exhaustive, Figure 4.4 provides an overview of the different solutions offered by several manufacturers.

SMART METER OF G4-G6 CLASS

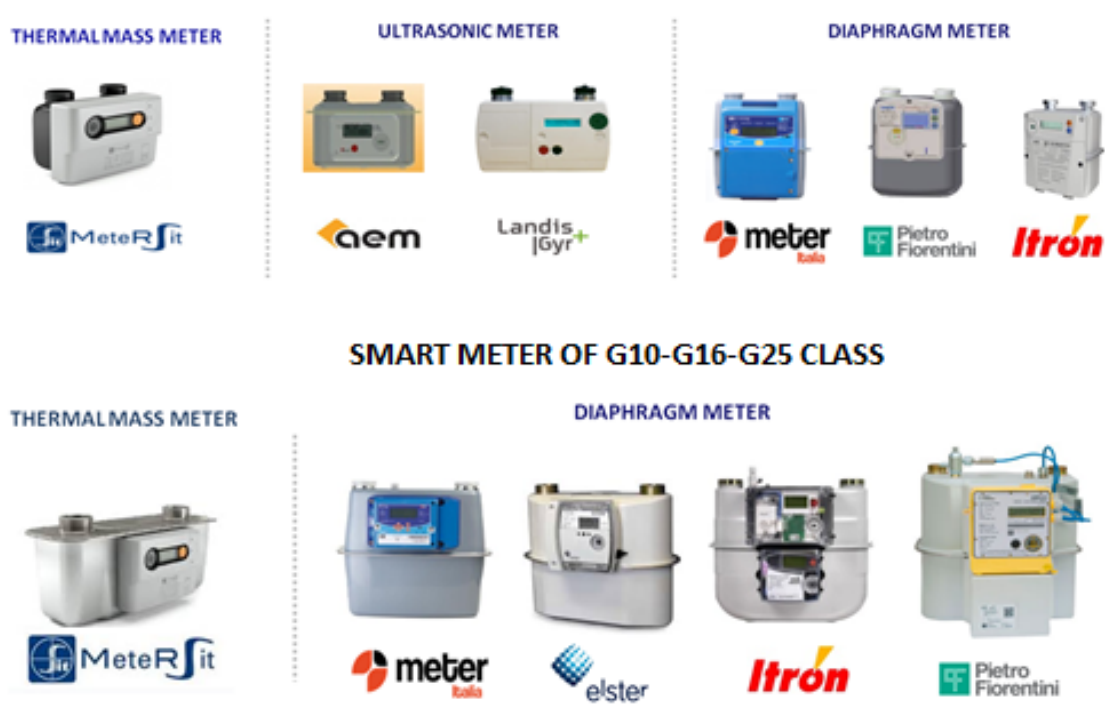

Figure 4.4. Different types of smart meters gas available on the market

In addition to that classification, the different models of the available meters can be classified according to two key characteristics: 
- Measurement technology. Apart from diaphragms meters, new measurement techniques have been implemented such as ultrasonic and thermal mass technologies.

- Communication technology. In order to allow the remote reading and updating of the new gas smart meters, a communication system have been provided. Different communication technologies are available on the market such as Wired M-Bus following EN 13757; Wireless M-Bus (868MHz, 433MHz, $169 \mathrm{MHz})$ following EN 13757; ZigBee (2,4GHz) and GSM/GPRS.

For the specific case of Italy, two types of communication architecture have been adopted:

a) Point-to-point (generally with public telecommunication network communication)

b) Point-multipoint, with concentrator.

For the first case, GSM/GPRS communication has been adopted, the $169 \mathrm{MHz}$ frequency radio communication has been chosen for the second one.

In order to fully exploit the potential of DR resources in the natural gas sector a detailed knowledge about the available gas smart meters is required. The next section describes the main characteristics of gas smart meters, highlighting their possible utilization in DR applications.

\subsection{Measurement technologies}

The new gas smart meters can be classified into two large categories:

- Dynamic smart meters, provided with rotating pistons, turbines or diaphragm technology. They are based on the movement of the internal mechanical components of the measurement unit.

- Static smart meters, based on ultrasonic and thermal mass technologies. Static smart meters are characterized by the absence of moving parts in the measuring chamber, which consequently reduces the interference between the fluid and the measuring unit.

Following, an overview on the measurement technologies used nowadays in the NG sector is given, with a special focus on the domestic sector. The advantages of each technology are emphasized in order to clarify which one of them would be more suited for their utilization in DR applications.

\subsubsection{Diaphragm smart meters}

As discussed in the previous paragraph, the first meter implemented for the gas consumption was based on the diaphragm technology. Today, diaphragm based meters have 
been 'smartened' with electronic components and a LCD display for real time reading of the consumed volume.

Under the point of view of the measurement technology, the measure principle is still based on the measure of the gas displacement between the two chambers. The size of each of these chambers matches with the measurement volume and they are exactly equal to a quarter of the cyclic volume. The smart device measures the total amount of gas that continuously fills and discharges the chambers.

As already introduced, the volume measured by the meters has to be properly corrected to the standard conditions of pressure and temperature (the gas volume at the standard conditions). One of the main improvements for this kind of meters is the introduction in the calculation of the gas volume that is shown at the LCD display of an algorithm for the intrinsic correction of temperature. For the modern electronic diaphragm meters, the regulation establishes the volume correction and remote reading of the corrected volume. The correction of the measured volumes is implemented according to the class (see Table 4.3) thorough the introduction of the following devices:

- A pulse emitter for industrial meters. Modern industrial gas meters are often equipped with an additional device called "pulse generator". It allows the acquisition and the transmission of data by means of a dedicated electronic system. On the counter plate data must be clearly indicated the value of the gas volume corresponding to one pulse (1 pulse $=\mathrm{X} \mathrm{m}^{3}\left(\right.$ or $\left.\mathrm{dm}^{3}\right)$ ). This additional device is considered an integral part of the meter and, therefore, it is connected to the counter at the time of the first verification. There are not special fix conditions regarding the influence on the metrological characteristics of the counter. Currently, all the counters on the market without this device in origin, virtually have (through the presence of a multipolar connector protected by a cap), the purpose of enabling the management of locally acquired data.

- For domestic meters, an integrated electronic calculator converts the volume measured according to the following expression, established in ISO 12213-3:

$$
V_{c}=V_{l} \cdot\left(\frac{P_{w}}{P_{b}}\right) \cdot\left(\frac{T_{b}}{T_{w}}\right) \cdot\left(\frac{Z_{b}}{Z}\right) \quad\left(\mathrm{Nm}^{3} / \mathrm{h}\right)
$$

where:

- $\mathrm{Pb}($ bar) and $\mathrm{Tb}(\mathrm{K})$ are the standard pressure and temperature, respectively.

- $\quad \mathrm{Pw}$ (bar) and Tw $(\mathrm{K})$ are the pressure and temperature at the working line, respectively.

- $Z$ and $Z_{b}$ are the compressibility factors.

The diaphragm smart meter shows the advantage of a low and medium gas flow rate with a lower variable trend between the MPE ranges, as shown in Figure 4.5. Unfortunately, 
because of the degradation of the mechanical components such as the synthetic membranes (that are chemically attached and the risk of laceration below $-5^{\circ} \mathrm{C}$ ), these meters still show less measure stability.
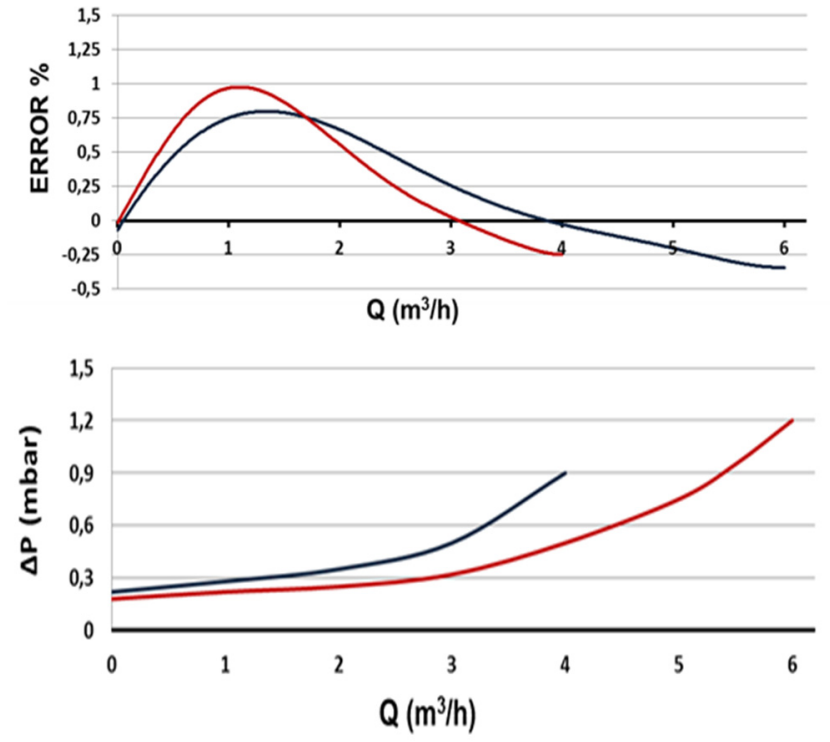

Figure 4.5. Trend of the MPE and Pressure drop in a Diaphragm smart meters.

\subsubsection{Ultrasonic meters}

Ultrasonic gas meters are devices for volume measuring with no mechanical moving parts inside. The principle of volume consumption measure is based on the "Repetitive Inverse Transit Time Difference Method". This method is based on the measurement of the time lap of an ultrasonic pulse, which passes through the gas flowing in the pipe. The method is known long time ago, being primarily used in the sector of water supply, but only in recent years it has started to be used for measure of gas [139].

Taking into account that the speed of sound waves in a medium depends on the flow speed in this medium, and considering that there is no transit of gas in the meter, the time of the ultrasonic beam to go from the point A to the point B (see Figure 4.6) is equal to the time required to run the distance 'BA' and vice versa.

The ultrasonic smart meter is equipped with two ultrasonic measuring sensors that simultaneously act as transmitter and receiver. They are set in line with the gas flow and alternatively transmit and receive ultrasound pulses. The time of transit of the sound waves from A to B, considering that there is no flow, can be calculated as follows: 


$$
t_{A B}=t_{B A}=\frac{L}{C}
$$

where:

- $\quad \mathrm{L}$ is the length of the ultrasonic beam (m)

- $\quad$ is the sound speed into the vacuum $(\mathrm{m} / \mathrm{s})$

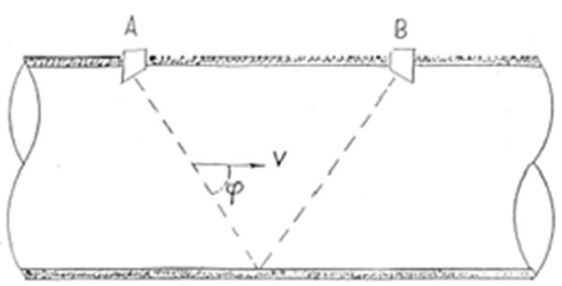

Figure 4.6. Ultrasonic smart meters

In case there is a gas flow transit into the meter, the time of transit would be different (from A to B and from B to A), being calculated for each case by the following expressions:

$$
\begin{aligned}
& t_{A B}=t_{B A}=\frac{L}{[C+v \cdot \cos (\varphi)]} \\
& t_{A B}=t_{B A}=\frac{L}{[C-v \cdot \cos (\varphi)]}
\end{aligned}
$$

The corrected volume of the gas flow into the meter for that technology is calculate taking into account the crossing area (section $\mathrm{A}$ ) and the speed profile ( $\mathrm{K}$ factor) in that section, depending on the Reynolds number:

$$
Q=\frac{L}{[2 \cdot \cos (\varphi)]} \cdot A \cdot K \cdot\left(\frac{1}{t_{A B}}-\frac{1}{t_{B A}}\right) \quad\left(\mathrm{Nm}^{3} / \mathrm{h}\right)
$$

The calculation of the consumed volume of gas $\left(\mathrm{Nm}^{3}\right)$ is carried out by an electronic control system, so-called "Signal Processing Unit" (SPU) which is included on the meter. The output signal is proportional to the gas flowing into the pipelines and, similarly to the diaphragm meters, it has to be converted according to the standard temperature by means of (4-3), which is automatically done by the smart meter. Among the advantages of the ultrasonic technology, it has a simple and compact design since it is a simple tube. It derives in a low weight and a high reliability with reduced transportation and storage 
cost. It can measure flow rates from 3 to $12,000 \mathrm{~L} / \mathrm{h}$, which covers a very wide range with a single ultrasonic sensor. Additionally, it is substantially insensitive to the presence of moisture, dirt, slag, etc. and it has a great resistance to the overloads. Besides, ultrasonic smart meters give an immediate response to changes in flow and exhibit extremely reduced loading losses. As the diaphragm smart meters, the limits within which the initial measurement error of ultrasonic meters is defined by the standard EN 14236 as follows:

- $\pm 3 \%$ when the flow rate is between the minimum and the transitional flow rate.

- $\pm 1.5 \%$ when the flow rate is comprised between the transitional and the maximum flow rate.

\subsubsection{Thermal mass technology}

The thermal-mass metering is the youngest technology applied to the domestic gas sector. They are based on the measurement of the heat transfer as the gas flows through a heated surface. Inside the measuring unit there are installed two high precision sensors a temperature sensor (PT 110 probe) and a flow sensor (Fig.4.25).

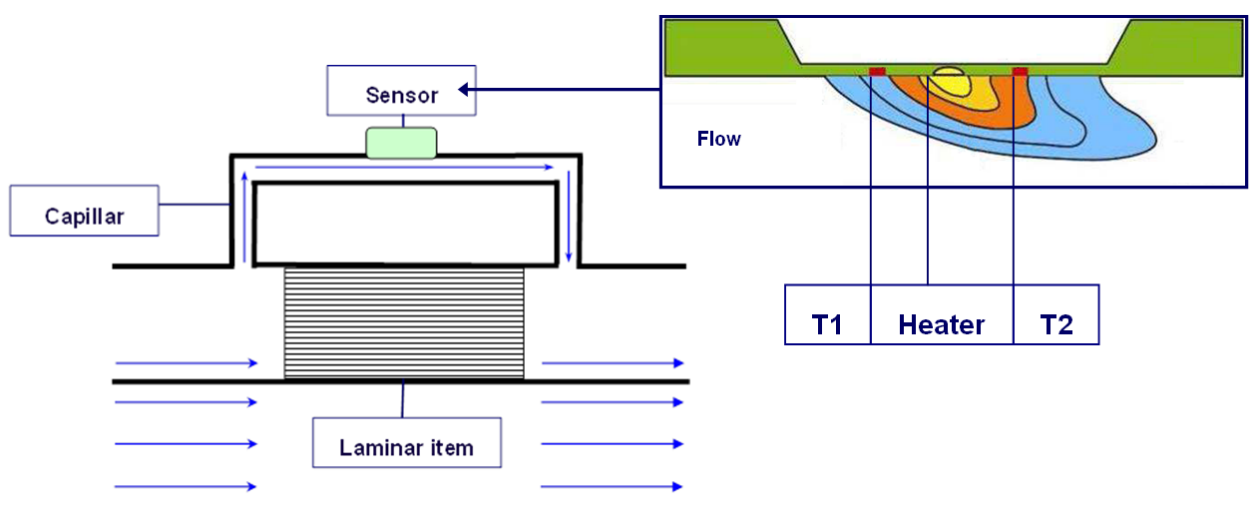

Figure 4.7. Operation of thermal mass meters (Source: www.metersit.it)

One of the two sensors measure the temperature of the flowing gas while the second one is heated to maintain a slight temperature difference (overheat). Depending on the cooling, it heats the gas flowing to a precisely defined temperature difference. The bigger is the mass flow, which flows across the heated temperature sensor, the more the sensor is cooled down and the bigger is the electrical current that is required for heating the sensor in order to maintain the temperature difference. The calculation of the flow takes place inside a capillary section of the outlet duct, through the measurement of heat transferred from a heating element to the gas flow. Therefore, the mass flow is calculated according the equation 4.7 as follow: 


$$
\frac{\partial m}{\partial t}=\frac{W}{C_{p}(T) \cdot\left(T_{\text {valley }}^{\text {gas }}-T_{\text {peak }}^{\text {gas }}\right)} \quad(\mathrm{kg} / \mathrm{h})
$$

where:

- $\mathrm{m}$ is the mass flow $(\mathrm{kg})$

- $t$ is the time of flow (h)

- $\mathrm{Cp}$ is the pressure coefficient $(\mathrm{kJ} / \mathrm{kg})$

- $\mathrm{T}$ is the temperature $(\mathrm{K})$

- $\mathrm{W}$ is the specific heat $(\mathrm{kJ} / \mathrm{kg} \cdot \mathrm{K})$

The difference of the temperatures upstream and downstream of the heating element is linearly proportional to the mass flow. The peculiarity of thermal mass smart meters is that the measurement does not need neither pressure nor temperature correction [140]. Moreover, it has an excellent sensitivity even at low flow rates. As the ultrasonic smart meters, it has a simple and compact design with a consequently low weight, high reliability and reduction in transportation and storage cost, as well as easy installation. Similarly to other smart metering technologies, the technical limits are defined in the standard EN 11625 as follows:

- $\pm 3 \%$ when the flow rate is between the minimum and the transitional flow rate.

- $\pm 1.5 \%$ when the flow rate is comprised between the transitional and maximum flow rate.

\subsection{New communication components and remote control device}

Traditional gas meters only measure total consumption that is necessary for invoicing purposes, but they do not register information on the daily or hourly based consumption. In order to promote DR programs, allowing the utilization of different prices which reflect the short-term situation of the grid, gas smart meters have to be enabled for the provision of such specific information.

The improvement of new technological characteristics has required the amendment of the traditional configuration of the gas meters and the introduction of new components in order to turn them into "smart", as it is shown in Figure 4.8. 


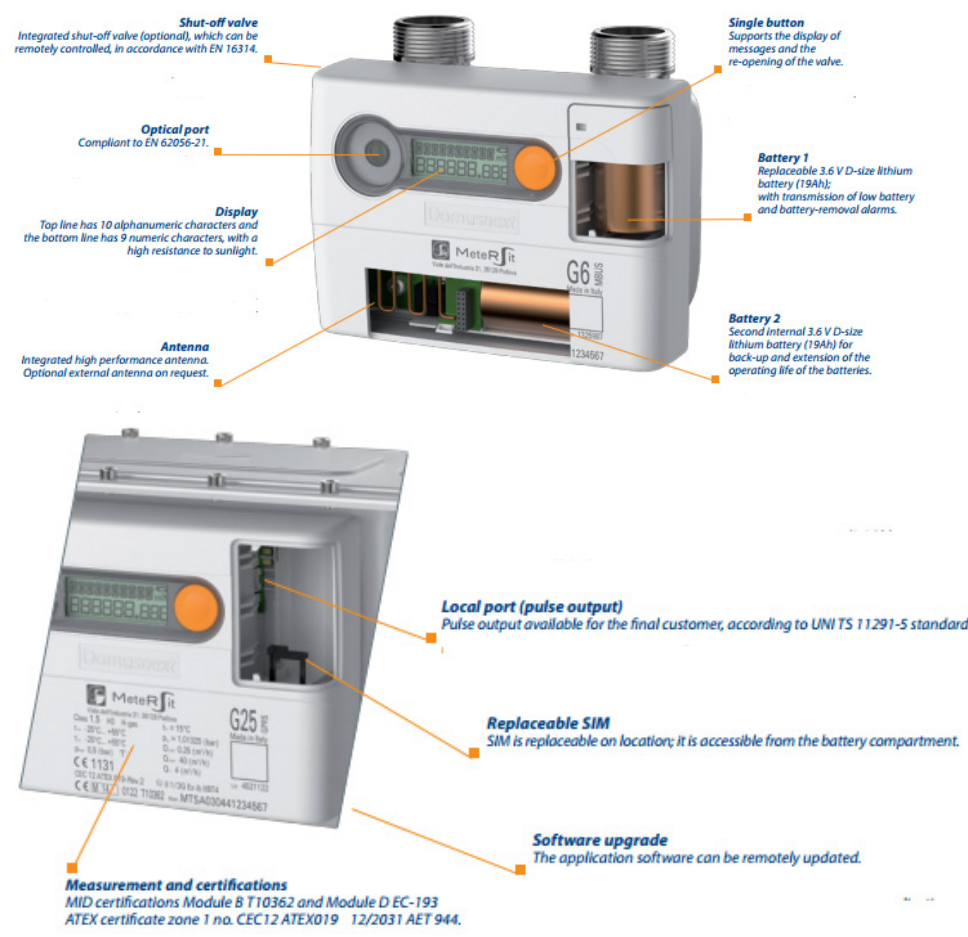

Figure 4.8. Description of the components of a gas smart meter (Source: http://www.metersit.com/images/catalogo-generale-it-en-metersit.pdf)

Technological characteristics that must be satisfied by gas smart meters are included in the new regulation on this matter. In particular, European standards indicate that gas smart meters have to be equipped with the following elements

- LCD display with accessible buttons in order to allows the end users to read the instantaneous volume consumption, as well as the corresponding reading of a previous period.

- Optical port for the local reading of the historical data consumption through a ZVEI probe and for the local opening of the shut off valve. The shut off valve should be remotely controlled so as to enable the remote interruption of the gas supply.

- Power supply system. Smart meters are generally equipped with lithium batteries for the energy support of the metrological and communication activities. 
- Electronic PCB Board. According the communication technologies, there is a radio-frequency (RF) module plus an antenna for the RF $169 \mathrm{MHz}$ communication system. Moreover, the board has a GPRS module and a SIM card for the GPRS communication system.

- Firmware (hardware and software) for the data registration, remote management and remote upgrading of the firmware, according to WELMEC $7^{53}$.

Each of the above new components introduced above contribute to the technological improvement of this measurement gas device. The advantages resulting from each amendments and new components mentioned above are analyzed below, where the contribution of each of them for a potential participation in the management of the gas system is highlighted.

\subsubsection{LCD Display and scrolling buttons}

Independently on their technology, natural gas meters have been always equipped with an indicator device, checked metrological. This indicator device represents the essential interface for the end user in order to know the gas consumption $\left(\mathrm{Nm}^{3}\right)$. So, it should be easily readable without the use of additional tools and it should properly operate during the whole life time of the meter under normal operation conditions. Unlike the gas smart meter, the traditional meter is equipped with a mechanical totalizer with a mechanical roller. According the regulation, the mechanical totalizer consists on an index that cannot not be reset while should have a sufficient number of digits in order to ensure a continuous flow of gas during, at least, 8,000 working hours.

The gas flow is indicated in cubic meters or decimal multiples or fractions of cubic meters. The symbol $\mathrm{m}^{3}$ is shown on the totalizer, near the numeric wheels of the quadrant, as shown in Figure 4.9. Standard EN 1359 provide some details, such as the minimum height of digits $(4 \mathrm{~mm})$ or their minimum width $(2.4 \mathrm{~mm})$.
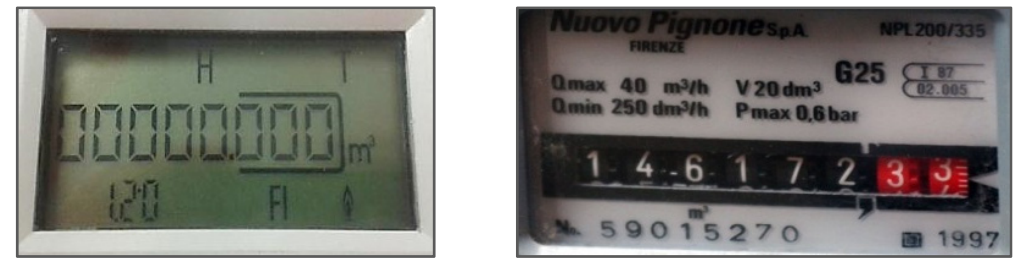

Figure 4.9. Electronic display vs a traditional totalizer

53 WELMEC is an entity composed of representative members from national authorities responsible for legal metrology in European Union and EFTA Member States. More information can be found at www.welmec.org 
At present, electronic meters have a liquid crystal display (LCD). A LCD is a flat-panel display that uses the light-modulating properties of liquid crystals. The use of the LCD gives a great flexibility in term of symbols or alphanumeric code that can be displayed. So, it gives the possibility to show a larger amount of information by means of more intuitive symbols and preset words, or digits more suited for a better understanding for the end user. Table 4.4 shows an example of possible parameters (alphanumeric code and symbols) that could be shown thanks to the use of a LCD display. The list of parameters and their sequence of visualization on the display differs among manufacturers and meters models, as there is still no standardization on this specific matter.

Table 4.4. Example of parameters shown on a LCD display

\begin{tabular}{cl}
\hline Main icons & Parameters \\
\hline $\mathrm{V}_{\mathrm{b}}$ & Current Totalizer - measured volume $\left(\mathrm{m}^{3}\right)$ \\
\hline $\mathrm{D}$ & Date \\
\hline $\mathrm{H}$ & Hours \\
\hline $\mathrm{ID}$ & $\begin{array}{l}\text { Identification of the gas delivery Point (available if activated the re- } \\
\text { mote management) }\end{array}$ \\
\hline $\mathrm{TA}$ & Totalizer of the alarm measured volume $\left(\mathrm{m}^{3}\right)$. Maintenance operations \\
\hline $\mathrm{SD}$ & Device status (maintenance operations) \\
\hline $\mathrm{DG}$ & Diagnostic (maintenance operations) \\
\hline $\mathrm{SN}$ & Serial number (maintenance operations) \\
\hline Fx & Current tariff \\
\hline $\mathrm{PT}$ & Identification of the tariff plan \\
\hline T1, T2, T3 & Consumption according to the tariffs $\left(\mathrm{m}^{3}\right)$ \\
\hline Qv & Max conventional flow rate $\mathrm{m}^{3} / \mathrm{h}$ \\
\hline DF & Date of the end of the tariff period \\
\hline HF & Hours of the end of the tariff period \\
\hline
\end{tabular}


Metering and communication technology: smart gas meters

\begin{tabular}{cl}
\hline Main icons & Parameters \\
\hline PRE PT & Identification of the tariff plan previous period \\
\hline PRE Vb & Totalizer at the end of the previous tariff period \\
\hline PRE TA & Totalizer of the previous alarm volume \\
\hline PRE T1, T2, T3 & Totalizer at F1, F2, F3 (previous tariff period) \\
\hline PRE Qv & Max conventional flow rate m3/h (previous tariff period) \\
\hline SW1 & Identification of the metrological SW (maintenance operations) \\
\hline Main symbol & Identification of the applicative SW (maintenance operations) \\
\hline & Valve status (maintenance operations) \\
\hline & Communication on \\
\hline & Alarms \\
\hline
\end{tabular}

For an electronic display (see Figure 4.9), when any digit passes from 9 to 0 , the higher digit (to the left seen from the front) must increase by 1 . According to the regulation, the display should be clear and easy to read within at least a minimum angle of $15^{\circ}$ respect to the normal axis, and within the temperature range of $-10^{\circ} \mathrm{C}$ and $55^{\circ} \mathrm{C}$ (that is the functioning range of temperature for the gas smart meters).

The interaction between the display and the end user takes place through the scrolling buttons. The gas smart meter gives to consumers the opportunity to check their gas consumption and the parameters listed in Table 4.4 just using such buttons. 
The availability of a LCD at the meter is a good starting point for enabling customers for DR applications. Actually, the display is very easy to use, and it gives to the user the possibility to quickly interact with the smart mete. End users can freely choose on the multifunctional display the information they want to know, increasing their awareness in terms of consumption and their energy habits. On the other hand, also alarm and diagnostic parameters that make aware consumers of the correct operation of the metering device can be shown on the LCD display. Thus, the interaction between end users and the smart meter improves not only the awareness about the self-consumption, but also the safety of the gas supply.

\subsubsection{Optical Port}

Data shown in the LCD display by scrolling the enter buttons are recorded inside the smart meters. Therefore, in case of failure of the LCD display, they can be recovered through the optical port installed on the front of meters (see Figure 4.10). Actually, the optical port allows the local configuration and management of the electronic meter thanks to the use of a software service toolbox. Currently, such software service tools are implemented by the manufacturers of the smart meters, so tools are different among meters and users would require specific training for their management. The physical connection between the software service tools and the smart meters is, in any case, an optical ZVEI probe, specified in IEC 62056-21.
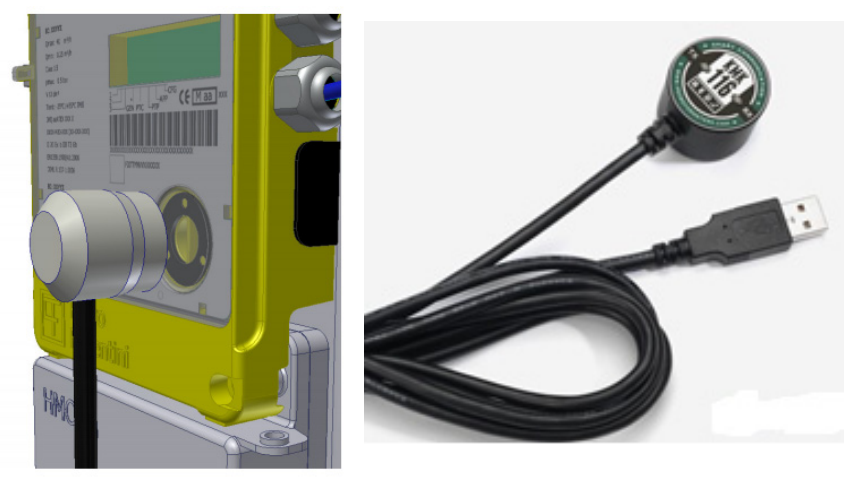

Figure 4.10. Optical port connected through a ZVEI probe (Source: www.fiorentini.com www.marcom.com)

The software service toolbox works in off-line mode, which allows the operator to view and save the essential parameters of the smart meter and also to recover the historical data (both measures and diagnostic events). For example, in case of failure of the batteries, through the optical port it is possible to read and export sensitive information (gen- 
erally all the data displayed on the LCD display) commonly called ' Data Log parameters". The "DATALOGS" section of the toolbox allows the operator to view historical data stored in the device and export them.

\subsubsection{Electro shut-off valve}

According to the UN TS11291-1-4 and UN TS 11291-6-6, the gas smart meter has to be able to remotely manage the gas supply and to allow the interception of the gas flow but exclusively for commercial issue. The gas shut-off valves is a mechanical tap combined with electronic sensors and remotely controlled (see Figure 4.11). The valve is located inside the inlet connection and is not accessible without causing permanent damage to the meter. In addition, the gas inlet connection where the shut valve is locate is protected by metrological seal, imposed by the Authority, which makes immediately visible any possible valve tampered due to vandalism actions.

The valve is designed to ensure its performance and properly functioning for at least 15 years (that represents the estimated life for gas the smart meter). It is managed by the smart meters microprocessor, which controls the close and open condition of valve and monitors its proper operation. The valve state is actually recorded into the diagnostic files of the smart meters.

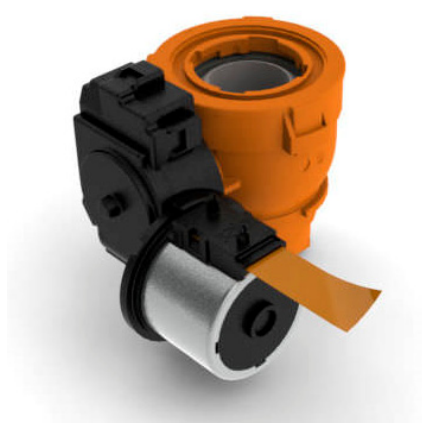

Figure 4.11. Gas shut off valve

For safety, the valve only can be locally opened via keyboard activation, according to a specific procedure that actually differs from each manufacturer and that is sometimes protected by a key password. The opening of the valve previously closed, must be remotely authorized in advance by the Control System (SAC) by the command 'Authorization to open'. Only after that, the valve could be locally open.

The introduction of this new components represents a highly significant improvement into the gas supply management. Actually, the possibility to remotely close the valve corresponds to the distributor, who can interrupt the gas supply in case of tampering 
attempts. This fact reduces the number of cases of customers with pending payments, meaning a reduction of cost for the operator system and retailers.

\subsubsection{Power supply system}

The introduction of electronic components has required to power the smart meters with an energy supply system. For this purpose, different alternatives have been worldwide evaluated, such as the connection to the electrical system and the use of batteries. In Italy, lithium batteries are the current energy supply for gas smart meters due to the unpredictability and variety of installation sites, which makes no feasible their connection to the electrical network. As a consequence, lithium batteries are used as power source for both the data gathering and communication, as well as for the metrological function. The smart meter could be equipped with rechargeable or not rechargeable lithium batteries. The current configurations available on the market are the following:

- One single battery for both metrological and communication functions

- Two batteries, one as metrological battery the other as communication battery

The metrological battery has to guarantee the functioning of the volume sensor in order to ensure the availability of the reading on field. Generally, this battery is not replaceable and not rechargeable, so that the duration of the battery must be in the order of the estimated life time of the meters. The battery is sealed in order to avoid thief acts.

Generally, the transmission battery support software upgrade activities and the data transmission of meters. In this case, batteries must ensure an autonomy up to 15 years, being possible their replacement when they run out.

The power supply system has to guarantee that the new technological characteristics of the gas smart meters have enough power to operate without supply problems. However, the duration indicated on the technical datasheet does not fit with the real value. Therefore, different studies are taking place in order to actually calculate the real consumption of the smart meter and the real duration of batteries for different manufacturers [141], [142].

\subsubsection{Electronic modules and communication devices}

In order to carry out the required measurement and communication functions, gas smart meters are equipped with two distinct modules (PCBs - printed circuit boards), each of them with its own role:

- Measurement module. It has to be certified because it is the only part of the meter that deals with metrological data (see Figure 4.12). It generally consists of a microcontroller that interacts with the LCD display, temperature sensors and optical port. The gas flow measurement is done via ultrasonic, diaphragm or thermal mass meter, depending on the measurement technology. In order to calculate the correct volume, a temperature and pressure sensor is also included. 
- Communication module. It is used as a translation mechanism between different communication protocols (e.g. MBUS to DLMS), being the link between the measurement module and the SAC.

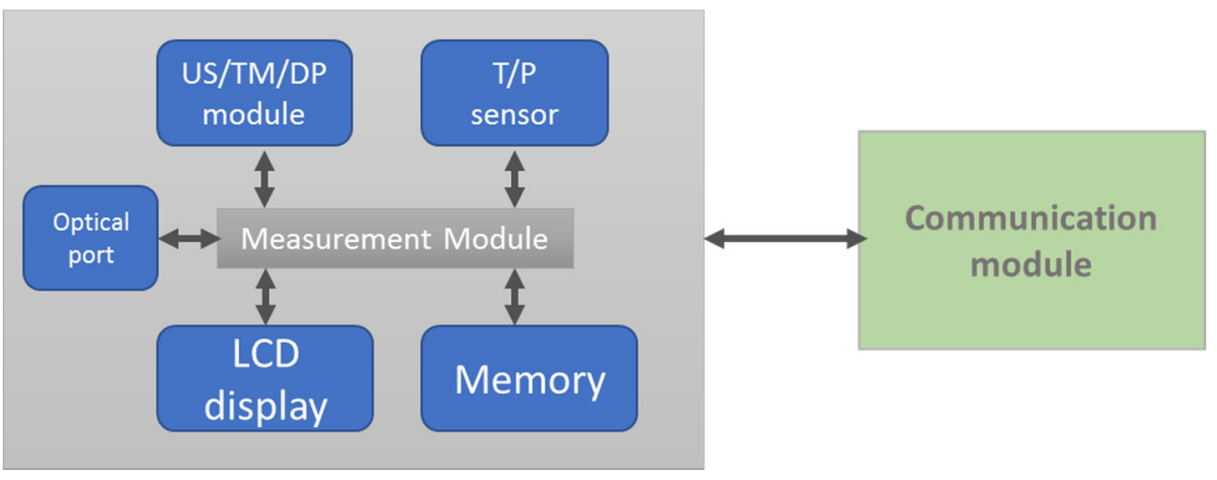

Figure 4.12. PCB boards

The European Measurement Instrument Directive (MID) ${ }^{54}$ and the Welmec 7.2 Software Guide provide the requirements for design, implementation and testing of the software for the measurement module. It allows the transmission of gas flow consumption every 2 seconds while in normal mode and once every $125 \mathrm{~ms}$ while in inspection mode. The software does not provide any function which could be used to reset or modify metrological data, but it enables the meter transmission of specific information via network. The Welmec Guide 7.2 provides the technical requirements of the software according to the MID (in particular those included in annex 1). According to that, the software must fulfil the following requirement ${ }^{55}$ :

- Requirements for basic configurations of measuring instruments (called type P), which are applicable to all instruments. The gas smart meter is considered as type $\mathrm{P}$ because is a built-for-purpose instrument with embedded software.

- Requirements for four IT configurations called extensions L, T, S and D. The gas smart meter should be able to have a long-term storage of measurement data (L) and the transmission of measurement data (T). In addition, it should allow the software download (D) and the software upgrade. Similarly, it should have the software separation (S), with the metrological software (legally relevant) on one side, separated from the not legally relevant software.

\footnotetext{
${ }^{54}$ Directive 2014/32/EU

${ }^{55}$ More information can be found at www.welmec.org
} 
The entire software on the measurement module is legally relevant and it is implemented in the C programming language, according to the ISO C99 standard. The software is identified by the software version and software checksum. The software version consists of a hexadecimal number stored in non-volatile memory and is protected by an XOR checksum.

As previously discussed, two different communication technologies are used in Italy: Radio-frequency (RF) and GPRS. According the communication technology and in order to communicate with the central system (SAC), gas smart meters have to be equipped as follows:

- RF smart meters are equipped with a radio module and an integral antenna that has to be compliant with the regulation in force (in Italy UN TS 11291-11-4 and similar). The RF module must include all the necessary features for secure twoway communication between the meter and the concentrator. The $169 \mathrm{MHz}$ Radio WM-BUS module has 2 main functions: it communicates via wireless with the Data Concentrator (DC) while it provides and collect/send specific data such as the index on tariffs, monthly self-readings at a specific time, profile load, instantaneous values and so on. The basic performance parameters of the radio module are the frequency band of $169 \mathrm{MHz}$ and the transmission power at $+30 \mathrm{dBm}(1000 \mathrm{~mW})$ of the antenna input level.

- GPRS smart meters are equipped with a GPRS module, an integral antenna and a SIM card. Generally, the Data Center (SAC) and the GPRS module communicate using the protocol DLMS/COSEM over TCP/IP using the GPRS services. The communication is via GPRS, and therefore, it requires an active SIM card to initiate communication with the server. If there is no SIM card inside the meters, the GSM is not initialized. For the proper operation of GPRS communication, such parameters as APN (access point name of the network provider authentication), type of authentication mechanism used, username or password should be properly set up.

The antenna is a very important component of the communication systems. The antenna is an electrical device which converts electric power into radio waves, and vice versa. It is habitually used with a radio transmitter or radio receiver. In transmission, a radio transmitter supplies an oscillating electric current at radio frequency (i.e. a high frequency alternating current) to the antenna's terminals, and the antenna converts the energy from the electric current into electromagnetic waves (radio waves). In reception, an antenna intercepts some of the power of an electromagnetic wave in order to produce a tiny voltage at its terminals, which is applied to a receiver to be amplified.

Typically, an antenna consists of an arrangement of metallic conductors (elements), electrically connected (often through a transmission line) to the receiver or transmitter. An oscillating current of electrons forced through the antenna by a transmitter creates an oscillating magnetic field around the antenna elements, while the charge of the electrons 
also creates an oscillating electric field along the elements. Antennas can be designed to transmit and receive radio waves in all horizontal directions equally (omnidirectional antennas), or preferentially in a particular direction (directional or high gain antennas).

The choice of the proper antenna is very important for a transmitting - receiving communication system. The antenna must be able to radiate or receive efficiently so the power supplied is not wasted. The RF antenna and radio module have to fulfil:

- The electromagnetic compatibility and radio spectrum matters (ERM)

- The standard on Short Range Devices (SRD)

- The standard about radio equipment to be used in the $25 \mathrm{MHz}$ to $1000 \mathrm{MHz}$ frequency range with power levels ranging up to $500 \mathrm{~mW}$ (Part 1: Technical characteristics and test methods and Part 2: Harmonized EN covering essential requirements under article 3.2 of the R\&TTE Directive).

The Italian norm UN TS 11291-11-4 defines the minimum characteristic that a RF antenna has to comply, as they are shown in Table 4.5.

Table 4.5. Minimum characteristic of RF antenna

\begin{tabular}{lll}
\hline \multicolumn{1}{c}{ Parameter } & \multicolumn{1}{c}{ Value range } & \multicolumn{1}{c}{ Notes } \\
\hline $\begin{array}{l}\text { TRP (total radiated } \\
\text { power) }\end{array}$ & $\geq 20 \mathrm{dBm}$ (Formula A) & \\
\hline & & $\pm 30 \mathrm{~s}$ in 115,7 \\
Clock drift & $\leq \pm 30 \mathrm{ppm}$ according the UN CE EN & $\mathrm{d}$ \\
& $13575-4: 2013$ & $\pm 60 \mathrm{~s}$ in 23,15 \\
& & $\mathrm{d}$ \\
\hline Gain & $\geq-8 \mathrm{dBi}$ & receiver \\
RSSE LBT threshold & Standard $-80 \mathrm{dBm}$ & \\
\hline & $-100 \mathrm{dBm} \leq \mathrm{RSSE} \leq-50 \mathrm{dBm}$ & Source: UNI TS 11291-11-4
\end{tabular}

Regarding the GPRS antenna, it has to be compliant with:

- The Global System for Mobile communications (GSM)

- Harmonized EN for mobile stations in the GSM 900 and GSM 1800 bands covering essential requirements under article 3.2 of the R\&TTE directive (1999/5/EC) and Digital cellular telecommunications system (Phase 2+)

- Mobile Station (MS) conformance specification (Part 1: Conformance specification (3GPP TS 51.010-1 version 4.9.0 Release 4).

The GPRS radio characteristics are summarized in Table 4.6. 
Table 4.6. Characteristic of GPRS communication system

\begin{tabular}{ll}
\hline $\begin{array}{l}\text { EUT modules composi- } \\
\text { tion }\end{array}$ & $\begin{array}{l}\text { GPRS Radio module integrated in the flux gas me- } \\
\text { ter }\end{array}$ \\
\hline Supply voltage & $3,6 \mathrm{~V}$ \\
GSM class & GMS Class 4 (2W) DCS class 1 (1W) GPRS Class 10 \\
Modulation & GMSK \\
Operating frequency & $850 / 900 / 180071900 \mathrm{MHz}$ \\
Antenna Type & Integral \\
Electromagnetically rele- & Radio module \\
vant components & Main board \\
\hline
\end{tabular}

The introduction of the aforementioned electronic devices is the core of the amendments performed on the gas meters in order to make them "smart". These components contribute to the implementation of the gas smart system, facilitating the application of suited DR initiatives.

\subsection{Smart grid communication architecture: focus on Italy}

Several pilot projects for the implemetation of multi utility and multiservice smart metering system have been deployed in countries like Italy, Spain or Switzerland. Such initiatives have the purpose to reduce greenhouse gas emission and improve the flexibility and reliability of the gas utility system. In order to succeed in reaching these targets, natural gas systems have been provided with "smart" infrastructures, especially those related to the metering. Some countries have implemented a massive roll-out of natural gas smart meters (as analyzed in section 3.4.2), including a communication structure able to allow the dual way communication and data collection between the smart meters and the SAC. In particular, depending on the considered country, some of the following communication technologies have been adopted:

- ZigBee as well as sub-GHz wireless communications have been adopted in UK in order to connect 30 million properties to the smart grid [114].

- Sub-GHz network such as 902-928 MHz has been chosen in the U.S. for communication between meters and from the meter to a data collector or concentrator.

- The international standard Wireless M-Bus $169 \mathrm{MHz}$ (169.40 to 169.81) according the EN 13757-4 and GHz wireless communications are currently in use in Italy. 
In European countries, the allocation of the frequencies and the management of the radio spectrum are administered by national regulatory authorities. These authorities work together within a harmonized framework established by international and European policy initiatives [143]. According to the regulations, smart metering application employ for the data transfer the ISM bands (Industrial, Scientific and Medical) and, in particular, the following bands of SRD (Short-Range Device):

- $868 \mathrm{MHz}(863-870 \mathrm{MHz})$, supported by the international standard Wireless MBus EN 13757-4, predominantly used for water smart meters.

- $169 \mathrm{MHz}$ (169.40 to 169.81$)$ allocated as the frequency for Smart Metering applications in Europe in 2008.

The utilization of these two band means that the intercommunication between different types of smart meter is not possible now, as they operate at a different frequency. Therefore, an appropriate module radio at $169 \mathrm{MHz}$ should be implemented in order to make possible the communication between the gas smart meters, water meters, and all the other utility meters. In Italy, a smart metering infrastructure giving the possibility of a twoway communication model between utility and customer using ICT is now on progress. Currently, the communication infrastructures for the natural gas metering are based on two configurations:

- Point-to-Multipoint (PMP) technical standard (169 MHz frequency)

- Point to Point (PP) technical standard (GPRS)

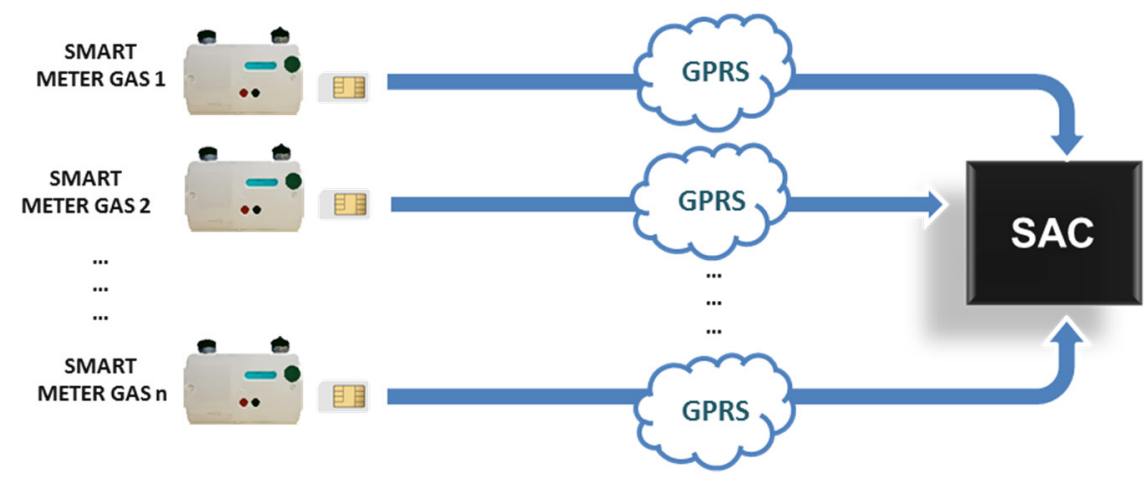

Figure 4.13. Point-to-Point Communication Technology

The PMP $169 \mathrm{MHz}$ communication is the cheapest alternative operationally talking, while the GPRS is the most mature technology. This consideration usually drives several gas companies to prefer GPRS to $169 \mathrm{MHz}$ (i.e. Italgas). However, PMP communication is considered to be the dominant option going forward, especially in areas with medium to high meter density. In general, the communication network architecture of a PP/GPRS 
technical standard consists of smart meter with a GPRS module/antenna and a SIM card, able to communicate with the SAC, as represented in Figure 4.13.

The main advantage of a GPRS communication network is the efficiency based on the following parameters [144]:

- Distance from base station. The speed decreases with the distance from the radio base station. Thus, fast algorithms (such as CS-4) are used near the radio stations, while slower algorithms (such as CS-1) are used when the user is far.

- The number of connected users per cell. The higher this number is, the slower the connection.

- Finally, the cost of the GPRS communication, based on the kilobytes transmitted and not on the time of connection such as for the PMP.

On the other side, the main components in a PMP infrastructure, in compliance with UNI TS 11291, are the gas smart meter, the data concentrator (DC) or the gateway (GW) and the central access system (SAC). In this case, as it is shown in Figure 4.14, multiple smart meters communicate to the DC that manages the transference of the collected data to the SAC.

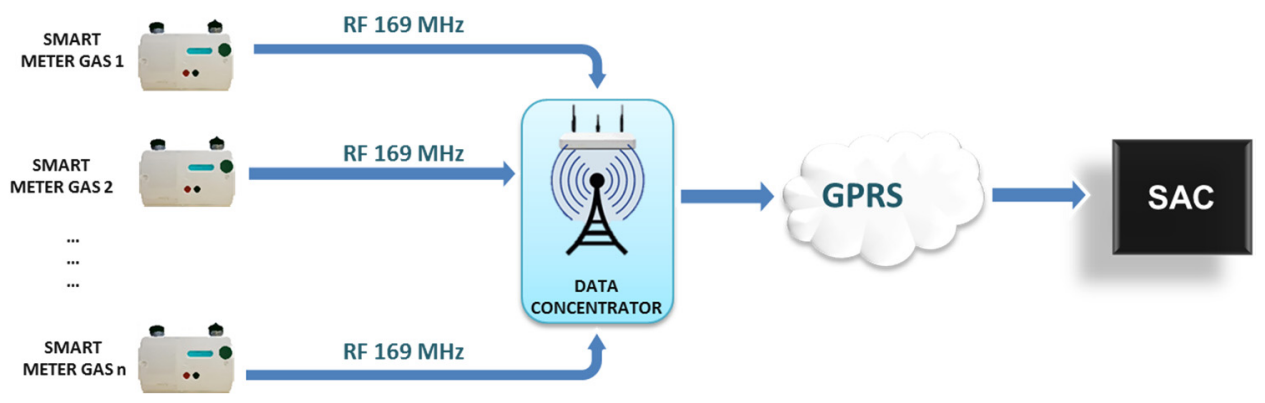

Figure 4.14. Point-to-Multipoint Communication Technology

A secondary component is the handheld unit (HHU), used for the installation and management on field. The DC/GW manages the transfer of data of the smart meter to the SAC system. It also communicates with the meters for control purposes and work also as router for each PMP network. In terms of performance, the concentration ratio (number of meters that could be tied to the same DC) in the PMP architecture tends to vary widely, with peak sustainable performance ranging from 500 to 4,000 meters per concentrator. However, the optimal balance between meter density, performance and redundancy is reached in the range of 800-1,000 meters per concentrator or less (generally 500 per DC) [109]. The handheld unit communicates with the meters and other systems equipment for installation management and maintenance on field, and is used to collect 
data from the counter when the connection between the DC / GW and meters is unavailable. The HHU also communicates with the SAC for installation and to transfer the collected data. The main advantages of a system that uses the PMP network are the easy installation, the reliable control of data collection, long battery life, and the characteristics of providing a flexible and extensible radio protocol.

For both technologies (PMP and PP), a universal communication standards is required to carry the information between the metering equipment and the data collection system. DLMS/COSEM ("Device Language Message specification/Companion Specification for Energy Metering") protocols are the common language and identification system for all metering data, which are now used in Italy for the domestic and commercial meters. This protocol allows the communication with the meter and to translate the data into a series of bytes, so that the partners can understand each other.

The fundamental communication devices will be described in following paragraphs.

\subsubsection{Data concentrator}

The data concentrator (DC) is a data collection and control device for various types of wireless peripherals and with different functional standards. It is generally equipped with a modular HW architecture that gives it a great flexibility for the simultaneous management of multi-utilities and multi-services (gas, water, etc.). The main functions performed by the $\mathrm{DC} / \mathrm{GW}$ are:

- It provides to the SAC the access to all the features of the smart meters.

- It makes available to the SAC, periodically or under explicit request, the data collected by the meters.

- It allow interoperability between its affiliated devices and the SAC of different operators

Depending on the requirements of the smart metering system, it can be integrated with additional communication modules in different combinations, even for different frequency bands and different protocols for a specific data service. Therefore, both bandwidths and operating protocol are configurable.

The collected data from the DC are brought to the SAC server (SAC) through wired connections (LAN) or wireless (GSM-GPRS). On the other hand, the device is equipped with a remote communication interface that operates at $169 \mathrm{MHz}$ WM-bus for point-tomultipoint communications to smart meters.

\subsubsection{SAC (Central acquisition systems)}

The SAC is the central acquisition system of the communication infrastructure. It should guarantee the interoperability between a high numbers of gas smart meter and between 
smart meters for other services (water, electricity, heat) with a high level of cyber security using application-level SSL certificates and sophisticated data encryption ${ }^{56}$. Generally, it could be equipped with different management modules, such as the following:

- A Data Acquisition module, which allows to collect data processed by gas smart meters (also from different ones). The collected data are elaborated by sophisticated algorithms that certify its validity and eventually regenerate the corrupted ones. After that the data are stored in the database, they are made available via export files to the customer.

- Data Processing module, which allows to obtain aggregate data, useful for a simpler and more immediate interpretation.

- Data Analysis module, which provides sophisticated analytical tools for the management of the deployment process.

- Data Presentation module, which shows the processed data to the operator via the Internet and using normal browsers. Ever-updated systems ensure security from external touches, while an articulated access management system allows the user to tailor memory and functionality to individual user privileges.

- Data Export of data collected. In addition to web presentation and Excel format reports, the data can be exported by automated systems.

The access to the database of the services center is however governed by efficient security procedures that ensure a high level of confidentiality.

The SAC may play a fundamental role in the exploitation of DR resources in smart natural gas systems. It would allow the monitoring of the network through alarm events that would be directly sent to the authorized operators via fax, email, SMS messages and so $\mathrm{on}^{57}$.

Nowadays, each distributor and manufacturer has its own SAC. Therefore, the standardization of this device is a preliminary step for the implementation of DR initiatives in the gas sector, so the communication and the data sharing between the different SACs would be possible.

\subsection{Communication and remote control devices for the DR integration}

As described in Chapter 3, smart grids are technological networks used for the provision of different network services (water, gas, electricity or heat) where the attribute "smart" refers to the ability of the grid to provide, thorough the use of the smart meters and smart

\footnotetext{
${ }^{56}$ https://www.globalsign.com/en

${ }^{57} \mathrm{http}: / /$ www.fiorentini.com/it/it/prodotti/servizi/servizi_remoto/sac
} 
sensors, a bi-directional architecture able to remotely transmit different relevant information about the consumption and diagnostic of the network infrastructure. The smart metering architecture has to favorize the diffusion of innovative services for the consumers such as the participation in DR programs. On te other hand, the implementeation of a smart network would facilitate the Trasmission (TSOs) and Distribution System Operators (DSOs) in the managements of fault detection, network balancing and storage integration.

In addition, within a DR framework, the labor of such agents as aggregator would enable them for more dynamic roles related to the real time management of the gas consumption. The usage of open communication and interfacing standards has the purpose to enable the connection between different smart meters and to bring to a multi service approach or, in other words, a multi energy vector monitored by the same data communication infrastructure [145].

Through it, the interoperability between the different utility system (gas, electricity, district heating and water) may be garanteed, facilitating an open and modular operation of the system. A reliable ITC (Information and communication technology) infrastructure is required to implement such flexible smart metering system. Basically, the ITC system should be provided with the following three main parts:

1) Automation of Distribution Network (ADN). The ADN should ensure an extensive control over transmission-level equipment, as well as an increasing control over the distribution-level equipment via the introduction of smart meters and intelligent remote control systems, able to detect pressure losses in real time and thus, reducing the risk of the interruption of the gas supply. The automation of the distribution network would facilitate the management of the gas consumption through demand response resources. Gas smart meters which are now on the market incorporate embedded software that is able to measure the gas consumption and to control the supply by the activation or deactivation of the shut off valve via a dual way communication with the SAC.

2) Advanced Measurement Infrastructure (AMI). The AMI enables two-way communication with the meter, which can gather data for remote reporting. Smart meters usually involve real-time or near real-time sensors and gas volume consumption alarms. The AMI is the technology which automatically collects consumption, diagnostic, and status data from metering devices, transferring later such data to a central database for billing, troubleshooting and analyzing. This allows to issue a billing do not based on estimated data, but real consumptions without the need of an operator to check the individual readings. Actually, this timely information coupled with the demand side analysis can help both suppliers and customers to better control the use and production of natural gas, similarly to the way already used for electricity. AMI technologies include handheld, mobile and network technologies based on telephony platforms (wired and wireless) and radio frequency [109]. 
3) Smart Management of natural gas Resources (SMR). The system operator should have access to the data collected by the SAC on an hourly base. For smaller consumers, the smart management of the gas should be carried on by the identification of new agents such as the aggregator, taking into account the sensitivity factors and data for the smart management of the gas supply to the end user.

In order to guarantee the smart management of the natural gas system, smart meters have to be able to communicate with the concentrator on one side and with the central acquisition system on the other side. A central cloud system would collect data from the concentrators and from meters. Data collection, fusion and mining algorithms have to be adopted. The interaction between smart metering technologies and demand response services may be facilitated by the introduction of remote control sensors that monitor the end user consumption and other technical parameters, making possible the remote managements.

Solutions already used in the electrical field should be adopted in the natural gas system. For example, smart thermostats with quick opening contact, able to the cut-in temperature and differential depending on the application should be here adopted. A reduction in temperature of the heater will result in a lower gas consumption during a peak. For DR programs that require a shift of the gas load consumption, an electronic timer able to program the natural gas consumption and to block the natural gas flow through the activation and deactivation of the shut-off valve could be introduced.

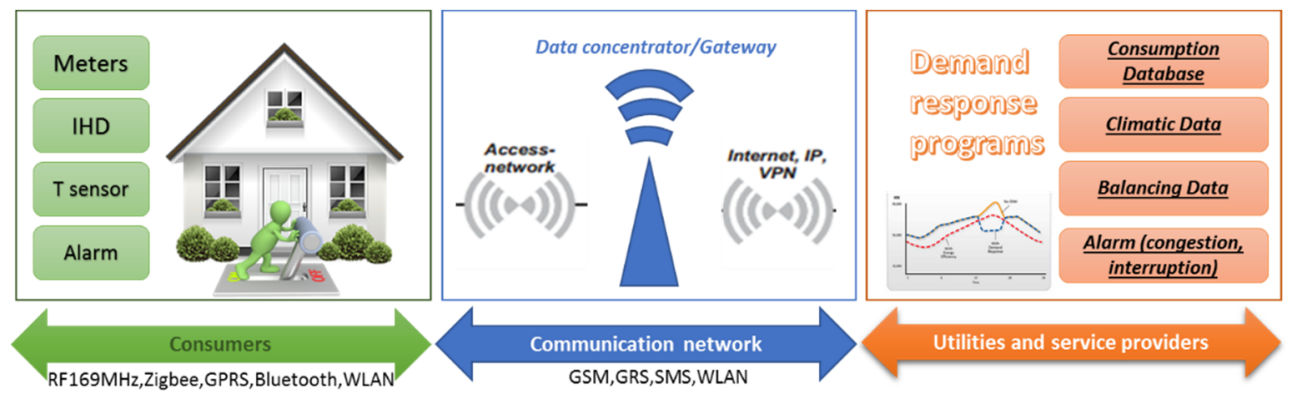

Figure 4.15. Energy supply systems with DR program devices

The management of the gas consumption would be actually easier due to the introduction of smart meter gas, provided by embedded software that would be able to measure the consumption and perform the orders received by the SAC, such as closing or opening the valve (in fact, this is something that the SAC could perform at present with the installed technology). Also the smart meter would be responsible for programming the data and hours for the remote shut-off valve closure and opening. On the side of the safety of supply, meters should be equipped with a seismic sensor and pressure sensor. 


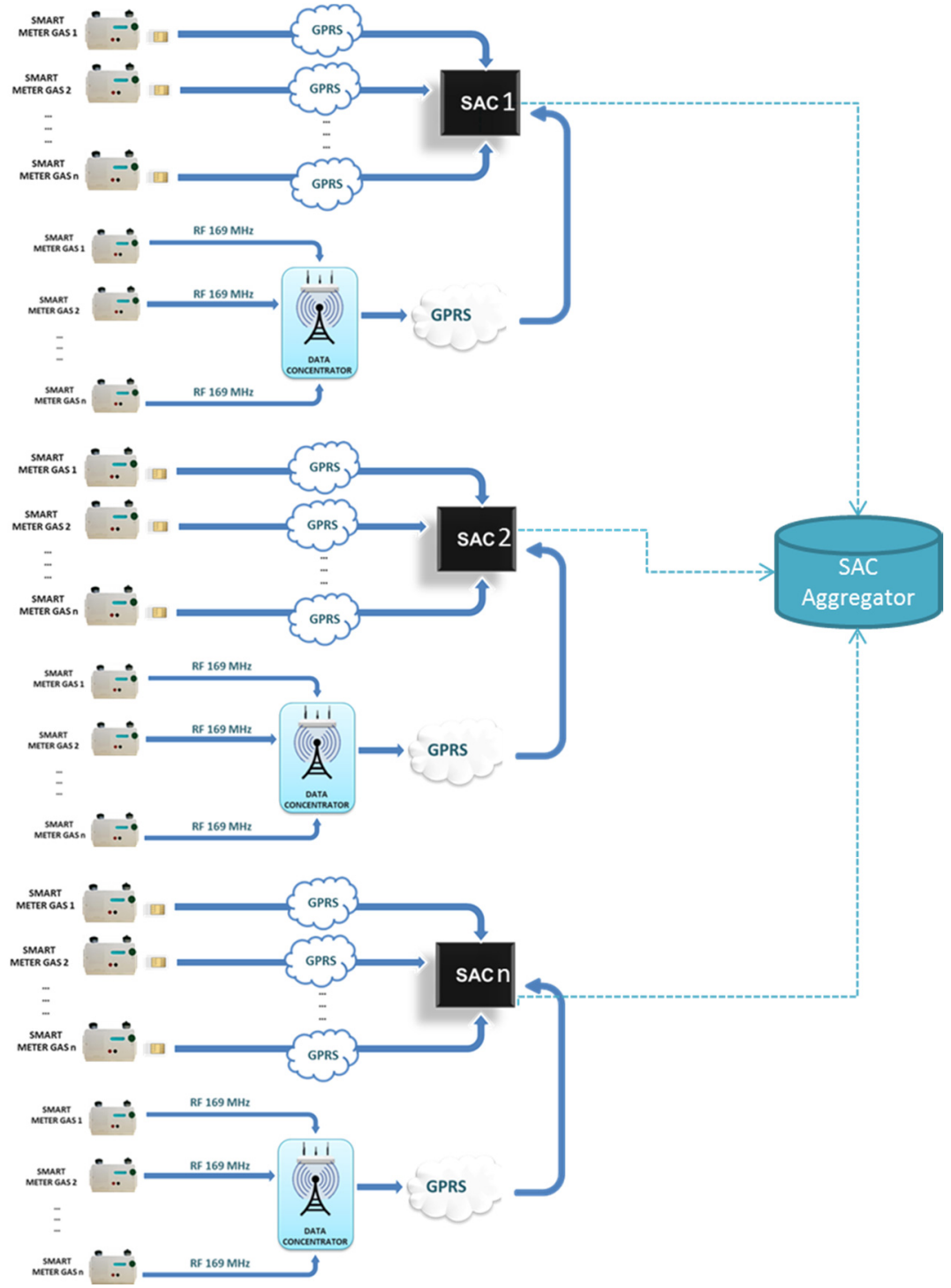

Figure 4.16. DR management communication infrastructure

This would improve monitoring of flow and would enable several safety functions that include the shutdown of gas supply upon the detection of earthquakes, low or high pressure, or abnormal gas flow potentially caused by dangerous gas leaks. [139]. 
On the user side, the introduction of IHD (In-Home-Display) is suggested. The IHD is a real time interface between the users and the natural gas consumption. The combination of the use of smart meters and in-home (or on-line) displays will provide to the customers with the information about their real time consumption, bringing to the concept of the multi-service management. The IHD has to be equipped with a well-designed program, easy to understand so as to successfully inform, engage, empower and motivate people. Although smart meters of different end users will remain separated, customers would have access to a single website through the IHD where finding all consumptions for the different supplies.

A strategic device for the integration of the demand side management should be the DR software. It would include a validated algorithm able to forecast the gas demand based on climatic data, historical consumption data collected from the previous years, exchange stock data of the wholesale gas market (day ahead and futures), interruption and congestions data, gas infrastructure maps and capacity of transmission pipelines data, etc.. The DR software should be able to analyze the sensitivity factor of the gas demand and to choose the best DR solution to provide affordable compensation to the end users.

A daily access to the following consumption and system data have to be provided with innovative services to the aggregator for the management of the system (Figure 4.16). Such service may include:

- Fault detection and detection of energy thefts

- Network balancing (congestion and interruption of the natural gas system)

- Storage availability and integration into the system.

- Energy integration (collection of both electrical and gas data of consumption in order to better balance the supply system since a holistic point of view)

\subsection{The role of the customers}

As discussed in the previous sections, the replacement of traditional gas meters by smart devices started in Italy by an Authority's initiative. First replaced meters were highercapacity counters (G40 and higher), being progressively extended to domestic meters (G4-G6 class). Gas smart meters record and automatically send by remote control the consumption of natural gas, and it enables a two-way communication between the meter and the central system. The metering intervals for consumption recording are regulated by the European directives, so they should be of an hour or less. Then, that information is communicated to the utility for monitoring and billing (telemetering). The benefits estimated for the end user should be different based on the level of technology of communication infrastructure implemented. The benefits expected for the customers provided by the smart metering include, among others: 
- The end of the estimated bills, which are a major source of complaints for many customers.

- Real time information about the gas consumption through the LCD display on the smart meter, that provide up-to-date information on gas consumption and permit more suited supply contracts.

- Better management of the gas use (saving money and reducing emissions) with the introduction of DR programs for a more efficient management of the grid.

- Reduction in costs due to the management of the contract (e.g. exchange supplier, decommissioning etc.) that can be carried out in automatic remote mode, and with greater frequency, without on-site intervention of the distributor.

- Interoperability between the communication systems. The Italian Gas Committee, according to the national regulation, has defined the technical rules for gas smart metering systems, with particular attention to the issues of interchangeability, understood as the possibility of smart metering simultaneously acceded by different stakeholders. The interoperability will facilitate the customer to change the gas supplier, making unnecessary the direct intervention of the operator, as well as contracting new services such as those related to DR programs.

In order to achieve the mentioned benefits, new smart devices have to be introduced in the gas smart metering chain, including:

- The IHD, that is able to increase the end-user awareness of their consumption and for the promotion of energy efficiency and rational use of resources.

- Interoperable DC/SAC for the different energy dimensions (electricity, gas, water, district heating), which provides better network management and better detection of technical and commercial losses.

- Gas Database, which facilitates the interchange of data, which may be accessible to different stakeholders.

- DR Planning software, so as to facilitate the implementation of the different actions related to the management of the involved services.

- Tele management of meters for the remote control of such devices as the shut off valve, as well as to receive information about the sensors installed at the metering point such as seismic, temperature and pressure.

The introduction of these smart devices would facilitate the connection between consumers and operators, between consumers and SACs, and between SACs and SACs of a different operator. Towns, cities or regional areas could be longer considered just a recipient of services, but "human sensor and actuator" where customers are not just simple consumers but active agents able to also provide operational services. The digitalization 
of the smart measurement devices will enable an intelligent and collaborative society of smart consumers, as it is schematically represented in Figure 4.17.

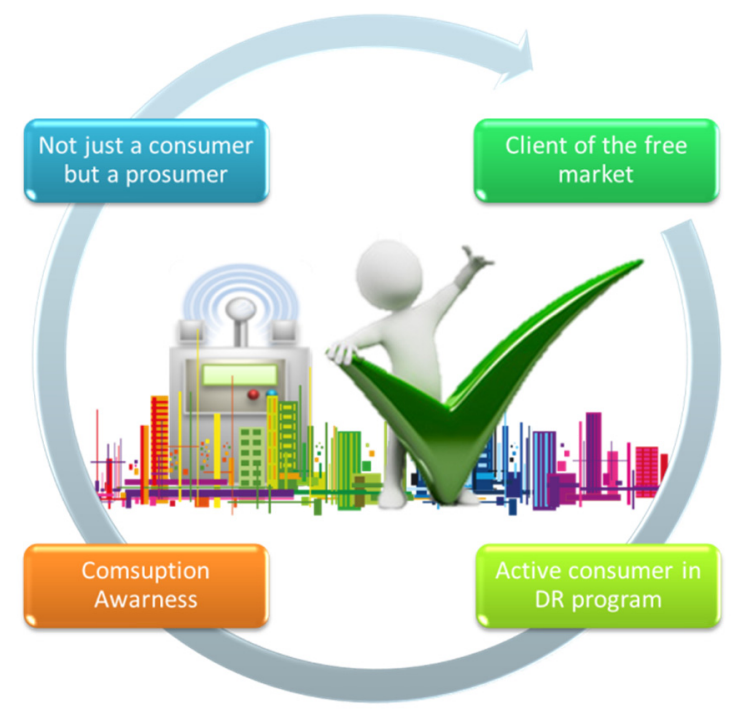

Figure 4.17. The role of a consumers in the smart meter system

Consumers play a fundamental role in the diffusion of DR programs as providers of DR services. So, the empowerment of the consumer role has to take place with the introduction of smart tools and training in order to increase their knowledge level regarding the natural gas consumption and management. In order to satisfy the he Energy Efficiency Directive ((2012/27/EU), end users have to be equipped with a competitively priced individual meter that accurately reflects their energy consumption and provides information on the time of their energy use [102].

The achievement of measurable energy savings will be the driving force to increase the motivation of the customers to participate in DR programs. In order to achieve this goal, there are still some adjustments to be performed into the natural gas system:

- Data should be more frequently gathered. At present, gas consumption is just read once a month for billing purposes. Smart meters should provide data with a major detail (at least hourly) as they are technically able to do it. This capacity would give the possibility to offer more sophisticated DR services.

- A database able to provide customers with the historical data of consumption should be developed, distinguishing historical data corresponding to billing intervals but also to other periods. 
- Energy audits should be performed on the customer side so as to explore their actual flexibility and the best strategies for energy consumption.

- Gas tariffs according to the time-of-use structure should be developed in order to favor a more efficient utilization of the network, similarly to the power grid. At present, natural gas contracts basically use a flat price, so that on-peak and off-peak periods are not taken into account. The methodology proposed in the following chapter of this dissertation would mean an initial step so as to define this kind of initiatives, as well as to evaluate the impact they may produce not just on the customer side, but also on the whole gas system. Telemetry and telemanagement provided by smart meters would be a key element for this purpose as they have the ability to quickly change these aspects (time periods, public holidays, etc.) in a massive way without the need of on field intervention.

- Introduction of the IHD. At present, the IHD is not part of the current rollout of smart meters. In the near future, thanks to this in-home display device that communicates wirelessly with the smart meter, customers would be able to monitor the gas usage and costs in real-time. It may allow them to adjust their usage in response to changes in prices or system reliability events, shifting consumption or shutting it off. This could be done manually or automatically by pre-programming the device, as discussed previously.

Regarding the remote reading, consumers would have to be provided with the following data:

- The detailed volume profile of gas consumed, where consumption peaks could be easily identified. In addition, the remote reading of data has to be done on an hourly basis (or lower, e.g. 30 minutes). The data must be stored, considering security and confidentiality of data issues. Finally, data must be made available to the customer or to any other stakeholder previously authorized by the customer. The data management should be a task developed by the distributor, as discussed in section 3.5.1.

- The status of the gas meter operation (register of diagnostic)

Until now, the roll out of the gas smart meters has resulted less successful than for electricity systems, not just for the low level of implementation (just a few countries have decided to do it) but also because just a few characteristics are used. It means that most of the potential of gas smart meters remain underexploited.

One of the main limitations of gas smart meters is the dependency on batteries for power supply, while power meters are directly supplied from the grid. This fact actually limits the autonomy of gas smart meters; however, the lower technology cost makes that the price of smart gas meters is lower than their equivalent on the electricity side [102].

In any case, significant progress has been done in the field of gas metering, as discussed in this chapter. The growing use of the natural gas, especially for acclimation ad power 
production, increases the interconnection between the electrical and natural gas markets, which one more time show their links and similarities.

\subsection{Conclusions of the chapter}

In this chapter, the technological progress on gas smart metering during the last years is analyzed, evidencing the obtained results that most of the potential of such devices remain underexploited. Smart meters can be used for many sophisticated applications, such as the implementation of DR initiatives; however, their utilization is limited at present to remotely take the monthly consumption reading for invoicing purposes.

In order to maximize the performance of smart meters for DR applications, the following technical requirements have been identified:

- Smart meters should be equipped and supported by some additional smart devices, such as a thermostatic sensor for the control of temperature or a seismic valve for the automatic closure of gas supply in case of earthquake.

- Connection to the power grid should be provided in order not to be dependent on the battery, as the more frequent utilization of the meter would make the battery insufficient for a longer and more intensive utilization.

- In residential facilities, an IHD should be installed so as to provide customers with an instantaneous interface.

- Smart meters already allow the programing of different periods of consumption, but gas tariffs are designed at a flat price. Therefore, the specification of timeof-use (TOU) tariffs should be promoted for a more efficient utilization of the network.

- A centralized database should be implemented in order to share customer information between aggregators, distributors or any other stakeholder, under permission of the data owner (e.g. the distributor).

Regarding communication issues, this chapter highlights the need of promoting the interoperability between different types of smart meter and SACs, as well as between the SACs of different operators. Today, the utilization of different communication bands in different frequencies makes more difficult the intercommunication between different devices, which results essential for the collection and interchange of data.

In previous chapters, different approaches have been done to the natural gas sector, specially focused on the identification of technics and mechanisms, based on the utilization of customers' flexibility, which may contribute to a more efficient operation of this energy systems. As a result, once these aspects have been analyzed, next chapter proposes a new methodology for the systematic evaluation of DR applications on the natural gas network. 


\section{Chapter 5 Methodology for the application of demand response principles to the natural gas system}

\subsection{Chapter overview}

This chapter presents the methodology developed in this dissertation for the evaluation of the impact when DR principles are used for operation purposes in the natural gas system. As it has been discussed in the previous chapters, the existing similarities between the electricity and natural gas systems permit to expect a successful application of DR concepts for a more efficient operation of natural gas systems by using the flexibility of customers to decrement or increment their consumption in specific periods of time.

Before considering the development of DR products in the natural gas system, it is essential to identify the services that customers may be able to offer. Therefore, the methodology includes as first step the analysis of the management actions that system operators must address every day in the management of the gas systems, such as balancing, pipeline congestion or reserve shortages in underground storages. This step is followed by the identification of similar services on the power system side, so that the application of DR products that have been successfully developed for power system operators is analyzed for the natural gas sector. 
After that, the metering and communication needs for the full exploitation of the flexibility in this sector have to be assessed. Communication should be fast enough so as to allow the utilization of DR services provided by customers according to the system operator needs. The utilization of smart gas meters and how existing devices can be used for DR purposes has to be analyzed, as well as the need of reinforcing these infrastructures or enabling them for new applications.

The methodology here presented will account the following issues:

- DR applications will distinguish the different types of customer (industrial, commercial, residential) due to the different use they may give to the natural gas. It includes from heating or cooking applications in the residential sector to specific thermal processes in the industry, but also power production, co-generation (CHP) or district heating.

- The role of aggregator needs to be enhanced in order to incorporate smaller consumers for operation purposes. To this regard, district heating operators will have special significance as they actually behave as a kind of aggregator, distributing not natural gas directly, but steam or hot water whose production requires a large natural gas consumption which may be centrally managed.

- The different DR applications need to be evaluated not only from a technical perspective, but also economic and environmental. Thus, gas system operators may use DR resources when they could be utilized for the solution of constraints or problems in the grid cheaper than other options. Moreover, the avoided greenhouse emissions related to the reduction of gas consumption may have a significant impact in the achievement of environmental objectives such as the H2020 in Europe or the Environmental Management Strategic Plan in the US.

\subsection{General structure of the methodology}

The methodology is divided into six phases, which detail the different steps to be given for the proper design of suited DR products in the natural gas sector. Moreover, the tasks to be done by the different agents involved in the provision or utilization of DR resources within each phase is also explicated. These agents are:

- The customer, as "generator" of the DR resource when using the flexibility they may have, not only reducing their consumption but also, since a general perspective, increasing it if required in low demand periods.

- The gas system operator (GSO), as the main user of DR resources. The gas operator will use the ability of customer to manage their consumption in order to solve different problems which may arise in the daily operation of the natural gas system infrastructure. 
- While large customers might directly provide their flexibility, it is not operative in the case of smaller gas consumers. Therefore, it appears here the figure of the aggregator, which is an intermediary between the DR providers and the DR users.

As it was mentioned in Chapter 3, aggregators can be classified into two blocks:

- When customers are directly using natural gas, the role of the aggregator will be very similar to the same one in electricity systems: the aggregator is not supplying the gas to the customer, but it represents the customer to the system operator for operation purposes, so that the aggregator receives the requirement from the GSO and manages the customers it has in its portfolio in order to create a flexible demand package according to the GSO request.

- A significant difference between the electricity and the natural gas system is the possibility to consider a second kind of aggregator: the manager of a district heating system (DHS). In this case, the DHS is the actual consumer of natural gas, while final customers are supplied with steam or hot water. Therefore, this manager can play with the downstream heat demand as customers can offer their flexibility not reducing their gas consumption, but their steam or hot water needs. Therefore, the DHS system will be able to offer to the GSO some flexibility in the natural gas consumption according to the flexibility of the final customers in consuming more or less steam or hot water.

In addition to the GSO, the aggregator and the customer, there are other involved agents. Large customers which do not require an aggregator for the provision of DR resources to the GSO could need some assistance in order to identify, to assess and to manage the flexibility they may have. Therefore, the need of someone to support large customers in this task arises. This role will be played by specialized entities which also exist in the electricity sector: Energy Service Companies or ESCOs. The participation of ESCOs is essential for the proper utilization of DR services as the providers of DR resources (customers) are not usually familiar with this kind of specialized knowledge, which is usually far away from the business they are devoted to. This lack of knowledge tends to make them reluctant to the participation in DR services, so that ESCOs have here an essential role in order to convince them and to demonstrate the benefits that the use of flexibility would mean for their enterprises.

Other entities which may be interested in the utilization of DR resources are the gas traders or suppliers. They may use DR resources in order to compensate the imbalances between the gas they purchase in the wholesale market and the real time consumption of the customers they have in their portfolio. However, this aspect would have made more complicated the methodology here presented, so that they have been left out of the scope of this work. Nevertheless, it is important to take them into account for further research and a subsequent improvement and development of this methodology.

The methodology is schematically presented in Figure 5.1. 
The activities to be developed by the different agents are marked in different colors: green for the GSO, yellow for the aggregator and red for the customer. Activities which should be jointly developed by customers and aggregators, or those related to large customers without the participation of the aggregator, are marked in orange.

The methodology accomplishes the following phases:

- Phase 1: Initial specification. The methodology starts with the identification of the system operator needs and the customer abilities. Based on that, a preliminary specification of the services to be based on customer's flexibility can be done.

- Phase 2: Technical evaluation. Technical characteristics of the services identified in the phase 1 are here assessed since a technical point of view, including the physical media (metering, communication and control requirements) that is necessary for the interchange of DR resources.

- Phase 3: Economic evaluation. This is probably one of the main phases of the methodology, as the success or not of the utilization of any DR product depends on the economic profitability that it can provide to both the customer and the GSO. The economic evaluation is based on a cost-benefit analysis, so that a DR product will success if the economic benefit it provides to all the involved agents is higher than the cost of its implementation, or the cost of any alternative solution.

- Phase 4: Environmental evaluation. The footprint reduction linked to the application of any considered DR product is here evaluated, considering not only the avoided $\mathrm{CO}_{2}$ emissions, but also the reduction of other greenhouse gases.

- Phase 5: Validation. Once the DR product has been evaluated from all the perspectives (technical, economic and environmental), a testing phase for the validation of the proposed actions is required in order to demonstrate with feasible evidences that the benefits theoretically evaluated can be actually achieved by all the involved agents.

- Phase 6: Final specification. The last step of the methodology resides on the final specification of the DR product designed and validated in the previous phases, so that the success when using it in the real interchange of DR services between DR providers (customers) and DR users (GSOs) would be guaranteed.

The different phases are detailed in the following sections. 
Methodology for the application of DR principles to the natural gas system

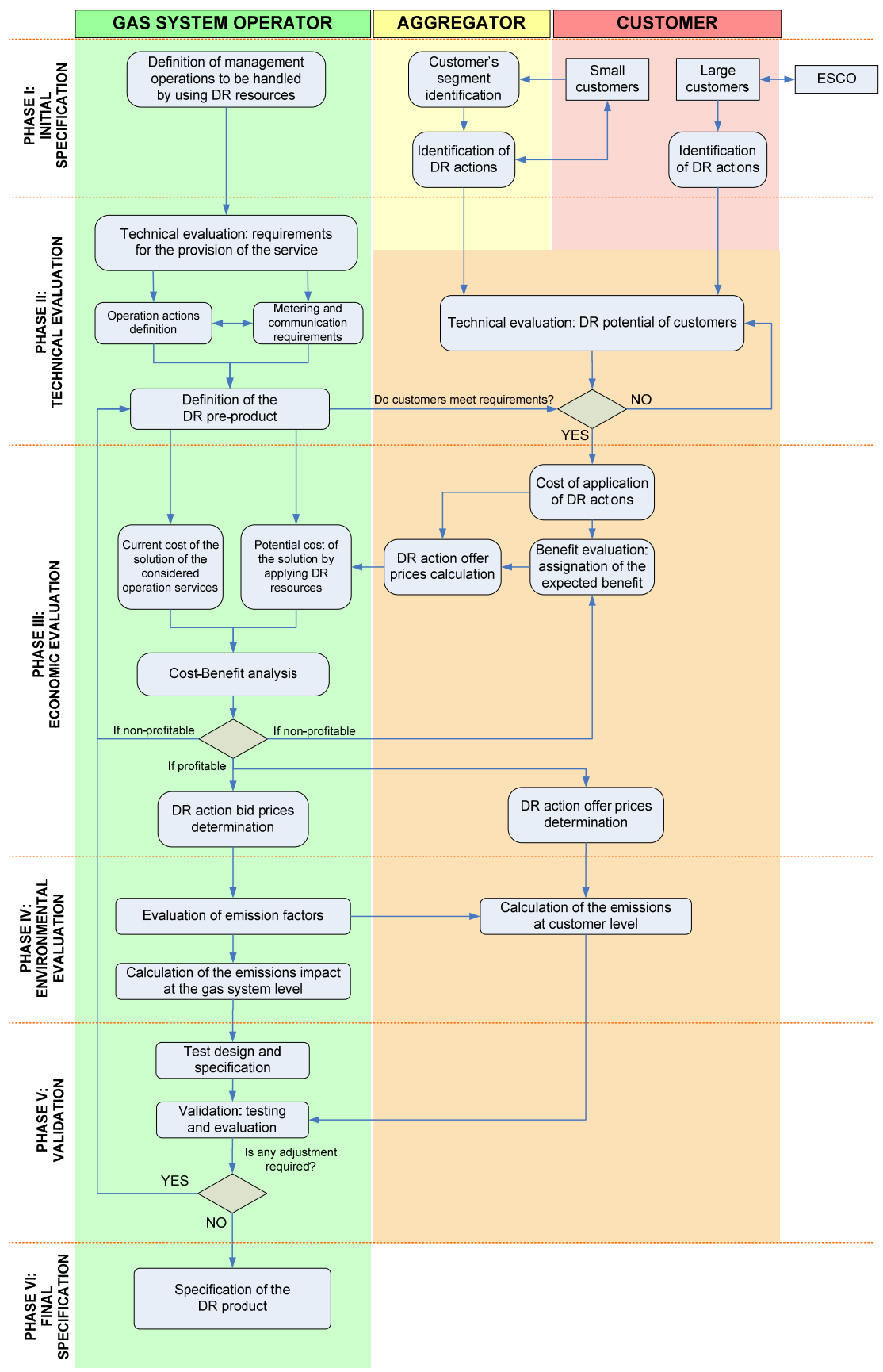

Figure 5.1. Methodology for the implementation of DR strategies in the natural gas sector 


\subsection{Phase I: Initial specification of actions}

\subsubsection{GSO activities}

The first task before proposing the solution of any problem is the identification of such problem. Therefore, the identification of the network problems that may be addressed by the demand side is the first step of this methodology.

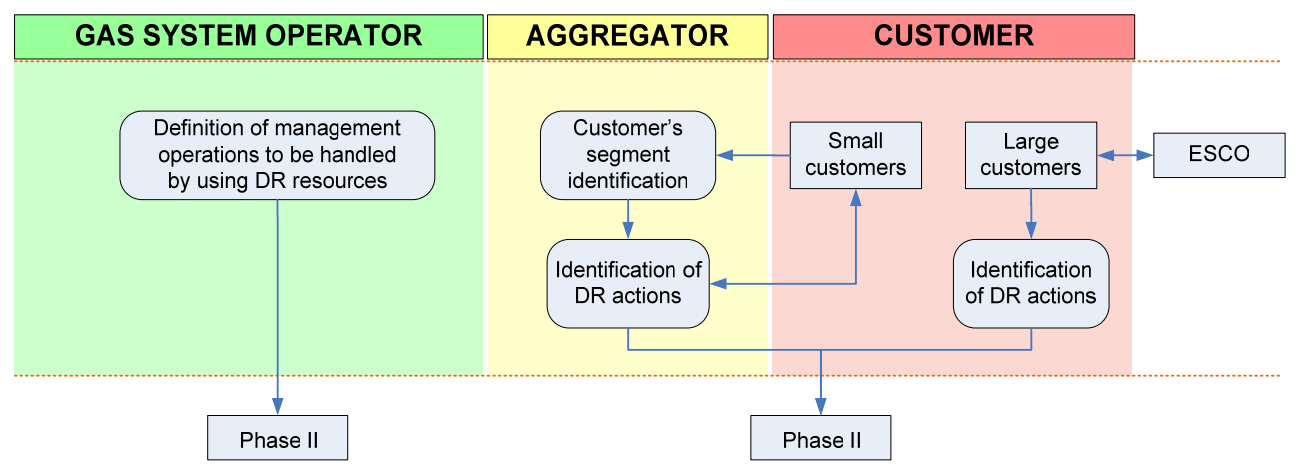

Figure 5.2. Phase 1: Initial Specification

DR may be used for one or several of the following services required by the GSO:

- Service 1: Balancing of natural gas in the transmission network. The amount of natural gas must be daily balanced in order to guarantee that the daily amount of natural gas consumed from and injected to the network is balanced. Moreover, a minimum level of filling of the gas pipelines of the transmission network must be maintained.

- Service 2: Maintenance of the storage level. The daily amount of natural gas inject to or extracted from an underground store must remain within the limits technically established. Therefore, the GSO has to buy in the wholesale market the required amount of gas to refill the store everyday up to the established limit. The use of DR resources may avoid exceeding such limit, reducing the consumption of customers when the daily storage limit is achieved.

- Service 3: Solution of technical constraints, which may produce transmission and distribution infrastructures overload or even interruption of supply to customers. Such technical constraints have been previously discussed in section 3.3.

\subsubsection{Customer and aggregator activities}

Customers are the providers of DR services (DRP). However, the direct utilization of very dispersed and little demand packages is not operative for the GSO. For that reason, 
it is a learned lesson that the direct participation of single customers in the provision of DR services should be restricted to large customers, whose individual offers may have some significance for the GSO.

Due to this lack of operability, the participation of small customers has been historically neglected in the provision of DR services in the electricity sector. Similarly, the few experiences of DR applications in the gas system, as analyzed in section 2.3, have been just focused on very large customers. Nevertheless, small customers may have a large potential that may be used if properly aggregated. Therefore, the role of aggregator arises here as the key for the full exploitation of the customer's flexibility in the natural gas sector.

As it has been mentioned in the previous section, the aggregator of DR resources in the natural gas sector has two different versions:

- The traditional aggregator, which represents and manage the flexibility of medium and small customers in order to create more significant DR packages so as to be offered to the GSO. Customers aggregated under this figure are natural gas consumers, which directly use this fuel in a boiler or a burning system for heating purposes.

- The manager of district heating systems (DHS). In this case, customers do not directly use the natural gas, but steam or hot water supplied by the DHS, who is the actual consumer of the fuel. Therefore, and diversely to the traditional one, this aggregator would be simultaneously the thermal energy supplier and the manager of the DR resources that may be offered by the supplied customers within its portfolio.

In both cases, the objective is the same: using the ability of customers to modify their usual pattern of consumption (consuming natural gas or any other thermal fluid) as a response to the aggregator.

Large customers, typically supplied at a high pressure (and frequently connected to the transmission network) usually are going to need some kind of support in order to identify the flexibility they may have in their facilities. Also they can require some training in order to start playing with this flexibility, or to assess the impact that such flexibility may have in their processes. This aspect is important, because the acceptability of this impact will decide if the customer modifies or not its consumption. Therefore, the participation of an external agent so as to provide large customers with this support is required. This external agent is the Energy Services Company (ESCO). This figure is not necessary in the case of smaller customers that do not directly participate but aggregately, provided that this role is played by the aggregator.

Some examples of DR actions that customers can consider in order to offer their flexibility are the following: 
- Similarly to the use of flexibility of air conditioning devices in DR applications in the electricity sector, the installation of smart thermostats for the remote management of heating devices may open the gate for the exploitation of a very large potential. Sometimes, the same thermostats can be used for cooling and heating purposes (e.g. in the United States, the installation of smart thermostats in acclimation systems is being rapidly deployed across the country and are expected to replace the compressor switches that are used to control air conditioners [12]). Programmable thermostats might be remotely controlled by the own customer but also by a third party (such as the aggregator)

- In addition to heating space devices which use natural gas, the management of other residential and commercial applications such as water heating or clothes drying may be very flexible.

- In large commercial and industrial applications, more specific processes would be considered, such as industrial washing machines, furnaces, boilers or air heaters. Direct control may be applied to those processes, which could be also related to some kind of interruptible gas contract.

Individual or aggregately, the output of this phase on the customer/aggregator side is the identification and definition of the DR actions that the interested natural gas customers can offer. Once this identification is done, the next step will be the technical evaluation of this potential, as it will be discussed in the next section.

\subsection{Phase II: Technical evaluation}

\subsubsection{Standardization of DR actions}

The technical evaluation of the DR actions identified in the previous task requires matching of the technical abilities of customers and the technical requirements of the GSO. Therefore, in order to allow this comparison, a standardized definition of the DR actions understandable for all the parties is required. The technical evaluation here proposed will be defined according to the following parameters ${ }^{58}$ :

a) Hourly gas flow reduction (HFR). As stated in section 2.4, the equivalent parameter to the contracted power of a natural gas facility is the maximum daily flow. Therefore, flexibility actions in the gas sector will be measured according to this variable. In this methodology, duration of 1 hour for a typical flexibility action will be considered. Consequently, the equivalent parameter to the flexible

\footnotetext{
${ }^{58}$ A proposal on the standardization of electrical DR actions was developed in the DRIP Project [42], [147]. Some of the parameters proposed in that project have been adapted here to the gas sector.
} 
power will be the flexible hourly gas flow. HFR is measured in $\mathrm{kWh} / \mathrm{h}$. Complementarily to HFR, the factor $\mathrm{H}_{\text {firm }}$ is defined as the maximum hourly gas flow to be demanded by the customer during the flexibility action.

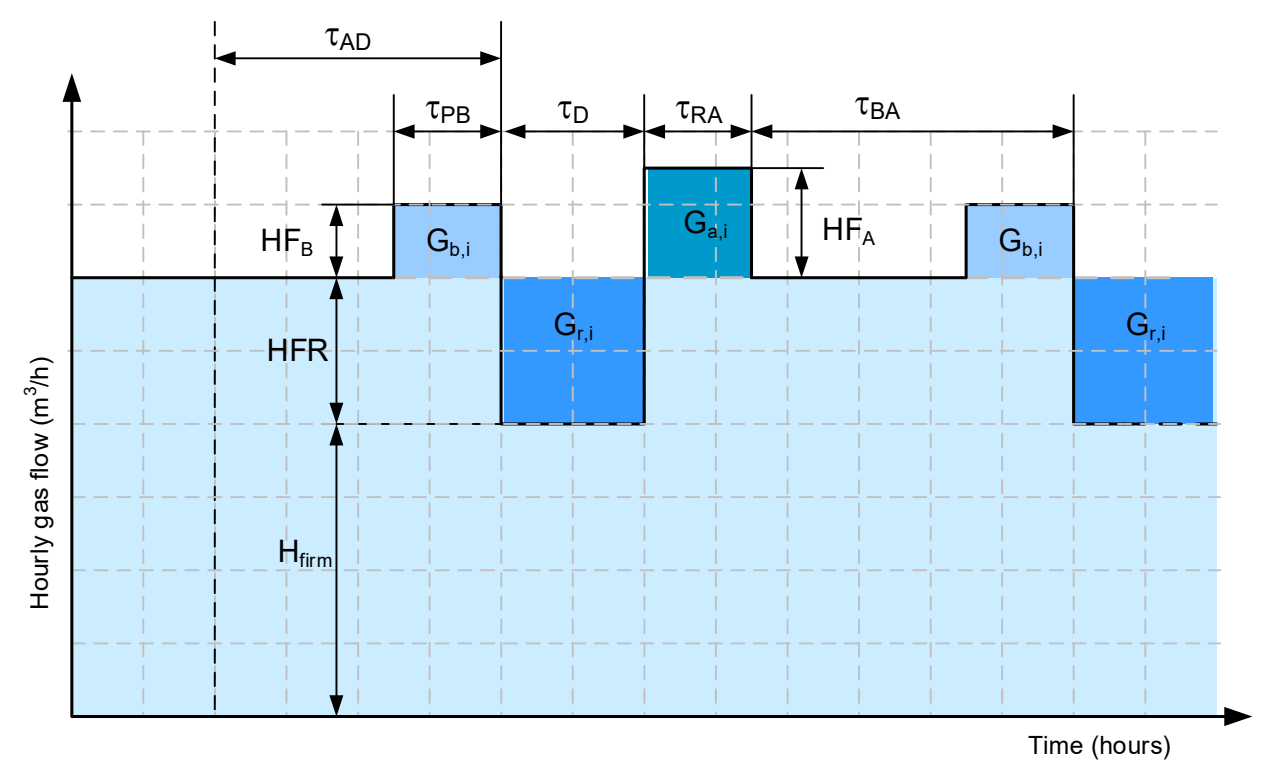

Figure 5.3. Standard definition of a DR action for a flexible gas consumer

a) Duration of the flexibility action ( $\left.\tau_{D}\right)$. If standard reductions have duration of 1 hour, the total duration of a flexibility action will be equal to the number of consecutive reductions that may take place at the customer facility.

b) Notification in advance $\left(\tau_{\mathrm{AD}}\right)$. This parameter indicates the time required by the customer in order to perform a flexibility action. It includes the time necessary for the adaptation of facilities and the physical management of the control devices.

c) Additional hourly flow demand before the $\mathrm{DR}$ action $\left(\mathrm{HF}_{\mathrm{B}}\right)$. If an extra demand before the implementation of the DR action is required for the preparation of the processes to be managed, HF-B will be equal to the maximum hourly flow that is necessary for the adaptation of the facilities. Similarly to HFR, $\mathrm{HF}_{\mathrm{B}}$ is measured in $\mathrm{kWh} / \mathrm{h}$.

d) Duration of the preparation period ( $\left.\tau_{\mathrm{PB}}\right)$. This parameter represents the time during which the customer demands the HF-B before the implementation of a DR action 
e) Additional hourly flow demand after the $\mathrm{DR}$ action $\left(\mathrm{HF}_{\mathrm{A}}\right)$. After the application of a DR action, an additional demand may be necessary in order to get back to the initial conditions (e.g. to reach the set point temperature). If this is the case, this demand overrun is considered by this parameter. $\mathrm{HF}_{\mathrm{A}}$ is measured in $\mathrm{kWh} / \mathrm{h}$.

f) Duration of the recovery period $\left(\tau_{R A}\right)$. Similarly to $\tau_{\mathrm{PB}}$, this parameter considers the duration of the recovery period, during which the customer retakes the initial conditions.

g) Availability frame (AF). This parameter defines the time frame during which the flexibility action can be implemented (e.g. on working days).

h) Minimum time between actions $\tau_{\mathrm{BA}}$. This is the time that must happen, at least, between the end of a flexibility action and the beginning of the next one.

Figure 5.3 shows the existing relation between the different parameters that would be used for a standard definition of a DR action that a flexible natural gas customer may implement.

\subsubsection{Assessment of the technical impact}

The amount of natural gas reduced by the customer when applying a flexibility action "i" is denoted by $\mathrm{G}_{\mathrm{r}, \mathrm{i}}$. If flexible demand packages have a standard duration of 1 hour, the total amount of energy reduced by the customer during the implementation of action "i" will be:

$$
G_{r, i}=H C V_{N G} \cdot H F R \cdot \tau_{D, i} \quad(\mathrm{kWh})
$$

where $\mathrm{HFR}_{\mathrm{i}}$ is the hourly gas flow reduction related to the action " $\mathrm{i}$ ", measured in $\mathrm{m}^{3} / \mathrm{h}$, and $\tau_{\mathrm{D}, \mathrm{i}}$ is the number or hours during which the action would take place. $\mathrm{HCV}_{\mathrm{NG}}$ is the higher calorific value of natural gas, whose value depends on the quality and composition of the gas supplied to the consumers. Usually, it takes values from 37.5 to $43.0 \mathrm{MJ} / \mathrm{m}^{3}$, which equals to values from 10.42 to $11.94 \mathrm{kWh} / \mathrm{m}^{3}$.

Similarly, the amounts of gas consumed before and after the application of the flexibility action in order to prepare the facilities or to get back the initial conditions would be calculated as follows:

$$
\begin{aligned}
& G_{b, i}=H C V_{N G} \cdot H F_{B, i} \cdot \tau_{P B, i} \quad(\mathrm{kWh}) \\
& G_{a, i}=H C V_{N G} \cdot H F_{A, i} \cdot \tau_{R A, i} \quad(\mathrm{kWh})
\end{aligned}
$$

According to the previous equations, the total amount of gas reduced during the application of action "i" will be: 


$$
G_{\text {reduced }}=H C V_{N G} \cdot\left[H F R_{i} \cdot \tau_{D, i}-H F_{B, i} \cdot \tau_{P B, i}-H F_{A, i} \cdot \tau_{R A, i}\right](\mathrm{kWh})
$$

Based on the proposed standard parametrization of gas flexibility, customers can assess the potential they may have when performing some of the actions identified in the previous phase (management of water heaters, modification of the temperature set point of air heaters, etc.). On the other hand, the GSO as the flexibility user will characterize the requirements that the operation of the natural gas and the solution of technical constraints may require by using the same code as consumers. Therefore, the matching between what customers offer and the GSO needs will be much easier achieved.

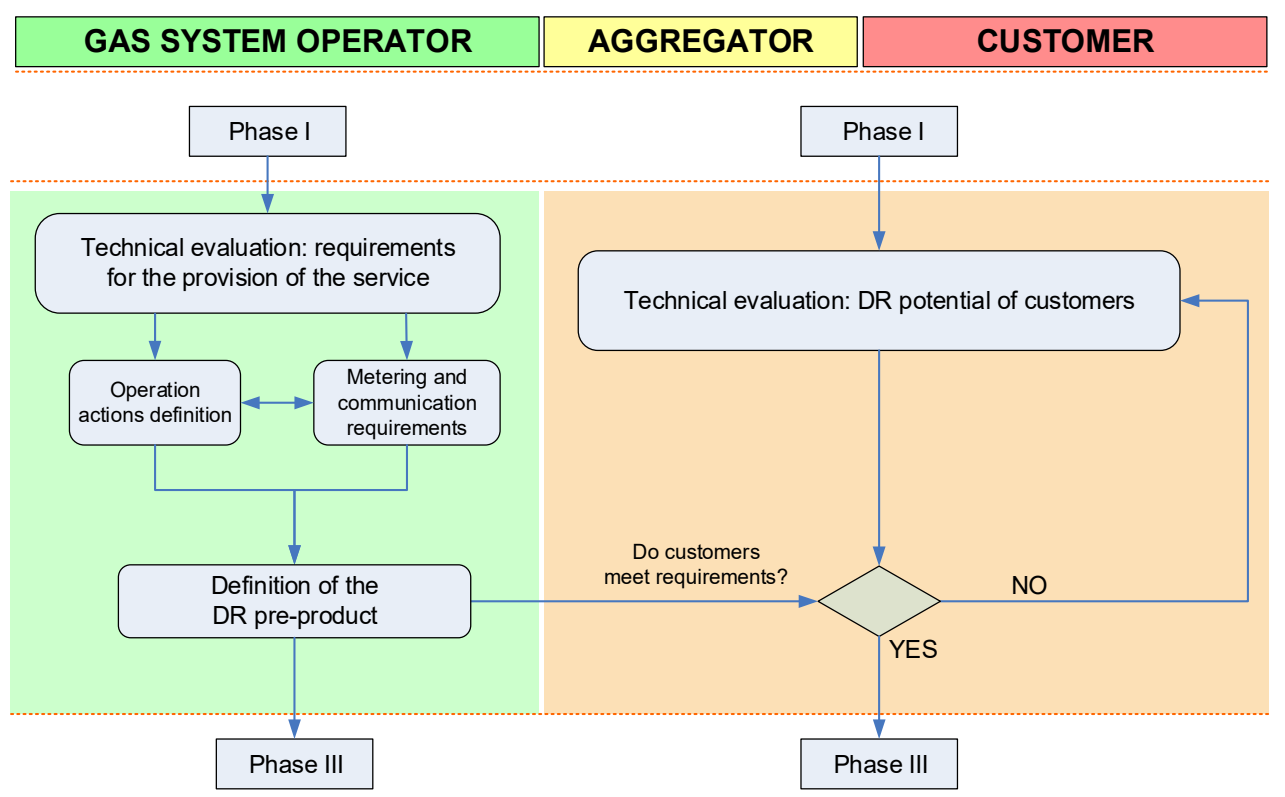

Figure 5.4. Phase 1I: Technical Evaluation

Together with the technical flexibility parametrization according to the previous statements, as shown in Figure 5.4, the GSO also needs to establish here the metering and communication requirements that will be necessary in order to properly use the flexibility of customers. Additionally, customers will be economically settled according to the degree of fulfilment of the DR service they are giving to the GSO. Therefore, the GSO must guarantee that the conditions established in the DR product have been satisfied. Metering and communication requirements will depend on the kind of service required by the GSO and how DR will be used and verified. An overview of possible equipment and configurations is provided in Chapter 4 . 
Once the DR product has been pre-defined according to the GSO needs, a verification step is necessary in order to check if the potential actions to be performed by customers fit the requirements of the GSO as DR user. If it happens, the technical evaluation has been successfully concluded and the economic evaluation performed in the next phase may be done. Otherwise, the abilities of customers would require a revision as they are not completely useful to the GSO needs as formulated at present. Therefore, an additional effort will be required from the customer/aggregator side so as to redefine what they can offer so as to mean a valuable service for the GSO.

\subsection{Phase III: Economic evaluation}

The economic evaluation here proposed will be based on a cost-benefit analysis, as it is intended that the success of a DR action will be based on the economic benefit that it may produce to all the parties involved in the transaction: the GSO as DR user and the customer or aggregator as DR provider.

From the DR provider perspective, the provision of DR services will be profitable when the incomes provided by the DR user are higher than the cost for the customer when performing such DR action.

On the other hand, the GSO would use DR resources so as to solve some problem that may appear in the gas network if the cost of using DR is lower than the cost of solving such problem by means of traditional mechanisms.

In both cases, the application of a DR action must benefit to both parties, so that this economic approach will be the kingpin in order to make a decision on using or not the flexibility that customers may have.

\subsubsection{Costs evaluation on the GSO side}

As mentioned above, the objective of this economic analysis is based on comparing the current operation costs that the GSO has to face so as to handle some kind of operation service and the cost that the utilization of DR resources provided by customers may have. Depending on the nature of the considered service, the GSO costs may be evaluated as follows:

- Cost of natural gas for balancing purposes $\left(C G_{h}^{B a}\right)$. The provisioning of natural gas for operation purposes is usually done in a daily basis. In general, the hourly cost of natural gas for operation could be calculated as follows:

$$
C G_{h}^{B a}=\left(\pi_{B a l}+\pi_{N G, d}\right) \cdot H F_{h}^{B a} \cdot H C V_{N G}(€ / \mathrm{h})
$$

where $H F_{h}^{B a}\left(\mathrm{~m}^{3} / \mathrm{h}\right)$ represents the hourly amount of natural gas used for operation purposes that is incorporated to or extracted from the network. The origin 
of $H F_{h}^{B a}$ could be an interconnection pipeline to an external gas system, the facilities of an internal producer or a regasification plant. If the hourly value is unknown, it may be estimated as the daily value divided into 24 . $\mathrm{HCV}_{\mathrm{NG}}$ $\left(\mathrm{kWh} / \mathrm{m}^{3}\right)$ is the higher calorific value of natural gas. On the other hand, $\pi_{\mathrm{NG}, \mathrm{d}}$ $(€ / \mathrm{kWh})$ is the price of the natural gas used for operation purposes which is incorporated to or extracted from the system. If the GSO needs more gas, $\pi_{\mathrm{NG}, \mathrm{d}}$ will be positive and it would represent the price of natural gas that the GSO must pay to the gas provider in the wholesale market. Otherwise, if there is an excess of gas, $\pi_{\mathrm{NG}, \mathrm{d}}$ will be negative and it would be the price at which the GSO sells the exceeding amount of gas to the wholesale market. Finally, $\pi_{\text {Bal }}(€ / \mathrm{kWh})$ is the hourly cost of operation of the network related to balancing operations.

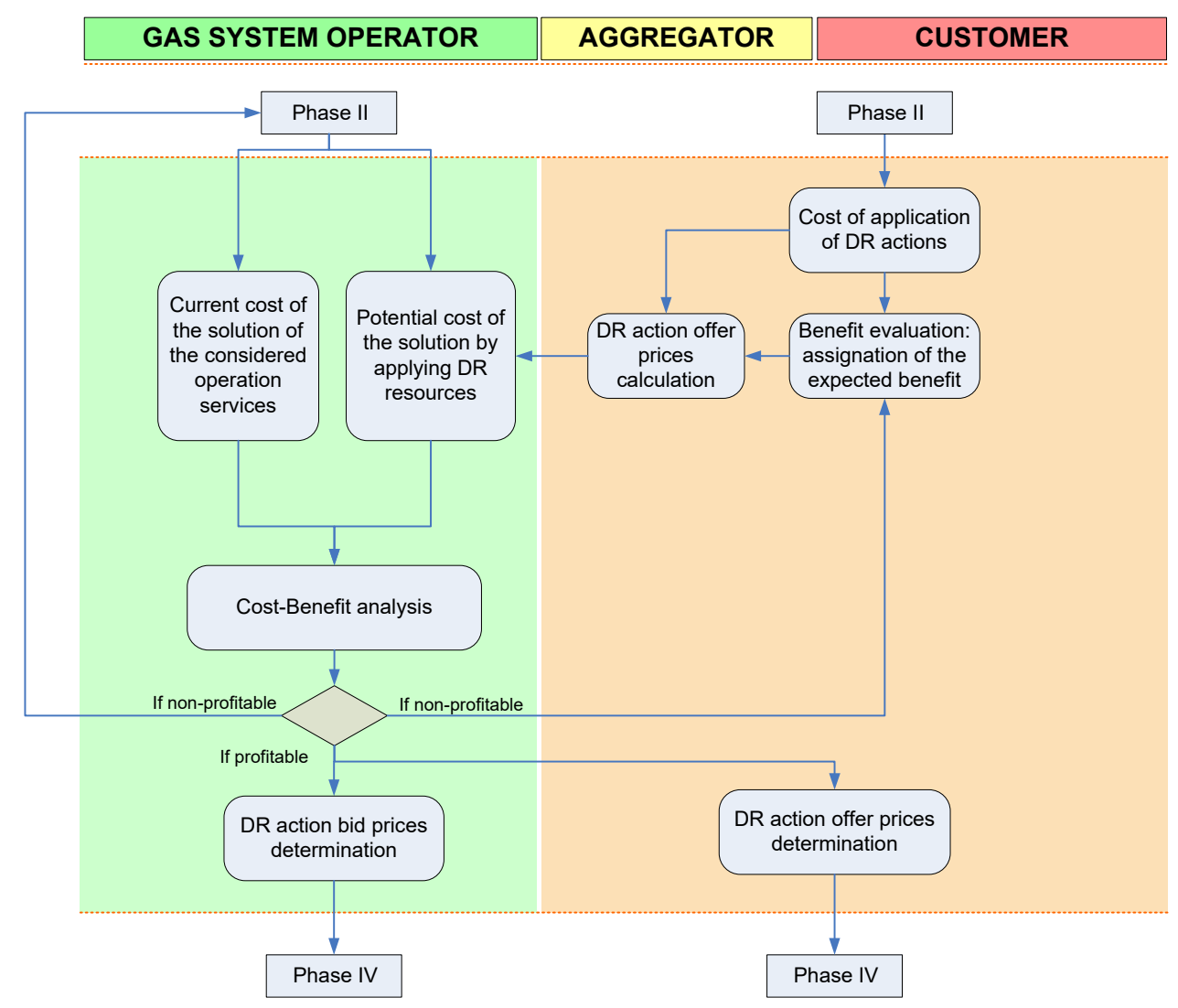

Figure 5.5. Phase 1II: Economic Evaluation 
- Maintenance of the storage level. The GSO must purchase from the wholesale market the amount of natural gas that is requested to as to restore the level of stored gas in case that the maximum admissible volume have been extracted during a day. The cost of this gas can be calculated as follows:

$$
C G_{h}^{S t}=\left(\pi_{N G, d}^{S t}+\pi_{O p}^{S t}\right) \cdot H C V_{N G} \cdot H F_{h}^{S t}(€ / \mathrm{h})
$$

where $H F_{h}^{S t}\left(\mathrm{~m}^{3} / \mathrm{h}\right)$ is the hourly amount of natural gas purchased by the GSO to restore the daily level of stored gas. If the hourly value is unknown, it may be estimated as the daily value divided into $24 . \mathrm{HCV}_{\mathrm{NG}}\left(\mathrm{kWh} / \mathrm{m}^{3}\right)$ is the higher calorific value of natural gas. On the other hand, $\pi_{N G, d}^{S t}(€ / \mathrm{kWh})$ is the price of the natural gas purchased by the GSO in the wholesale market for storage purposes and $\pi_{O p}^{S t}(€ / \mathrm{kWh})$ is the hourly cost of storage (operation and maintenance).

- Cost of non-supply $\left(C_{N S}\right)$. This is the cost in that the GSO incurs when there is a gas shortage due to some constraint, such as delay in the discharge of tankers or lack of capacity in the pipelines. This cost could be evaluated as follows:

$$
C_{h}^{N S}=\alpha_{h}^{N S}+\beta_{h}^{N S} \cdot H F_{h}^{N S}(€ / \mathrm{h})
$$

where $\alpha_{h}^{N S}(€ / \mathrm{h})$ and $\beta_{h}^{N S}\left(€ / \mathrm{m}^{3}\right)$ are, respectively, the fix and the variable price to be paid by the GSO to the customers not supplied during the hour h due to operational issues; $N S_{h}^{N S}$ is the hourly flow that is not supplied to the customers, measured in $\mathrm{m}^{3} / \mathrm{h}$. Prices $\alpha_{h}^{N S}$ and $\beta_{h}^{N S}$ are usually given by the local regulation as they are considered as a compensation to customers as they are not delivered the committed amount of gas.

\subsubsection{Cost evaluation on the customer/aggregator side}

The costs related to the use of flexibility in the customer/aggregator side can be structured according to the direct and indirect costs classification that can be found in [141] applicable to the electricity sector.

According to this classification, direct hourly costs would include:

- The cost of control $\left(C_{C t r, h}^{D R P}\right)$, which includes the different management actions oriented to the application of flexibility in the customer side. This cost includes both the operational costs linked to control and the necessary investments for the control equipment acquisition and installation.

- The cost of metering and monitoring $\left(C_{M t M, h}^{D R P}\right)$, that is necessary in order to evaluate the potential of customers at any hour and also to validate the fulfillment of a flexibility contract. Similarly to the cost of control, this cost also includes 
the necessary investments for the metering and monitoring equipment that may be necessary.

- The cost of dual supply $\left(C_{D S, h}^{D R P}\right)$, which takes into account the possibility to use an alternative energy source when the main natural gas supply fails. It may include burners which use a different fuel (diesel, fuel) or electric heaters.

- Finally, the cost of amortizations $\left(C_{A m, h}^{D R P}\right)$, that considers the annual amortization related to the necessary investments so as to adapt the customer facilities for DR implementations.

Regarding indirect costs, the following concepts can be considered:

- The cost of additional manpower $\left(C_{M P, h}^{D R P}\right)$ that could be necessary in order to apply flexibility in the facility. It includes the extra working hours of related workers or even the hiring of some additional employee to be responsible of this new activity in the facility. In the case of small customers (residential or small commercial), this cost would include the payments to an external agent that may be necessary in order to manage the flexibility of the facilities.

- The cost of losses $\left(C_{L S, h}^{D R P}\right)$, which entail the loss of comfort for residential and commercial customers, or even the loss of productivity in the case if the industry. The evaluation of this cost is not easy, especially when considering the loss of comfort as it may be quite subjective. However, it is important to evaluate well this concept as it may have a strong influence in the final decision on activating or not some flexibility actions.

The hourly cost of implementation of a DR action will be thus calculated as follows:

$$
C_{h}^{D R P}=\sum C_{k, h}^{D R P}=C_{C t r, h}^{D R P}+C_{M t M, h}^{D R P}+C_{D S, h}^{D R P}+C_{A m, h}^{D R P}+C_{M P, h}^{D R P}+C_{L s, h}^{D R P}
$$

\subsubsection{Cost-benefit balance}

Once the different costs have been evaluated, the cost-benefit analysis of a DR action can be evaluated. A specific DR action will success when it provides a benefit to both sides: the GSO and the customer.

The benefit that is required for customers/aggregators in order to provide the DR Service would be established in advance, so that when a DR offer is sent to the GSO, either the costs that customers/aggregators incur in and the benefit margin they require so as to provide this service will be included in the offer. Therefore, the price required by the DR provider so as to provide the GSO with the service "i" would be calculated as follows:

$$
\operatorname{Pr}_{i}^{\text {offer }}=\tau_{D, i} \cdot \frac{\left(C_{h}^{D R P}-\Delta H F_{h}^{D R P}\right)}{G_{r, i}}+B_{h}^{D R P} \quad(€ / \mathrm{kWh})
$$


where $\tau_{\mathrm{D}, \mathrm{i}}(\mathrm{h})$ is the number or hours during which the action would take place; $C_{h}^{D R P}$ $(€ / \mathrm{h})$ is the hourly cost for the customer/aggregator when performing the DR action, as calculated in equation (5-8); $G_{r, i}(\mathrm{kWh})$ is the total amount of energy reduced by the customer during the implementation of action " $\mathrm{i}$ ", as calculated in equation (5-1); $B_{h}^{D R P}$ $(€ / \mathrm{kWh})$ is the benefit margin required by the customer to be willing to offer the flexibility it may have, and will be fixed according to the own strategy defined by the customer or aggregator; finally, $\Delta H F_{h}^{D R P}(€ / \mathrm{h})$ represents the impact of the DR action on the cost of the gas consumption for the customer related to the cost when the DR action is not implemented, being calculated according to the following expressions:

$$
\Delta H F_{h}^{D R P}=\left(G_{r, i}-G_{b, i}-G_{a, i}\right) \cdot \pi_{i, h}^{\text {contract }}(€ / \mathrm{h})
$$

$\Delta \mathrm{HF}_{\mathrm{h}}^{\mathrm{DRP}}(€ / \mathrm{kWh})$ is the price that the customer pays for the natural gas according to the contract of supply, and $\mathrm{G}_{\mathrm{ri}}, \mathrm{G}_{\mathrm{bi}}$ and $\mathrm{G}_{\mathrm{ai}}$ are calculated according to equations (5-1), (5-2) and (5-3).

The operation service "i" for which the GSO may require the participation of customer's flexibility would be based on a price, calculated according to the following expression:

$$
\operatorname{Pr}_{i}^{b i d}=\left\{\begin{array}{l}
\frac{\pi_{B a l}+\pi_{N G, d}}{H C V_{N G}} \text { if service } 1 \\
\frac{\pi_{O p}^{S t}+\pi_{N G}^{S t}}{H C V_{N G}} \text { if service } 2 \\
\frac{1}{H C V_{N G}} \cdot\left[\frac{\alpha_{h}^{N S}}{H F_{h}^{N S}}+\beta_{h}^{N S}\right] \text { if service } 3
\end{array} \quad(€ / \mathrm{kWh})\right.
$$

When the price required by the customer/aggregator is lower than the price offered by the GSO, the transaction may be established. If this is the case, the customer will obtain a benefit, given by the margin $B_{h}^{D R P}$ used in the calculation of the offer price. Moreover, the GSO will obtain also a benefit, as it would receive from the demand side a service that is cheaper than other alternatives.

This methodology proposes a "pay as bid" settlement, so that the customer/aggregator would receive the required price when offering the service, which already includes its own benefit. The hourly benefit $B_{h}^{D R R}$ of the GSO would be calculated as the difference between the cost that the GSO has to face when solving the network service by means 
of traditional means and the payment to be given to the customer when providing such service:

$$
B_{h}^{D R R}=\frac{G_{r, i} \cdot\left(\operatorname{Pr}_{i}^{\text {bid }}-\operatorname{Pr}_{i}^{\text {offer }}\right)}{\tau_{D, i}}(€ / \mathrm{h})
$$

$G_{r, i}(\mathrm{kWh}), P r_{i}^{\text {bid }}(€ / \mathrm{kWh})$ and $P r_{i}^{o f f e r}(€ / \mathrm{kWh})$ are calculated by equations (5-1), (5-9) and $(5-10)$, and $\tau_{\mathrm{D}, \mathrm{i}}(\mathrm{h})$ is the number or hours during which the action would take place.

If the proposed actions do not provide a net benefit to both stakeholders (the GSO as DR requester and the customer/aggregator as DR provider), actions to be performed by the demand side should be redefined and adjusted, going back to the phase II, as well as the service requested by the GSO. Otherwise, obtained prices may be accepted so as to establish a DR market between both parties.

\subsection{Phase IV: Environmental evaluation}

The combustion of natural gas produces three greenhouse gases: $\mathrm{CO}_{2}, \mathrm{SO}_{2}, \mathrm{NO}, \mathrm{N}_{2} \mathrm{O}$ and $\mathrm{CH}_{4}$. Therefore, any reduction in the consumption of natural gas derived from the activation of some kind of DR product will have an impact on the carbon footprint and other emissions. However, the natural gas is the fossil fuel with the lowest environmental impact. This is true not only in the utilization stage, but also in the phases of extraction, production and transmission.

According to Eurogas ${ }^{59}$, the high hydrogen-to-carbon ratio of natural gas results in a production of $\mathrm{CO} 2$ a $30 \%$ lower than for oil and $50 \%$ less than for coal per unit of energy produced during combustion. Additionally, natural gas emits less nitrogen and sulphur oxides, as well as particles than any other fuel fossil.

Table 5.1. Greenhouse emission factors for natural gas. Source: EPA, 2014

\begin{tabular}{ccc}
\hline $\begin{array}{c}\mathbf{C O}_{2} \\
\mathbf{k g} / \mathbf{N m}^{3}\end{array}$ & $\begin{array}{c}\mathbf{C H}_{4} \\
\mathbf{m g} / \mathbf{N m}^{\mathbf{3}}\end{array}$ & $\begin{array}{c}\mathbf{N}_{2} \mathbf{O} \\
\mathbf{m g} / \mathbf{N m}^{\mathbf{3}}\end{array}$ \\
\hline 2.07 & 39.16 & 3.80 \\
\hline
\end{tabular}

The environmental impact of DR actions on the natural gas emissions can be evaluated by multiplying the emission factors of the different sub-products resulting from the gas

\footnotetext{
${ }^{59}$ Eurogas is an association representing the European gas wholesale, retail and distribution sectors. www.eurogas.org
} 
combustion by the energy saved when flexibility is used. According to EPA [142], emission factors of the main combustion products of natural gas are given in Table 5.1.

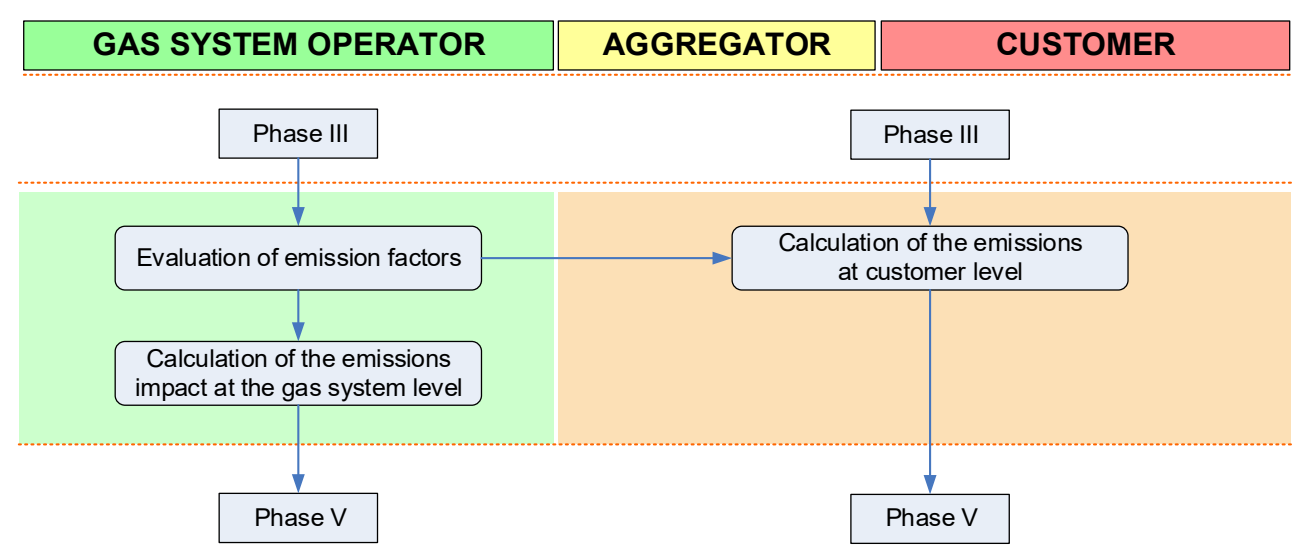

Figure 5.6. Phase IV: Environmental Evaluation

If $G_{\text {reduced }}(\mathrm{kWh})$, calculated in equation (5-4), is the net amount of natural gas saved when applying a DR action, the greenhouse emissions related to that application for each type of emission is:

$$
\text { Greenhouse Emission }=\left\{\begin{array}{l}
G_{\text {reduced }} \cdot \frac{2.07}{H C V_{N G}} \text { if } \mathrm{CO}_{2} \\
G_{\text {reduced }} \cdot \frac{39.16 \cdot 10^{-6}}{H C V_{N G}} \text { if } \mathrm{CH}_{4} \\
G_{\text {reduced }} \cdot \frac{3.8 \cdot 10^{-6}}{H C V_{N G}} \text { if } \mathrm{N}_{2} \mathrm{O}
\end{array}\right.
$$

$\mathrm{HCV}_{\mathrm{NG}}$ is the higher calorific value of natural gas, which takes values from 10.42 to $11.94 \mathrm{kWh} / \mathrm{m}^{3}$, depending on the quality and composition of the gas supplied to the consumers. 


\subsection{Phase V: Validation}

Once a DR product has been specified and adjusted, the last step before launching it into the market is the validation, where the different aspects theoretically evaluated in the previous steps will be actually demonstrated with a real application.

The success of this validation will reside in a good design and specification of the tests to be performed. Such design must include not only the technical and economic characteristics of the DR action to be implemented, but also the metering and communication needs, which are essential for the activation of a DR service and the subsequent assessment for settlement purposes.

The phase of design should also specify the number of customers to be considered for the implementation of tests so as to get significant results that may be extrapolated for larger populations.

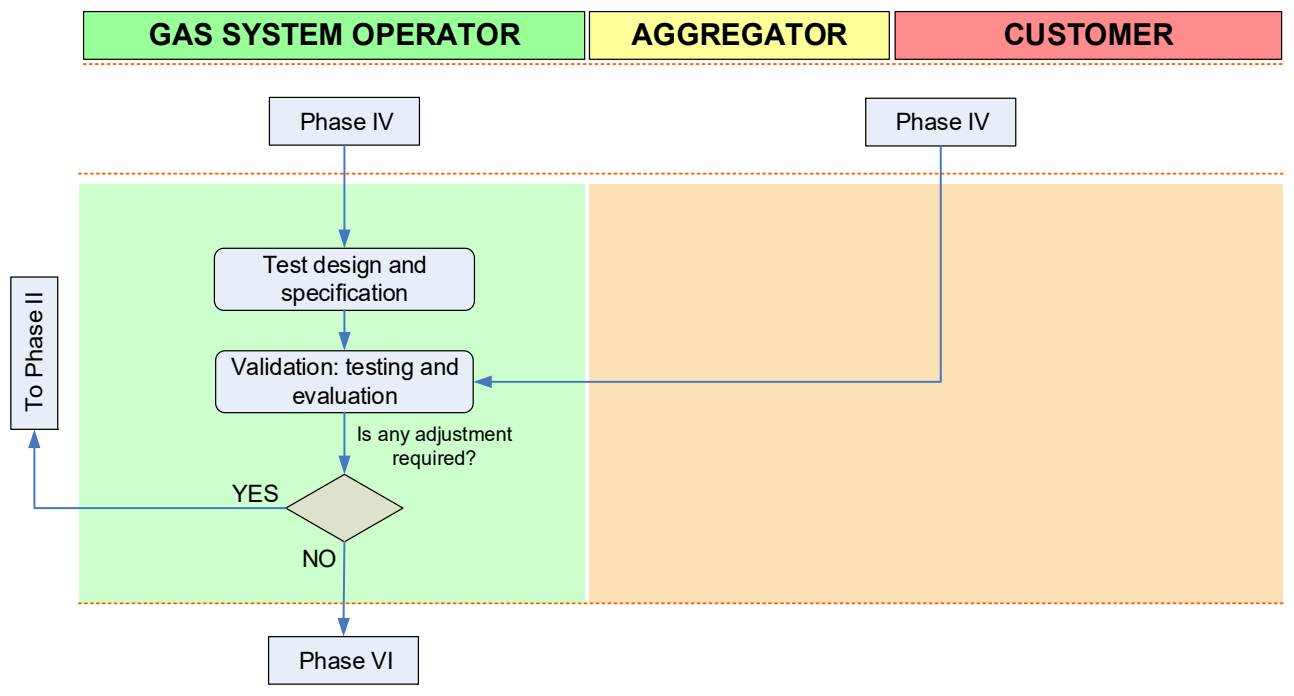

Figure 5.7. Phase V: Validation

Once all the variables are specified, a set of tests will be done, being the GSO responsible to verify the suitability of the DR product according to its specifications. If the obtained results do not success, some adjustments may be requested, so that going back to the Phase II of this methodology would be necessary. Otherwise, the DR product would be ready to be used for the provision of DR services into the market. 


\subsection{Phase VI: Final specification of DR products}

The last phase of this methodology is the final specification of DR products, when the validation phase has been successfully completed.

Since a technical point of view, the used parameters so as to define the DR product should be those detailed in Figure 5.3. Then, the economic evaluation should have demonstrated the profitability that the designed DR product means for the GSO and the customer/aggregator. Also, a reduction in the GHG emissions may be obtained if the use of flexibility has achieved net reductions in the gas consumption of customers.

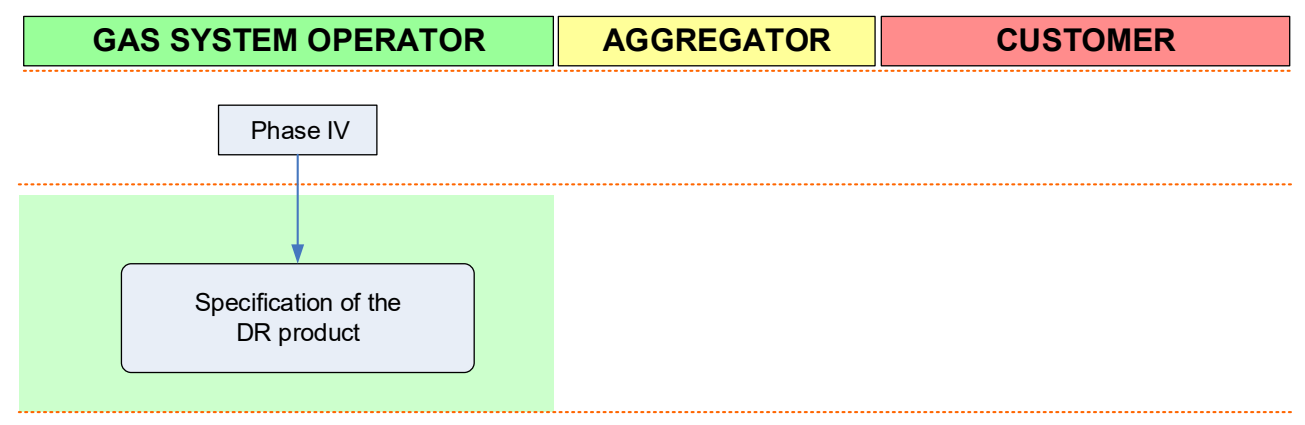

Figure 5.8. Phase VI: Final specification of DR products

The DR product specification has to also include the requirements regarding communication and metering equipment, as well as the settlement mechanism that would be used by the GSO so as to remunerate the consumer/aggregator as DR provider.

\subsection{Conclusions of the chapter}

A new methodology for the systematic design and evaluation of DR products to be used in the natural gas sector is presented in this chapter. This methodology is one of the most significant contributions of this dissertation, where the potential provision of operation services to the GSO is enhanced and evidenced.

The demonstrated value of the demand side participation in the power market permits expecting similar results if DR initiatives were implemented in the natural gas sector, whose development has taken place in parallel to the electricity market.

Both electricity and natural gas are the most significant energy vector in the world. However, the participation of customers for operation purposes has been traditionally left aside in the gas system. This methodology provides a systematic procedure for the design, evaluation and validation of DR products that can be used by the GSO in the daily operation of the grid, taking advantage of the flexibility of customers and reducing the operational costs of the whole natural gas network. 
The methodology that is discussed in this chapter has been applied to a real case in the next chapter, providing empirical evidence about the effect that the use of DR entails on existing gas infrastructures. 



\section{Chapter 6 Case of application: DR evaluation in the Italian natural gas system}

\subsection{Chapter overview}

The methodology developed in the previous chapter is here applied to a real case, so that the suitability of the proposed method is validated. The methodology has been applied to the natural gas system of a city of 16,000 inhabitants, located in the region of The Marches, Italy. In this town, an estimation of the DR potential has been done considering that natural gas consumers would participate in the provision of balancing services. As it has been demonstrated, the utilization of DR resources may help to reduce the imbalances in the natural gas system, reducing also the cost related to the management of such imbalances, as well as the cost of purchasing additional amounts of gas in the wholesale market for balancing purposes.

\subsection{Considered scenarios: DR strategies and case description}

According to the methodology presented in the previous chapter, three possible DR strategies may be initially considered for the utilization of gas consumers' potential: 
- Service 1: Balancing of natural gas in the transmission network. The amount of natural gas must be daily balanced in order to guarantee that the daily amount of natural gas consumed from and injected to the network is balanced. Therefore, the flexibility of consumers may be used so as to reduce the imbalances in the natural gas network, reducing the daily difference between the gas extracted and injected.

- Service 2: Maintenance of the storage level. The daily amount of natural gas inject to or extracted from an underground store must remain within the limits technically established. The use of DR resources may avoid exceeding such limit, reducing the consumption of customers when the daily storage limit is achieved.

- Service 3: Solution of technical constraints, which may produce transmission and distribution infrastructures overload or even interruption of supply to customers.

In this chapter, it is considered the participation of flexible consumers for balancing purposes, which covers the first of the mentioned services.

\subsubsection{Period of analysis and characterization of the natural gas balancing service}

The information related to prices of imbalances and amounts of energy extracted from and injected to the gas network has been obtained from the Italian GSO Snam Rete Gas S.p.A.

The period of analysis includes one whole year, from $1^{\text {st }}$ October 2015 to $30^{\text {th }}$ September 2016.

Every day, the GSO has to balance the amount of natural gas in the network so as to balance the system. According to the difference between the amount of natural gas in the network and the net demand of customers during the day, the system can be in three different states:

- If the gas consumed by customers is higher than the amount purchased in the wholesale market, the system is said to be short. Therefore, when the system is short, the GSO has to purchase an additional amount of gas in order to balance the network.

- If the gas consumed by customers is lower than the amount purchased in the wholesale market, the system is said to be long. Consequently, the GSO has to sell to the wholesale market the gas excess so as to balance the network.

- When customers consume exactly the amount of gas purchased in advance in the wholesale market, the system is said in equilibrium and the GSO does not need neither purchase nor sell any amount of gas for balancing purposes. Nevertheless, it is hardly difficult if not impossible that the system remains in equilibrium as there is always some difference between the energy pre-purchased 
and actually consumed. Therefore, practically speaking, the system would be actually long or short, so that the GSO should buy or sell some amount of gas for balancing purposes at the end of the day.

According to equation (5-5), there are two prices which have to be defined:

- The hourly cost of operation of the network related to balancing operations $\pi_{\mathrm{Bal}}$. According to the annual report of Snam, the annual cost of balancing operations for 2015 was 1,800 million of euros [143]. As the annual amount of energy involved in balancing services was 29,586,788 $\mathrm{MWh}$, an average value of 60.84 $€ / \mathrm{MWh}$ has been considered for this concept.

- The price of the natural gas in the wholesale market for balancing purposes $\pi_{\mathrm{NG}, \mathrm{d}}$. This price is published monthly by Snam and it is available in the website of the GSO. The prices considered for the evaluation presented in this chapter, together with the daily amounts of natural gas purchased and sold in the wholesale market from October 2015 to September 2016 are shown in Figure 6.1

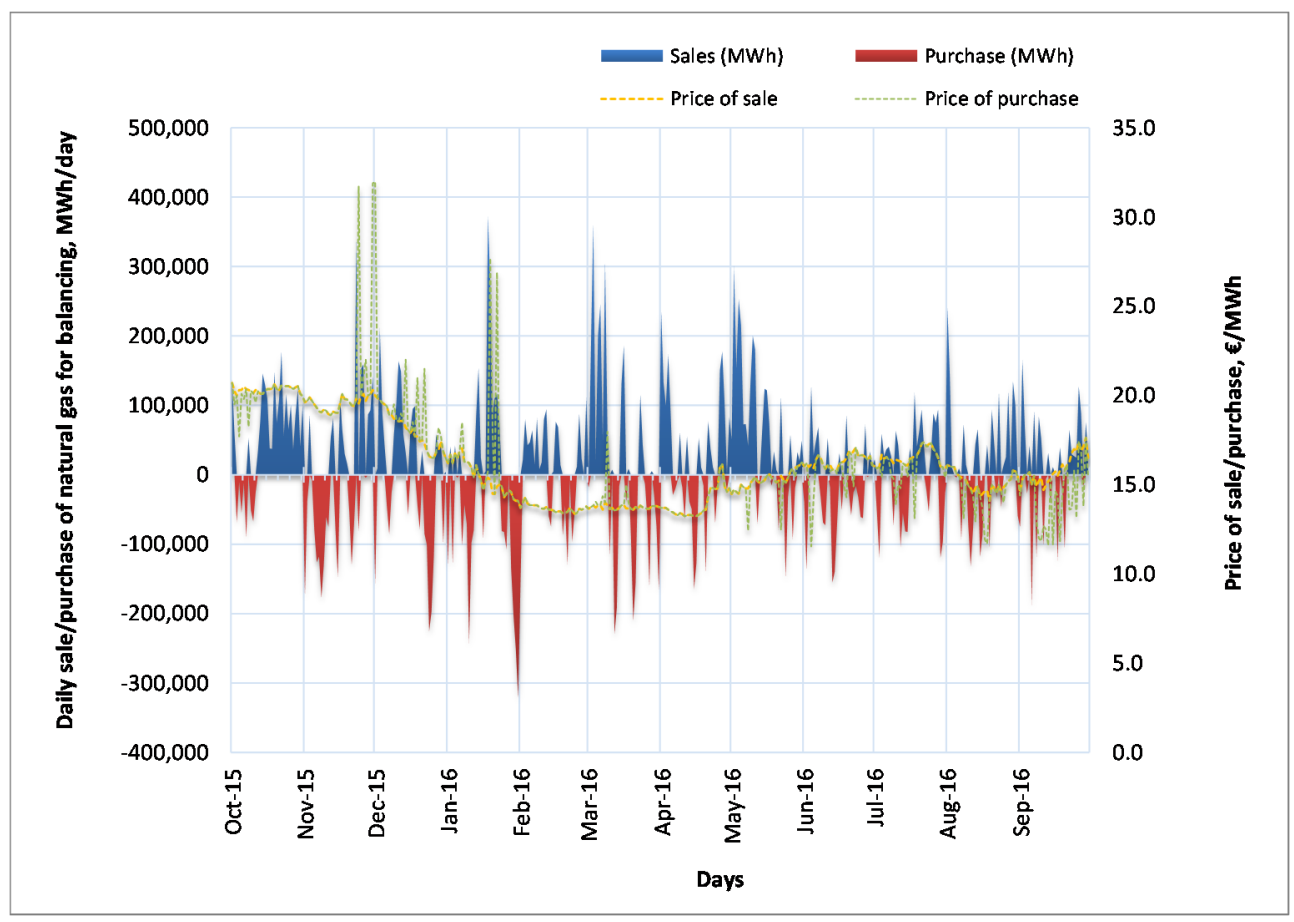

Figure 6.1. Prices and amounts of gas for balancing in Italy 2015-2016 (source: Snam)

The price of sale is the amount received by the GSO in days when the gas system is long (there is a surplus of natural gas that the GSO has to sell in the wholesale market because 
the demand has been lower than the amount of gas purchased the day before). Conversely, the price of purchase is the amount to be paid by the GSO in the wholesale market for the amount of gas that needs to be incorporated to the network in short days (when the demand exceeds the amount of gas purchased the day before).

The case analyzed in this chapter will assess the impact of using the flexibility of customers so as to minimize the need to purchase or sell for balancing purposes, reducing the cost for the whole system.

\subsubsection{Description of consumers}

\subsubsection{Location and size}

The aforementioned DR strategies will be applied to a town of 16,000 inhabitants, located in the region of The Marches, in the central area of Italy (see Figure 6.2). This region is especially interesting due to the high risk of earthquakes which may damage the natural gas infrastructures. Therefore, the utilization of customers' flexibility may help in the solution of some of the technical constrains that may appear as a consequence of the lack of some pipelines or ancillary facilities.

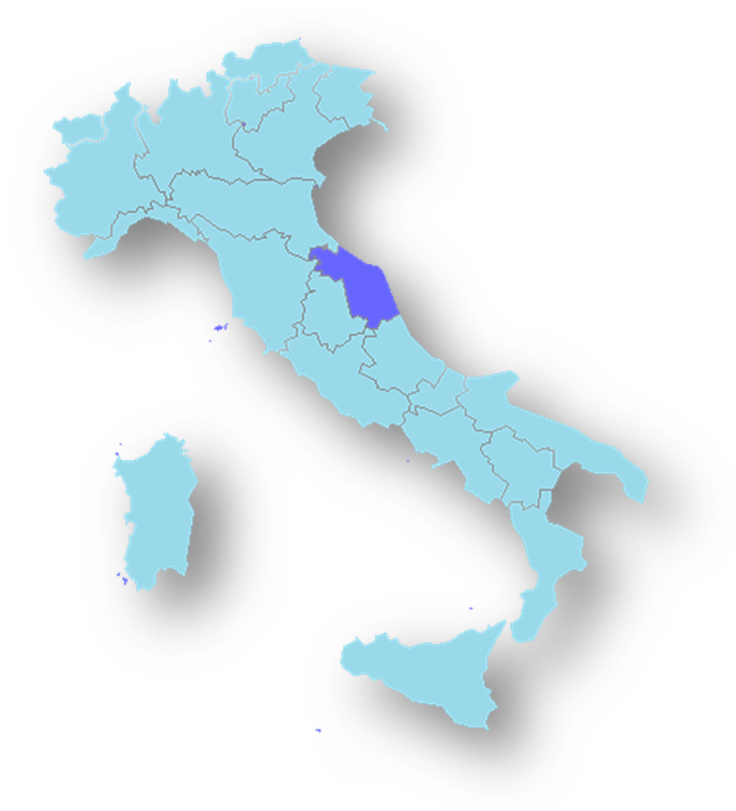

Figure 6.2. Location of the region of The Marches in Italy

Figure 6.3 shows the number of towns in the region of The Marches, grouped according to the number of inhabitants. The town which has been chosen for the application of the 
methodology belongs to the group marked in red, which includes the towns with a population between 10,000 and 20,000 inhabitants. This group is composed of 20 towns with a total population of 270,918 inhabitants (2012), which represents the $18 \%$ of the total population of this region.

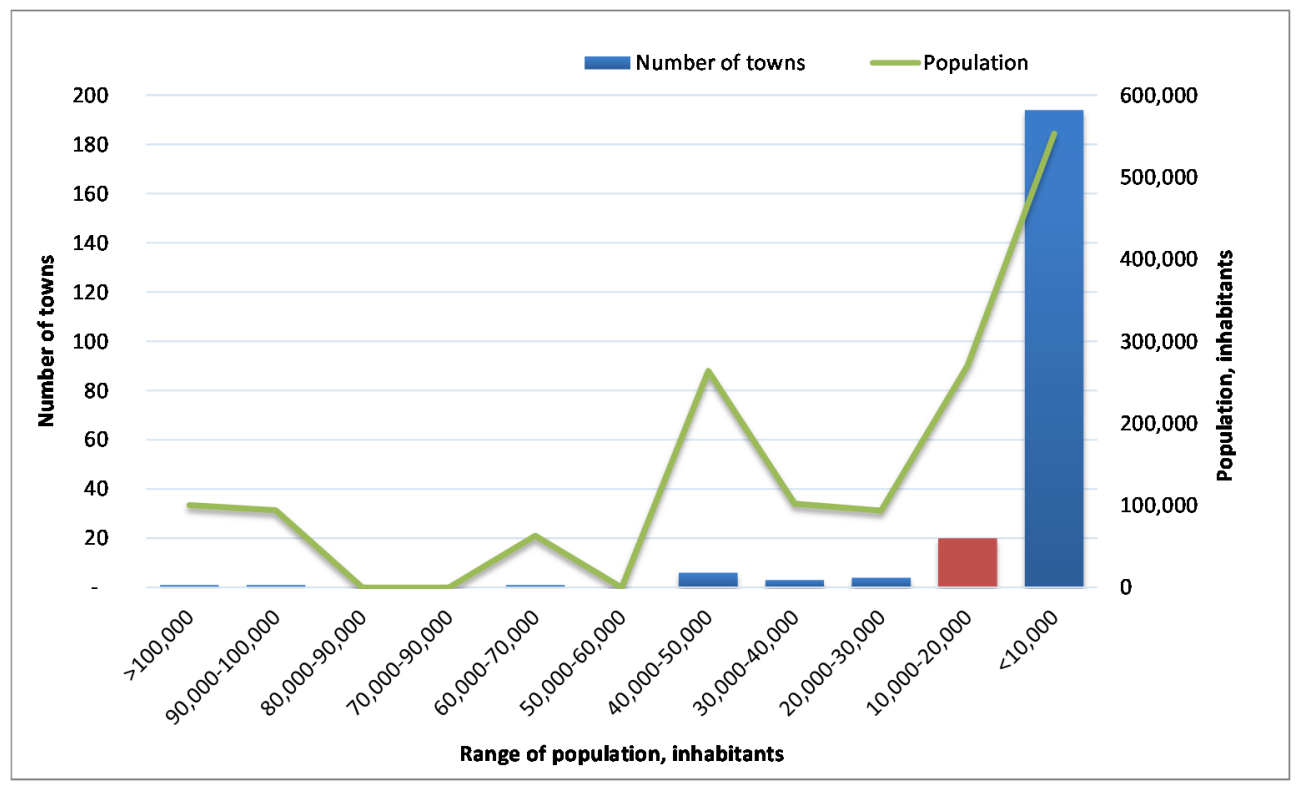

Figure 6.3. Towns' classification in the region of The Marches, Italy (2012)

The distributor of natural gas for this town is the company $2 i$ Rete Gas S.p.A., who has provided the consumption data considered in this chapter. The considered town has 557 points of supply (388 residential and 169 non-residential), with a total annual consumption of $1,704,400 \mathrm{Nm}^{3} /$ year.

\subsubsection{Classification of consumers}

According to the data provided by the distributor, gas consumers have been divided into two blocks:

- Residential: It includes domestic consumers which use natural gas for homes.

- Non-Residential: It includes commercial and industrial applications, others than domestic uses.

Non-residential consumers are divided into six categories, according to the standard classification of gas consumers in Italy based on the final use that is given to the natural gas [84], as explained in section 3.2.4.4: 
- C1: The natural gas is mainly used for space heating

- $\mathrm{C} 2$ : The natural gas is mainly used for cooking and hot water production

- C3: The natural gas is used for space heating, cooking and hot water production

- C5: The natural gas is used for space heating and cooling

- T1: The natural gas is used for industrial processes

- T2: The natural gas is used for industrial processes and space heating

Another category (C4) also exists in the Italian regulation, including consumers which use natural gas for space cooling. However, this category is not considered here as there are not customers under this classification in the studied town.

\subsubsection{Monthly gas consumptions per category}

The daily consumption of consumers under each category has been accounted for the period under analysis, which covers from October 2015 to September 2016. Figure 6.4 shows the gas daily load curve for the mentioned period, where the consumption of customers under each category has been plotted in different colors.

The load profile of gas consumers per category is also detailed in Figure 6.5. Notice that teach chart is represented in different scale, according to the size of the category.

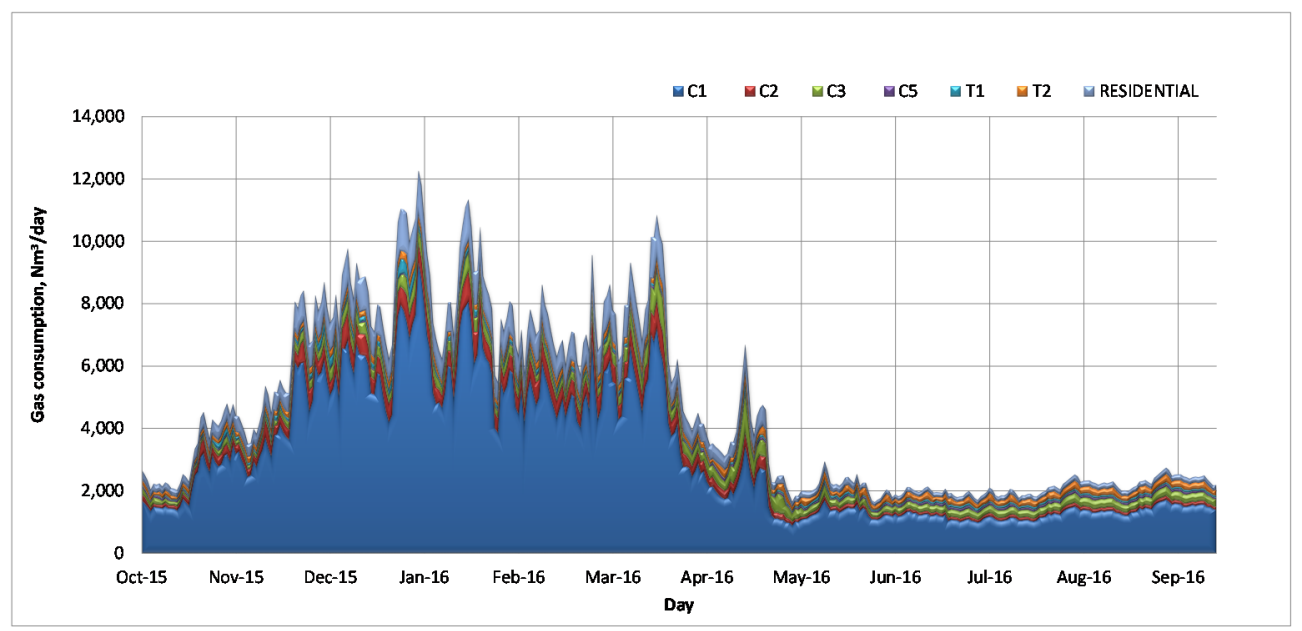

Figure 6.4. Natural gas load curve profile of consumers in a town of 16,000 inh.

For this evaluation, a mean high calorific value $(\mathrm{HCV})$ of $10.74 \mathrm{kWh} / \mathrm{Nm}^{3}$ has been considered for the natural gas, according to the standard value considered by the distributor. By means of this factor, the energy consumption of natural gas per category has been obtained, as it is shown in Table 6.1. 

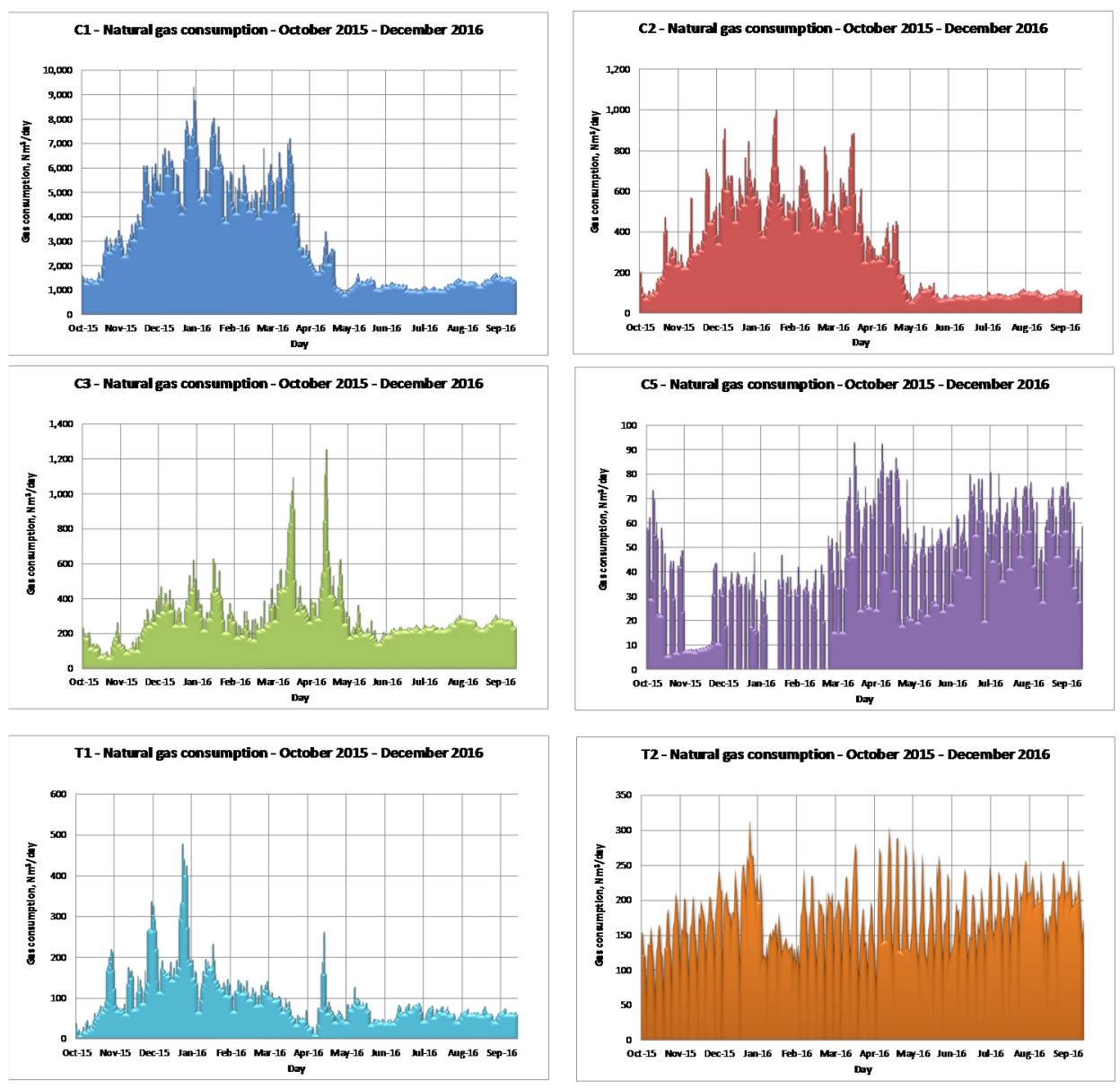

Figure 6.5. Natural gas load curve profiles per category

According to this table, as well as it is shown in the previous figures, most of the consumption is related to space heating (category $\mathrm{C} 1$ ). It means that most of flexibility of gas customers in the analyzed town would be coming from the modification of the temperature set-point of devices used for acclimatization. This is especially interesting when comparing the flexibility sources of power and gas customers, as one of the most flexible end uses in the electricity consumption is the air conditioning. One more time, the similarities between DR resources either in the electricity and gas sector arise, so that a similar potential may be expected.

The total monthly consumption per category is finally represented in Figure 6.6. As it may be expected, the highest consumption takes place during the winter months (from 
November to March) while demand is lower in summer as the heating requirements are lower.

Table 6.1. Annual consumption of gas per category

\begin{tabular}{lrr} 
& $\mathbf{N m}^{\mathbf{3}} /$ year & MWh/year \\
\cline { 2 - 3 } $\mathrm{C} 1$ & $1,154,437.94$ & $12,398.66$ \\
$\mathrm{C} 2$ & $116,718.77$ & $1,253.56$ \\
$\mathrm{C} 3$ & $112,436.08$ & $1,207.56$ \\
$\mathrm{C} 5$ & $15,934.59$ & 171.14 \\
$\mathrm{~T} 1$ & $37,693.04$ & 404.82 \\
$\mathrm{~T} 2$ & $66,581.22$ & 715.08 \\
Residential & $200,592.67$ & $2,154.37$ \\
\hline TOTAL & $\mathbf{1 , 7 0 4 , 3 9 4 . 3 0}$ & $\mathbf{1 8 , 3 0 5 . 1 9}$ \\
\hline
\end{tabular}

If the monthly rate of consumption of this town is compared to the total amount of natural gas supply in the whole country by the distributor $2 i$ Rete Gas S.p.A.(Figure 6.7), the obtained profile for both cases is very similar, being the standard deviation lower than $1.7 \%$ in all the months. Therefore, it can be concluded that gas consumers in the selected town behave according to the usual patterns and, therefore, the obtained results may be extrapolated to the whole country.

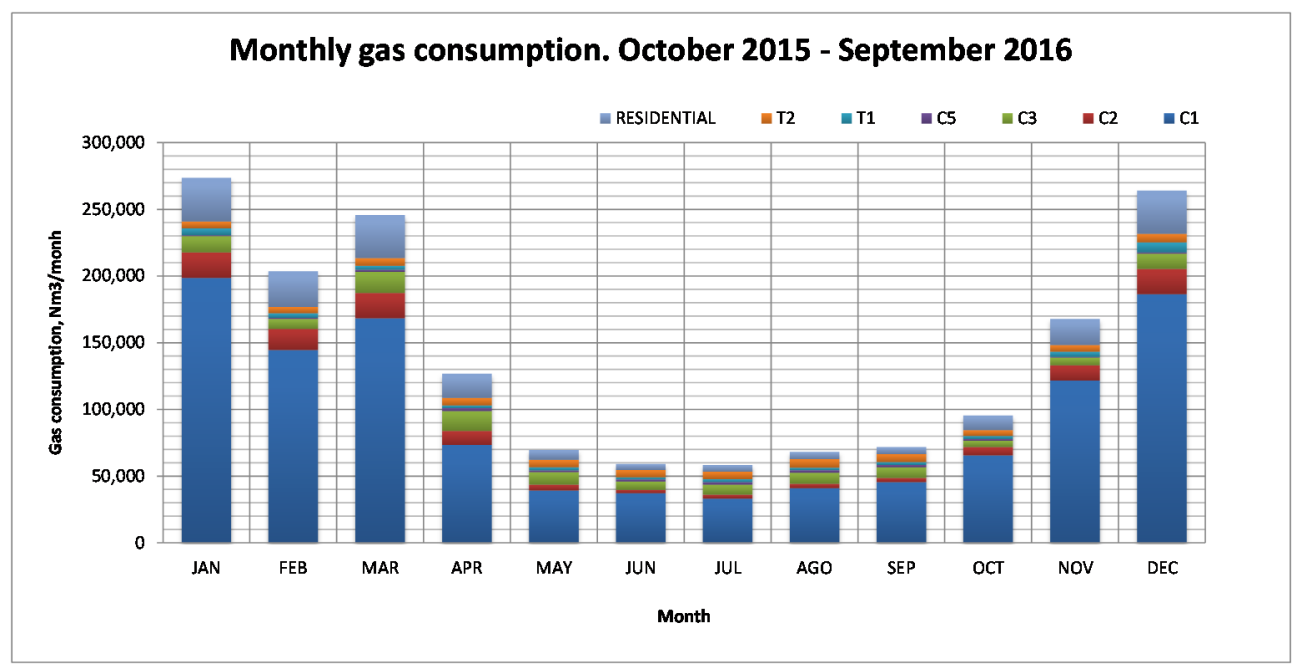

Figure 6.6. Monthly gas consumption for the considered town of $16,000 \mathrm{inh}$. October 2015 - September 2016 


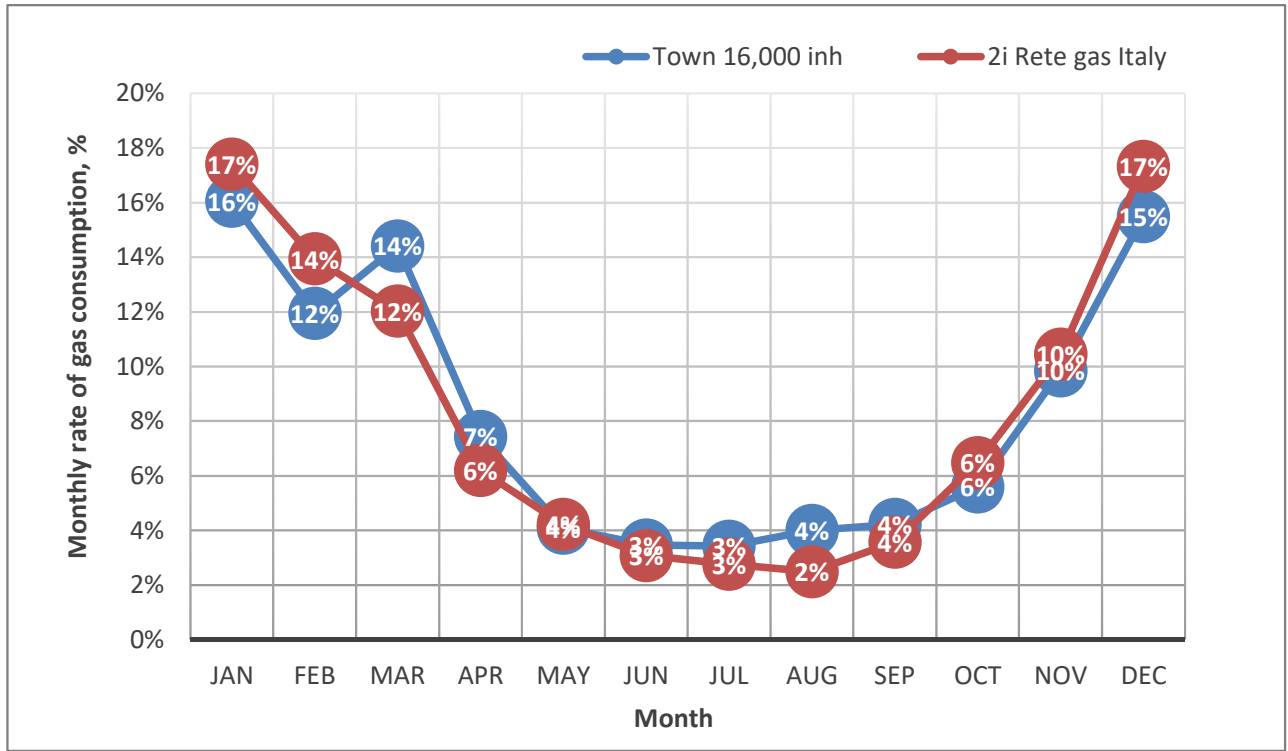

Figure 6.7. Comparison between the monthly rate of consumption for the considered rate and the whole distribution area of $2 \mathrm{i}$ Rete gas in Italy

\subsection{Technical evaluation}

\subsubsection{Evaluation of the flexibility potential}

The utilization of the flexibility of gas consumers in the considered town has been evaluated so as to help the GSO in the balance of the network. Therefore, the flexibility potential has to be evaluated according to the amount of energy that consumers may reduce or shift from one specific period to another one.

The evaluation of flexibility is not an easy task, and it requires detailed energy audits at the customer side where energy patterns are identified and the potential manageability of such consumptions is evaluated.

The mentioned detailed evaluation of flexibility is out of the scope of this dissertation, so that in this case, the consumers' potential has been assessed by means of simulations of Monte Carlo, considering that the flexibility of customers for each category may take aleatory values from 0 to $50 \%$ of the daily consumption every hour. This percentage also takes into account the participation of customers under each category in the DR program that may be established. The hypothesis here considered is moderately conservative, so that a detailed evaluation at customer's facilities may show a higher potential.

Consequently, 3,000 simulations have been done for each hour of the year, considering different aleatory participation factors for each category. After that, results have been 
analyzed according to the Monte Carlo method in order to assess the most frequent values within each hour.

The flexible power of each group of consumers have been then aggregated in blocks of $500 \mathrm{kWh}$ of manageable power (from 500 to $69,000 \mathrm{kWh}$ ), obtaining the probability of each block within the 3,000 hourly simulations. The flexible gas consumption per simulation has been obtained as follows:

$$
G_{s, h}^{r e d}=\sum_{i=1}^{7} \xi_{s, h}^{C a t} \cdot G_{h}^{C a t} \quad(\mathrm{kWh} / \mathrm{h})
$$

where $G_{s, h}^{r e d}(\mathrm{kWh} / \mathrm{h})$ is the amount of energy which may be reduced in the hour $h$ according to the simulation $s ; \xi_{s, h}^{C a t}(\%)$ is an aleatory variable taking values from $0 \%$ to $50 \%$ which represents the rate of flexible consumption of consumers in category Cat (C1, C2, C3, C5, T1, T2 or Residential), in the hour $h$ according to the simulation $s$; and $G_{h}^{\text {Cat }}(\%)$ is the total consumption of gas of consumers in category Cat during the hour $h$.

Then, the flexible gas consumption has been calculated in each hour according to this expression:

$$
G_{h}^{r e d}=\sum_{i=1}^{3000} \psi_{s, h}^{C a t} \cdot G_{s, h}^{r e d} \quad(\mathrm{kWh} / \mathrm{h})
$$

where $G_{h}^{\text {red }}(\mathrm{kWh} / \mathrm{h})$ is the amount of energy which may be reduced in the hour $h$ for the whole town; $\psi_{s, h}^{C a t}(\%)$ is the probability factor for simulation $s$ according to the Monte Carlo method, which takes values from 0 to 1 ; and $G_{s, h}^{r e d}(\mathrm{kWh} / \mathrm{h})$ is the amount of energy which may be reduced in the hour $h$ according to the simulation $s$.

\subsubsection{Evaluation of customer's participation in gas balancing services}

Based on the method discussed in the previous section, a flexible consumption has been estimated on a daily basis, depending on the type of day (short of long) since the balancing point of view.

It is important to take into account that this flexibility has been evaluated aggregately for a group of many different consumers. It means that all the customers would not be reducing their consumption every day, but the aggregator would achieve a global reduction of the magnitude here presented by activating the flexibility of different consumers in different days.

As it was shown in Figure 6.1, flexibility is not always related to reductions of consumption, as some days it would be necessary to increment demand when the gas system is 
long. Consequently, the evaluation here presented considers that consumers would reduce their consumptions according to the potential evaluated and shown in Figure 6.8 when the system is short, shifting such consumptions to the days when the system is long and increasing consumptions is necessary. In order to verify the viability of this option, the number of consecutive days during which reductions may be required has been accounted. The results are shown in Figure 6.9.

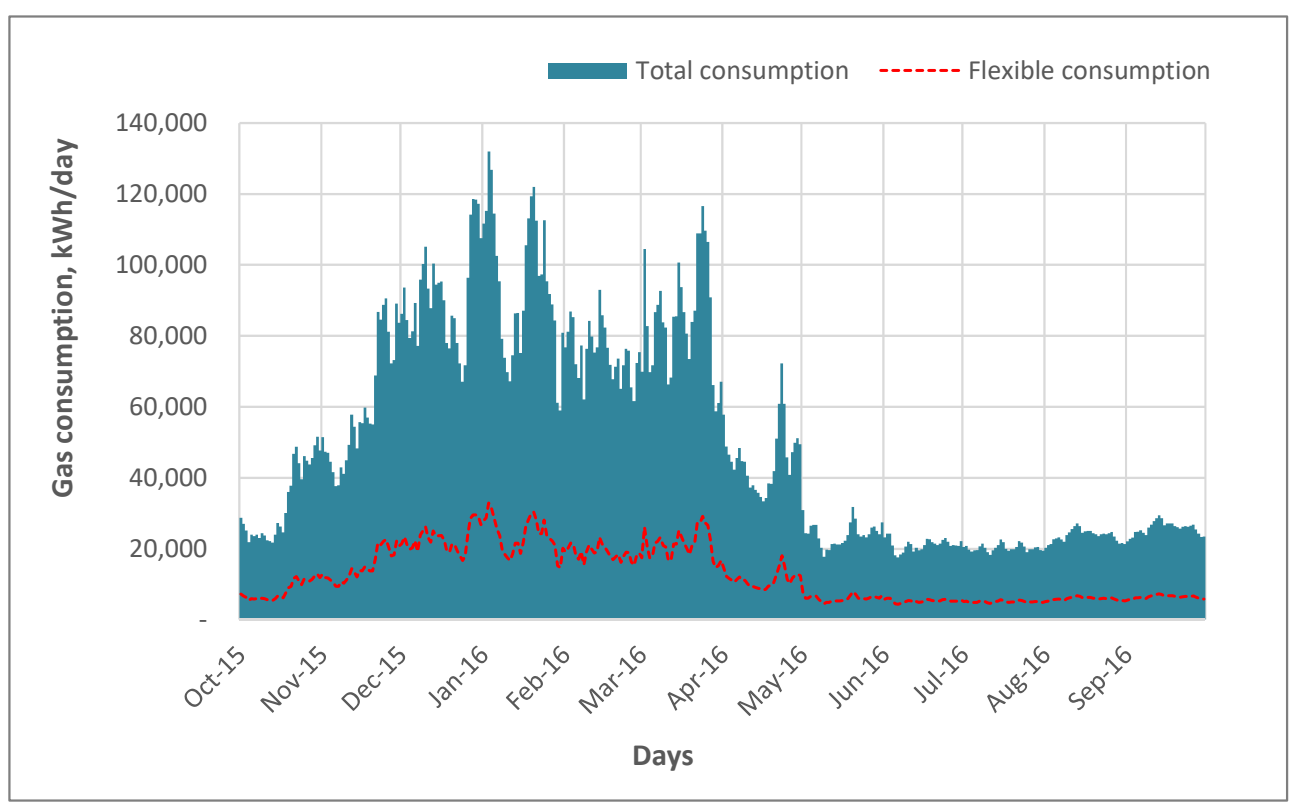

Figure 6.8. Estimated flexibility potential of gas customers in a town of 16,000 inh.

As it is shown in the histogram, the $90 \%$ of energy reductions take place for 6 consecutive days or less ( $65 \%$ of cases is just for 1 day of energy reduction), while the longest reduction was for 20 days and took place just one time during the year. Therefore, it is reasonable to plan energy shifting from days during which the system was short to days where the system was long. It means that customers may be asked not to purely reduce consumptions neatly (with the subsequent loss of service) but to shift this consumption to other period of time.

On the other hand, the aggregator could plan the recovery of consumptions not to make customers recover their consumptions some days later, but the day after. Thus, a different group of customers may reduce the consumption so as to allow the group which reduced the consumption the day before to recover their set-point (see Figure 6.10). In this way, the aggregator may manage the consumptions in order to implement the recoveries when the system is long, contributing also to the balancing service during those days. 


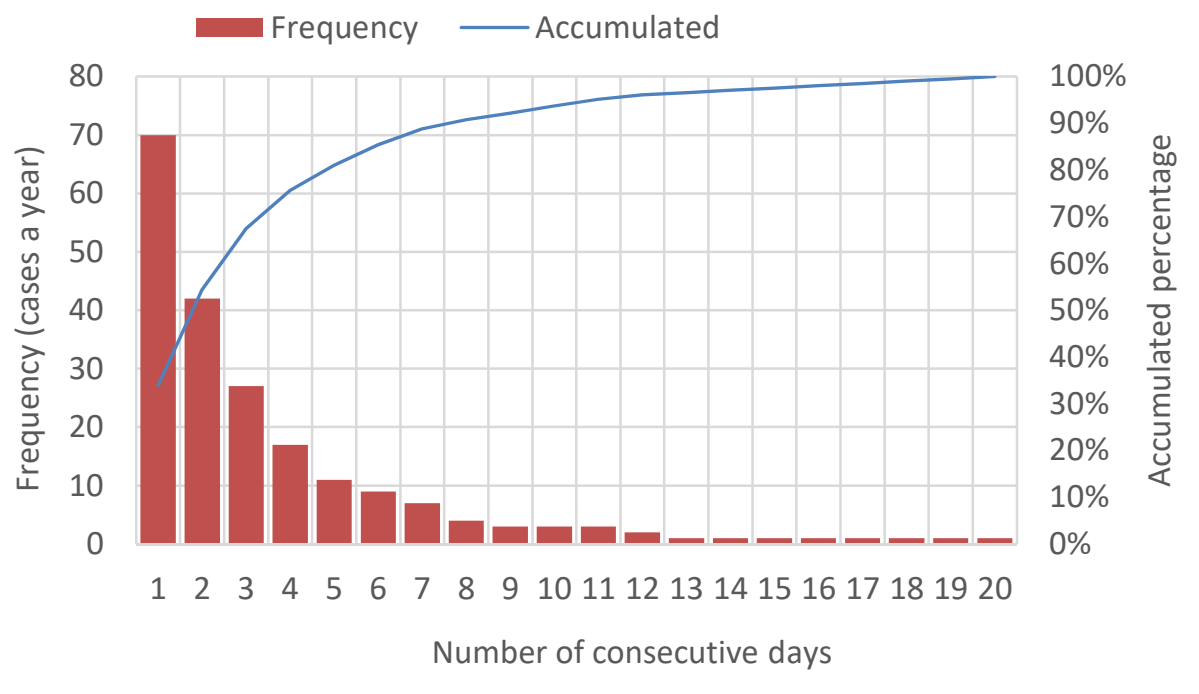

Figure 6.9. Histogram on the number of consecutive days of gas reduction for balances

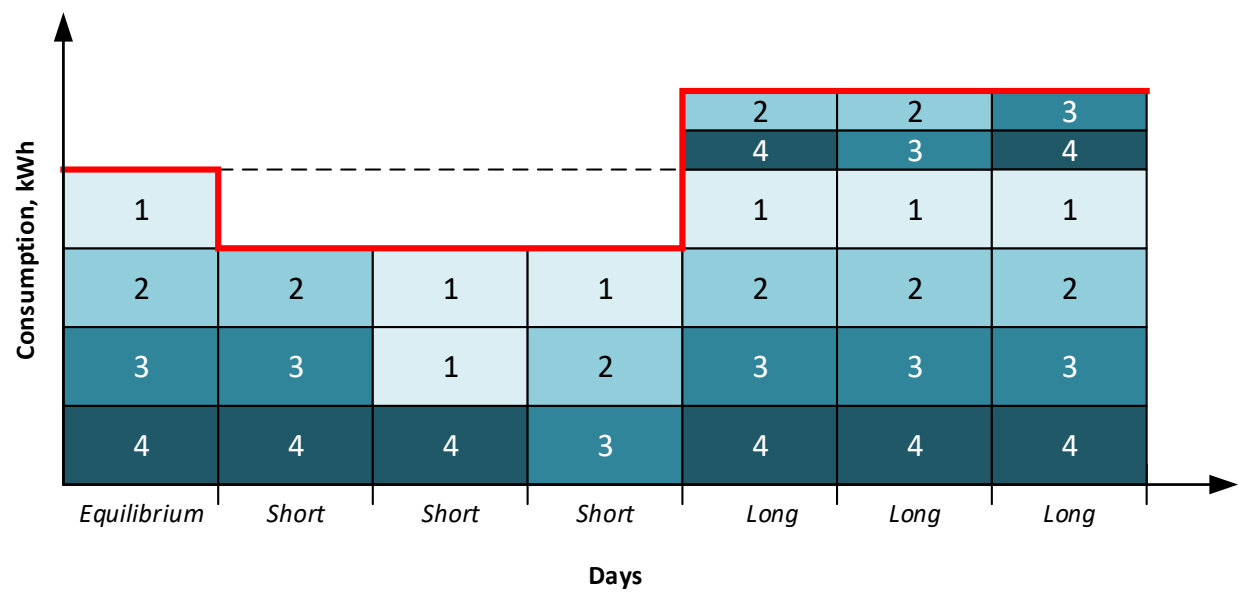

Figure 6.10. Example of gas demand packages managed by an aggregator for balancing purposes 
In this example shown in Figure 6.10, the total number of customers have been divided into four groups with a similar amount of flexible gas consumption. For the first short day, the aggregator can activate the flexibility of group 1 , which will recover the reduced energy during the next day. As the following day is also short, the aggregator may order a reduction to groups 2 and 3 , which may be able to recover such energy some days later. After three short days, part of the energy reduced by groups 2 and 4 in the short days can be recovered, helping the GSO to reduce the excess of gas in the network. During the following days, the energy reduced during the short days by groups 2, 3 and 4 would be recovered, so that three long days after, the consumption set-point would be restored.

According to this idea, the case presented in this chapter considers that customer would reduce their consumption according to the evaluated potential, being recovered during the following days where the GSO may require from customers to increase their consumption. Regarding the gas distribution in long days, it has been considered that the consumption reduced in short days would be recovered during the following days when the system is long. To do this, it has been considered that the total amount of energy reduced during a group of consecutive short days is recovered during the following group of long days, recovering each day this total amount of energy divided into the number of long days during which such consumption will be recovered.

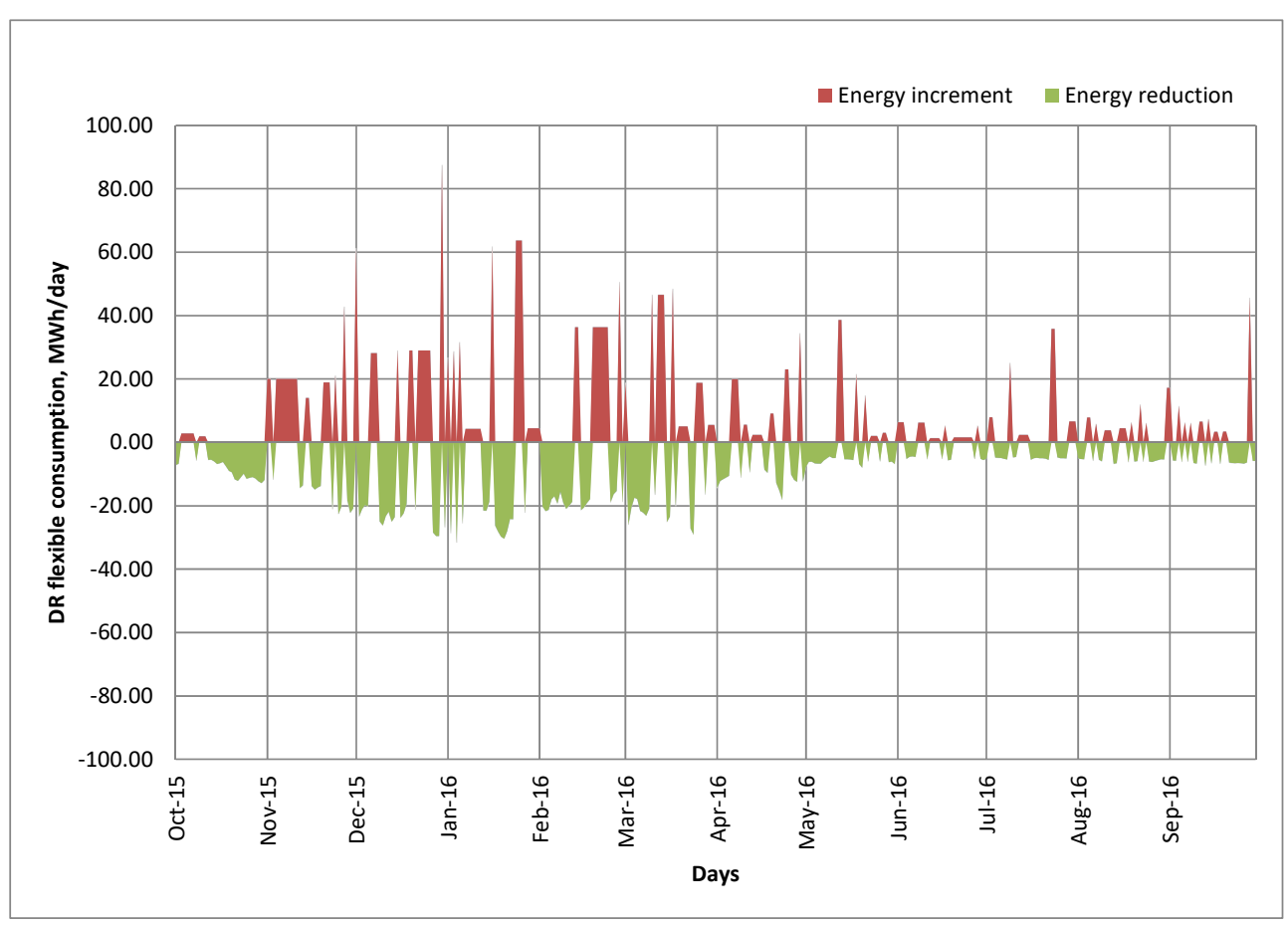

Figure 6.11. Daily schedule of DR resources to be used for balancing purposes 
As a result of the previous considerations, the daily schedule of flexible energy to reduce or increment is shown in Figure 6.11. Since energy reduced is later recovered, the DR actions here considered are actually energy shifts but not net reductions, so that the annual energy savings are equal to zero. It implies a manageable energy of 2,627 MWh a year.

\subsection{Economic evaluation}

As indicated in the methodology, the economic evaluation is based on a cost-benefit analysis, so that customers would be willing to modify their usual pattern of consumption when the cost of applying flexibility is lower than the payment they receive from the GSO. On the other hand, the GSO would be willing to use DR resources when payments required by customers are lower than the cost of solution of the considered service by other means. Therefore, the cost that the application of flexibility may entail for customers is evaluated firstly. Later, the cost-benefit analysis on the GSO side is performed so as to assess the economic impact of the considered actions.

\subsubsection{Costs for consumers}

The estimated cost for consumers when applying a DR action is summarized in Table 6.2 .

The considered smart meters correspond to those chosen by the distributor $2 i$ Rete gas for the considered town, according to the following models:

- G4 Ultrasonic GPRS for residential customers

- G10 Diaphragm, G16 Diaphragm and G25 Diaphragm for non-residential customers, depending on the flow capacity.

According to the technical evaluation of flexibility done in section 6.3.1, the average flexible consumption of residential and non-residential customers in the considered town is equal to 2,154 and $16,151 \mathrm{MWh} /$ year, respectively. Considering these figures, together with the average daily cost indicated in Table 6.2, the mean cost of flexibility for customers results in $6.43 € / \mathrm{MWh}$, estimating a total of 100 hours of participation in the DR service per customer.

According to the methodology, customers may provide their flexibility when they cover their cost while obtaining an additional benefit. This benefit would be determined according to the strategy defined by each customer. In order to establish a criteria for the calculation of this case of application, and according to the criteria proposed by [141] for the estimation of the price requested by consumers in DR services for electricity systems, an additional benefit equal to the cost of applying flexibility would be considered. Therefore, the price required by customers so as to activate their flexibility in this analysis will be equal to $12.87 € / \mathrm{MWh}$. 
Application to the Italian natural gas system

Table 6.2. Estimated cost of flexibility for customers

\begin{tabular}{|c|c|c|c|c|}
\hline \multirow{10}{*}{$\begin{array}{l}\text { DIRECT } \\
\text { COSTS }\end{array}$} & Cost of smart meter & Residential & Non-residential & \\
\hline & Capital cost & 85.00 & 336.00 & $€$ \\
\hline & Expected life time & 15.00 & 15.00 & years \\
\hline & Days/year & 100.00 & 100.00 & days/year \\
\hline & Amortization & 0.06 & 0.22 & $€ /$ day \\
\hline & Cost of control equipment & Residential & Non-residential & \\
\hline & Capital cost & 400.00 & $1,000.00$ & $€$ \\
\hline & Expected life time & 15.00 & 15.00 & years \\
\hline & Days/year & 100.00 & 100.00 & days/year \\
\hline & Amortization & 0.27 & 0.67 & $€ /$ day \\
\hline \multirow{8}{*}{$\begin{array}{l}\text { INDIRECT } \\
\text { COSTS }\end{array}$} & Annual personnel costs & Residential & Non-residential & \\
\hline & Hours/week & - & $30,000.00$ & $€ /$ employee \\
\hline & Weeks/year & - & 40.00 & hours/week \\
\hline & Cost of working hour & - & 50.00 & weeks/year \\
\hline & $\begin{array}{l}\text { Time used for a flexibility } \\
\text { action }\end{array}$ & - & 15.00 & $€ /$ hour \\
\hline & Labor cost & - & 10.00 & $\min /$ action \\
\hline & $\begin{array}{l}\text { Labor cost of implementing } \\
\text { DR }\end{array}$ & - & 0.10 & $€ /$ day \\
\hline & $\begin{array}{l}\text { Total AVG daily cost } \\
\text { per customer }\end{array}$ & 0.32 & 0.99 & $€ /$ day \\
\hline
\end{tabular}

\subsubsection{Cost-benefit analysis}

As it was stated in section 6.2.1, the cost of balancing for the GSO takes into account two different prices: the hourly cost of operation of the network related to balancing operations, evaluated in $60.84 € / \mathrm{MWh}$, and the price of natural gas in the wholesale market for operation purposes. This price, published by Snam, could be referred to the price that the GSO has to pay if the system is short, or the price at which the GSO is paid for the excess of gas when the system is long.

The price of gas when the system is short during the considered period (October 2015September 2016) varies between 11.6 and $32.0 € / \mathrm{MWh}$. Therefore, the specific cost for the GSO, considering also the cost of operation, would take values from 72.4 and 92.8 $€ / \mathrm{MWh}$.

On the other hand, when the system is long and the GSO has to resell the excess of gas in the wholesale market, the participation of customers in order to reduce this excess 
would mean a reduction in the incomes that the GSO would have. It means that the GSO would save the corresponding specific cost for operation $(60.8 € / \mathrm{MWh})$ but the incomes for selling energy would be lower. The net benefit for the GSO when the system is long could be calculated as the difference between the reductions in cost of operation minus the benefit of reselling the excess of energy. The price at which the GSO is pays in the wholesale market takes values from 13.2 and $20.7 € / \mathrm{MWh}$ Therefore, the specific cost for the GSO when the system is long would vary from 40.1 and $47.6 € / \mathrm{MWh}$.

These specific costs represent the maximum price that the GSO would be willing to pay to customers when providing operation services by using their flexibility. When customers can provide this service at a lower price, it would mean that the GSO would be obtaining an additional benefit, equal to the difference between those specific costs and the amount paid to the customers.

As it was calculated in section 6.4.1, the average price requested by customers would be equal to $12.87 € / \mathrm{MWh}$, including the additional benefit in exchange for their participation. As this price is lower to the specific cost of the GSO in all of cases, it means that the utilization of DR resources would be profitable for the GSO every day for the considered period.

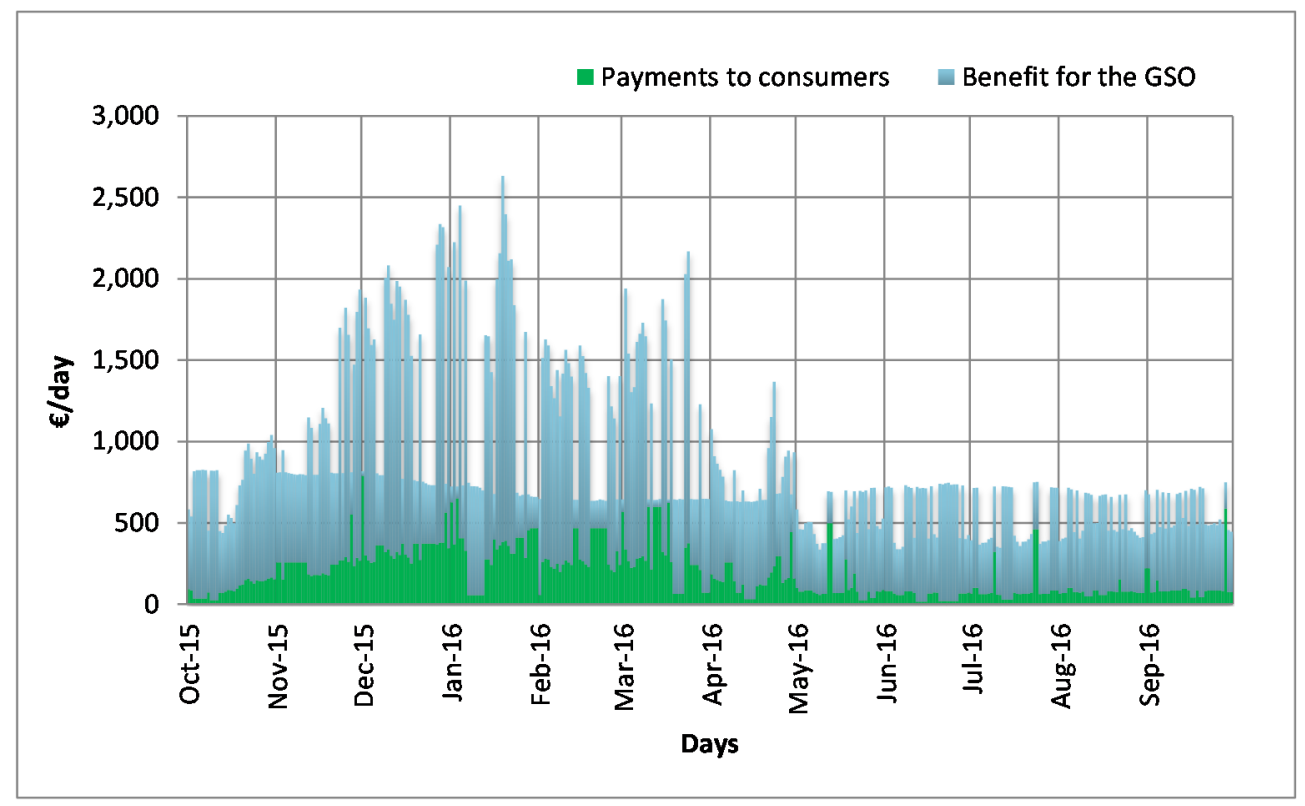

Figure 6.12. Economic evaluation of DR participation in balancing of the gas network

Figure 6.12 shows the economic impact of DR participation in balancing of the natural gas network for the considered annual period. 
The green area represents the daily payment to customers, which includes the incurred costs and the required benefit for participation. The blue area is the benefit for the GSO, compared to the traditional solution of imbalances by using the negotiation in the wholesale market. This benefit is equal to the difference between the cost of balances without DR participation and the cost required for customers when providing this service. As it can be seen, the benefit for the GSO is, in most of days, much higher than the payment required by customers, which demonstrates the high profitability of using DR resources for operation purposes. Table $\mathrm{X}$ summarizes the monthly economic result for all the parties.

Table 6.3. Monthly summary of DR participation in gas balancing services

\begin{tabular}{crrr}
\hline Month & $\begin{array}{c}\text { Payment to } \\
\text { customers } \\
\boldsymbol{\epsilon}\end{array}$ & $\begin{array}{c}\text { Cost for the GSO } \\
\text { without DR } \\
\boldsymbol{\epsilon}\end{array}$ & $\begin{array}{c}\text { Benefit for the } \\
\text { GSO }\end{array}$ \\
\hline Oct-15 & 2,934 & 23,483 & \multicolumn{1}{c}{$\boldsymbol{\epsilon}$} \\
Nov-15 & 7,341 & 31,777 & 24,549 \\
Dec-15 & 10,959 & 44,121 & 33,162 \\
Jan-16 & 10,137 & 40,186 & 30,049 \\
Feb-16 & 8,746 & 33,224 & 24,478 \\
Mar-16 & 8,994 & 34,870 & 25,876 \\
Apr-16 & 4,765 & 23,380 & 18,615 \\
May-16 & 3,318 & 16,328 & 13,010 \\
Jun-16 & 1,556 & 18,103 & 16,547 \\
Jul-16 & 3,045 & 16,018 & 12,973 \\
Aug-16 & 2,474 & 16,807 & 14,333 \\
Sep-16 & 3,027 & 17,049 & 14,022 \\
\hline Annual & 67,297 & 315,347 & 248,050 \\
\hline
\end{tabular}

According to these results, it can be seen as the payments to customers involve the $21 \%$ of the total cost of balancing for the GSO for the related amount of managed energy. It means that the GSO would save about $79 \%$ of the cost when using DR resources.

In order to compare the benefit for customers to the annual cost they have to face for their gas supply, the average prices for residential and non-residential customers included in Table 6.4 have been taken into account. These prices are applicable to Italy for 2015, as provided by the Italian regulator AEEGSI (Autorità per l'energia elettrica il gas e il sistema idrico). According to these prices and the annual consumption of gas of final customers summarized in Table 6.1, the total cost of gas to be paid by final customers 
would be equal to $894,200 €$. It means that the incomes received by customers when participating in the balancing service would represent the $7.5 \%$ of their annual cost. A half of this rate would be destined to pay their self-cost of using their flexibility, which implies a net benefit of $3.8 \%$ over the total cost of gas for the customer.

Table 6.4. Price of natural gas in the Italian retail market

\begin{tabular}{ccc} 
& $\begin{array}{c}\text { Annual consumption } \\
\boldsymbol{m}^{3} / \mathbf{y e a r}\end{array}$ & $\begin{array}{c}\text { Price (excl. taxes) } \\
\boldsymbol{c t s} \boldsymbol{\epsilon} / \boldsymbol{m}^{3}\end{array}$ \\
\hline \multirow{3}{*}{ Residential } & $<525$ & 89.94 \\
& $525-5,254$ & 57.52 \\
& $>5,254$ & 46.27 \\
\hline \multirow{3}{*}{ Non-residential } & $<26,000$ & 51.79 \\
& $26,000-263,000$ & 42.35 \\
& $263,000-2,627,000$ & 33.25 \\
& $2,627,000-26,268,000$ & 29.41 \\
& $>26,268,000$ & 28.02 \\
\hline
\end{tabular}

An economic benefit of 3.8\% may not be attractive to customers so as to provide their flexibility, so that a higher price should be probably considered. Moreover, the benefit for the GSO is $78.7 \%$ of the cost of solution of the involved imbalances by traditional mechanisms. Therefore, a sensitivity analysis is done in the next section in order to evaluate the impact of increasing the price paid to customers, shifting part of the benefit from the GSO to the customers' side.

\subsubsection{Sensitivity analysis}

A price equal to twice the cost of flexibility was considered in the previous section for the calculation of the price payable to customers when they offer their flexibility to the GSO for balancing purposes. However, a higher price could be considered as the benefit of using DR for the GSO is much higher than the benefit provided to customers. According to this premise, the sensitivity of the economic benefit receiver by both customers and the GSO to the variation of the price paid to customers has been evaluated.

The results of the sensitivity analysis are presented in Table 6.5. As it is shown in this table, as the price paid to customers increases, the number of days during which the application of flexibility is profitable decreases, as the amount required by customers is higher than the solution of imbalances by traditional mechanisms.

The considered step for increasing the price has been the cost of flexibility, so that the different prices which have been evaluated are multiples of this cost. 
The first evaluated case is that in which the price is exactly the cost of implementing flexibility for the customer side, so that the benefit for the customer is zero. As the price required by customers increases, the benefit received by customers is higher while the benefit for the GSO is lower.

Table 6.5. Sensitivity analysis: economic benefits of DR for different offer prices

\begin{tabular}{cccc}
\hline $\begin{array}{c}\text { Price paid } \\
\text { to consumers } \\
\boldsymbol{\epsilon} / \mathbf{M W h}\end{array}$ & $\begin{array}{c}\text { Payment } \\
\text { to consumers } \\
\boldsymbol{\epsilon} / \mathbf{y e a r}\end{array}$ & $\begin{array}{c}\text { Benefit } \\
\text { for the GSO } \\
\boldsymbol{\epsilon} / \mathbf{y e a r}\end{array}$ & $\begin{array}{c}\text { Participating } \\
\text { days a year } \\
\text { days/year }\end{array}$ \\
\hline 6,43 & 33.622 & 281.725 & 365 \\
12,86 & 67.245 & 248.102 & 365 \\
19,29 & 82.146 & 231.242 & 347 \\
25,72 & 92.848 & 218.193 & 324 \\
32,15 & 100.256 & 210.306 & 308 \\
38,58 & 114.347 & 195.740 & 300 \\
45,01 & 119.416 & 192.600 & 292 \\
51,44 & 135.309 & 177.256 & 290 \\
57,87 & 148.790 & 164.891 & 285 \\
64,30 & 164.214 & 150.213 & 283 \\
70,73 & 173.942 & 139.374 & 102 \\
77,16 & 74.974 & 269.194 & - \\
83,59 & 2.485 & 373.107 & 278 \\
\hline
\end{tabular}

According to the table, the total benefit is shared in equal parts between customers and the GSO for a price equal to 10 times the cost of flexibility. For this price, the benefit for customers would be equal to $164,214 € /$ year, which is equivalent to the $18.4 \%$ of the annual cost of the gas supply. It means that if the cost of flexibility is $3.8 \%$, the net benefit for customers would be equal to $14.6 \%$ of the annual cost of gas.

The relative benefit for customers compared to the total cost of supply of natural gas in an annual basis, once the cost of implementing the flexibility has been discounted is shown in Table 6.6. Similarly, the benefit for the GSO is also represented referred to the cost of balancing the amount of gas that may be managed by customers if customers were not providing their flexibility.

The evolution of benefits with the price payable to customers is represented in Figure 6.13. As it is shown, the benefit of customers increases until the price is $70.73 € / \mathrm{MWh}$, equivalent to 11 times the cost of flexibility. For this price, the incomes for customers would be equal to $173,942 € /$ year (19.5\% of the annual cost of gas) while the benefit for 
the GSO may reach $139,374 €$ /year (44.5\% of the cost of solution of imbalances by traditional means). From this point, the number of hours when flexibility can be applied reduces dramatically, so that the customers' benefit also reduces.

Table 6.6. Sensitivity analysis: relative benefits of stakeholders

\begin{tabular}{cccc}
\hline $\begin{array}{c}\text { Price paid } \\
\text { to consumers } \\
\mathbf{E} / \mathbf{M W h}\end{array}$ & $\begin{array}{c}\text { Energy } \\
\text { involved } \\
\text { MWh/year }\end{array}$ & $\begin{array}{c}\text { Benefit of customers } \\
\text { compared to the cost } \\
\text { of gas supply } \\
\text { \% }\end{array}$ & $\begin{array}{c}\text { Benefit for the GSO } \\
\text { compared to the cost } \\
\text { of balances } \\
\text { \% }\end{array}$ \\
\hline 6.43 & 5,229 & 0.0 & 89.3 \\
12.86 & 5,229 & 3.8 & 78.7 \\
19.29 & 4,258 & 5.4 & 73.8 \\
25.72 & 3,609 & 6.6 & 70.1 \\
32.15 & 3,118 & 7.5 & 67.7 \\
38.58 & 2,963 & 9.0 & 63.1 \\
45.01 & 2,653 & 9.6 & 61.7 \\
51.44 & 2,630 & 11.4 & 56.7 \\
57.87 & 2,571 & 12.9 & 52.6 \\
64.30 & 2,553 & 14.6 & 47.8 \\
70.73 & 2,459 & 15.7 & 44.5 \\
77.16 & 971 & 4.6 & 78.2 \\
83.59 & 29 & -3.5 & 99.3 \\
\hline
\end{tabular}

In any case, the benefits of using DR resources for the solution of imbalances in the natural gas system results evident for all the stakeholders. Therefore, the need of applying the DR principles to the natural gas system arises as the natural solution for reducing the operational costs related to the management of the whole network, similarly to how this kind of strategies has been applied to the electricity sector. 
Application to the Italian natural gas system

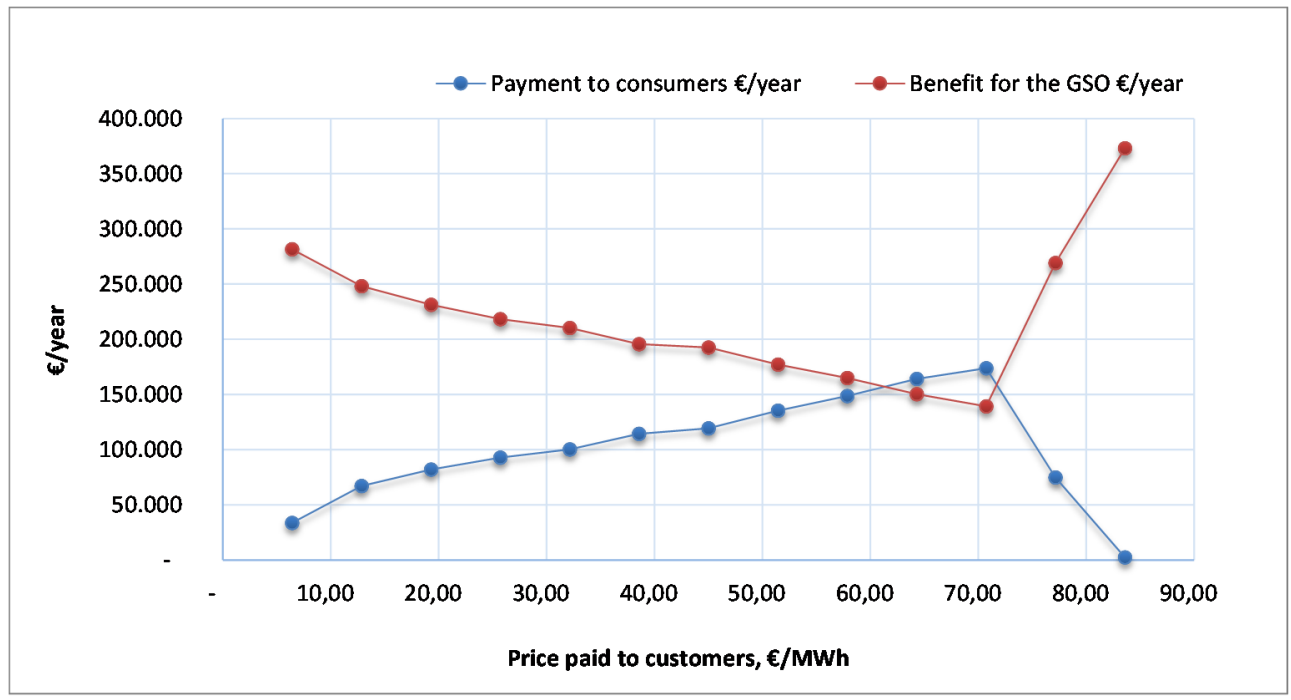

Figure 6.13. Economic benefits for customers and the GSO for different DR prices

\subsection{Extrapolation of results}

It is not the objective of this dissertation the evaluation of the DR potential of the natural gas consumers in Italy. However, once the assessment of DR applications have been done for a town of 16,000 inhabitants, some general figures, even if not exhaustive, can be obtained applicable to the full country.

The number of towns similar to those considered in this chapter have been accounted in Table 6.7. According to the table, a number of 707 towns similar to that considered for this application case can be identified.

As discussed in section 6.3, the annual gas flow that customers in the analyzed town of 16,000 inh may shift may be estimated in 2,627 MWh. On the other hand, the total amount of balanced energy (first reduced and later recovered) for Italy from October 2015 to September 2016 was equal to $12,583 \mathrm{GWh}$. It means that the flexibility of customers located in the studied town just represent the $0.02 \%$. However, if the 707 towns similar to that studied in this chapter had a similar potential, a total flexible consumption of around $1,857 \mathrm{GWh}$ could be assessed. This amount is more significant, as it would mean the $15 \%$ of the total amount of energy balanced during the year in the whole country.

From an economic point of view, the participation of the 707 towns between 10,000 and 20,000 inhabitants in a similar way to the studied town would mean savings for the GSO between $9.8 \%$ (for the strategy where the customer asks for a price equal to twice the 
cost of applying flexibility) and 5.5\% (for the strategy of maximum benefit for the customer $)^{60}$. The estimated potential by region, according to the number of towns under the considered classification, is represented in Figure 6.14.

Table 6.7. Number of towns with a population between 10,000 and 20,000 inhabitants in Italy, per region

\begin{tabular}{|c|c|}
\hline Region & $\begin{array}{l}\text { Number of towns of population } \\
\text { between } 10,000 \text { and } 20,000 \text { inh. }\end{array}$ \\
\hline Abruzzo & 11 \\
\hline Apulia & 49 \\
\hline Basilicata & 10 \\
\hline Calabria & 22 \\
\hline Campania & 64 \\
\hline Sardinia & 26 \\
\hline Emilia-Romagna & 58 \\
\hline Friuli-Venezia Giulia & 18 \\
\hline Lazio & 39 \\
\hline Liguria & 11 \\
\hline Lombardy & 125 \\
\hline Marches & 20 \\
\hline Molise & 1 \\
\hline Piedmont & 39 \\
\hline Sicily & 52 \\
\hline Tuscany & 52 \\
\hline Trentino-Alto Adige & 8 \\
\hline Umbria & 10 \\
\hline Aosta Valley & 0 \\
\hline Veneto & 92 \\
\hline Total & 707 \\
\hline
\end{tabular}

As it has been indicated before, the figures arising from this extrapolation are just a rough estimation in order to put in evidence the large potential that the implementation of DR

60 This calculation is done considering an annual cost of balances equal to 1,800 million of euro, as justified in section 6.2.1 
strategies may entail for the operation of the gas system. Additionally, it must be taken into account that these numbers have been obtained just considering the towns with a similar population to the studied one, so that a large hidden potential remains unexplored within the rest of municipalities of the country.

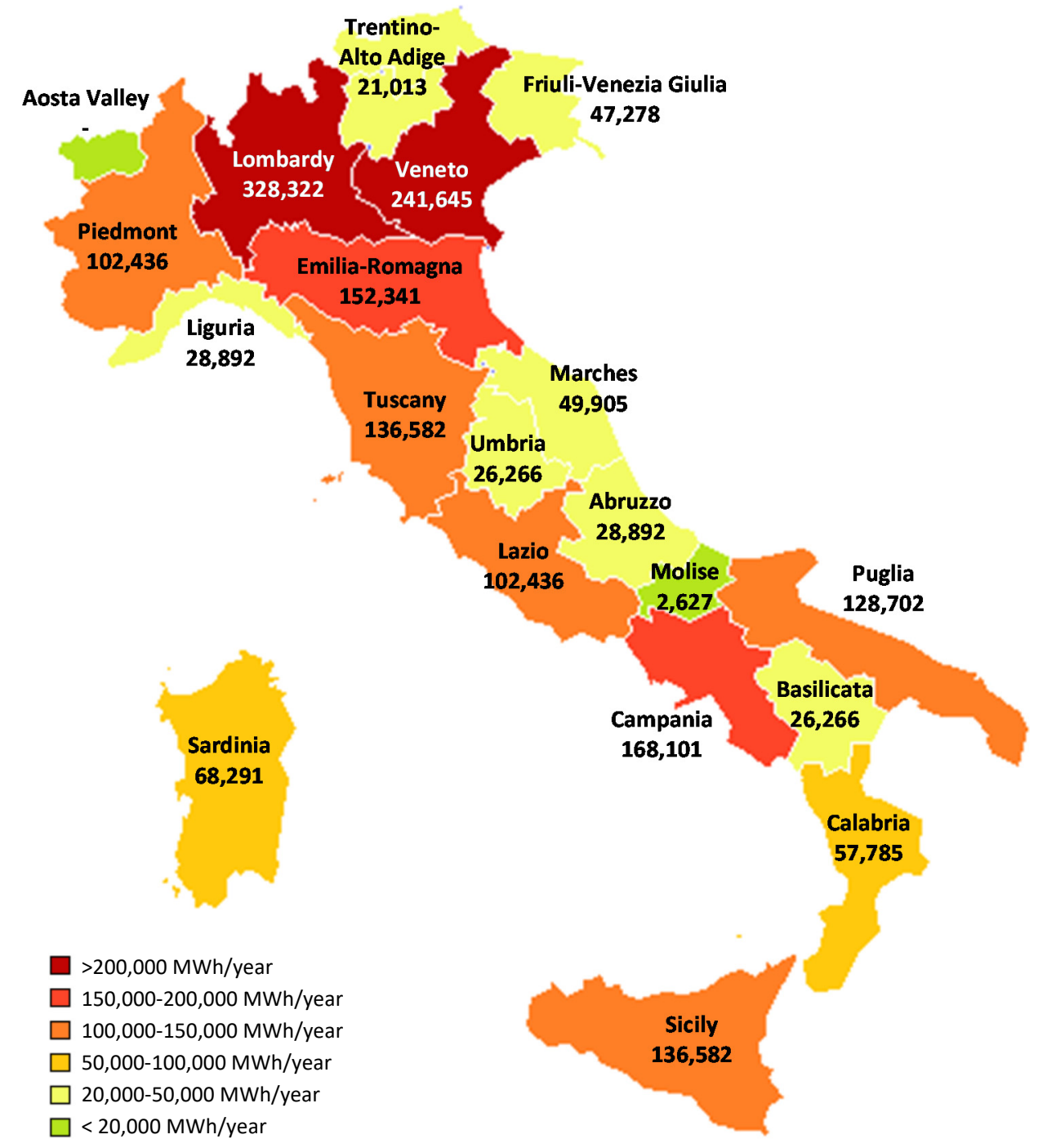

Figure 6.14. Gas DR Potential in towns with a population between 10,000 and 20,000 inhabitants, per region (MWh/year) 


\subsection{Conclusions of the chapter}

The methodology developed in Chapter 5 has been here applied to the evaluation of DR applications for the balancing of the natural gas system in Italy. The potential of gas consumers located in a town of 16,000 inhabitants in central Italy has been evaluated, as well as the impact of using this potential so as to help the GSO to solve the imbalances which appear in the grid daily.

The economic profitability of DR applications has been demonstrated, reaching a benefit for customers between $15 \%$ and $20 \%$ of the annual cost of the gas supply. At the same time, the GSO may obtain a significant reduction in the cost of balancing the system, which takes values around the $50 \%$ of the annual cost of balances for the involved amount of gas.

These results should drive regulators to incentive the utilization the flexibility of customers so as to increment the efficiency of the natural gas system. It reduces the total cost of operation at the same time that favor the involvement of customers in a more dynamic energy structure. This customers' participation results essential for the proper management of smart energy systems, which are called to be energy networks of the future. 


\section{Chapter 7 Conclusions}

This chapter highlights the main conclusions that can be stated according to the research activities described in this dissertation, along with the relevance of the contributions achieved. After that, the research lines to be considered for future developments that complement the present study are discussed.

\subsection{Conclusions of the dissertation}

This dissertation highlights the high potential of consumers of natural gas for contributing to a more efficient operation of the network, as well as it justifies and quantify the profitability that using customers' flexibility may have not only for customers, but for the natural gas system as a whole. As a consequence, a new methodology for the proper evaluation for the design of suited DR products applied to the natural gas sector and the full exploitation of such resources has been designed and validated.

In this framework, the most significant contributions provided in this dissertation can be grouped into the following points:

\subsubsection{Identification of electricity and natural gas analogies for DR applications}

Demand response has been used for years in power systems, being demonstrated as a useful tool for a more efficient and operative management of the energy system. However, customer's flexibility has been never used as an operation mechanism for the management of natural gas networks.

This dissertation provides a comparative analysis between both electricity and natural gas system in terms of operability and related to the physical parameters that characterize each of them. Thus, similarities between the infrastructures, system architecture, markets and operation mechanisms related to electricity and natural gas networks have been empathized. This fact has evidenced that strategies successfully used in electricity systems 
may find a similar accomplishment when applied to natural gas systems, favoring the more efficient utilization and management of the whole system in terms not only technical, but also economic and environmental.

\subsubsection{Identification of promising DR potential applicable to the natural gas system}

Existing DR products which at present are used in electricity systems in different countries have been analyzed, being highlighted the characteristics of these products which may be adapted and applied to natural gas grids. In particular, three direct applications where DR may mean a significant contribution are foregrounded:

- Balancing of natural gas in the transmission network so as to guarantee that the daily amount of natural gas consumed from and injected to the network is balanced.

- Maintenance of the gas level in underground storages, in order to guarantee that the daily amount of natural gas inject to or extracted from an underground store must remain within the limits technically established.

- Solution of technical constraints, which may produce overload in the system infrastructures and may even lead interruption of supply to customers.

The revision presented in the dissertation allows to forecast that the adoption of a DR vision on the natural gas sector is just a matter of time, being the natural consequence of the evolution of energy systems towards a smart grid configuration, where the participation of customers will be necessarily higher.

The few international experiences where DR concepts have been applied to the natural gas system have been also analyzed. In some of them, even if just being experimental pilots, potential savings up to $21 \%$ have been demonstrated for residential applications in Canada and the U.S., based on the modification of the temperature set point of thermostats for heating purposes.

Moreover, it has been evidenced as the utilization of smart technologies and standard platforms such as smart meters (which are being massively installed in some countries) is technically contributing to enable natural gas customers for the provision of DR services, which will hopefully happen sooner rather than later.

\subsubsection{Enhancement of the smart grid architecture in the natural gas system for DR utilization}

The architecture of the natural gas system based on a smart grid configuration is analyzed in detail in the dissertation, and this novel concept is compared to the main characteristics of the traditional structure of natural gas systems around the world.

The different roles to be played by the agents emerging from the smart grid configuration are identified and characterized. Among such roles, aggregators arise as fundamental 
agents for valorizing the utilization of DR resources in the natural gas sector and enabling small and medium customers so as to participate.

A significant contribution of this dissertation is the approach to district heating system managers as aggregators of DR resources. In fact, district heating plants using natural gas as primary fuel may be used for the provision of DR services to the natural gas system if managers reduce or increase their gas consumption when requested by the gas system operator. Therefore, this flexibility would be finally given by customers supplied not by gas, but by the steam or hot water produced by the district heating plant. In Europe, district heating systems cover $10 \%$ of the energy market, reaching in some countries such as Finland and Romania values higher than $60 \%$ of their thermal needs. Therefore, this new role of district heating operators may entail a new business opportunity for this kind of companies while helping in the operation of the natural gas system under a smart grid configuration.

\subsubsection{Development of a methodology for the specification of DR products in the natural gas system}

The most significant contribution of this dissertation is the design and development of a new methodology for the creation, evaluation and validation of DR products to be used in the natural gas sector. This methodology establishes a systematic procedure by means of which, the impact of the application of DR strategies under both the customer and the network operator perspectives can be assessed since a technical, economic and environmental point of view.

The methodology allows the calculation of the prices associated to the trading of DR resources, not just for the customer side (prices of the offer) but also for the stakeholder interested in using such flexibility (prices of bids). The methodology considers the utilization of DR resources by the gas system operator (GSO). However, any other party potentially interested in the utilization of customer's flexibility may be considered as DR requester.

The methodology can be used for individual customers willing to directly offer their flexibility into a DR market, but also for aggregators that may offer some kind of flexibility on behalf of smaller end users.

\subsubsection{Application of the methodology: Evaluation and assessment of DR applica- tions in the Italian natural gas system}

The methodology developed in this dissertation has been implemented in a real application for the evaluation of the impact of DR resources in the Italian natural gas system, so that the procedure here presented has been validated and the potential benefits of DR for the natural gas system have been also demonstrated. Thus, the potential benefits that the use of flexibility may provide to natural gas consumers located in a town of 16,000 inhabitants in central Italy has been evaluated, considering the utilization of such resources by the gas system operator for balancing services. 
As a result, the profitability of DR applications, provided by natural gas customers, has been demonstrated, reaching profits for customers up to $20 \%$ in the annual cost of the natural gas supply. Similarly, the gas system operator may obtain a significant reduction in the cost of balancing the system compared to the purchase of gas in the wholesale market for this purpose, getting a reduction up to the $50 \%$ of the annual cost of balances for the involved amount of gas.

The case of application also includes a sensitivity analysis by means of which different strategies related to the price required by DR providers have been simulated. It allows to compare the distribution of the welfare produced between DR providers (consumers or aggregators) and DR requesters (in this case, the gas system operator) so as to better adjust the prices generated for the bids and offers of flexible demand packages.

The application concludes with an extrapolation of the DR potential provided by towns similar to that considered for the case of application to the whole Italy. Thus, a total potential to be provided by towns between 10,000 and 20,000 inhabitants in a similar way to the studied town would mean savings for the GSO between $9.8 \%$ (for the strategy where the customer asks for a price equal to twice the cost of applying flexibility) and $5.5 \%$ (for the strategy of maximum benefit for the customer) compared to the annual cost that the GSO faces for balancing purposes.

\subsection{Future developments}

This dissertation opens the gate to an innovative point of view on the evaluation of flexibility among natural gas customers integrated in smart grid structures, provided that they are traditionally considered rigid. It also provides a novel approach to the management of network infrastructures in order to exploit customers' flexibility in natural gas markets. Taking this study as a starting point, the following lines of research could be further developed in the future:

- Deployment of energy audits at gas consumers facilities in order to accurately evaluate the flexibility they can provide to the network. For the evaluation presented in Chapter 6, customers' flexibility has been estimated by Monte Carlo simulations. However, the actual ability of customers should be studied more in detail, performing an on-site assessment and a closer contact with the final consumers.

- Application of the methodology for the evaluation of gas demand response resources in operation services others than balancing (e.g. operation of underground storage and solution of technical constraints). Moreover, other potential stakeholders may benefit from the utilization of DR resources (e.g. energy traders may use DR resources in order to compensate the imbalances between the gas they purchase in the wholesale market and the real time consumption of the 
customers they have in their portfolio). These aspects taken into account in further research would mean a significant improvement and development of the methodology here presented.

- Application of the methodology to other geographical areas. Natural gas can be used for different applications so that customers may consume this resource differently depending, among others, from the climate or the gas usage habits (gas utilization may be different at the mountain or next to the beach. Moreover, the location of consumers in urban or semi-urban areas and how customers are concentrated according to these configurations may affect to the involved DR potential of natural gas consumers. Similarly, customers in northern European countries would consume gas for different purposes than in southern countries). On the other side, the Italian case (specifically in a medium-size town in the north-central region of the country) has been analyzed in this dissertation, but the market rules are different in other countries, so the impact of flexibility may be diverse. Therefore, this methodology could be applied so as to evaluate this flexibility for each particular case.

- Implementation of pilot experiences with district heating operators (DHOs) as demand response aggregators. This new role has been identified in the dissertation. However, the actual provision of DR services by managers of district heating networks should be tested, not just for the evaluation of the potential of customers, but also the ability of DHOs to deal with the flexibility of customers. Thus, the lack of knowledge of these agents may be better identified and a proper training on DR issues could be assessed and planned.

\subsection{Publications}

During the development of this doctoral dissertation, the following works have been published, or sent for publication, into the indexed journals mentioned below:

- Montuori L, Alcázar-Ortega M, Álvarez-Bel C, Domijan A: “Integration of renewable energy in microgrids coordinated with demand response resources: Economic evaluation of a biomass gasification plant by Homer Simulator". Published in the journal Applied Energy, vol. 132, pp. 15-22, November 2014. This publication has had a significant impact on researchers of this field, reaching 41 citations in less than 3 years (source: Scopus)

- Montuori L, Vargas C, Alcázar-Ortega M: "Impact of the throat sizing on the operating parameters in an experimental fixed bed gasifier: Analysis, evaluation and testing". Published in the journal Renewable Energy, vol. 83, pp. 615625, November 2015. 
- Montuori L. "Optimization of a micro-power bioenergy system providing grid backup and off-grid power". Submitted to the journal Applied Energy. Under review.

- Montuori L, Alcázar-Ortega M, Álvarez-Bel C: “Application of demand response strategies for the management of natural gas systems: application to the Italian case”. Submitted to the journal Energy. Under review.

- Montuori L, Alcázar-Ortega M, Álvarez-Bel C: "Methodology for the evaluation of demand response strategies for the management of natural gas systems". Submitted to the journal Energy. Under review 


\section{References}

[1] Congress of the United States, "Energy Independence and Security Act. Public Law 110-140," Washington D.C., 2007.

[2] C. Manville, G. Cochrane, J. Cave, J. Millard, J. K. Pederson, R. K. Thaarup, A. Liebe, M. Wissner, R. Massink and B. Kotterink, "Mapping Smart Citties in the EU," European Parliment. Diurectorate General for Internal Policies, Brussels, 2014.

[3] J. Dehaeseller, "Smart grids in the gas sector," Marcogaz, technical association of the European natural gas industry, 2011.

[4] R. Deng, Z. Yang, M.-Y. Chow and J. Chen, "A survey on Demand Response in Smart Grids: Mathematical models and approaches," IEEE Transactions on Industrial Informatics, vol. 11, no. 3, pp. 570-582, 2015.

[5] C. Srinivaspura, "Demand Response for Natural Gas," 2017. [Online]. Available: http://www.energycentral.com/c/pip/demand-response-natural-gas. [Accessed 27 February 2017].

[6] F. W. Bliek, A. Van den Noort, B. Roosien, R. Kamphuis, J. de Wit, J. Van der Velde y M. Eijgelaar, «The role of natural gas in smart grids,» Journal of Natural Gas Science and Engineering, vol. 3, nº 5, pp. 608-616, 2011.

[7] US Department of Energy, "Natural gas infrastucture. Implications of decreased demand from the electric power sector," DOE, Washington DC, 2015.

[8] European Environment Agency, "Primary Energy Consumption by fuel," EEA, Copenhagen, 2016.

[9] A. Honoré, "The outlook for natural gas demand in Europe," The outlook for natural gas demand in Europe, Oxford, 2014. 
[10] European Commission, "EU Reference scenario 2016. Energy, transport and GHG emissions: trends to 2050," EC, Brussels, 2016.

[11] B. Rossert, The Western European gas market. ISBN 92-827-7021-4, Luxembourg: European Investment Bank, 1996.

[12] The Brattle Group/Brown Rudnick LLP, "Gas Demand Response: A solution to the electricity/gas interface issue?," The Brattle Group, 2014.

[13] L. Montuori, Integration of renewable energy sources in microgrids coordinated with demand response resources: application to a biomass gasification plant coupled with an internal combustion engine for power generation, Valencia: Universidad Politécnica de Valencia, 2013.

[14] The Federal Energy Regulatory Commission Staff, "Draft for comment of the National Action Plan on Demand Response," 2010.

[15] A. Chiu, A. Ipakchi, A. Chuang, B. Qiu, D. Brooks, E. Koch, J. Zhou, M. Zientara, P. Precht, R. Burke and R. Crowder, "Framework for integrated demand response and distributed energy resources models," 2009.

[16] M. H. Albadi and E. F. El-Saadany, "A summary of demand response in electricity markets," Power Systems Research, vol. 78, pp. 1989-1996, 2008.

[17] S. Valero, M. Ortiz, M. Senabre, C. Álvarez, F. G-Franco and A. Gabaldón, "Methods for customer and demand response policies selection in new electricity markets," IET Ge. Transm. Distrib., vol. 1, pp. 104-110, 2007.

[18] The California Energy Commission, «Energy Systems Integration - Demand Response,» Sacrament, CA.

[19] Energy Information Administration, «Energy Information Administration Glossary,» Official Energy Statistics from the U.S.A., Washington D.C., 2016.

[20] C. Mickle, «Energy Services and DSM in the competitive energy supply market,» IEE, London, 1994.

[21] J. Torriti, M. G. Hassan y M. Leach, «Demand response experience in Europe: Policies, programmes and implementation,» Energy, vol. 35, pp. 1575-1583, 2010.

[22] B. Kirby, «Demand response for power system reliability: FAQ,» Oak Ridge National Laboratory, Oak Ridge, TN, 2006. 
[23] C. Goldman, M. Reid, R. Levy y A. Silverstein, «Coordination of energy efficiency and demand response,» Laurence Berkeley National Laboratory, Berkeley, CA, 2010.

[24] International Energy Agency, «Demand Response Resources - Task XIII».

[25] The birth of a EUropean Distributed EnErgy Partnership that will help the largescale implementation of distributed energy resources in Europe (EUDEEP), «European Project supported by the Sixth Framework Programme for Research and Technological Development,» 2010.

[26] Demand Response in Industrial Production (DRIP), «European Project funded by the EC through the programme Life+,» 2015.

[27] US Department of Energy, «Benefits of demand response in electricity markets and recommendations of achieving them,» Report to the United States Congress, Washington D.C., 2006.

[28] G. Heffner, «Configuring load as a resource for competitive electricity markets review of demand response programs in the U.S. and around the world,» de 14th Annual Conference of the Electric Power Supply Industry CEPSI, Fukoka, 2002.

[29] M. H. Albadi y E. F. El-Saadany, «Demand response in electricity markets: an overview,» de IEEE/PES GM, Montreal, 2007.

[30] C. Gellings y J. Chamberlin, Demand side management: Concepts and methods, Tulsa, OK: PennWell Publishing Company, 1993.

[31] European Commission, "Quarterly Report on European Electricity Markets - Q2 and Q3 2016. Market observatory for energy, volume 9, issue 2 \& 3," EC, Brussels, 2016.

[32] Everis \& Mercados EMI, "From regional markets to a single European market. Final report," 2010.

[33] L. Trevino, «Liberalization of the electricity market in Europe: an overview of the electricity technology and the market place,» College of Management of Technology. Federal Polytechnic School of Lausanne, Lausanne, 2008.

[34] C. Álvarez, M. Alcázar-Ortega, G. Escrivá y A. Gabaldón, «Technical and economical tools to assess customer demand response in commercial sector,» Energy conversion and management, vol. 50, pp. 2605-2612, 2009. 
[35] A. Chardon, O. Almén, P. E. Lewis, J. Stromback y B. Château, «Demand Response: A decisive breackthrough for Europe,» Capgemini Consulting, Brussels, 2008.

[36] Smart Energy Demand Coalitions, «Maping Demand Resonse in Europe today,» SEDC, 2015.

[37] Autorità per l'energia elettrica il gas e il sistema idrico, «Schema di linee strategiche per il quadriennio 2015-2018,» Dipartimento per la regolazione, Milan, 2014.

[38] Terna (the Italian TSO), «Grid Code: The code for transmission, dispatching, developing and security of the grid. Chapter 4,» 2005.

[39] P. Bertoldi, P. Zancanella y B.-K. Benigna, «Demand Response status in EU Member States - JRC Science for Policy Report,» European Commission, Ispra, 2016.

[40] G. Hathaway, «Demand side opportunities,» Nationalgrid UK, London, 2009.

[41] Schneider Electric, «Services \& projects: Demand Response Programme. Technical brochure,» 2010.

[42] DRIP Consortium, "Demand Response in Industrial Production, DRIP Project funded by the EU Commission," 2015. [Online]. Available: www.drip-project.eu. [Accessed 1202 2017].

[43] Amprion, "Interruptible Loads program," December 2012. [Online]. Available: http://www.amprion.net/en/interruptible-loads. [Accessed February 2017].

[44] N. G. Paterakis, O. Erdinç and J. P. Catalao, "An overview of Demand Response: Key-elements and international experience," Renewable and Sustainable Energy Reviews, vol. 69, pp. 871-891, 2017.

[45] Platts, "Belgian TSO Elia in demand response first," 2016.

[46] European Transmission System Operators, "Demand Response as a resource for de adequacy and operational reliability of the power systems," ENTSOE, 2007.

[47] A. Ng'uni y L. A. Tan, «Interruptible load and demand response: Worldwide picture and the situation in Sweeden,» de IEEE 38th Annual North American Power Symposium, Carbondale, IL, 2006.

[48] U. Hammarstedt y M. Nilsson, «Demand response in the strategic reserve: the case of Sweden,» Elforsk, Stockholm, 2014. 
[49] Fingrid, «Rules for the maintaining of readiness for use of facilities capable of demand response of electricity covered by the peak load capacity system, for the use of such facilities and for making the electricity consumption available to the market,» 2015.

[50] F. M. Andersen, S. G. Jensen, H. V. Larsen, P. Meibom, H. Ravn, K. Skytte y M. Togeby, "Analyses of Demand Response in Denmark,» Riso National Laboratory. Ea Energy Analyses, 2006.

[51] Statnett (The Norwegian System Operator), «Tariff brochure,» Statnett, 2017.

[52] J. Osborne y D. Warrier, «A primer on demand response. The power grid: Evolving from a "dumb" network to a "smart grid",» Thoma Weisel Partners, 2007.

[53] Federal Energy Regulatory Commission, «State of the markets annual report 2015,» FERC, Washinton DC, 2016.

[54] P. Cappers, C. Goldman y D. Kathan, «Demand response in US electricity markets: empirical evidence,» Lawrence Berkeley National Laboratory, Berkeley, 2009.

[55] Southwest Power Pool, «2009 Annual Report,» SSP Inc., Little Rock, AR, 2010.

[56] Federal Enery Regulatory Commission, «State of the markerts annual report 2012,» FERC, Washington DC, 2013.

[57] Federal Energy Regulatory Commission, «Assessment of Demand Response and Advanced Metering,» FERC, Wasington DC, 2016.

[58] N. G. Paterakis, O. Erdinç y J. P. Catalao, «An overview of Demand Response: Key-elements and international experience,» Renewable and Sustainable Energy Reviews, vol. 69, pp. 871-891, 2017.

[59] U.S. Energy Information Administration, «Annual Energy Outlook 2016,» EIA, Wasington DC, 2016.

[60] A. Faruqui y J. Weiss, «Gas Demand Response,» Spark Fortnightly, 2010.

[61] M. M. Manning, M. C. Swinton, F. Szadkowski, J. Gusdorf y K. Ruest, «The effects of thermostat set-back and set-up on seasonal energy consumption, surface temperatures and erecovery times at the CCHT Twin House Facility,» ASHRAE Transactions, vol. 113, $\mathrm{n}^{\circ}$ 1, pp. 1-12, 2007. 
[62] State of California, "Public Utilities Code: AB-37 Smart grid deployment: smart meters (2011-2012)," Sacramento, 2010.

[63] K. Tweed, "EnerNOC moves into Demand Response for Natural Gas," Greentech Media, 18 April 2012.

[64] A. Backer, "Britain's interruptible gas contracts," Reuters, 8 January 2010.

[65] G. Huitema, N. Szirbik, H. Wortmann, A. Ittoo and A. Dzousa, "Embedding flexibility in combined gas and electricity infrastructures," in 4th Research Day EDGaR, Hilversum, Netherlands, 2012.

[66] M. Alcázar-Ortega, C. Calpe, T. Theisen y J. F. Carbonell-Carretero, «Methodology for the identification, evaluation and prioritization of market handicaps which prevent the implementation of Demand Response: Application to European electricity markets,» Energy Policy, vol. 86, pp. 529-543, 2015.

[67] G. A. Coffee, "Gas Demand Response Programs Are Appealing But Impractical," Winston \& Strawn LLP, 2016.

[68] Energy Information Administration, "Natura gas. Annual Report," EIA, Washington DC, 2016.

[69] M. Nava, "U.S. natural gas exports: a reliable supply of energy to the rest of the world," BBVA Research U.S., Bilbao, Spain, 2016.

[70] S. M. Olmstead, L. A. Muehlenbachs, J. S. Shih, Z. Chu and A. J. Krupnick, "Shale gas development impacts on surface water quality in Pennsylvania," Proceedings of the National Academy of Sciences of the United States of America, vol. 110, no. 13, pp. 4962-4967, 2013.

[71] S. Levine, P. Carpenter and A. Thapa, "Understanding natural gas markets," American Petroleum Institute, 2014.

[72] I. Parry, A. Morris and R. C. Williams, Implementing a US Carbon Tax: Challenges and Debates (Routledge Explorations in Environmental Economics), Oxon: University of Stirling, 2015.

[73] S. Petrick, K. Rehdanz and R. S. J. Tol, "The impact of temperature changes on residential energy consumption," Kiel Institute for the World Economy, Kiel, Germany, 2010.

[74] S. C. Davis, S. E. Williams and R. G. Boundy, "Transportation Energy data book, ed. 35," Oak Ridge National Laboratory, Tennessee, 2016. 
[75] Center for climate and energy solutions, "Natural gas use in the transportation sector," The University of Texas at Austi, Austin, TX, 2012.

[76] J. Bjornmose, F. Roca, T. Turgot and D. S. Hansen, "An assessment of gas and oil pipelines in Europe," European Parliment, Brussels, 2009.

[77] G. Erbach, "Shale gas and EU energy security," European Parliment, Brussels, 2014.

[78] T. I. Williams, A history of the British gs industry, Oxford University Press, 1981.

[79] SNAM Rete Gas, "Piano decennale di sviluppo delle reti di trasporto di gas naturale 2016-2025," SNAM Rete Gas S.p.A., San Donato Milanese, 2016.

[80] British Petroleum, "BP statistical review of World energy," London, 2016.

[81] U.S. Energy Information Administration, «Factors Affecting Natural Gas Prices,» EIA, 2016.

[82] United Nations, "Adoption of the Paris Agreement COP.21," in Framework Convention on Climate Change, Paris, 2015.

[83] Autorità per l'energia elettrica, il gas e il sistema idrico, "Relazione annuale sullo stato dei servizi e sull'actività svolta," AEEGSI, Roma, 2016.

[84] Autorità per l'energia elettrica il gas e il sistema idrico, "Testo integrato delle disposizioni per la regolazione delle partite fisiche ed economiche del servizio di bilanciamento del gas naturale. Allegato A alla deliberazione 31 maggio 2012, 229/2012/R/gas," 2012.

[85] Gestore Mercati Energetici 2016, "Gli andamenti del mercato italiano del gas," Newsletter del GME, vol. 100, pp. 10-11, 2017.

[86] Snam Rete Gas S.p.A, "Ten-year development plan of the natural gas transmission network 2014-2023," Snam, San Donato Milanese, 2013.

[87] S. Dilaveroglu, Optimization for Design and Operation of Natural Gas Transmission Networks, College Station, TX: Texas A\&M University, 2012.

[88] N. Petrihos and K. VanWyhe, "U.S. Natural gas pipelines. All infastructure crisis," American Action Forum, 2016.

[89] B. O'Neil, P. Hopkins and J. Gressley, "The economic benefits of natural gs pipeline deveopment on the manufacturing sector," IHS Economics, 2016. 
[90] U.S. Department of Energy, Office of Energy Policy and Systems Analysis, «Natural gas infrastruture. Modernization programs at local distribution companies: key issues and considrations,» DOE, Washington DC, 2017.

[91] D. Hagan and J. E. Rueger, "Unlocking demand for natural gas pipelines," White \& Case LLP, 2014.

[92] M. Verda, "The Italian Natural Gas Market: an Endless Crisis?," Istituto per gli studi di politica internazionale, 2014.

[93] TERNA S.p.A., "Sintesi del sistema elettrico dell'anno 2015," Terna, 2016.

[94] M. Dolce, S. Giovinazzi, I. Iervolino, E. Nigro and A. Tang, "La gestione dell'emergenza per i sevizi essenziali e le lifelines a seguito dell'evento de L'Aquila," Università degli Studi di Napoli "Federico II", 2016.

[95] Trans Adriatic Pipeline AG, "Trans Adriatic Pipeline," Baar, 2017.

[96] F. R. Saule, "Infrstrutture, prezzi e regolamentazione dei mercati del gas naturale. Doctoral Dissertation," Università degli studi di Trieste, 2010.

[97] M. Batty, K. W. Axhausen, F. Giannotti, A. Pozdnoukhov, A. Bazzani, M. Wachowicz, G. Ouzounis and Y. Portugali, "Smart cities of the future," The European Physical Journal Special Topics, vol. 214, no. 1, pp. 481-518, 2012.

[98] United Nations, "Cities and climate change: Global report on human settlement 2011," UN, Nairobi, 2012.

[99] Focus Group on Smart Sustainable Cities, "Smart sustainable cities: An analysis of definitions," International Telecommunication Union, 2014.

[100] C. Benevolo and P. Dameri, "La smart city come strumento di green development. Il caso de Genova Smart City," Electronic Journal of Management, no. 3, pp. 1-30, 2013.

[101] E. Patti, E. Pons, D. Martellacci, F. B. Castagnetti, A. Acquaviva and E. Macii, "Architecture for energy vectors with active prosumers," in International Conference on Smart Cities and Green ITC Systems, Lisbon, 2015.

[102] USmartConsumer Project, "European Smart Metring Landscape Report. "Utilities and Consumers"," European Commission, Madrid, 2016.

[103] Institute of Communication \& Computer Systems of the National Technical University of Athens, "Study on cost benefit analysis of Smart Metering Systems," European Commission, 2015. 
[104] Autorità per l'energia elettrica, il gas e il sistma idrico, "Schema di linee strategiche per il quadriennio 2015-2018," AEEGSI, Roma, 2014.

[105] D. Muallem, "Smart gas metering Europe - an untapped opportunity?," Metering \& Smart Energy International, 7 June 2013.

[106] M. Stronzik and M. Wissner, "Smart Metering Gas," WIK Consult, 2014.

[107] E. Brodin, A. Elwén, E. Grahn, E. Larsson, K. Abrahamsson, G. Morén y J. Roupe, «The Swedish electricity and natural gas markets 2015 - Ei R2016:10,» The Swedish Energy Markets Inspectorate, Eskilstuna, 2016.

[108] C. Poletti, G. Cervigni, M. Di Castelnuovo and A. Sileo, "Costs and benefits of the Italian smart gas metering programme," The Center for Research on Energy and Environmental Economics and Policy at Bocconi University, Milan, 2011.

[109] J.-F. Segalotto and R. Bigliani, "Gas Smart Metering in Italy: Rollout Update and Emerging Communications Technologies for Utility-Grade IoT," IDC Energy Insights, 2016.

[110] Commission for Energy Regulation, "CER Plans National Roll-out of Energy Smart Meters in Ireland," CER, 2011.

[111] IBM, "Oxxio uses smart utility metering technology to give more control and options to customers," IBM Corporation, 2006.

[112] A. Bouw, J. Oost and S. Gibiino, "Smart meters in the Netherlands - DSOs are leading the way," IBM Corporation, 2013.

[113] D. o. E. a. Climate, "Smart meter roll-out for the domestic and small and medium non-domestic sectors (GB): Impact Assessment," British Government, 2015.

[114] Silicon Labs, "ZigBee propagation for smart metering networks," Silicon Laboratories Inc., 2013.

[115] J. Rodríguez-García, M. Alcázar-Ortega, J. Carbonell-Carretero, C. Álvarez-Bel and P. Pesantez, Análisis para la implementación de redes inteligentes en Ecuador, Valencia: C.A.B., 2016.

[116] SNAM Rete Gas S.p.A., "Chapter 12: Pressioni di consegna e riconsegna," in Codice di Rete, SNAM, 2016.

[117] Euroheat \& Power, "District heating in buildings," E\&P, Brussels, 2011. 
[118] L. Montuori, C. Vargas and M. Alcázar-Ortega, "Impact of the throat sizing on the operating parameters in an experimental fixed bed gasifier: Analysis, evaluation and testing," Renewable Energy, vol. 83, pp. 615-625, 2015.

[119] World Nuclear, "Nuclear power in Russia," 22 March 2017. [Online]. Available: http://www.world-nuclear.org/information-library/country-profiles/countries-os/russia-nuclear-power.aspx. [Accessed 17 April 2017].

[120] K. Sugiyama, Y. Shimazu, K. Atsushi and N. Ishitani, "Nuclear district heating: the Swiss experience," Nippon Genshiryoku Gakkai-Shi, vol. 48, no. 2, pp. 119$124,2006$.

[121] "District Heating and Cooling Market - Global Industry Analysis, Size, Share, Growth Trends and Forecast 2016 - 2024," 2017.

[122] "The Holly Manufacturing Company 1858-1916," 2015. [Online]. Available: http://lockportcave.com/holly-manufacturing/. [Accessed 26 April 2017].

[123] J. Iken, "Renaissance of district heating in the US," Sun \& Wind Energy, no. 10, pp. 210-213, 2010.

[124] P. Ulloa, "Potential for Combined Heat and Power and District Heating and Cooling from Waste-to-Energy Facilities in the U.S. - Learning from the Danish Experience," Columbia University, New York, 2017.

[125] DESMI, "Energy efficient pumps and pump sollutions for district energy: District heating "Made in Denmark"".

[126] R. Barilli, "Hera Group develompent in District Heating: track records and perspectives," in 34th Euroheat \& Power Congress, Venice, 2009.

[127] D. Bennink and J. Benner, "District Heating in the Netherlands," October 2009. [Online]. Available: http://www.cedelft.eu/publicatie/district_heat_in_the_netherlands/980 [Accessed 17 April 2017].

[128] Euroheat \& Power, "District Energy in Finland," 01 March 2015. [Online]. Available: https://www.euroheat.org/knowledge-centre/district-energy-finland/. [Accessed 25 April 2017].

[129] Euroheat and Power, "Finland: District Heating Year 2015," 15 January 2016. [Online]. Available: https://www.euroheat.org/news/finland-district-heatingyear-2015/ . [Accessed 25 April 2017]. 
[130] Eoruheat \& Power, "District Heating in Italy," 1 March 2015. [Online]. Available: https://www.euroheat.org/knowledge-centre/district-energy-italy/. [Accessed 29 April 2017].

[131] Italian National Agency for New Technologies, Energy and Sustainable Economic Development, "Energy efficiency trends and policies in Italy," Enea, Rome, 2015.

[132] Gestore dei Servizi Energetici, "Valutazione del potenziale nazionale di applicazione della cogenerazione ad alto rendimento e del teleriscaldamento efficiente," GSE, Roma, 2015.

[133] G. Trotta, M. Ripa and S. Lorek, "Consumers and Energy Efficiency - Contry report Italy. An inventory of policies, business and civil society initiatives, focusing on heating, hot water and the use of electricity," EUFORIE - European Futures for Energy Efficiency, 2015.

[134] F. Gaudio, "1982-2012: 30 anni di teleriscaldamento a Torino," IREN Energia, Turin, 2013.

[135] S. e. a. o. Ireland, "Cost Benefit Analysis of the potential for High-Efficiency Cogeneration and Efficient District Heating \& Cooling in Ireland," AECOM, Dublin, 2015.

[136] T. Mitchell and S. Bennet, "In A State Of Great Forwardness: Manchester \& The Coming Of The Gas Industry," The Manchester Association of Engineers, Boston, 2006.

[137] IN.CO.Edile, "Contatori gas - Contatori a membrana (pareti deformabili," 23 September 2016. [Online]. Available: http://incoedile.altervista.org/blog/contatori-gas-contatori-membrana-paretideformabili/. [Accessed 25 April 2017].

[138] ENI S.p.A., Italgas S.p.A. and Associazioni dei Consummatori, "Protocollo di intesa sui conguagli per i contatori domestici," Roma, 2008.

[139] T. Oowaku, A. Asada and K. Nishiguchi, "Development of a new ultrasonic smart gas meter for domestic customers," in International Gas Union Research Conference, Copenhagen, 204.

[140] W. Shannon, "Fundamentals of Thermal Mass Flow Measurement: Why are pressure and temperature correction not required?," SAGE Metering, Monterey, CA, 2015. 
[141] T. Dittrich, "Battery concepts for smart utility meters - The requirements and proving their suitability," Tardian Batteries GmbH, Lake Success, NY, 2012.

[142] N. Chang, "Smart gas and water meter trends: impacts on meter designs," Metering International, no. 4, pp. 38-39, 2012.

[143] European Parliment, "Decision No 676/2002/EC of the European Parliament and of the Council of 7 March 2002 on a regulatory framework for radio spectrum policy in the European Community (Radio Spectrum Decision)," EC, Brussels, 2002 .

[144] H. Andre, "Connessioni a confronto: GSM, GPRS, Edge, 3G e HSDPA. Tutte le differenze," 25 February 2012. [Online]. Available: http://www.tecnologici.net/connessioni-a-confronto-gsm-gprs-edge-3g-hsdpatutte-le-differenze/3/. [Accessed 2017 April 18].

[145] F. Boni-Castagnetti, G. Garofalo and S. Hjort, "Flexible smart metering for multiple energy vectors with active prosumers - FLEXMETER Project," Europen Union Funding for Researcn \& Innovation, 2015.

[146] M. Alcázar-Ortega, Evaluation and assessment of new demand response products based on the use of flexibility in industrial processes: application to the food industry, Tampa, FL: University of South Florida - Universidad Politécnica de Valencia, 2011.

[147] United States Environmental Protection Agency, «Emission factors for Greenhouse Gas Inventories,» EPA, Washington DC, 2014.

[148] Snam Rete Gas, S.p.A., "Relazione Finanziaria Annuale 2015," San Donato Milanese, 2016.

[149] S. Newell and A. Hajos, "Demand response in the Midwest ISO: An evaluation of wholesale market design," The Battle Group, 2010.

[150] Red Eléctrica de España, "Annual Report," REE, Madrid, 2007.

[151] Red Eléctrica de España, "Annual Report Progress," REE, Madrid, 2016.

[152] M. Alcázar-Ortega, C. Calpe, T. Theisen y J. Rodríguez-García, «Certification prerequisites for activities related to the trading of demand response resources,» Energy, vol. 93, pp. 705-715, 2015.

[153] U. Farinelli and M. Gusmerotti, "Evaluation of the long-term evolution of electricity demand in the European union," in 26th USAEE/IAEE North American Conference, Ann Arbor, MI, 2006. 